\title{
Pharmacotherapeutic options in sarcoidosis : how can we improve them?
}

Citation for published version (APA):

Cremers, J. P. (2014). Pharmacotherapeutic options in sarcoidosis : how can we improve them? [Doctoral Thesis, Maastricht University]. Maastricht University. https://doi.org/10.26481/dis.20140626jc

Document status and date:

Published: 01/01/2014

DOI:

10.26481/dis.20140626jc

Document Version:

Publisher's PDF, also known as Version of record

\section{Please check the document version of this publication:}

- A submitted manuscript is the version of the article upon submission and before peer-review. There can be important differences between the submitted version and the official published version of record.

People interested in the research are advised to contact the author for the final version of the publication, or visit the DOI to the publisher's website.

- The final author version and the galley proof are versions of the publication after peer review.

- The final published version features the final layout of the paper including the volume, issue and page numbers.

Link to publication

\footnotetext{
General rights rights.

- You may freely distribute the URL identifying the publication in the public portal. please follow below link for the End User Agreement:

www.umlib.nl/taverne-license

Take down policy

If you believe that this document breaches copyright please contact us at:

repository@maastrichtuniversity.nl

providing details and we will investigate your claim.
}

Copyright and moral rights for the publications made accessible in the public portal are retained by the authors and/or other copyright owners and it is a condition of accessing publications that users recognise and abide by the legal requirements associated with these

- Users may download and print one copy of any publication from the public portal for the purpose of private study or research.

- You may not further distribute the material or use it for any profit-making activity or commercial gain

If the publication is distributed under the terms of Article $25 \mathrm{fa}$ of the Dutch Copyright Act, indicated by the "Taverne" license above, 
Pharmacotherapeutic options

in sarcoidosis

How can we improve them? 
C Johanna Petronella Cremers, Nuth 2014

Cover illustration: 'Vogelperikelen' by Wim van Ratingen

Cover photography: Theo Finger

Layout: Tiny Wouters

Production: Datawyse, Universitaire Pers Maastricht

ISBN: 978-90-78076-08-7

The research published in this thesis was financially supported by the ild care foundation and Teva Nederland B.V.

The printing of this thesis was financially supported by AbbVie B.V., Boehringer Ingelheim B.V., ild care foundation, Intermune Benelux B.V., Nederlandse Vereniging voor Hepatologie, Roche Nederland B.V., Sarcoïdose Belangenvereniging Nederland, Teva Nederland B.V. 


\title{
Pharmacotherapeutic options
}

\author{
in sarcoidosis
}

\section{How can we improve them?}

\author{
PROEFSCHRIFT
}

ter verkrijging van de graad van doctor

aan de Universiteit Maastricht,

op gezag van de Rector Magnificus, Prof. dr. L.L.G. Soete

volgens het besluit van het College van Decanen,

in het openbaar te verdedigen

op donderdag 26 juni 2014 om 14.00 uur

door

Johanna Petronella Cremers 


\section{Promotor}

Prof. dr. M. Drent

\section{Copromotor}

Dr. T.L.Th.A. Jansen (Universitair Medisch Centrum Nijmegen)

\section{Beoordelingscommissie}

Prof. dr. A.C. Nieuwenhuijzen Kruseman (voorzitter)

Prof. dr. J.W.J. Bijlsma (Universitair Medisch Centrum Utrecht)

Prof. dr. M.P. van Dieijen-Visser

Prof. dr. P.M.M. Geusens

Prof. dr. C. Neef 
'Life isn't about waiting for the storm to pass... It's about learning to dance in the rain.'

Anonymous, the Barrett Centre, University of Cincinnati Medical Centre 



\section{Contents}

Abbreviations 9

Chapter $1 \quad$ General introduction 13

Chapter 2 Extent of disease activity assessed by ${ }^{18}$ F-FDG PET/CT in a Dutch 39 sarcoidosis population

Chapter $3 \quad$ Body composition profiling in a Dutch sarcoidosis population 55

Chapter $4 \quad$ Liver test abnormalities in sarcoidosis 75

Chapter $5 \quad$ Therapeutic approach of hepatic sarcoidosis 89

Chapter 6 Multinational evidence-based World Association of Sarcoidosis 109 and Other Granulomatous Disorders recommendations for the use of methotrexate in sarcoidosis: integrating systematic literature research and expert opinion of sarcoidologists worldwide

Chapter 7 Practical eminence and experience-based recommendations for use of TNF- $\alpha$ inhibitors in sarcoidosis

Chapter 8 Association of the TNF- $\alpha$ G-308A polymorphism with

TNF-inhibitor response in sarcoidosis

Chapter 9 Summary, general discussion and directions for future research

Samenvatting (summary in Dutch)

List of publications

Dankwoord (acknowledgements)

Curriculum vitae

Appendix 1 Overview of studies on the use of methotrexate in sarcoidosis

Appendix 2 Mobile application 'MTX in sarcoidosis'

Appendix 3 Overview of studies on the use of TNF- $\alpha$ inhibitors in sarcoidosis 



\section{Abbreviations}

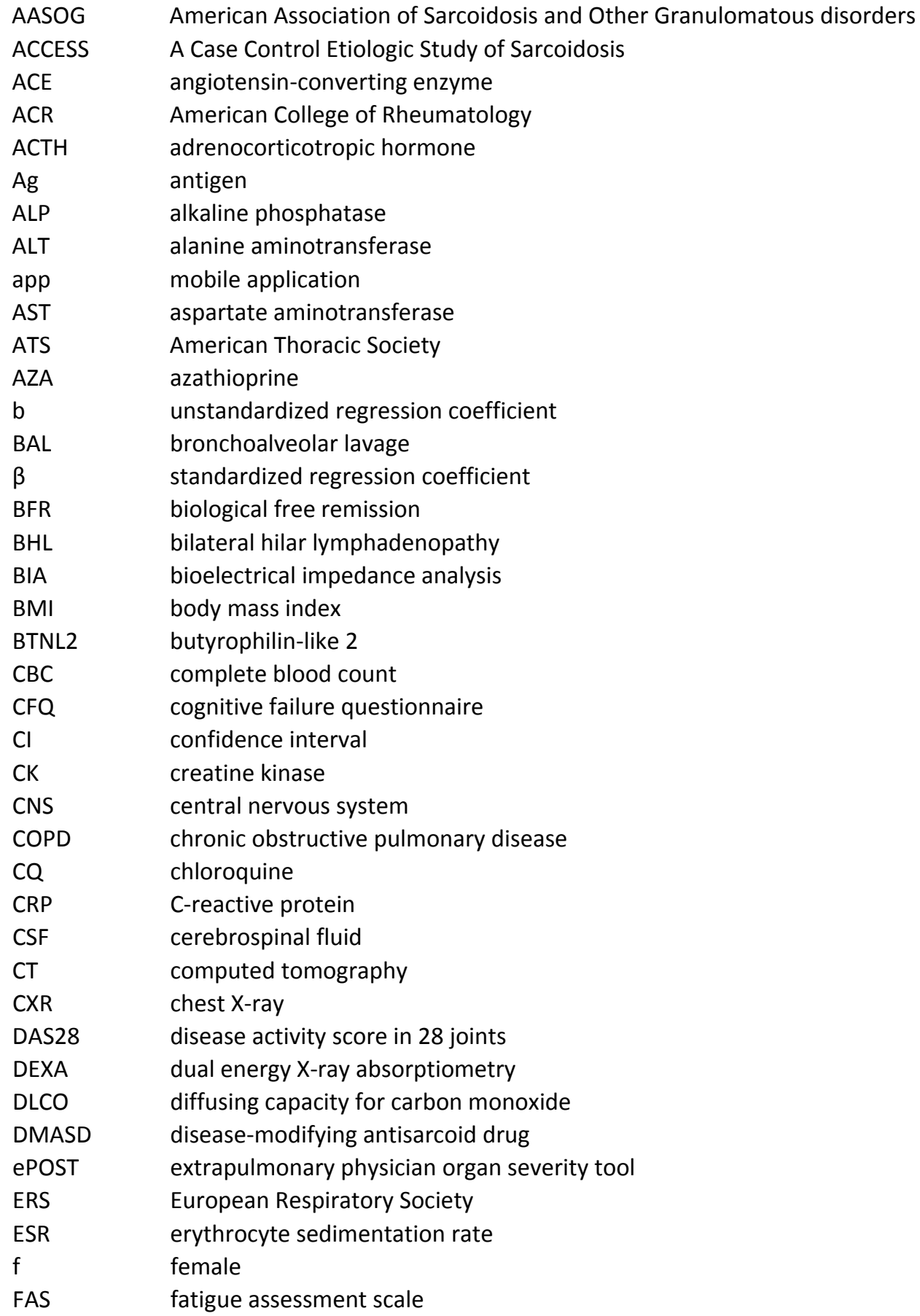




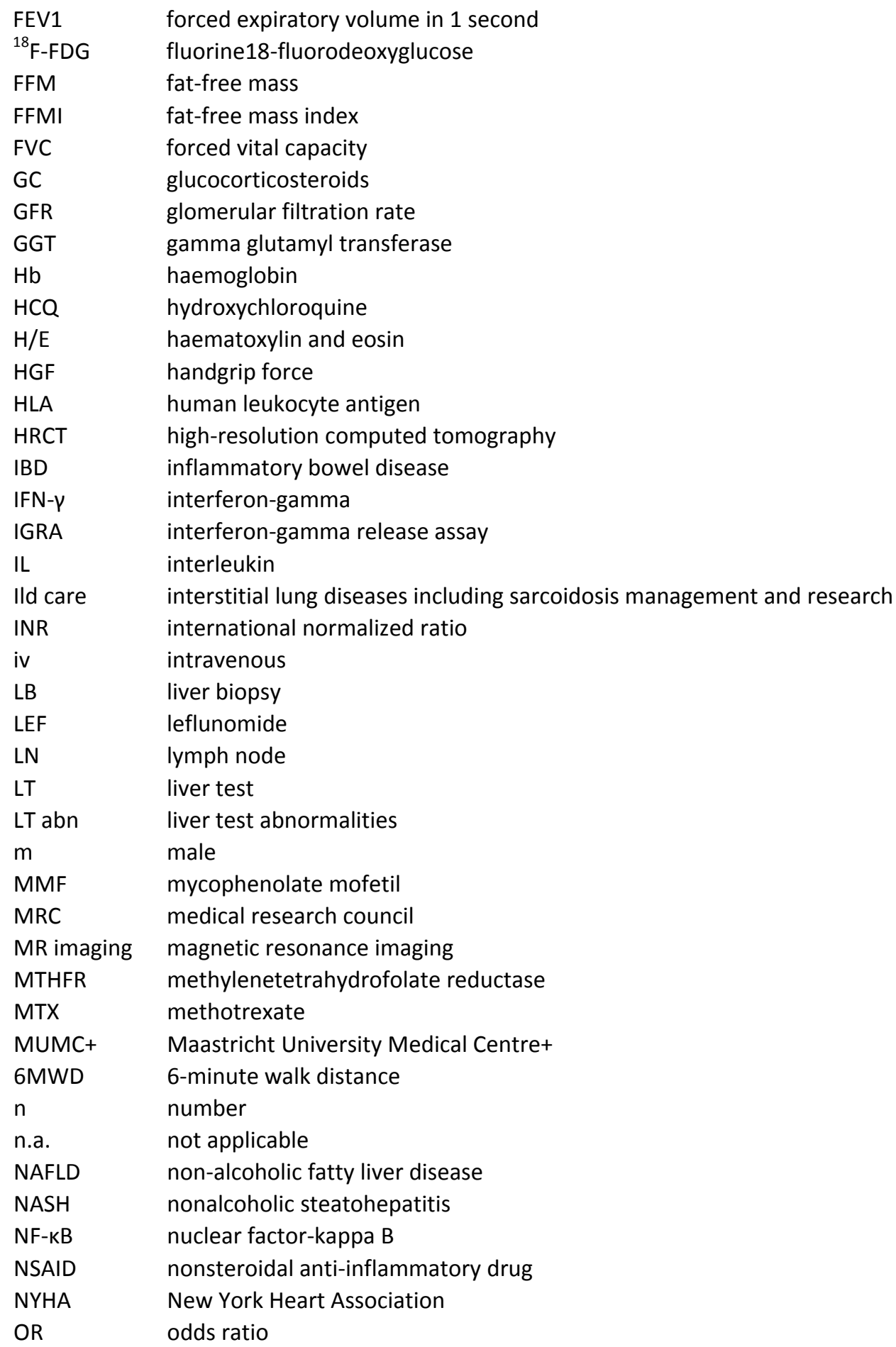




\begin{tabular}{|c|c|}
\hline PET & positron emission tomography \\
\hline $\mathrm{PI}$, max & maximal inspiratory pressure \\
\hline POF & pentoxifylline \\
\hline PT & prothrombin time \\
\hline QFT-GIT & QuantiFERON-TB Gold In-Tube \\
\hline RA & rheumatoid arthritis \\
\hline RCT & randomized controlled trial \\
\hline REE & resting energy expenditure \\
\hline RFC1 & reduced folate carrier 1 \\
\hline RFI & respiratory functional impairment \\
\hline ROS & reactive oxygen species \\
\hline RR & relative risk \\
\hline RTX & rituximab \\
\hline SC & subcutaneous \\
\hline SD & standard deviation \\
\hline SE & standard error \\
\hline SF-36 & short form-36 \\
\hline SFN & small fiber neuropathy \\
\hline SFNSL & small fiber neuropathy screenings list \\
\hline SIL2R & soluble-interleukin2-receptor \\
\hline SLE & systemic lupus erythematosus \\
\hline Spearman's $\rho$ & Spearman's rank-correlation coefficient \\
\hline SUVmax & maximum standardized uptake value of ${ }^{18} \mathrm{~F}$-FDG PET/CT \\
\hline TB & tuberculosis \\
\hline TCR & T cell receptor \\
\hline TGF- $\beta$ & transforming growth factor-beta \\
\hline Th cell & T helper cell \\
\hline TLC & total lung capacity \\
\hline TNF- $\alpha$ & tumor necrosis factor-alpha \\
\hline TPMT & thiopurine S-methyltransferase \\
\hline UDCA & ursodeoxycholic acid \\
\hline ULN & upper limit of normal \\
\hline VAS & visual analog scale \\
\hline VC & vital capacity \\
\hline VIP & vasoactive intestinal peptide \\
\hline $\mathrm{VO}_{2} \max$ & maximal oxygen uptake \\
\hline WASOG & World Association of Sarcoidosis and Other Granulomatous disorders \\
\hline WBC & white blood cell \\
\hline$X_{L}^{2}$ & log-likelihood chi-squares \\
\hline y & years \\
\hline
\end{tabular}





\title{
Chapter 1
}

\author{
General introduction
}




\section{Sarcoidosis}

Sarcoidosis is a multiorgan disease of unknown cause, characterized by inflammatory activity with formation of noncaseating granulomas in various organ systems. ${ }^{1}$ Sarcoidosis has been known for more than 100 years; it was first described in 1877 by the English physician Hutchinson, and several years later by two dermatologists, Besnier and Boeck. ${ }^{1}$ It primarily affects the lungs and the lymphatic system, but virtually any organ system can be involved, such as the liver, skin, eyes, heart, and nervous system. $^{1}$

The disease occurs throughout the world, affecting both genders, and all ages and races. ${ }^{1}$ However, epidemiologic studies show that it most commonly affects individuals in the third to fourth decade of their lives. ${ }^{2}$ Furthermore, the highest prevalence rates have been found in Scandinavian European countries and African-Americans in the United States had about a 3.8-fold higher age-adjusted annual incidence rate (35.5 cases per 100000 ) compared with Caucasians (10.9 per 100000$) \cdot{ }^{1,3,4}$ The prevalence in the Netherlands is thought to be about $30-40$ per $100000 .^{5}$

\section{Pathogenesis}

Although there has been tremendous progress in understanding the pathogenesis, the cause of sarcoidosis remains unclear. ${ }^{6}$ Sarcoidosis is probably the end result of a process consisting of an immune response to a variety of environmental triggers in a genetically susceptible individual, in which also oxidative stress appears to play an important role. ${ }^{2,6-8}$

\section{Immunopathogenesis}

The development and accumulation of granulomas constitute the fundamental abnormality in sarcoidosis. ${ }^{8}$ Granulomas are compact collections, characterized by a core of monocyte-derived epithelioid histiocytes and multinucleated giant cells encircled by CD4+ T lymphocytes (Figure 1.1). ${ }^{6}$ In more mature granulomas, fibroblasts and collagen encase the ball-like cluster of cells, sometimes with sclerosis and altered organ architecture and function. ${ }^{8}$ The presence of granulomas is not specific for sarcoidosis, but can also occur in other lung diseases such as hypersensitivity pneumonitis, drug reactions, and tuberculosis, or other diseases such as common variable immunodeficiency, and Crohn's disease. ${ }^{1,9}$ 

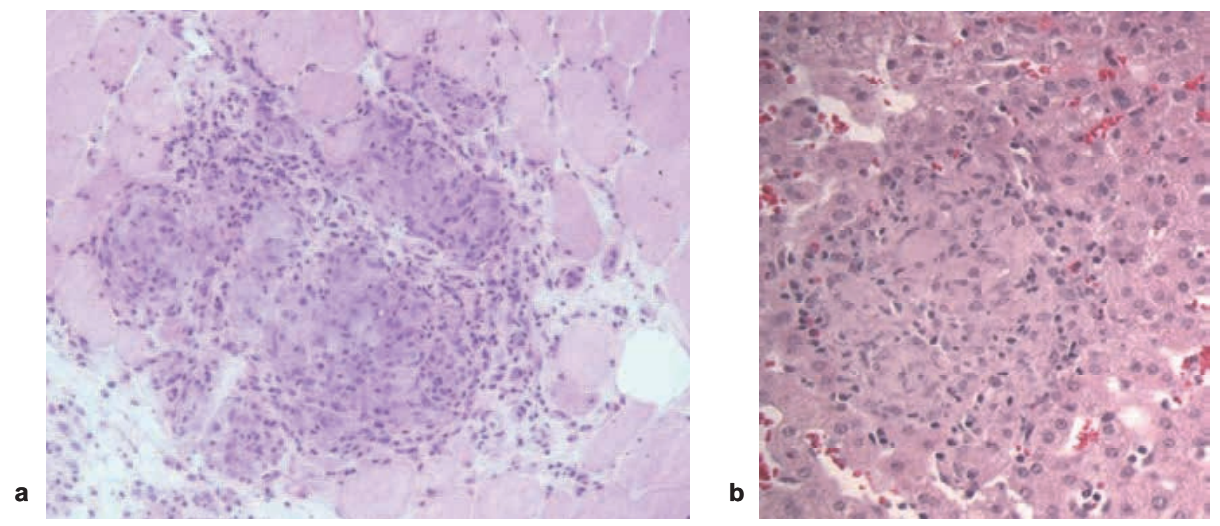

Figure 1.1 a. Noncaseating granuloma present in a biopsy obtained from the left quadriceps muscle of a sarcoidosis patient ( $\mathrm{H} / \mathrm{E}$, magnification $10 \mathrm{x})$. b. Noncaseating granuloma present in a liver biopsy section of a sarcoidosis patient (H/E, magnification 20x). Both granulomas consist of epithelioid histiocytes and giant cells surrounded by a rim of lymphocytes. H/E, haematoxylin and eosin.

Granuloma formation and maintenance is initiated by the recruitment of macrophages and monocytes, which internalize antigens and become antigen presenting cells. ${ }^{2}$ CD4+ T cells interact with the major histocompatibility complex class II molecules on these antigen presenting cells. ${ }^{2,8}$ The activated CD4+ T cells differentiate into T helper 1 (Th1) like cells and secrete predominantly interleukin (IL)-2 and interferon-gamma (IFN- $\gamma$ ), augment macrophage tumor necrosis factor-alpha (TNF- $\alpha$ ) production, and amplify the local cellular immune response. ${ }^{8}$ IL-2 acts as a local growth factor for T lymphocytes, whereas IFN- $\gamma$ enhances the accessory and cytotoxic functions of T cells and regulates the secretion of other lymphokines. ${ }^{2}$ TNF- $\alpha$, IL-12, and IL-18 play critical roles in supporting the Th1 cell response by inducing IFN- $\gamma$ production and enhancing $T$ cell cytotoxicity. ${ }^{2,10}$ This facilitates the formation of granulomas. The formed granuloma can resolve spontaneously, but may persist and can lead to a chronic inflammatory status. ${ }^{6}$ In case of ongoing antigen presentation, a shift from cytokines produced by Th1 cells to cytokines produced by Th2 cells (e.g. transforming growth factor- $\beta$ ), appears to stimulate fibroblast proliferation and collagen production, leading to fibrosis. ${ }^{8}$ Persistent granulomatous inflammation may in part be due to failure of immune regulatory mechanisms to resolve the inflammatory process. ${ }^{6}$ Figure 1.2 shows a schematic presentation of granuloma formation in sarcoidosis. 


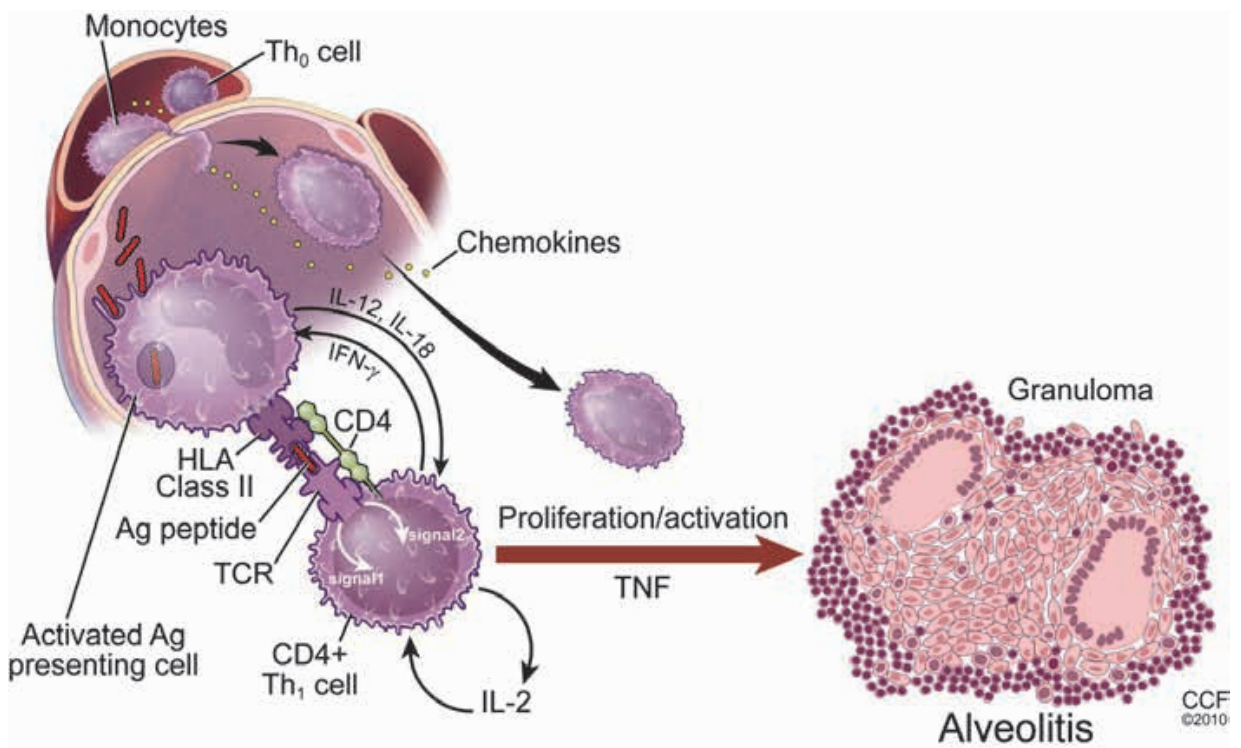

Figure 1.2 A schematic presentation of the inflammatory response with granuloma formation in sarcoidosis. An antigen induces antigen-specific, Th1 mediated granulomatous inflammation with production of Th1 cytokines (IFN- $\gamma$, IL-2). Granuloma formation is set in motion by activated macrophages and $T$ cells along with other effector cells (e.g. fibroblasts) under the regulatory influence of local cytokine production. Removal of the antigen allows down regulation of the immune response. Alveolar macrophages activated in the context of a predominant Th2 response appear to stimulate fibroblast proliferation and collagen production, leading to progressive fibrosis. ${ }^{8} \mathrm{Ag}$, antigen; HLA, human leukocyte antigen; IFN- $\gamma$, interferongamma; IL, interleukin; TCR, T cell receptor; Th, T helper; TNF, tumor necrosis factor. Adapted from Baughman et al. ${ }^{6}$

\section{Environmental causes}

Sarcoidosis probably requires exposure to one or more exogenous antigens. ${ }^{6}$ It is quite possible that the triggering antigen varies depending on ethnicity, geographic location, and individual genetic background. ${ }^{6}$ Mycobacterial, fungal, and other microbial antigens, are suspected as possible causative agents. ${ }^{6,8,11}$ Furthermore, environmental and occupational exposures are associated with the development of sarcoidosis. ${ }^{11} \mathrm{~A}$ Case Control Etiologic Study of Sarcoidosis (ACCESS) study identified several exposures associated with sarcoidosis risk, including insecticides and working in musty environments with bioaerosol exposure. ${ }^{12}$ Also exposure to inorganic particulate matter can promote an inflammatory response leading to granuloma formation. ${ }^{11}$ Occupational studies have shown positive associations with service in the United States Navy, metalworking, firefighting, and the handling of building supplies. ${ }^{8}$ 


\section{Genetic features}

Familial clustering of sarcoidosis has been demonstrated. ${ }^{13}$ In the ACCESS study, sarcoidosis patients were almost five times more likely than controls to report a sibling or a parent with a history of sarcoidosis. ${ }^{14}$ There is a higher familial relative risk in whites compared with African-Americans. ${ }^{14} \mathrm{~A}$ range of different genes and polymorphisms have been investigated and found to have an influence on the disease. Genetics studies have focused on human leukocyte antigen (HLA) genes. ${ }^{1}$ HLA are cell surface proteins that are essential for immune recognition and function. For example, carriage of HLA-DRB1*1101 and HLA-DPB1*0101 alleles is found to be a risk factor for sarcoidosis, ${ }^{15}$ whereas HLA-DQB1*0201 and HLA-DRB1*03 are strongly associated with acute disease and a good prognosis. ${ }^{16-18}$ of the TNF genes, the TNF- $\alpha$ polymorphisms have been extensively studied. ${ }^{18}$ The presence of a TNF- $\alpha-308 \mathrm{~A}$ variant allele is associated with a favorable prognosis. ${ }^{18}$ Furthermore, the presence of a single nucleotide polymorphism in the butyrophilin-like 2 (BTNL2) gene, which normally reduces proliferation and cytokine production from activated T cells, increases the risk of developing sarcoidosis and doubles the risk of progressing to persistent pulmonary sarcoidosis. ${ }^{19-21}$ These findings illustrate that genetic predisposition appears not to be dependent upon a single gene and/or polymorphism.

\section{Oxidative stress}

An important role for oxidative stress in the etiology of sarcoidosis has also been proposed, as the consequence of an imbalance between the presence of and the protection against reactive oxygen species (ROS). ${ }^{7,22-25}$ ROS are capable of reducing endogenous defence levels and enhancing inflammation. ${ }^{7}$ It has been shown that oxidized proteins are elevated in the bronchoalveolar lavage (BAL) fluid of sarcoidosis patients. ${ }^{26,27}$ Another consequence of the occurrence of oxidative stress is a reduced redox state, as is reported in the erythrocytes of female sarcoidosis patients. ${ }^{24}$ Furthermore, the transcription factor nuclear factor-kappa beta (NF-kB), known to be activated by radical damage, is increased in alveolar macrophages and mononuclear blood cells of active sarcoidosis patients compared to those of healthy controls. ${ }^{25}$ And finally, the total antioxidant capacity in sarcoidosis patients is approximately $75 \%$ of that of matched controls. ${ }^{7}$

\section{Clinical presentation}

The presentation and the course of sarcoidosis are highly variable, depending on the ethnicity, duration of the illness, the specific site and extent of organ involvement, and the fluctuating activity of the granulomatous process. ${ }^{1,2}$ Sarcoidosis activity can lead to a wide range of disease severity, varying from minimal involvement to derangement of organ physiology with functional impairment. ${ }^{1,2,6,28}$ 
Patients can present with various clinical signs and symptoms depending on the organs involved. ${ }^{1,2}$ Furthermore, nonspecific constitutional symptoms, such as fever, malaise, and weight loss, occur in about one-third of patients. ${ }^{1}$ In addition, patients can also suffer from generic disease symptoms, such as fatigue, exercise intolerance and muscle weakness, with substantial impact on the quality of life of patients and their families. $^{1,29-32}$

The acute form of sarcoidosis, i.e. Löfgren's syndrome, is characterized by fever, polyarthritis, erythema nodosum, and bilateral hilar lymphadenopathy. ${ }^{1}$ In general, the prognosis of an acute onset of disease is good with usually spontaneous resolution within 2 years. ${ }^{1,33,34}$ However, in $10-30 \%$ of the cases sarcoidosis has an insidious onset, and in these patients the disease can become chronic with an often relapsing course in which spontaneous remission is less likely. ${ }^{2,34}$ A worse prognosis is associated with certain patient and disease characteristics, like black race, extrapulmonary (especially neurological, cardiac and osseous) involvement, and advanced pulmonary disease (Table 1.1). ${ }^{1,33-38}$ The mortality rate of sarcoidosis is approximately $5 \%$, usually the result of cardiac or neurological involvement, or respiratory failure due to pulmonary fibrosis. $^{2}$

Table 1.1 Adverse prognostic factors in sarcoidosis. ${ }^{1,33-38}$

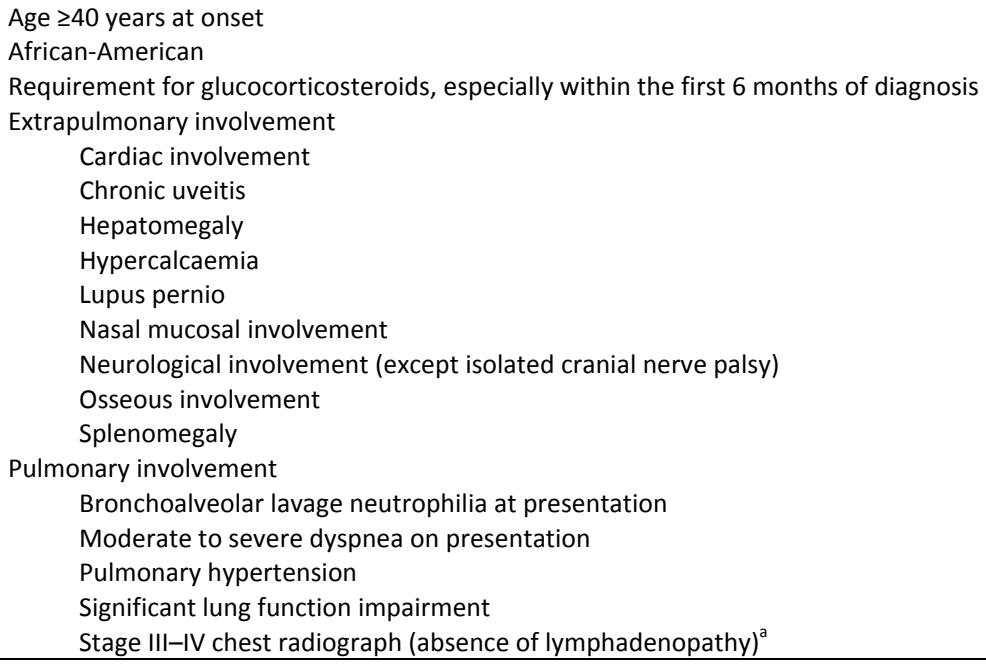

\footnotetext{
${ }^{a}$ According to the Scadding radiographic staging system: stage 0, normal chest radiography; stage I, bilateral hilar lymphadenopathy (BHL); stage II, BHL and parenchymal abnormalities; stage III, parenchymal abnormalities without BHL; and stage IV, advanced lung fibrosis. ${ }^{1}$ Adapted from Lazar and Culver. ${ }^{35}$
} 


\section{Diagnostic procedures}

The diagnosis of sarcoidosis is supported by a compatible clinical and radiographic presentation together with histological evidence of noncaseating granulomas on biopsy. ${ }^{1,2}$ Important procedures available for the diagnostic work-up include assessment of laboratory parameters, pulmonary function and exercise capacity tests, radiographs and high-resolution computed tomography (HRCT) of the chest, fluorine18fluorodeoxyglucose positron emission tomography/computed tomography $\left({ }^{18} \mathrm{~F}-\mathrm{FDG}\right.$ $\mathrm{PET} / \mathrm{CT}$ or $\mathrm{PET}$ ) and magnetic resonance (MR) imaging to complement more routinely used imaging techniques, and biopsy. ${ }^{1,6}$ Both pulmonary and extra-pulmonary localizations should be assessed. ${ }^{1}$

\section{Laboratory parameters}

Inflammatory sarcoidosis activity is reflected by an increase in serological markers of inflammatory activity, i.e. angiotensin-converting enzyme (ACE), soluble-interleukin2receptor (sIL2R), C-reactive protein (CRP), and neopterin. ${ }^{6,39-42}$ These serological markers are not specific for sarcoidosis and are not used for establishing the diagnosis, but for the assessment of inflammatory activity. ${ }^{6}$

Elevated calcium levels can be found in both serum and independently in the urine of sarcoidosis patients, resulting from overproduction of 1,25-dihydroxyvitamin D3 by activated macrophages in granulomas. ${ }^{8,43}$ Furthermore, laboratory abnormalities as a consequence of specific organ involvement can be found, such as liver test abnormalities, anaemia, leucocytopenia, and thrombocytopenia. ${ }^{8,44,45}$

\section{Pulmonary function and exercise capacity tests}

Depending on the severity of the sarcoidosis process in the lung, deterioration of pulmonary function with a wide spectrum of lung function abnormalities can occur. ${ }^{46,47}$ Abnormal pulmonary function tests, including the diffusing capacity for carbon monoxide (DLCO) and forced vital capacity (FVC), are used as indicators for treatment. ${ }^{46}$

A substantial number of sarcoidosis patients are hindered by reduced exercise capacity, as established using the 6-minute walk distance (6MWD). ${ }^{30,48}$ Exercise intolerance is shown to correlate among others with reduced peripheral muscle strength. $^{30,49}$ Information about body composition profiles in sarcoidosis is lacking. However, a trend towards lower levels of fat-free mass (FFM) in sarcoidosis patients with reduced leg muscle strength was found. ${ }^{30}$ Furthermore, cardiopulmonary exercise testing, including maximal oxygen uptake $\left(\mathrm{VO}_{2} \mathrm{max}\right)$, offers added value in monitoring impaired gas exchange during exercise in sarcoidosis patients with disabling symptoms, even in those with normal DLCO at rest. ${ }^{50}$ 


\section{Imaging techniques}

The majority of sarcoidosis patients (between 85 and 95\%) have chest radiograph abnormalities. ${ }^{47}$ According to the Scadding radiographic staging system, five stages of radiographic abnormality can be recognized: stage 0 , normal chest radiography; stage $\mathrm{I}$, bilateral hilar lymphadenopathy (BHL); stage II, BHL and parenchymal abnormalities; stage III, parenchymal abnormalities without BHL; and stage IV, advanced lung fibrosis. $^{1,51}$

HRCT makes it possible to view the lung structure in detail and detect abnormal changes of the lung parenchyma at earlier stages than with chest radiographs. ${ }^{46,47,52-54}$ Furthermore, HRCT is more valuable in making a specific diagnosis compared with chest radiography. ${ }^{55}$ A HRCT scoring system, adapted from one previously described by Oberstein et al. ${ }^{56}$, demonstrated to have a good agreement in intra- and inter-reader reproducibility and moreover, appeared to predict the presence of respiratory functional impairment in sarcoidosis. ${ }^{55}$

In sarcoidosis, PET can be of added value in patients with unexplained persistent disabling symptoms, especially in those without serological signs of inflammatory activity (Figure 1.3), in patients with radiological signs of fibrosis, and in the detection of active cardiac sarcoidosis. ${ }^{41,57-62}$ Furthermore, PET is useful in the assessment of the extent of disease with specific organ involvement to uncover a suitable location for biopsy (for diagnosis) or to explain persistent symptoms. ${ }^{41,57-62}$

MR imaging can be useful for assessment of extrapulmonary sarcoidosis. ${ }^{62}$ Its value in cardiac sarcoidosis and neurosarcoidosis has been demonstrated. ${ }^{62-66}$ In cardiac sarcoidosis, the combined use of PET and cardiac MR imaging may provide optimal detection of the disease by differentiating between patients with active granulomatous inflammation and those with fibrous lesions. ${ }^{62}$ Furthermore, MR imaging can also be helpful when assessing bone marrow and muscular sarcoidosis involvement. ${ }^{62}$

\section{Biopsy}

In the presence of a compatible clinicoradiographic picture, the establishment of granulomas by biopsy can ascertain the diagnosis sarcoidosis. ${ }^{1} \mathrm{~A}$ biopsy is not required in all cases. ${ }^{6}$ A presumptive diagnosis without tissue biopsy can also be made in some special situations, which include the presence of bilateral hilar adenopathy on the chest radiograph of an asymptomatic patient, the presentation with a classic Löfgren's syndrome, and Heerfordt syndrome (uveitis, parotiditis, and fever). ${ }^{1,6}$

A typical clinicoradiographic picture can be combined with the results of BAL fluid analysis to establish the diagnosis of sarcoidosis, without the need for histological confirmation by biopsy. ${ }^{1}$ Furthermore, BAL is also useful in the differential diagnosis of interstitial lung diseases. ${ }^{67}$ In sarcoidosis, the majority of patients have an increased number of lymphocytes and a normal amount of eosinophils and neutrophils in BAL fluid. ${ }^{67,68}$ Furthermore, in most patients an increased CD4/CD8 ratio can be found, which has a high specificity (92-94\%), but low sensitivity (55-59\%). ${ }^{1}$ Since the CD4/CD8 
ratio in BAL can also be normal or decreased, it is of limited diagnostic value in the individual patient. $^{67,68}$

a

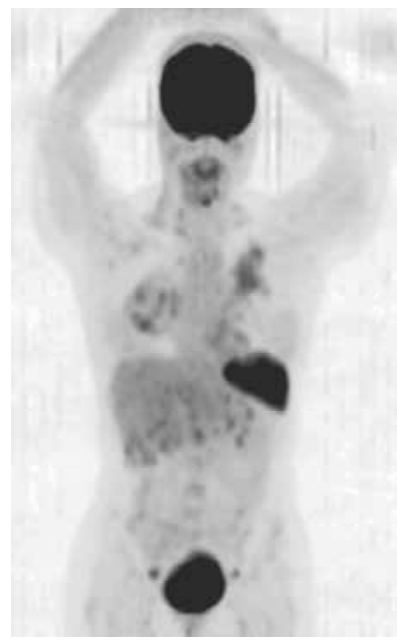

b

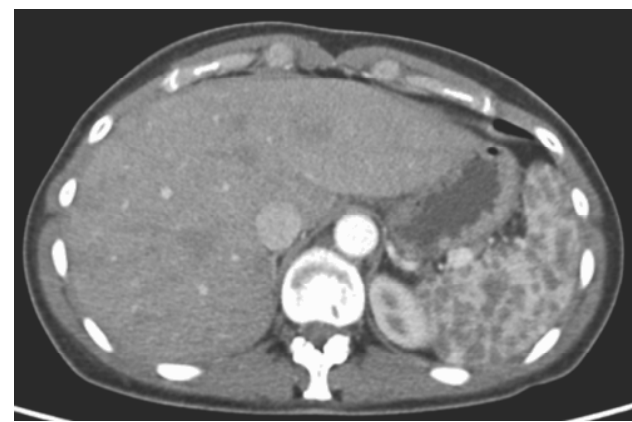

Figure 1.3 A 42-year-old woman with a 2-year history of biopsy-proven sarcoidosis had been suffering from disabling symptoms, such as fatigue, exercise intolerance and muscle weakness for more than a year, without abnormal inflammatory serum parameters. A ${ }^{18}$ F-FDG PET scan was performed. a. The whole-body PET scan showed very high metabolic activity in the spleen and less intense activity in the liver (black). Abnormalities were also seen in the lungs as well as in the para-aortic, para-iliacal and inguinal lymph nodes. Normal physiological glucose uptake was seen in the brain and bladder. b. CT scan showed multiple hypodense lesions in the liver and especially in the spleen.

\section{Therapeutic options}

Most sarcoidosis patients show spontaneous resolution of the disease and do not require systemic therapy. ${ }^{34,51}$ However, for patients with a severe disease course and poor prognosis a timely implementation of a potent individual treatment regimen is important to avoid or slow down the development of complications and to alleviate the disease burden. ${ }^{51}$ Individual series of cases of sarcoidosis have found that the need for systemic therapy ranges from 20 to $70 \%$ of patients. ${ }^{34,69-71}$ of those patients who have commenced therapy, at least half appear to require systemic treatment for more than 2 years. $^{33,34,70}$

Factors which are associated with a good prognosis without the need for systemic therapy are the presence of hilar adenopathy alone, the presence of Lögren's syndrome and the absence of needing systemic therapy within the first 6 months of 
diagnosis. ${ }^{34}$ While these patients in general do well, approximately $10 \%$ will need longterm systemic therapy. ${ }^{33,34,70}$ Patients with adverse prognostic factors (Table 1.1) are more likely to become chronic, requiring long-term treatment. ${ }^{1,33-38}$ However, the majority of these patients can be maintained on a relatively low-dose immunosuppression regimen. ${ }^{34,72}$ A subset of patients require more aggressive treatment. $^{34}$ In a survey of sarcoidosis clinics across the world, this represented approximately $10 \%$ of all patients who were still being seen 5 years after their original diagnosis. $^{34,73}$

The published data on the different treatment options in sarcoidosis are limited and the treatment remains therefore mostly empiric. ${ }^{34,74}$ In particular, there have been only a few high quality placebo controlled, double blind studies of the classical drugs used to treat sarcoidosis. ${ }^{74}$ One of the difficulties has been the lack of standardized validated follow-up measures to assess response to therapy. ${ }^{74}$ However, recommendations for clinical evaluation of the outcome measurements have recently been established. ${ }^{74,75}$

Several pharmacological options exist for patients who require therapy. However, none of these drugs are curative. In cutaneous sarcoidosis, topical treatment can be sufficient to control the disease. ${ }^{6}$ Nonsteroidal anti-inflammatory drugs (NSAIDs) can be effective for symptom relief in patients with arthralgia/arthritis. ${ }^{76,77}$ Furthermore, the antioxidant quercetin is shown to have beneficial effects in sarcoidosis. ${ }^{22}$ This flavonoid offers protection against ROS-induced oxidative damage and has anti-inflammatory capacities by a reducing effect on among others TNF- $\alpha{ }^{22}$

The decision on whether to start systemic immunosuppressive treatment or not should be based on the patient's symptomatology, including those that affect quality of life, as well as the extent of compromised organ function. ${ }^{6,34,74,78}$ Although several immunosuppressive drugs are available, there is a lack of standardized management strategies for sarcoidosis. ${ }^{78}$

\section{First-line therapy: glucocorticosteroids}

In general, glucocorticosteroids are considered the first-line therapy for acute and chronic pulmonary and extrapulmonary sarcoidosis. ${ }^{74,78,79}$ Glucocorticosteroid therapy has been the standard therapy for over 50 years. ${ }^{74}$ Prolonged glucocorticosteroid use is associated with significant side-effects, such as weight gain/obesity, diabetes mellitus or osteoporosis, making glucocorticosteroids undesirable for chronic disease management. ${ }^{78,80}$ Tapering to the lowest effective dose is an ultimate treatment goal and alternative glucocorticosteroid-sparing treatment agents are needed. $6,34,74,78$ Furthermore, in steroid-refractory cases, second-line nonsteroidal drugs, which are referred to as disease-modifying antisarcoid drugs (DMASDs), and third-line therapies, offer alternative strategies. ${ }^{6,34,74,78}$ 


\section{Second-line therapy: disease-modifying antisarcoid drugs}

Several agents have been used as DMASDs in both pulmonary and extrapulmonary sarcoidosis. Table 1.2 summarizes the most important second- and third-line therapeutic agents. Knowledge of second-line agents in sarcoidosis is based on only a few placebo controlled, double blind, randomized trials, but mainly is derived from retrospective clinical trials and case reports. ${ }^{74,78}$

Table 1.2 Overview of second-line and third-line agents for the treatment of sarcoidosis. ${ }^{81-112}$

\begin{tabular}{lc}
\hline Second-line therapeutic agents & Third-line therapeutic agents \\
\hline Methotrexate (MTX) & TNF- $\alpha$ inhibitors \\
Azathioprine (AZA) & Infliximab \\
Leflunomide (LEF) & Adalimumab \\
Mycophenolate mofetil (MMF) & New experimental treatment modalities \\
Pentoxifylline (POF) & Rituximab (RTX) \\
Thalidomide & Vasoactive intestinal peptide (VIP) \\
Cyclosporine A & Apremilast \\
Cyclophosphamide & Armodafinil (in fatigue) \\
(Hydroxy)chloroquine $((\mathrm{H}) \mathrm{CQ})$ & Methylphenidate (in fatigue) \\
& Intravenous immunoglobulins (in SFN) \\
\end{tabular}

SFN, small fiber neuropathy; TNF- $\alpha$, tumor necrosis factor-alpha.

\section{Methotrexate}

Methotrexate (MTX) has been the most widely studied second-line therapeutic agent for sarcoidosis. ${ }^{74}$ The efficacy of MTX has been demonstrated in pulmonary sarcoidosis, but also in cutaneous, ocular, musculoskeletal, liver, and neurological sarcoidosis. ${ }^{82-}$ 84,113-118 MTX is often considered the first-choice DMASD used for patients with sarcoidosis, with $80 \%$ of physicians reporting MTX as their preferred second-line option (Figure 1.4). ${ }^{34,119}$

Initially, the anti-inflammatory effects of MTX were ascribed to its inhibition of cellular proliferation through the inhibition of the enzyme folate reductase, the cytostatic mechanism of action in the treatment of cancer. ${ }^{120,121}$ However, current evidence has shown that its anti-inflammatory action differs from its cytostatic activity. ${ }^{120}$ A proposed mechanism of action of MTX is the reduction of intracellular glutathione levels by an oxidant-associated mechanism, which leads to inhibition of macrophage recruitment and function. ${ }^{121} \mathrm{~A}$ third mechanism is the inhibition of the synthesis of the potentially toxic compounds spermine and spermidine (transmethylation products). ${ }^{121}$ However, the most likely explanation of the antiinflammatory actions of MTX is the stimulation of adenosine release. ${ }^{120,121}$ Adenosine suppresses the inflammatory functions of neutrophils, macrophage/monocytes, dendritic cells and lymphocytes. ${ }^{120,121}$ 


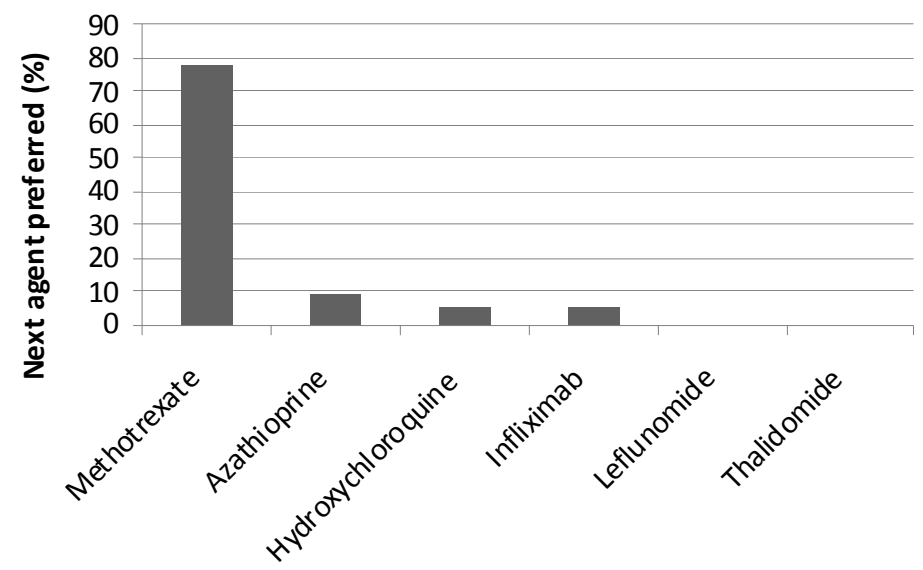

Figure 1.4 Results of a Delphi analysis, showing which agent is preferred as the next agent chosen to add to or to replace glucocorticosteroids for sarcoidosis patients experiencing an inadequate response to glucocorticosteroid use. Data taken from Schutt et al. ${ }^{34,119}$

Many of the typical side-effects of MTX are due to its antifolate properties, including leucocytopenia, anaemia, stomatitis, and alopecia. ${ }^{120}$ Administration of folic acid reduces gastrointestinal and hepatic toxicity without affecting efficacy. ${ }^{122,123}$ Adenosine release may also help explain the MTX induced hepatic toxicity, since adenosine, acting at $A_{1}$ and $A_{2 B}$ receptors, stimulates hepatic steatosis and adenosine, acting at $A_{2 A}$ receptors, plays an important role in the development of hepatic fibrosis. ${ }^{120}$ MTX can also lead to pulmonary toxicity; unexplained cough should lead to evaluation for MTX toxicity (Figure 1.5). ${ }^{74}$ However, the frequency of life threatening interstitial lung disease from MTX is only $1 \% .^{74,124}$

\section{Azathioprine}

Azathioprine (AZA) has been reported as effective in treating pulmonary and extrapulmonary sarcoidosis. ${ }^{74}$ The reports usually have been case series. Compared to MTX, AZA demonstrates a similar efficacy in pulmonary and extrapulmonary sarcoidosis. ${ }^{78,82}$ Both drugs have been shown to be effective steroid-sparing agents in pulmonary sarcoidosis, but more infections were reported with AZA. ${ }^{82}$ 


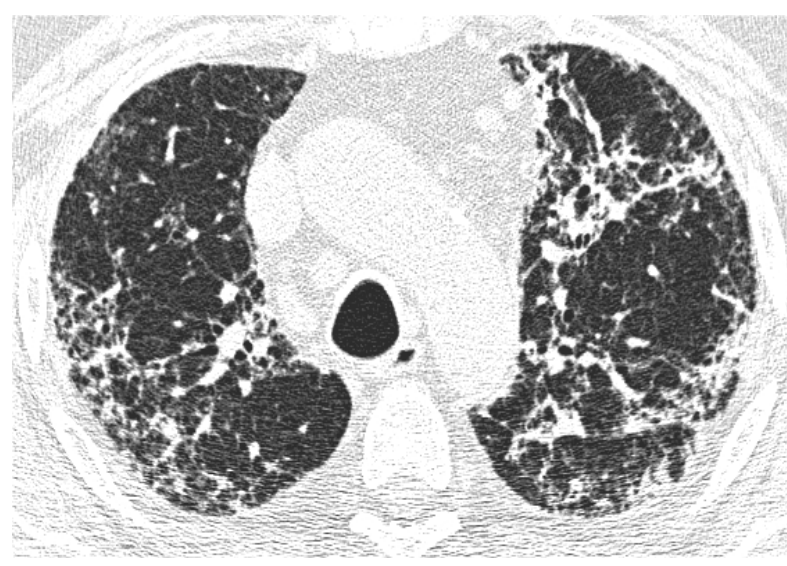

Figure 1.5 High-resolution computed tomography study showing the consequences of pulmonary toxicity caused by methotrexate. There is an irregular reticular pattern with areas of confluent opacities, small cystic changes and a few traction bronchiectasis. These abnormalities are predominantly located in the dorsal and basal part of both lungs. Although on this slice there is some extension of disease in the anterior part of the left lung.

AZA inhibits nucleotide synthesis by feedback inhibition in the early stages of purine metabolism and it prevents $T$ cell and $B$ cell proliferation. ${ }^{125} \mathrm{AZA}$ is metabolized by the enzyme thiopurine S-methyltransferase (TPMT) to 6 -mercaptopurine. ${ }^{74}$ AZA is associated with nausea and leucocytopenia. ${ }^{74}$ Furthermore, it can lead to severe hepatotoxicity. $^{74,126}$ Patients with low or deficient TPMT levels are at higher risk of developing drug-related toxicity. ${ }^{127}$ Heterozygous individuals with intermediate enzymatic activity comprise $5-15 \%$ of patients, while approximately $0.3 \%$ are homozygous, with very low or absent enzymatic activity. ${ }^{128}$ Therefore, measuring TPMT before initiating AZA therapy is recommended. ${ }^{127}$

\section{Leflunomide}

Leflunomide (LEF) is used as an alternative or in addition to MTX. ${ }^{74,78}$ However, there are no studies directly comparing the effectiveness and side-effects of LEF and MTX. LEF has been reported as effective in two observational case series. ${ }^{88,89}$ A complete or partial response for cutaneous, ocular, and sinonasal involvement was seen, but LEF was less effective for neurological and musculoskeletal manifestations. ${ }^{78}$

LEF inhibits the enzyme dihydroorotase in the pyrimidine synthesis. ${ }^{78}$ Major toxicities are similar to $\mathrm{MTX} .^{74,78}$ There is no difference in hepatic or haematologic changes during long-term monitoring in patients treated with both LEF and MTX compared with patients who were treated with MTX alone. ${ }^{74}$ Worrisome side-effects reported for LEF include severe weight loss and peripheral neuropathy. ${ }^{78,88,89}$ Pulmonary toxicity has been reported with LEF, but at a lower rate than that reported 
with MTX. ${ }^{78,124}$ A recently reported safety issue with LEF is silent fibrosis. ${ }^{78}$ Patients with rheumatoid arthritis who received concomitant LEF and MTX for more than 6 months had an increased risk of silent liver fibrosis. ${ }^{78,129}$

\section{Mycophenolate mofetil}

Mycophenolate mofetil (MMF) is an inosine monophosphate dehydrogenase inhibitor that has an antiproliferative effect on lymphocytes and profoundly attenuates the production of autoantibodies by $B$ cells. ${ }^{78}$ A recent study, which evaluated MMF as a steroid-sparing agent in 10 patients with chronic pulmonary sarcoidosis, found significantly reduced daily glucocorticosteroid doses. ${ }^{78,90}$ Furthermore, in four patients a reduction of pulmonary symptoms and radiological signs and improvements in pulmonary function were seen; whereas, the other six patients' diseases remained stable. ${ }^{90} \mathrm{MMF}$ might also have a role in neurosarcoidosis affecting the central nervous system. ${ }^{130}$ Combining MMF with systemic glucocorticosteroids did not cause any severe side-effects. ${ }^{90,130}$ Adding MMF to glucocorticosteroids may be a viable and safe treatment option in chronic pulmonary and central nervous system sarcoidosis, but additional studies are necessary.

\section{Pentoxifylline}

Pentoxifylline (POF), a methylxanthine derivative, inhibits phosphodiesterase resulting in reduction of inflammation by inhibition of a number of pro-inflammatory cytokines, including TNF- $\alpha{ }^{74}$ Some studies reported POF to be an effective therapeutic option in acute pulmonary sarcoidosis, with improvement of DLCO and a trend for the drug to be steroid-sparing. ${ }^{91,92}$ The drug is associated with significant gastrointestinal toxicity, which limits its use in treatment of chronic sarcoidosis. ${ }^{35,74}$

\section{Thalidomide}

Thalidomide is a synthetic derivate of glutamic acid and has several molecular targets. The most important function in sarcoidosis is the inhibition of TNF- $\alpha$ production. ${ }^{125}$ It was first reported as an effective treatment in chronic cutaneous sarcoidosis. ${ }^{131}$ In pulmonary sarcoidosis, thalidomide has been proven effective in improving pulmonary function, whereas in some cases the drug was steroid-sparing. ${ }^{93,94}$ Recent in vitro research showed inhibitory effects of thalidomide on lung fibroblasts, which needs further investigation in vivo. ${ }^{132}$ Thalidomide has severe teratogenic effects. Side-effects include peripheral neuropathy, hypersomnulance, and an increased risk for deep venous thrombosis and pulmonary embolism. ${ }^{94}$ 


\section{Cyclosporine A}

Cyclosporine is a fungal peptide that suppresses $\mathrm{T}$ cell activation. ${ }^{125}$ In some case reports it was thought to be effective for refractory disease. ${ }^{74,133}$ However, a double blind, randomized trial of chronic pulmonary sarcoidosis found no significant benefit from adding cyclosporine $A$ to glucocorticosteroids therapy in terms of pulmonary function or steroid-sparing potency. ${ }^{95}$ The drug is associated with major side-effects, including hypertension, renal dysfunction, increased risk for opportunistic infections, and malignancy. ${ }^{95}$ Therefore, cyclosporine $A$ is rarely used to treat sarcoidosis. ${ }^{74}$

\section{Cyclophosphamide}

Cyclophosphamide is metabolized in the liver into active alkylating metabolites, which inhibit lymphocyte number and function with suppression of both cellular and humoral immunity. ${ }^{78,125}$ In sarcoidois, cyclophosphamide is typically used for cardiac sarcoidosis or neurosarcoidosis. ${ }^{78,134-136}$ Adverse events are generally mild, mainly consisting of gastrointestinal symptoms. ${ }^{78}$ However, major side-effects, like hemorrhagic cystitis, recurrent pneumonia, and liver test abnormalities, require cyclophosphamide discontinuation. ${ }^{137}$ It also possesses the risk of ovarian failure in women of reproductive age. $^{78}$

\section{Chloroquine and hydroxychloroquine}

The antimalarial agents, chloroquine (CQ) and hydroxychloroquine (HCQ), have demonstrated efficacy in sarcoidosis, most likely as a result of their immunomodulatory properties. $^{74,78} \mathrm{CQ}$ has been used for both cutaneous and pulmonary sarcoidosis, whereas HCQ is mostly effective for cutaneous sarcoidosis. ${ }^{74,78,96,138,139} \mathrm{CQ}$ is associated with significant gastrointestinal and ocular toxicity, which is dose dependent. ${ }^{74,140} \mathrm{HCQ}$ has been preferred, but monitoring for ocular toxicity is still necessary. ${ }^{74,141}$

\section{Third-line therapy: TNF- $\alpha$ inhibitors and new experimental treatment modalities}

For some patients with sarcoidosis, glucocorticosteroids and DMASDs may not control disease. $^{74}$ In certain patients, excessive production of TNF- $\alpha$ by alveolar macrophages retrieved by BAL has been reported. ${ }^{142}$ Several biological agents which specifically inhibit TNF- $\alpha$ have become available and have demonstrated efficacy in sarcoidosis, especially in patients refractory to other treatments. ${ }^{74,78}$ Furthermore, some new experimental treatment modalities can form alternative third-line therapeutic options (Table 1.2). ${ }^{74,78}$ 


\section{TNF- $\alpha$ inhibitors}

TNF- $\alpha$ inhibitors might be a valuable treatment option for patients with pulmonary and/or extrapulmonary sarcoidosis refractory to conventional therapy, on the condition that they are used with caution. ${ }^{78}$ Infliximab is a biological chimeric monoclonal antibody that binds to free TNF- $\alpha$, blocking its interaction with the TNF-receptor, and sometimes to cell surface TNF- $\alpha .{ }^{125}$ Two double blind, placebo controlled trials of infliximab in patients with chronic pulmonary sarcoidosis showed a significant improvement of $\mathrm{FVC}^{98,99}$ and in one study improvement in chest radiographs. ${ }^{98}$ Judson et al. ${ }^{143}$ used an extrapulmonary physician organ severity tool for evaluation of specific organ involvement in sarcoidosis. Although the sample size was low, their results suggest that infliximab may be beneficial in extrapulmonary sarcoidosis. A recent retrospective study investigated the sustainability of infliximab response in pulmonary and extrapulmonary sarcoidosis for up to 85 months and concluded that infliximab has the capacity to maintain improvements in sarcoidosis over time, based on the finding that $58,5 \%$ of the organs evaluated achieved improvement. ${ }^{97}$

Adalimumab is a recombinant fully human monoclonal antibody against TNF- $\alpha .^{74}$ Prospective observational studies have shown effectiveness of adalimumab in treating refractory posterior uveitis $^{100}$, in decreasing total sarcoidosis disease activity as measured by $\mathrm{PET}^{101}$, and in improving radiological abnormalities. ${ }^{102}$ Adalimumab also has a positive effect on cognition and fatigue in sarcoidosis. ${ }^{144}$ Furthermore, a recent study has shown adalimumab to be a possible effective and relatively safe treatment in cutaneous sarcoidosis. ${ }^{145}$

Etanercept is a TNF-receptor antagonist. ${ }^{74}$ It has been reported effective in some cases of refractory sarcoidosis, but in an open label trial of pulmonary sarcoidosis etanercept alone was associated with treatment failure in 12 of 17 cases. $^{103}$ Furthermore, the drug failed in a double blind, placebo controlled trial of patients with refractory sarcoidosis uveitis. ${ }^{146}$ These results are in line with observations in Crohn's disease. ${ }^{147}$

For all TNF- $\alpha$ inhibitors similar toxicities have been reported. ${ }^{148}$ These include allergic reaction to the agents, which is most likely to occur with infliximab since this agent is a chimeric antibody. ${ }^{74}$ The concurrent use of MTX or other cytotoxic drugs has been advised to reduce the risk of antibody formation directed against infliximab. ${ }^{149}$ There is a marked increased risk for reactivation of tuberculosis and increased severity of tuberculosis course associated with the use of TNF- $\alpha$ inhibitors. ${ }^{78}$ Prior to starting anti-TNF- $\alpha$ therapy, screening for latent tuberculosis, using interferon-gamma release assays (IGRAs), is recommended. ${ }^{74,78,150}$ Furthermore, there have been several reports of sarcoidosis like reactions during the use of TNF- $\alpha$ inhibitors in other diseases. Fortunately, the prognosis is good, with complete resolution of the event after discontinuation in most cases. ${ }^{74,78,151,152}$ 


\section{New experimental treatment modalities}

Rituximab (RTX), a chimeric monoclonal antibody that targets CD-20 cells and considerably reduces the number of mature $B$ lymphocytes in the circulation. ${ }^{74,78}$ It has been reported as effective for refractory sarcoidosis in case reports. ${ }^{104-106,153,154}$ The drug has significant toxicity, including increased risk for viral infections. ${ }^{74,106}$

Inhaled vasoactive intestinal peptide (VIP) is reported to be associated with significant changes in the release of several cytokines by alveolar macrophages retrieved by BAL. ${ }^{107}$ There was not a change in the FVC. ${ }^{107}$ This study was small with a short follow-up time. ${ }^{74}$ The drug was well tolerated, but due to a large number of treatments per day its application may be limited. ${ }^{74}$

A new phosphodiesterase inhibitor, apremilast, has been reported as effective for chronic cutaneous sarcoidosis. ${ }^{74,78,108}$ It has not yet been reported in the treatment of pulmonary sarcoidosis.

Sarcoidosis can be accompanied by devastating fatigue and by serious symptoms caused by small fiber neuropathy (SFN). These features do not always respond to the treatment options discussed above. Reduction in sarcoidosis-associated fatigue was demonstrated in patients treated with the neurostimulant methylphenidate and the central nervous system stimulant armodafinil. ${ }^{29,109,110}$ In SFN, standard treatment options, such as antidepressants, anticonvulsants, topical anesthetics, and opioids, are only effective for symptom relieve in $30-60 \%$ of patients. $^{78,111}$ Intravenous immunoglobulins seem to be promising, but require further study. ${ }^{78,111}$ A novel therapy is ARA 290, a nonhaematopoietic erythropoietin analogue designed to activate the innate repair receptor, with potent anti-inflammatory and tissue protective properties. ${ }^{111,112}$ Recently, the efficacy of ARA 290 was shown in a pilot study in patients with sarcoidosis suffering from SFN. ${ }^{112}$

\section{Scope and aims of this thesis}

In current clinical practice, there is a lack of standardized management strategies for sarcoidosis, despite the availability of several immunosuppressive therapeutic options. Evidence-based recommendations for the optimized use of the consecutive first-, second-, and third-line therapies are lacking. Sarcoidosis is a disease which can present to any one of a variety of organ specialists, which explains that therapeutic decisions are highly dependent on the individual specialist's expertise. Inexperience among physicians can lead to suboptimal application of pharmacotherapeutic possibilities.

Optimization of therapeutic options is important to avoid unnecessary exposure of patients to consecutive pharmacological agents. Furthermore, in view of the promising results of biological agents for refractory sarcoidosis patients, a trend seems to be emerging amongst the healthcare providers towards a low threshold for switching from second-line to third-line agents. However, the drawbacks of using biological agents on a 
large scale are potential major side-effects and considerable costs. It is important to improve the use of less expensive, but effective DMASDs, in order to keep the healthcare system affordable and accessible to all. Biologicals should only be started for the correct indication and under experienced supervision. Since sarcoidosis is not one disease, but rather a mixed group of conditions, individualized therapy is inevitable guided by appropriate diagnostic procedures to assess the extent of the disease. Optimal use of pharmacotherapeutic options can serve to help pursue personalized medicine for the individual patient.

The aim of the studies presented in this thesis was to improve the pharmacotherapeutic management of sarcoidosis patients. Several aspects in terms of amelioration of treatment were investigated, with emphasis on the meaning of body composition profiling in sarcoidosis, the desirable handling of liver test abnormalities, the development of practical recommendations for the use of MTX and TNF- $\alpha$ inhibitors, and the exploration of possible factors identifying responders to TNF- $\alpha$ inhibitors.

Chapter 2 provides an overview of the extent, distribution and consistency of organ involvement detected by PET in 158 sarcoidosis patients with persistent disabling symptoms. Chapter 3 reports on the prevalence of cachexia and muscle atrophy in 423 Dutch sarcoidosis patients, and the association of these body composition profiles with sarcoidosis disease activity and severity. Chapter 4 describes the presence and severity of liver test abnormalities in 837 patients with confirmed sarcoidosis. Additionally, the association between severity of liver test abnormalities and histopathological abnormalities in hepatic sarcoidosis was evaluated. Chapter $\mathbf{5}$ provides an overview of therapeutic options for sarcoidosis liver involvement, and combines these data into recommendations for the optimal therapeutic approach of hepatic sarcoidosis. Chapter 6 presents the development of practical recommendations, on behalf of the World Association of Sarcoidosis and Other Granulomatous Disorders (WASOG), for the use of MTX in sarcoidosis by integrating the evidence obtained through a systematic literature review and the expert opinions of 113 sarcoidologists worldwide. Chapter 7 describes the development of practical recommendations for the use of the TNF- $\alpha$ inhibitors infliximab and adalimumab in sarcoidosis by combining the evidence from both a systematic literature search and the opinions of the world's leading sarcoidosis experts. Chapter 8 assesses the association between the presence of the TNF- $\alpha$ G-308A polymorphism and the response to TNF- $\alpha$ inhibitors amongst 111 patients with refractory sarcoidosis. Chapter 9 summarizes the findings presented in this thesis and argues their implications. Finally, directions for future research are discussed. 


\section{References}

1. Statement on sarcoidosis. Joint Statement of the American Thoracic Society (ATS), the European Respiratory Society (ERS) and the World Association of Sarcoidosis and Other Granulomatous Disorders (WASOG) adopted by the ATS Board of Directors and by the ERS Executive Committee, February 1999. Am J Respir Crit Care Med 1999;160:736-755.

2. Iannuzzi MC, Fontana JR. Sarcoidosis: clinical presentation, immunopathogenesis, and therapeutics. Jama 2011;305:391-399.

3. Pietinalho A, Hiraga $Y$, Hosoda $Y$, Lofroos AB, Yamaguchi M, Selroos O. The frequency of sarcoidosis in Finland and Hokkaido, Japan. A comparative epidemiological study. Sarcoidosis 1995;12:61-67.

4. Rybicki BA, Major M, Popovich J, Jr., Maliarik MJ, lannuzzi MC. Racial differences in sarcoidosis incidence: a 5-year study in a health maintenance organization. Am J Epidemiol 1997;145:234-241.

5. Wirnsberger RM, De Vries J, Wouters EF, Drent M. Clinical presentation of sarcoidosis in The Netherlands an epidemiological study. Neth J Med 1998;53:53-60.

6. Baughman RP, Culver DA, Judson MA. A concise review of pulmonary sarcoidosis. Am J Respir Crit Care Med 2011;183:573-581.

7. Boots AW, Drent M, Swennen EL, Moonen HJ, Bast A, Haenen GR. Antioxidant status associated with inflammation in sarcoidosis: a potential role for antioxidants. Respir Med 2009;103:364-372.

8. Iannuzzi MC, Rybicki BA, Teirstein AS. Sarcoidosis. N Engl J Med 2007;357:2153-2165.

9. Prasse A, Kayser G, Warnatz K. Common variable immunodeficiency-associated granulomatous and interstitial lung disease. Curr Opin Pulm Med 2013;19:503-509.

10. Shigehara K, Shijubo N, Ohmichi M, Takahashi R, Kon S, Okamura H, Kurimoto M, Hiraga Y, Tatsuno T, Abe S, Sato N. IL-12 and IL-18 are increased and stimulate IFN-gamma production in sarcoid lungs. J Immunol 2001;166:642-649.

11. Newman KL, Newman LS. Occupational causes of sarcoidosis. Curr Opin Allergy Clin Immunol 2013;12:145-150.

12. Newman LS, Rose CS, Bresnitz EA, Rossman MD, Barnard J, Frederick M, Terrin ML, Weinberger SE, Moller DR, McLennan G, Hunninghake G, DePalo L, Baughman RP, lannuzzi MC, Judson MA, Knatterud GL, Thompson BW, Teirstein AS, Yeager H, Jr., Johns CJ, Rabin DL, Rybicki BA, Cherniack R. A case control etiologic study of sarcoidosis: environmental and occupational risk factors. Am J Respir Crit Care Med 2004;170:1324-1330.

13. Iannuzzi MC. Genetics of sarcoidosis. Monaldi Arch Chest Dis 1998;53:609-613.

14. Rybicki BA, lannuzzi MC, Frederick MM, Thompson BW, Rossman MD, Bresnitz EA, Terrin ML, Moller DR, Barnard J, Baughman RP, DePalo L, Hunninghake G, Johns C, Judson MA, Knatterud GL, McLennan G, Newman LS, Rabin DL, Rose C, Teirstein AS, Weinberger SE, Yeager H, Cherniack R. Familial aggregation of sarcoidosis. A case-control etiologic study of sarcoidosis (ACCESS). Am J Respir Crit Care Med 2001;164:2085-2091.

15. Rossman MD, Thompson B, Frederick M, Maliarik M, lannuzzi MC, Rybicki BA, Pandey JP, Newman LS, Magira E, Beznik-Cizman B, Monos D. HLA-DRB1*1101: a significant risk factor for sarcoidosis in blacks and whites. Am J Hum Genet 2003;73:720-735.

16. Sato H, Grutters JC, Pantelidis P, Mizzon AN, Ahmad T, Van Houte AJ, Lammers JW, Van den Bosch JM, Welsh KI, Du Bois RM. HLA-DQB1*0201: a marker for good prognosis in British and Dutch patients with sarcoidosis. Am J Respir Cell Mol Biol 2002;27:406-412.

17. Grunewald J. HLA associations and Löfgren's syndrome. Expert Rev Clin Immunol 2012;8:55-62.

18. Wijnen PA, Nelemans PJ, Verschakelen JA, Bekers O, Voorter CE, Drent M. The role of tumor necrosis factor alpha G-308A polymorphisms in the course of pulmonary sarcoidosis. Tissue antigens 2010;75:262-268.

19. Wijnen PA, Voorter CE, Nelemans PJ, Verschakelen JA, Bekers O, Drent M. Butyrophilin-like 2 in pulmonary sarcoidosis: a factor for susceptibility and progression? Hum Immunol 2011;72:342-347.

20. Valentonyte R, Hampe J, Huse K, Rosenstiel P, Albrecht M, Stenzel A, Nagy M, Gaede KI, Franke A, Haesler R, Koch A, Lengauer T, Seegert D, Reiling N, Ehlers S, Schwinger E, Platzer M, Krawczak M, Muller-Quernheim J, Schurmann M, Schreiber S. Sarcoidosis is associated with a truncating splice site mutation in BTNL2. Nat Genet 2005;37:357-364. 
21. Wennerstrom A, Pietinalho A, Lasota J, Salli K, Surakka I, Seppanen M, Selroos O, Lokki ML. Major histocompatibility complex class II and BTNL2 associations in sarcoidosis. Eur Respir J 2013;42:550-553.

22. Boots AW, Drent M, De Boer VC, Bast A, Haenen GR. Quercetin reduces markers of oxidative stress and inflammation in sarcoidosis. Clin Nutr 2011;30:506-512.

23. Kanoh S, Kobayashi H, Motoyoshi K. Exhaled ethane: an in vivo biomarker of lipid peroxidation in interstitial lung diseases. Chest 2005;128:2387-2392.

24. Rothkrantz-Kos S, Drent M, Vuil H, De Boer M, Bast A, Wouters EF, Roos D, Van Dieijen-Visser MP. Decreased redox state in red blood cells from patients with sarcoidosis. Sarcoidosis Vasc Diffuse Lung Dis 2002;19:114-120.

25. Drent M, Van den Berg R, Haenen GR, Van den Berg H, Wouters EF, Bast A. NF-kappaB activation in sarcoidosis. Sarcoidosis Vasc Diffuse Lung Dis 2001;18:50-56.

26. Lenz AG, Costabel U, Maier KL. Oxidized BAL fluid proteins in patients with interstitial lung diseases. Eur Respir J 1996;9:307-312.

27. Rottoli P, Magi B, Cianti R, Bargagli E, Vagaggini C, Nikiforakis N, Pallini V, Bini L. Carbonylated proteins in bronchoalveolar lavage of patients with sarcoidosis, pulmonary fibrosis associated with systemic sclerosis and idiopathic pulmonary fibrosis. Proteomics 2005;5:2612-2618.

28. Reich JM. On the nature of sarcoidosis. Eur J Intern Med 2011;23:105-109.

29. Drent M, Lower EE, De Vries J. Sarcoidosis-associated fatigue. Eur Respir J 2012;40:255-263.

30. Marcellis RG, Lenssen AF, Elfferich MD, De Vries J, Kassim S, Foerster K, Drent M. Exercise capacity, muscle strength and fatigue in sarcoidosis. Eur Respir J 2011;38:628-634.

31. Marcellis RG, Lenssen AF, Kleynen S, De Vries J, Drent M. Exercise capacity, muscle strength, and fatigue in sarcoidosis: a follow-up study. Lung 2013;191:247-256.

32. Sharma OP. Fatigue and sarcoidosis. Eur Respir J 1999;13:713-714.

33. Baughman RP, Judson MA, Teirstein A, Yeager H, Rossman M, Knatterud GL, Thompson B. Presenting characteristics as predictors of duration of treatment in sarcoidosis. Qjm 2006;99:307-315.

34. Baughman RP, Nunes H. Therapy for sarcoidosis: evidence-based recommendations. Expert Rev Clin Immunol 2012;8:95-103.

35. Lazar CA, Culver DA. Treatment of sarcoidosis. Semin Respir Crit Care Med 2010;31:501-518.

36. Baughman RP, Teirstein AS, Judson MA, Rossman MD, Yeager H, Jr., Bresnitz EA, DePalo L, Hunninghake G, lannuzzi MC, Johns CJ, McLennan G, Moller DR, Newman LS, Rabin DL, Rose C, Rybicki B, Weinberger $\mathrm{SE}$, Terrin ML, Knatterud GL, Cherniak R. Clinical characteristics of patients in a case control study of sarcoidosis. Am J Respir Crit Care Med 2001;164:1885-1889.

37. Neville E, Walker AN, James DG. Prognostic factors predicting the outcome of sarcoidosis: an analysis of 818 patients. Q J Med 1983;52:525-533.

38. Mana J, Salazar A, Manresa F. Clinical factors predicting persistence of activity in sarcoidosis: a multivariate analysis of 193 cases. Respiration 1994;61:219-225.

39. Rothkrantz-Kos S, Van Dieijen-Visser MP, Mulder PG, Drent M. Potential usefulness of inflammatory markers to monitor respiratory functional impairment in sarcoidosis. Clin Chem 2003;49:1510-1517.

40. Ziegenhagen MW, Benner UK, Zissel G, Zabel P, Schlaak M, Muller-Quernheim J. Sarcoidosis: TNF-alpha release from alveolar macrophages and serum level of sIL-2R are prognostic markers. Am J Respir Crit Care Med 1997;156:1586-1592.

41. Mostard RL, Voo S, Van Kroonenburgh MJ, Verschakelen JA, Wijnen PA, Nelemans PJ, Erckens RJ, Drent M. Inflammatory activity assessment by F18 FDG-PET/CT in persistent symptomatic sarcoidosis. Respir Med 2011;105:1917-1924.

42. Grutters JC, Fellrath JM, Mulder L, Janssen R, Van den Bosch JM, Van Velzen-Blad H. Serum soluble interleukin-2 receptor measurement in patients with sarcoidosis: a clinical evaluation. Chest 2003;124:186-195.

43. Vucinic V, Skodric-Trifunovic V, Ignjatovic S. How to diagnose and manage difficult problems of calcium metabolism in sarcoidosis: an evidence-based review. Curr Opin Pulm Med 2011;17:297-302.

44. Lower EE, Smith JT, Martelo OJ, Baughman RP. The anemia of sarcoidosis. Sarcoidosis 1988;5:51-55.

45. Mostard RL, Prompers L, Weijers RE, Van Kroonenburgh MJ, Wijnen PA, Geusens PP, Drent M. F-18 FDG $\mathrm{PET} / \mathrm{CT}$ for detecting bone and bone marrow involvement in sarcoidosis patients. Clin Nucl Med 2012;37:21-25.

46. Consensus conference: activity of sarcoidosis. Third WASOG meeting, Los Angeles, USA, September 811, 1993. Eur Respir J 1994;7:624-627. 
47. Keir G, Wells AU. Assessing pulmonary disease and response to therapy: which test? Semin Respir Crit Care Med 2010;31:409-418.

48. Baughman RP, Lower EE. Six-minute walk test in managing and monitoring sarcoidosis patients. Curr Opin Pulm Med 2007;13:439-444.

49. Spruit MA, Thomeer MJ, Gosselink R, Troosters T, Kasran A, Debrock AJ, Demedts MG, Decramer M. Skeletal muscle weakness in patients with sarcoidosis and its relationship with exercise intolerance and reduced health status. Thorax 2005;60:32-38.

50. Marcellis RG, Lenssen AF, De Vries GJ, Baughman RP, Van der Grinten CP, Verschakelen JA, De Vries J, Drent $M$. Is there an added value of cardiopulmonary exercise testing in sarcoidosis patients? Lung 2013;191:43-52.

51. Hunninghake GW, Costabel U, Ando M, Baughman R, Cordier JF, du Bois R, Eklund A, Kitaichi M, Lynch J, Rizzato G, Rose C, Selroos O, Semenzato G, Sharma OP. ATS/ERS/WASOG statement on sarcoidosis. American Thoracic Society/European Respiratory Society/World Association of Sarcoidosis and other Granulomatous Disorders. Sarcoidosis Vasc Diffuse Lung Dis 1999;16:149-173.

52. Verschakelen JA. The role of high-resolution computed tomography in the work-up of interstitial lung disease. Curr Opin Pulm Med 2010;16:503-510.

53. Murata K, Khan A, Herman PG. Pulmonary parenchymal disease: evaluation with high-resolution CT. Radiology 1989;170:629-635.

54. Wells A. High resolution computed tomography in sarcoidosis: a clinical perspective. Sarcoidosis Vasc Diffuse Lung Dis 1998;15:140-146.

55. Drent M, De Vries J, Lenters M, Lamers RJ, Rothkranz-Kos S, Wouters EF, Van Dieijen-Visser MP, Verschakelen JA. Sarcoidosis: assessment of disease severity using HRCT. Eur Radiol 2003;13:24622471.

56. Oberstein A, von Zitzewitz H, Schweden F, Muller-Quernheim J. Non invasive evaluation of the inflammatory activity in sarcoidosis with high-resolution computed tomography. Sarcoidosis Vasc Diffuse Lung Dis 1997;14:65-72.

57. Mostard RL, Van Kroonenburgh MJ, Drent M. The role of the PET scan in the management of sarcoidosis. Curr Opin Pulm Med 2013;19:538-544.

58. Teirstein AS, Machac J, Almeida O, Lu P, Padilla ML, lannuzzi MC. Results of 188 whole-body fluorodeoxyglucose positron emission tomography scans in 137 patients with sarcoidosis. Chest 2007;132:1949-1953.

59. Keijsers RG, Grutters JC, Thomeer M, Du Bois RM, Van Buul MM, Lavalaye J, Van den Bosch JM, Verzijlbergen FJ. Imaging the inflammatory activity of sarcoidosis: sensitivity and inter observer agreement of (67)Ga imaging and (18)F-FDG PET. Q J Nucl Med Mol Imaging 2011;55:66-71.

60. Keijsers RG, Van den Heuvel DA, Grutters JC. Imaging the inflammatory activity of sarcoidosis. Eur Respir J 2012;41:743-751.

61. Treglia G, Taralli S, Giordano A. Emerging role of whole-body 18F-fluorodeoxyglucose positron emission tomography as a marker of disease activity in patients with sarcoidosis: a systematic review. Sarcoidosis Vasc Diffuse Lung Dis 2011;28:87-94.

62. Soussan M, Augier A, Brillet PY, Weinmann P, Valeyre D. Functional Imaging in Extrapulmonary Sarcoidosis: FDG-PET/CT and MR Features. Clinical nuclear medicine 2013;Epud ahead of print.

63. Youssef G, Beanlands RS, Birnie DH, Nery PB. Cardiac sarcoidosis: applications of imaging in diagnosis and directing treatment. Heart 2011;97:2078-2087.

64. Sekhri V, Sanal S, Delorenzo LJ, Aronow WS, Maguire GP. Cardiac sarcoidosis: a comprehensive review. Arch Med Sci 2011;7:546-554.

65. Vignaux O, Dhote R, Duboc D, Blanche P, Devaux JY, Weber S, Legmann P. Detection of myocardial involvement in patients with sarcoidosis applying T2-weighted, contrast-enhanced, and cine magnetic resonance imaging: initial results of a prospective study. J Comput Assist Tomogr 2002;26:762-767.

66. Ginat DT, Dhillon G, Almast J. Magnetic resonance imaging of neurosarcoidosis. J Clin Imaging Sci 2011;1:15.

67. Meyer KC, Raghu G, Baughman RP, Brown KK, Costabel U, du Bois RM, Drent M, Haslam PL, Kim DS, Nagai S, Rottoli P, Saltini C, Selman M, Strange C, Wood B. An official American Thoracic Society clinical practice guideline: the clinical utility of bronchoalveolar lavage cellular analysis in interstitial lung disease. Am J Respir Crit Care Med 2012;185:1004-1014. 
68. Drent M, Mansour K, Linssen C. Bronchoalveolar lavage in sarcoidosis. Semin Respir Crit Care Med 2007;28:486-495.

69. Rizzato G, Montemurro L, Colombo P. The late follow-up of chronic sarcoid patients previously treated with corticosteroids. Sarcoidosis Vasc Diffuse Lung Dis 1998;15:52-58.

70. Gottlieb JE, Israel HL, Steiner RM, Triolo J, Patrick H. Outcome in sarcoidosis. The relationship of relapse to corticosteroid therapy. Chest 1997;111:623-631.

71. Gibson GJ, Prescott RJ, Muers MF, Middleton WG, Mitchell DN, Connolly CK, Harrison BD. British Thoracic Society Sarcoidosis study: effects of long term corticosteroid treatment. Thorax 1996;51:238247.

72. Johns CJ, Michele TM. The clinical management of sarcoidosis. A 50-year experience at the Johns Hopkins Hospital. Medicine 1999;78:65-111.

73. Baughman RP, Nagai S, Balter M, Costabel U, Drent M, du Bois R, Grutters JC, Judson MA, Lambiri I, Lower EE, Muller-Quernheim J, Prasse A, Rizzato G, Rottoli P, Spagnolo P, Teirstein A. Defining the clinical outcome status (COS) in sarcoidosis: results of WASOG Task Force. Sarcoidosis Vasc Diffuse Lung Dis 2011;28:56-64.

74. Baughman RP, Nunes H, Sweiss NJ, Lower EE. Established and experimental medical therapy of pulmonary sarcoidosis. Eur Respir J 2013;41:1424-1438.

75. Baughman RP, Drent M, Culver DA, Grutters JC, Handa T, Humbert M, Judson MA, Lower EE, Mana J, Pereira CA, Prasse A, Sulica R, Valyere D, Vucinic V, Wells AU. Endpoints for clinical trials of sarcoidosis. Sarcoidosis Vasc Diffuse Lung Dis 2012;29:90-98.

76. Torralba KD, Quismorio FP, Jr. Sarcoid arthritis: a review of clinical features, pathology and therapy. Sarcoidosis Vasc Diffuse Lung Dis 2003;20:95-103.

77. Sweiss NJ, Patterson K, Sawaqed R, Jabbar U, Korsten P, Hogarth K, Wollman R, Garcia JG, Niewold TB, Baughman RP. Rheumatologic manifestations of sarcoidosis. Semin Respir Crit Care Med 2010;31:463473.

78. Korsten P, Mirsaeidi M, Sweiss NJ. Nonsteroidal therapy of sarcoidosis. Curr Opin Pulm Med 2013;19:516-523.

79. Grutters JC, Van den Bosch JM. Corticosteroid treatment in sarcoidosis. Eur Respir J 2006;28:627-636.

80. Baughman RP. Pulmonary sarcoidosis. Clin Chest Med 2004;25:521-530, vi.

81. Baughman RP, Winget DB, Lower EE. Methotrexate is steroid sparing in acute sarcoidosis: results of a double blind, randomized trial. Sarcoidosis Vasc Diffuse Lung Dis 2000;17:60-66.

82. Vorselaars AD, Wuyts WA, Vorselaars VM, Zanen P, Deneer VH, Veltkamp M, Thomeer M, Van Moorsel $\mathrm{CH}$, Grutters JC. Methotrexate versus azathioprine in second line therapy of sarcoidosis. Chest 2013;144:805-812.

83. Lower EE, Baughman RP. Prolonged use of methotrexate for sarcoidosis. Arch Intern Med $1995 ; 155: 846-851$.

84. Vucinic VM. What is the future of methotrexate in sarcoidosis? A study and review. Curr Opin Pulm Med 2002;8:470-476.

85. Baughman RP, Lower EE. Alternatives to corticosteroids in the treatment of sarcoidosis. Sarcoidosis Vasc Diffuse Lung Dis 1997;14:121-130.

86. Muller-Quernheim J, Kienast K, Held M, Pfeifer S, Costabel U. Treatment of chronic sarcoidosis with an azathioprine/prednisolone regimen. Eur Respir J 1999;14:1117-1122.

87. Lewis SJ, Ainslie GM, Bateman ED. Efficacy of azathioprine as second-line treatment in pulmonary sarcoidosis. Sarcoidosis Vasc Diffuse Lung Dis 1999;16:87-92.

88. Baughman RP, Lower EE. Leflunomide for chronic sarcoidosis. Sarcoidosis Vasc Diffuse Lung Dis 2004;21:43-48.

89. Sahoo DH, Bandyopadhyay D, Xu M, Pearson K, Parambil JG, Lazar CA, Chapman JT, Culver DA. Effectiveness and safety of leflunomide for pulmonary and extrapulmonary sarcoidosis. Eur Respir $J$ 2011;38:1145-1150.

90. Brill AK, Ott SR, Geiser T. Effect and Safety of Mycophenolate Mofetil in Chronic Pulmonary Sarcoidosis: A Retrospective Study. Respiration 2012;Epub ahead of print.

91. Zabel P, Entzian P, Dalhoff K, Schlaak M. Pentoxifylline in treatment of sarcoidosis. Am J Respir Crit Care Med 1997;155:1665-1669. 
92. Park MK, Fontana, Jr., Babaali H, Gilbert-McClain LI, Stylianou M, Joo J, Moss J, Manganiello VC. Steroidsparing effects of pentoxifylline in pulmonary sarcoidosis. Sarcoidosis Vasc Diffuse Lung Dis 2009;26:121-131.

93. Judson MA, Silvestri J, Hartung C, Byars T, Cox CE. The effect of thalidomide on corticosteroiddependent pulmonary sarcoidosis. Sarcoidosis Vasc Diffuse Lung Dis 2006;23:51-57.

94. Baughman RP, Judson MA, Teirstein AS, Moller DR, Lower EE. Thalidomide for chronic sarcoidosis. Chest 2002;122:227-232.

95. Wyser CP, Van Schalkwyk EM, Alheit B, Bardin PG, Joubert JR. Treatment of progressive pulmonary sarcoidosis with cyclosporin A. A randomized controlled trial. Am J Respir Crit Care Med 1997;156:13711376.

96. Baltzan M, Mehta S, Kirkham TH, Cosio MG. Randomized trial of prolonged chloroquine therapy in advanced pulmonary sarcoidosis. Am J Respir Crit Care Med 1999;160:192-197.

97. Russell E, Luk F, Manocha S, Ho T, O'Connor C, Hussain H. Long term follow-up of infliximab efficacy in pulmonary and extra-pulmonary sarcoidosis refractory to conventional therapy. Semin Arthritis Rheum 2013;43:119-124.

98. Baughman RP, Drent M, Kavuru M, Judson MA, Costabel U, du Bois R, Albera C, Brutsche M, Davis G, Donohue JF, Muller-Quernheim J, Schlenker-Herceg R, Flavin S, Lo KH, Oemar B, Barnathan ES. Infliximab therapy in patients with chronic sarcoidosis and pulmonary involvement. Am J Respir Crit Care Med 2006;174:795-802.

99. Rossman MD, Newman LS, Baughman RP, Teirstein A, Weinberger SE, Miller W, Jr., Sands BE. A doubleblinded, randomized, placebo-controlled trial of infliximab in subjects with active pulmonary sarcoidosis. Sarcoidosis Vasc Diffuse Lung Dis 2006;23:201-208.

100. Erckens RJ, Mostard RL, Wijnen PA, Schouten JS, Drent M. Adalimumab successful in sarcoidosis patients with refractory chronic non-infectious uveitis. Graefes Arch Clin Exp Ophthalmol 2012;250:713720.

101. Milman N, Graudal N, Loft A, Mortensen J, Larsen J, Baslund B. Effect of the TNF-alpha inhibitor adalimumab in patients with recalcitrant sarcoidosis: a prospective observational study using FDG-PET. Clin Respir J 2012;6:238-247.

102. Kamphuis LS, Lam-Tse WK, Dik WA, Van Daele PL, Van Biezen P, Kwekkeboom DJ, Kuijpers RW, Hooijkaas H, Van Laar JA, Bastiaans J, Baarsma GS, Van Hagen PM. Efficacy of adalimumab in chronically active and symptomatic patients with sarcoidosis. Am J Respir Crit Care Med 2011;184:1214-1216.

103. Utz JP, Limper AH, Kalra S, Specks U, Scott JP, Vuk-Pavlovic Z, Schroeder DR. Etanercept for the treatment of stage II and III progressive pulmonary sarcoidosis. Chest 2003;124:177-185

104. Bomprezzi R, Pati S, Chansakul C, Vollmer T. A case of neurosarcoidosis successfully treated with rituximab. Neurology 2010;75:568-570.

105. Belkhou A, Younsi R, El Bouchti I, El Hassani S. Rituximab as a treatment alternative in sarcoidosis. Joint Bone Spine 2008;75:511-512.

106. Gottenberg JE, Guillevin L, Lambotte O, Combe B, Allanore Y, Cantagrel A, Larroche C, Soubrier M, Bouillet L, Dougados M, Fain O, Farge D, Kyndt X, Lortholary O, Masson C, Moura B, Remy P, Thomas T, Wendling D, Anaya JM, Sibilia J, Mariette X. Tolerance and short term efficacy of rituximab in 43 patients with systemic autoimmune diseases. Ann Rheum Dis 2005;64:913-920.

107. Prasse A, Zissel G, Lutzen N, Schupp J, Schmiedlin R, Gonzalez-Rey E, Rensing-Ehl A, Bacher G, Cavalli V, Bevec D, Delgado M, Muller-Quernheim J. Inhaled vasoactive intestinal peptide exerts immunoregulatory effects in sarcoidosis. Am J Respir Crit Care Med 2010;182:540-548.

108. Baughman RP, Judson MA, Ingledue R, Craft NL, Lower EE. Efficacy and safety of apremilast in chronic cutaneous sarcoidosis. Arch Dermatol 2012;148:262-264.

109. Lower EE, Malhotra A, Surdulescu V, Baughman RP. Armodafinil for sarcoidosis-associated fatigue: a double-blind, placebo-controlled, crossover trial. J Pain Symptom Manage 2013;45:159-169.

110. Lower EE, Harman S, Baughman RP. Double-blind, randomized trial of dexmethylphenidate hydrochloride for the treatment of sarcoidosis-associated fatigue. Chest 2008;133:1189-1195.

111. Heij L, Dahan A, Hoitsma E. Sarcoidosis and pain caused by small-fiber neuropathy. Pain Res Treat 2012;2012:256024.

112. Heij L, Niesters M, Swartjes M, Hoitsma E, Drent M, Dunne A, Grutters JC, Vogels O, Brines M, Cerami A, Dahan A. Safety and efficacy of ARA 290 in sarcoidosis patients with symptoms of small fiber neuropathy: a randomized, double-blind pilot study. Mol Med 2012;18:1430-1436. 
113. Baughman RP, Lower EE, Ingledue R, Kaufman AH. Management of ocular sarcoidosis. Sarcoidosis Vasc Diffuse Lung Dis 2012;29:26-33.

114. Zeitlin JF, Tami TA, Baughman R, Winget D. Nasal and sinus manifestations of sarcoidosis. Am J Rhinol 2000;14:157-161.

115. Dev S, McCallum RM, Jaffe GJ. Methotrexate treatment for sarcoid-associated panuveitis. Ophthalmology 1999;106:111-118.

116. Lower EE, Broderick JP, Brott TG, Baughman RP. Diagnosis and management of neurological sarcoidosis. Arch Intern Med 1997;157:1864-1868.

117. Lower EE, Baughman RP. The use of low dose methotrexate in refractory sarcoidosis. Am J Med Sci 1990;299:153-157.

118. Veien NK, Brodthagen H. Cutaneous sarcoidosis treated with methotrexate. Br J Dermatol 1977;97:213216.

119. Schutt AC, Bullington WM, Judson MA. Pharmacotherapy for pulmonary sarcoidosis: a Delphi consensus study. Respir Med 2010;104:717-723.

120. Cronstein B. How does methotrexate suppress inflammation? Clin Exp Rheumatol 2010;28:S21-23.

121. Cronstein BN. Low-dose methotrexate: a mainstay in the treatment of rheumatoid arthritis. Pharmacol Rev 2005;57:163-172.

122. Visser K, Katchamart W, Loza E, Martinez-Lopez JA, Salliot C, Trudeau J, Bombardier C, Carmona L, Van der Heijde D, Bijlsma JW, Boumpas DT, Canhao H, Edwards CJ, Hamuryudan V, Kvien TK, Leeb BF, Martin-Mola EM, Mielants H, Muller-Ladner U, Murphy G, Ostergaard M, Pereira IA, Ramos-Remus C, Valentini G, Zochling J, Dougados M. Multinational evidence-based recommendations for the use of methotrexate in rheumatic disorders with a focus on rheumatoid arthritis: integrating systematic literature research and expert opinion of a broad international panel of rheumatologists in the $3 \mathrm{E}$ Initiative. Ann Rheum Dis 2009;68:1086-1093.

123. Shea B, Swinden MV, Tanjong Ghogomu E, Ortiz Z, Katchamart W, Rader T, Bombardier C, Wells GA, Tugwell P. Folic acid and folinic acid for reducing side effects in patients receiving methotrexate for rheumatoid arthritis. Cochrane Database Syst Rev 2013;5:CD000951.

124. Emery P, Breedveld FC, Lemmel EM, Kaltwasser JP, Dawes PT, Gomor B, Van den Bosch F, Nordstrom D, Bjorneboe O, Dahl R, Horslev-Petersen K, Rodriguez De La Serna A, Molloy M, Tikly M, Oed C, Rosenburg R, Loew-Friedrich I. A comparison of the efficacy and safety of leflunomide and methotrexate for the treatment of rheumatoid arthritis. Rheumatology (Oxford) 2000;39:655-665.

125. Moller DR. Treatment of sarcoidosis -- from a basic science point of view. J Intern Med 2003;253:31-40.

126. Romagnuolo J, Sadowski DC, Lalor E, Jewell L, Thomson AB. Cholestatic hepatocellular injury with azathioprine: a case report and review of the mechanisms of hepatotoxicity. Can J Gastroenterol 1998;12:479-483.

127. Bakker JA, Drent M, Bierau J. Relevance of pharmacogenetic aspects of mercaptopurine metabolism in the treatment of interstitial lung disease. Curr Opin Pulm Med 2007;13:458-463.

128. Booth RA, Ansari MT, Tricco AC, Loit E, Weeks L, Doucette S, Skidmore B, Hoch JS, Tsouros S, Sears M, Sy R, Karsh J, Mani S, Galipeau J, Yurkiewich A, Daniel R, Tsertsvadze A, Yazdi F. Assessment of thiopurine methyltransferase activity in patients prescribed azathioprine or other thiopurine-based drugs. Evid Rep Technol Assess (Full Rep) 2010:1-282.

129. Lee SW, Park HJ, Kim BK, Han KH, Lee SK, Kim SU, Park YB. Leflunomide increases the risk of silent liver fibrosis in patients with rheumatoid arthritis receiving methotrexate. Arthritis Res Ther 2012;14:R232.

130. Androdias G, Maillet D, Marignier R, Pinede L, Confavreux C, Broussolle C, Vukusic S, Seve P. Mycophenolate mofetil may be effective in CNS sarcoidosis but not in sarcoid myopathy. Neurology 2011;76:1168-1172.

131. Carlesimo M, Giustini S, Rossi A, Bonaccorsi P, Calvieri S. Treatment of cutaneous and pulmonary sarcoidosis with thalidomide. J Am Acad Dermatol 1995;32:866-869.

132. Tseng CM, Hsiao YH, Su VY, Su KC, Wu YC, Chang KT, Perng DW. The suppression effects of thalidomide on human lung fibroblasts: cell proliferation, vascular endothelial growth factor release, and collagen production. Lung 2013;191:361-368.

133. Rebuck AS, Stiller CR, Braude AC, Laupacis A, Cohen RD, Chapman KR. Cyclosporin for pulmonary sarcoidosis. Lancet 1984;1:1174.

134. Doty JD, Mazur JE, Judson MA. Treatment of corticosteroid-resistant neurosarcoidosis with a shortcourse cyclophosphamide regimen. Chest 2003;124:2023-2026. 
135. Israel RH, Poe RH. Massive pericardial effusion in sarcoidosis. Respiration 1994;61:176-180.

136. Bradley DA, Lower EE, Baughman RP. Diagnosis and management of spinal cord sarcoidosis. Sarcoidosis Vasc Diffuse Lung Dis 2006;23:58-65.

137. Poormoghim H, Moradi Lakeh M, Mohammadipour M, Sodagari F, Toofaninjed N. Cyclophosphamide for scleroderma lung disease: a systematic review and meta-analysis. Rheumatol Int 2012;32:24312444.

138. Siltzbach LE, Teirstein AS. Chloroquine therapy in 43 patients with intrathoracic and cutaneous sarcoidosis. Acta Med Scand Suppl 1964;425:302-308.

139. Chloroquine in the treatment of sarcoidosis. A report from the Research Committee of the British Tuberculosis Association. Tubercle 1967;48:257-272.

140. Leecharoen S, Wangkaew S, Louthrenoo W. Ocular side effects of chloroquine in patients with rheumatoid arthritis, systemic lupus erythematosus and scleroderma. J Med Assoc Thai 2007;90:52-58.

141. Jones SK. Ocular toxicity and hydroxychloroquine: guidelines for screening. Br J Dermatol 1999;140:3-7.

142. Ziegenhagen MW, Rothe ME, Zissel G, Muller-Quernheim J. Exaggerated TNFalpha release of alveolar macrophages in corticosteroid resistant sarcoidosis. Sarcoidosis Vasc Diffuse Lung Dis 2002;19:185-190.

143. Judson MA, Baughman RP, Costabel U, Flavin S, Lo KH, Kavuru MS, Drent M. Efficacy of infliximab in extrapulmonary sarcoidosis: results from a randomised trial. Eur Respir J 2008;31:1189-1196.

144. Elfferich MD, Nelemans PJ, Ponds RW, De Vries J, Wijnen PA, Drent M. Everyday cognitive failure in sarcoidosis: the prevalence and the effect of anti-TNF-alpha treatment. Respiration 2010;80:212-219.

145. Pariser RJ, Paul J, Hirano S, Torosky C, Smith M. A double-blind, randomized, placebo-controlled trial of adalimumab in the treatment of cutaneous sarcoidosis. J Am Acad Dermatol 2013;68:765-773.

146. Baughman RP, Lower EE, Bradley DA, Raymond LA, Kaufman A. Etanercept for refractory ocular sarcoidosis: results of a double-blind randomized trial. Chest 2005;128:1062-1047.

147. Osterman MT, Lichtenstein GR. Current and Future Anti-TNF Therapy for Inflammatory Bowel Disease. Curr Treat Options Gastroenterol 2007;10:195-207.

148. Wiens A, Venson R, Correr CJ, Otuki MF, Pontarolo R. Meta-analysis of the efficacy and safety of adalimumab, etanercept, and infliximab for the treatment of rheumatoid arthritis. Pharmacotherapy 2010;30:339-353.

149. Baughman RP, Lower EE, Drent M. Inhibitors of tumor necrosis factor (TNF) in sarcoidosis: who, what, and how to use them. Sarcoidosis Vasc Diffuse Lung Dis 2008;25:76-89.

150. Redelman-Sidi G, Sepkowitz KA. Interferon Gamma Release Assays in the Diagnosis of Latent Tuberculosis Infection Among Immunocompromised Adults. Am J Respir Crit Care Med 2013;188:422431.

151. Vigne C, Tebib JG, Pacheco Y, Coury F. Sarcoidosis: an underestimated and potentially severe side effect of anti-TNF-alpha therapy. Joint Bone Spine 2013;80:104-107.

152. Bhamra K, Stevens R. Pulmonary Sarcoidosis following Etanercept Treatment. Case Rep Rheumatol 2012;2012:724013.

153. Lower EE, Baughman RP, Kaufman AH. Rituximab for refractory granulomatous eye disease. Clin Ophthalmol 2012;6:1613-1618.

154. Beccastrini E, Vannozzi L, Bacherini D, Squatrito D, Emmi L. Successful treatment of ocular sarcoidosis with rituximab. Ocul Immunol Inflamm 2013;21:244-246. 


\section{Chapter 2}

Extent of disease activity assessed by ${ }^{18}$ F-FDG PET/CT in a Dutch sarcoidosis population

J Cremers, M van Kroonenburgh, R Mostard, S Vöö,

P Wijnen, G Koek, M Drent

Sarcoidosis Vasc Diffuse Lung Dis 2014;31:37-45 


\section{Abstract}

\section{Background}

Sarcoidosis is characterized by a wide range of disease manifestations. In the management and follow-up of sarcoidosis patients, knowledge of extent of disease, activity and severity is crucial. The aim of this study was to assess the extent, distribution and consistency of inflammatory organ involvement using ${ }^{18} \mathrm{~F}$-FDG PET/CT (PET) in sarcoidosis patients with persistent disabling symptoms.

\section{Methods}

Retrospectively, sarcoidosis patients who underwent a PET between 2005 and 2011 ( $n=158$ ) were included. Clinical data were gathered from medical records and PET scans were evaluated. Positive findings were classified as thoracic and/or extrathoracic.

\section{Results}

Of the studied PET positive sarcoidosis patients ( $n=118 / 158 ; 75 \%), 93 \%$ had intrathoracic activity (79\% mediastinal and 64\% pulmonary activity, respectively) and $75 \%$ displayed extrathoracic activity (mainly peripheral lymph nodes, bone/bone marrow, and spleen). Hepatic positivity was always accompanied by splenic activity, whereas the majority of patients with parotid gland, splenic or bone/bone marrow activity showed lymph node activity. A substantial number of patients with PET positive pulmonary findings $(86 \%)$ had signs of respiratory functional impairment. No obvious association between hepatic, splenic or bone/bone marrow activity and their corresponding laboratory abnormalities suggestive of specific organ involvement, was found.

\section{Conclusion}

The majority of studied patients appeared to have PET positive findings $(75 \%)$, of which a high proportion (75\%) displayed extrathoracic activity. Hence, PET can be especially useful in the assessment of extent, distribution and consistency of inflammatory activity in sarcoidosis to provide an explanation for persistent disabling symptoms and/or to provide a suitable location for biopsy. 


\section{Introduction}

Sarcoidosis is a multisystemic disease characterized by inflammatory activity with formation of noncaseating granulomas in various organ systems. ${ }^{1,2}$ Although the lungs are most commonly affected, no organ is immune to sarcoidosis. ${ }^{3}$ Sarcoidosis activity can lead to a wide range of disease severity, varying from minimal involvement to derangement of organ physiology with functional impairment, such as pulmonary fibrosis or devastating extrapulmonary complications. ${ }^{1,2,4-6}$ Since practically every organ can be involved, patients may present with a wide variety of clinical signs and symptoms. ${ }^{1,2}$ Since the clinical course of sarcoidosis is extremely variable, careful assessment of disease extension, severity and activity by organ, with emphasis on vital target organs, is warranted. ${ }^{2,7}$ The assessment of inflammatory disease activity is helpful to monitor the course of the disease and guide therapeutic strategies and also in defining endpoints of various disease manifestations for clinical trials. ${ }^{2,4,8}$

An objective system for specific organ assessment to estimate sarcoidosis disease activity, cause and extent, is still lacking. In general, there is no single test or marker available to evaluate specific organ involvement. Each of the currently available markers has its shortcomings and assessment of specific organ involvement may be beyond the scope of the diagnostic tools used. ${ }^{9}$ A correct estimation of the incidence of organ involvement is therefore, hampered by the difficulty of a reliable confirmation of disease activity for each separate organ. In the ACCESS (A Case Control Etiologic Study of Sarcoidosis) research group study, organ involvement was determined by using an assessment system based on findings from history, physical examination, and laboratory testing. ${ }^{3,10}$ In recent years, fluorine18-fluoro-deoxyglucose positron emission tomography/computed tomography $\left({ }^{18} \mathrm{~F}-\mathrm{FDG}\right.$ PET/CT or PET) has been shown to be a sensitive method to assess inflammatory activity and the extent of disease in sarcoidosis. $^{11-21}$

The aim of this retrospective study was to assess the extent, distribution and consistency of organ involvement detected by PET in sarcoidosis patients with persistent disabling symptoms.

\section{Methods}

\section{Study population}

The material and methods used in this study have been previously described by our group. ${ }^{18,19,22}$ Between June 2005 and September 2011 a PET was performed in 191/608 sarcoidosis patients referred to the former ild (interstitial lung disease) care team, a tertiary referral centre of the Department of Respiratory Medicine of the Maastricht University Medical Centre+ (MUMC+) in the Netherlands. The indication for the PET was the presence of unexplained disease related disabling symptoms that persisted for 
at least 1 year. Persistent disabling symptoms were defined as the presence of more than one symptom that had substantial influence on quality of life, and that could not be explained with the results of routine investigations, including lung function tests or chest radiograph. These symptoms included fatigue (fatigue assessment scale (FAS) $\geq 22$ ), ${ }^{23}$ symptoms compatible with small fiber neuropathy (SFN; SFN screenings list (SFNSL) score $\geq 11$ ), ${ }^{24}$ arthralgia and/or muscle pain, dyspnea (medical research council (MRC) dyspnea scale $\geq 3$ ), exercise intolerance or cough. Lung function testing and laboratory tests were performed within an interval of less than two weeks of the PET scanning. In the routine workup, all patients completed the FAS ${ }^{23}$ and the SFNSL. ${ }^{24}$ Sarcoidosis was proven by the presence of noncaseating granulomas on biopsy according with a compatible clinical picture. Moreover, other causes of granulomatous disease were excluded, according with the consensus statement on sarcoidosis of the American Thoracic Society (ATS)/European Respiratory Society (ERS)/ World Association of Sarcoidosis and Other Granulomatous Disorders (WASOG). ${ }^{1}$ Exclusion criteria consisted of other diseases that are able to cause PET positive findings. Therefore, five patients with common variable immunodeficiency, five patients with malignancy and one patient with both rheumatoid arthritis and amyloidosis were excluded. Due to an inappropriate interval between PET scanning and obtaining blood samples, another 22 patients were excluded. Finally, 158 patients were included. Inflammatory activity was considered to be present in case the PET demonstrated positive findings. Relevant clinical data were gathered retrospectively. This study was approved by the Medical Ethics Board of the MUMC+ (METC 11-4-116) and all patients signed an informed consent.

\section{Laboratory tests}

Serum levels of angiotensin-converting enzyme (ACE), soluble-interleukin2-receptor (sIL2R), C-reactive protein (CRP), alanine aminotransferase (ALT), and alkaline phosphatase (ALP) were determined as described previously. ${ }^{22}$ Serum liver test abnormalities were defined as being present, if the level of the upper limit of normal times 1.5 was exceeded by ALT (>60 U/I for men and >52.5 U/l for women) and/or ALP (>187.5 U/l for both men and women). Haemoglobin ( $\mathrm{Hb}$ ) level, white blood cell (WBC) count and thrombocyte count were determined on a Sysmex XE-5000 (Sysmex, Hamburg, Germany), according to the manufacturer's instructions. Lower reference values for $\mathrm{Hb}$ were $7.3 \mathrm{mmol} / \mathrm{l}$ for the female population and $8.2 \mathrm{mmol} / \mathrm{l}$ for the male population; $3.5 \times 10^{9} / /$ for $W B C$ and $150 \times 10^{9} /$ I for thrombocyte count.

\section{Pulmonary function tests}

Forced expiratory volume in 1 second (FEV1) and the forced vital capacity (FVC) were measured with a pneumotachograph (Masterlab, Jaeger). The diffusing capacity for carbon monoxide (DLCO) was measured by the single-breath method (Masterlab, Jaeger, Würzburg, Germany). ${ }^{25}$ Values were expressed as a percentage of predicted 
values. $^{25}$ Respiratory functional impairment (RFI) was defined as present if FEV1 was $<80 \%$, FVC was $<80 \%$, or DLCO was $<80 \%$. $^{25}$

\section{${ }^{18}$ F-FDG PET/CT}

A ${ }^{18}$ F-FDG PET/CT scan was performed. Patients were scanned using a Gemini ${ }^{\circledR}$ PET/CT (Philips Medical Systems) scanner with time-of-flight capability, together with a 64-slice Brilliance CT scanner. This scanner has a transverse and axial field of view of respectively 57.6 and $18 \mathrm{~cm}$. The transverse spatial resolution is around $5 \mathrm{~mm}$. Patients were fasting for at least 6 hours before the examination. In all patients, blood glucose was measured to ensure that the blood glucose was below $10 \mathrm{mmol} / \mathrm{l}$. ${ }^{18} \mathrm{~F}-\mathrm{FDG}$ (GE Health, Eindhoven, The Netherlands) was injected intravenously and followed by physiologic saline $(10 \mathrm{ml})$. The injected total activity of FDG depended on the weight of the patient. Mean injected dose was $200 \mathrm{MBq}$. After a resting period of 45 minutes (time needed for uptake of FDG), PET and CT images were acquired from the head to the feet. A low dose CT scan was performed without intravenous contrast and used for attenuation correction of the PET images. Typical values were $120 \mathrm{kVp} ; 30 \mathrm{mAs}$; volume computed dose index, and $1.8 \mathrm{mGy}$. The PET images were acquired in 5-minute bed positions. The complete PET data set was reconstructed iteratively, with a reconstruction increment of $5 \mathrm{~mm}$ to provide isotropic voxel.

All PET scans were evaluated blinded and independently by two experienced nuclear physicians (MvK and SV). The inter-observer agreement concerning the PET scores was excellent (weighted kappa varied from 0.912-1.000). ${ }^{18}$ Findings were scored as either positive or negative. PET findings were described as positive if increased FDGuptake was seen in the mediastinum, lung parenchyma or on extrathoracic sites including peripheral lymph nodes, spleen, liver, bone/bone marrow, parotid glands, nasopharynx, skin, muscle, and myelum. Positive findings were classified as thoracic and/or extrathoracic. Positive thoracic PET findings were subdivided as PET positive findings in the pulmonary parenchyma and/or mediastinal lymph nodes.

\section{Statistical procedure}

Statistical analyses were performed using SPSS, version 16.0 for Windows (SPSS Inc., Chicago, Illinois, USA). Results are presented as means ( $\pm S D$ ) for normally distributed continuous variables and as absolute numbers and percentages for nominal or ordinal variables. Differences between groups in demographic and clinical characteristics were tested for statistical significance using the Student's t-test iteratively for independent samples in case of continuous variables or Pearson's Chi-squared test in case of nominal or ordinal variables. A $p$ value of $\leq 0.05$ was considered to indicate statistical significance. 


\section{Results}

\section{Demographic and clinical characteristics}

In Figure 2.1 the enrolment and outcome of interpretation of the PET scans of the studied sarcoidosis sample are shown. A summary of the demographic and clinical characteristics of the 158 studied patients, subdivided in patients with PET negative ( $n=40: 25 \%)$ and PET positive ( $n=118: 75 \%)$ findings, is shown in Table 2.1. The total group consisted of 146 Caucasians, eight were of African-American origin and four of Asian origin. Reported disabling symptoms consisted of fatigue (81\%; FAS $\geq 22$ ), symptoms compatible with SFN (72\%; SFNSL score $\geq 11$ ), arthralgia and/or muscle pain (58\%), dyspnea (48\%; MRC dyspnea scale $\geq 3$ ), exercise intolerance (38\%), and/or cough (20\%). The FAS score of the total studied population was $30.4 \pm 7.8$ and the SFNSL 24.9 \pm 14.8 , without significant differences between PET positive and PET negative patients (data not shown). Mean sIL2R level in PET positive patients was significantly higher compared with PET negative patients $(p<0.001)$, whereas ACE and CRP did not significantly differ between the two groups.

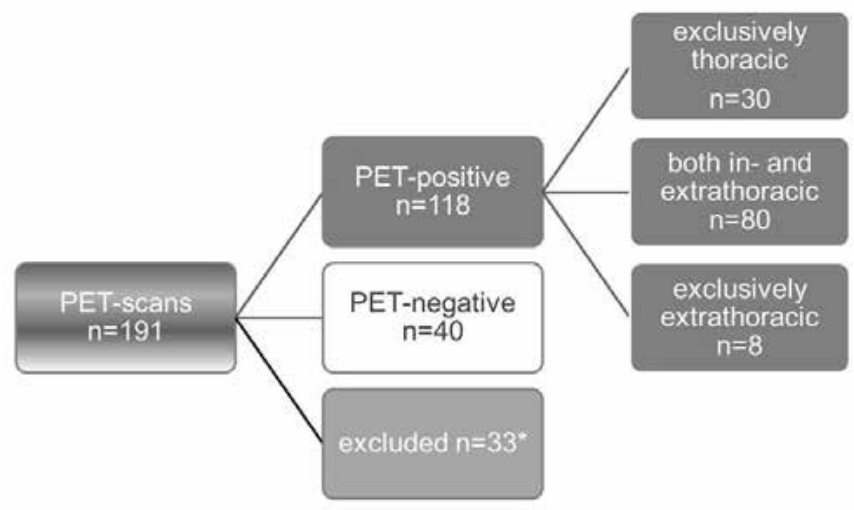

Figure 2.1 Enrolment, exclusion and outcome of interpretation of the PET scans of the studied Dutch sarcoidosis sample. *A total of 33 PET scans, obtained from 33 patients, were excluded due to comorbity $(n=11)$ or an inappropriate interval between PET scanning and obtaining blood samples ( $n=22)$. PET, ${ }^{18}$ F-FDG PET/CT.

At inclusion 41 patient (25.9\%) were on pharmacological treatment: 10 of these patients (24.4\%) used prednisone alone (median dose $15 \mathrm{mg}$ daily (range 10-40 mg)), 18 patients (43.9\%) used methotrexate (MTX) alone (median dose $10 \mathrm{mg}$ a week (range 7.5-12.5 mg)), and 13 patients (31.7\%) used a prednisone and MTX combination (all patients $10 \mathrm{mg}$ prednisone daily and median dose MTX $10 \mathrm{mg}$ a week (range 10-12.5 $\mathrm{mg})$ ). 


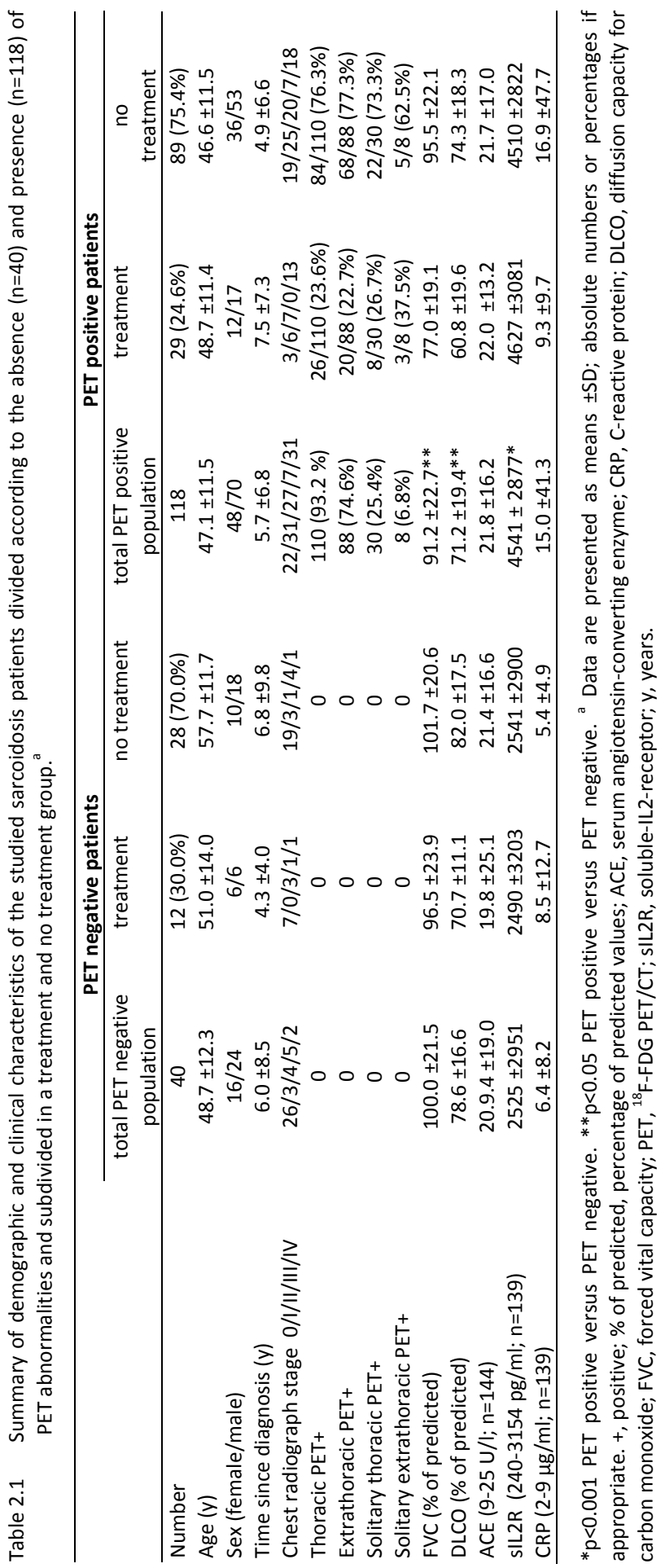




\section{Distribution of organ involvement in PET positive patients}

Of the PET positive patients ( $n=118,69 \%$ female and mean age $47.1 \pm 11.5$ years), $93 \%$ demonstrated thoracic involvement, whereas $75 \%$ showed one or more positive extrathoracic localizations (Table 2.1). In 30 patients (25\%) the PET activity was limited to the thorax, and in eight patients (7\%) this activity was limited to extrathoracic localizations. In almost one fifth of patients $(21 ; 18 \%)$ one single organ was positive, whereas in 38 (32\%) two organs, in $22(19 \%)$ three organs, in $14(12 \%)$ four organs, and in $23(20 \%)$ five or more organs, respectively, with PET activity were found. One of these patients had eight organs involved, as depicted in Figure 2.2.

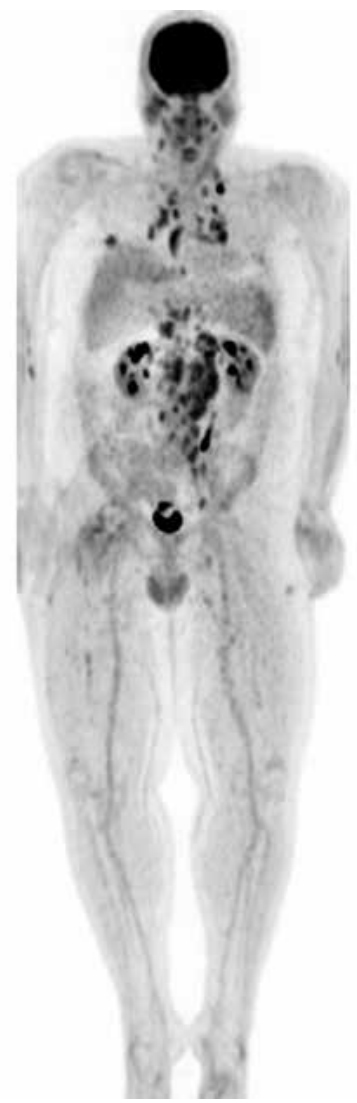

Figure 2.2 Example of a 45-year-old male patient with a history of 8 years of sarcoidosis. Multiple signs of inflammatory activity were seen on ${ }^{18}$ F-FDG PET/CT in the parotid glands, nasopharynx, and in cervical, mediastinal and hilar lymph nodes. Extensive lymphadenopathy was observed in the abdominal and inguinal region. Lung, liver and spleen showed locations with increased ${ }^{18}$ F-FDG uptake, which could also be seen in the muscles and bone/bone marrow. 
The distribution of specific organ involvement is shown in Table 2.2. Thoracic lesions were seen most frequently (PET positive mediastinal lymph nodes in $79 \%$ and pulmonary PET positive findings in $64 \%$ of the patients, respectively), followed by extrathoracic lesions consisting of peripheral lymph nodes (51\%), bone/bone marrow (35\%), spleen (22\%), and parotid gland (19\%). Nasopharyngeal, muscle, liver, skin, and neurological activity were seen in a small number of the PET positive scans.

In Table 2.2, the distribution of organ involvement assessed by PET is compared with the data reported by the ACCESS study. ${ }^{3,10}$ Ocular inflammation is not detectable using a PET scan. Due to normal renal uptake and excretion of ${ }^{18}$ F-FDG, detection of renal involvement is less reliable and therefore not mentioned in our results. Furthermore, for the evaluation of cardiac PET activity, the use of a cardiac protocol, consisting of among others dietary preparation of the patient, is necessary. Hence this was not performed routinely, establishment of the incidence of cardiac PET activity was not possible.

Table 2.2 Number and percentage of sarcoidosis patients with specified organ involvement according to PET findings $(n=118)$ and comparison with results from the ACCESS research group, in which organ involvement was determined using an assessment system based on findings from history, physical examination, and laboratory testing $(n=736) .{ }^{3,10}$

\begin{tabular}{|c|c|c|c|c|}
\hline \multirow[b]{2}{*}{ Organ involvement } & \multicolumn{2}{|c|}{$\begin{array}{l}\text { PET positive population } \\
(\mathrm{n}=118)\end{array}$} & \multicolumn{2}{|c|}{$\begin{array}{c}\text { ACCESS study } 2001^{3,10} \\
(n=736)\end{array}$} \\
\hline & Number & Percent & Number & Percent \\
\hline Mediastinal lymph node(s) & 93 & 78.8 & n.a. & n.a. \\
\hline Lung & 76 & 64.4 & 699 & 95.0 \\
\hline Extrathoracic lymph node(s) ${ }^{a}$ & 60 & 50.8 & 112 & 15.2 \\
\hline Bone/Bone marrow ${ }^{b}$ & 41 & 34.7 & 33 & 4.4 \\
\hline Splenic & 26 & 22.0 & 49 & 6.7 \\
\hline Parotid gland $^{c}$ & 22 & 18.6 & 29 & 3.9 \\
\hline$E T^{d}$ & 15 & 12.7 & 22 & 3.0 \\
\hline Muscle & 14 & 11.9 & 3 & 0.4 \\
\hline Liver & 10 & 8.5 & 85 & 11.5 \\
\hline Skin & 4 & 3.4 & 117 & 15.9 \\
\hline Neurologic ${ }^{e}$ & 3 & 2.5 & 34 & 4.6 \\
\hline Eye & n.a. & n.a. & 87 & 11.8 \\
\hline Renal & n.a. & n.a. & 5 & 0.7 \\
\hline Cardiac & n.a. & n.a. & 17 & 2.3 \\
\hline
\end{tabular}

a Involvement of aortal, liver, abdominal, iliacal, inguinal, cervical, axillary or popliteal lymph nodes. ${ }^{b}$ Involvement of bone and bone marrow in present study, involvement of bone, joints and/or bone marrow in ACCESS study. ${ }^{10} \mathrm{c}$ Involvement of parotid gland in present study, involvement of parotid and/or salivary glands in ACCESS study. ${ }^{10 d}$ Nasopharyngeal involvement in the present study, nasopharyngeal and/or ear involvement in ACCESS study. ${ }^{10}$ e Involvement of myelum in the present study, involvement of cranial nerve, brain, leptomeningeal and/or peripheral nerve in ACCESS study. ${ }^{10}$ ACCESS, A Case Control Etiologic Study of Sarcoidosis; n.a., not applicable; PET, ${ }^{18}$ F-FDG PET/CT. 


\section{Associations of PET positivity between various organs}

In Table 2.3, the distribution of PET positivity between various organs is shown. All patients with hepatic PET positive findings demonstrated splenic and pulmonary PET positivity, and PET positive findings in the mediastinal lymph nodes were present in the majority of these patients (80\%). Every organ (system) assessed, demonstrated in majority of cases the concurrent presence of peripheral and/or mediastinal lymph node activity, with especially high percentages for the parotid gland $(100 \%)$, spleen $(85 \%)$ and bone/bone marrow (81\%). In these cases, pulmonary PET positivity was less often concurrently present $(60-80 \%)$. Furthermore, pulmonary PET positivity and mediastinal lymph node PET positivity appeared to be concurrently present in $78 \%$ of cases.

\section{Respiratory functional impairment, laboratory abnormalities and PET results}

Patients with PET positive lung parenchyma ( $n=76,64 \%$ of PET positive patients) demonstrated a substantial higher percentage of RFI compared with patients without PET activity in the lungs: $86 \%$ versus $58 \%$, respectively ( $p=0.003$; Table 2.4). Furthermore, impaired lung function (FVC and DLCO) was associated with PET positivity ( $p<0.05 ;$ Table 2.1).

Hepatic PET activity was established in 10 of the 118 PET positive patients (9\%; Table 2.2). However, in none of these patients serological liver test abnormalities could be observed. Furthermore, the serological albumin levels were normal in all patients with liver PET activity. However, in $13.4 \%$ of the PET positive patients without hepatic PET activity liver test abnormalities were found (elevated ALP in 5.3\% and ALT in $13.0 \%$ of patients). Signs of decreased haematopoiesis were present in two of 41 patients with bone/bone marrow PET activity (4.9\%). One young female had a slight anaemia ( $\mathrm{Hb} 6.8$ $\mathrm{mmol} / \mathrm{l}$ ) and a minor leucocytopenia (WBC count $\left.3.2 \times 10^{9} / \mathrm{I}\right)$. Another young female had a $\mathrm{Hb}$ level of $5.9 \mathrm{mmol} / \mathrm{l}$. Two PET positive patients without bone/bone marrow activity (2.6\%) demonstrated signs of decreased haematopoiesis. No patients with splenic PET activity demonstrated thrombocytopenia.

\section{Discussion}

The extent, distribution and consistency of inflammatory organ involvement assessed by PET in the studied sarcoidosis patients with persistent disabling symptoms appeared to be remarkably high. The majority of patients displayed PET positive findings $(75 \%)$, of which, besides intrathoracic positivity (93\%), a high proportion (75\%) had extrathoracic activity (mainly peripheral lymph nodes, bone marrow and spleen). Hence, PET can be especially useful in assessment of extent and distribution of inflammatory activity in sarcoidosis. 


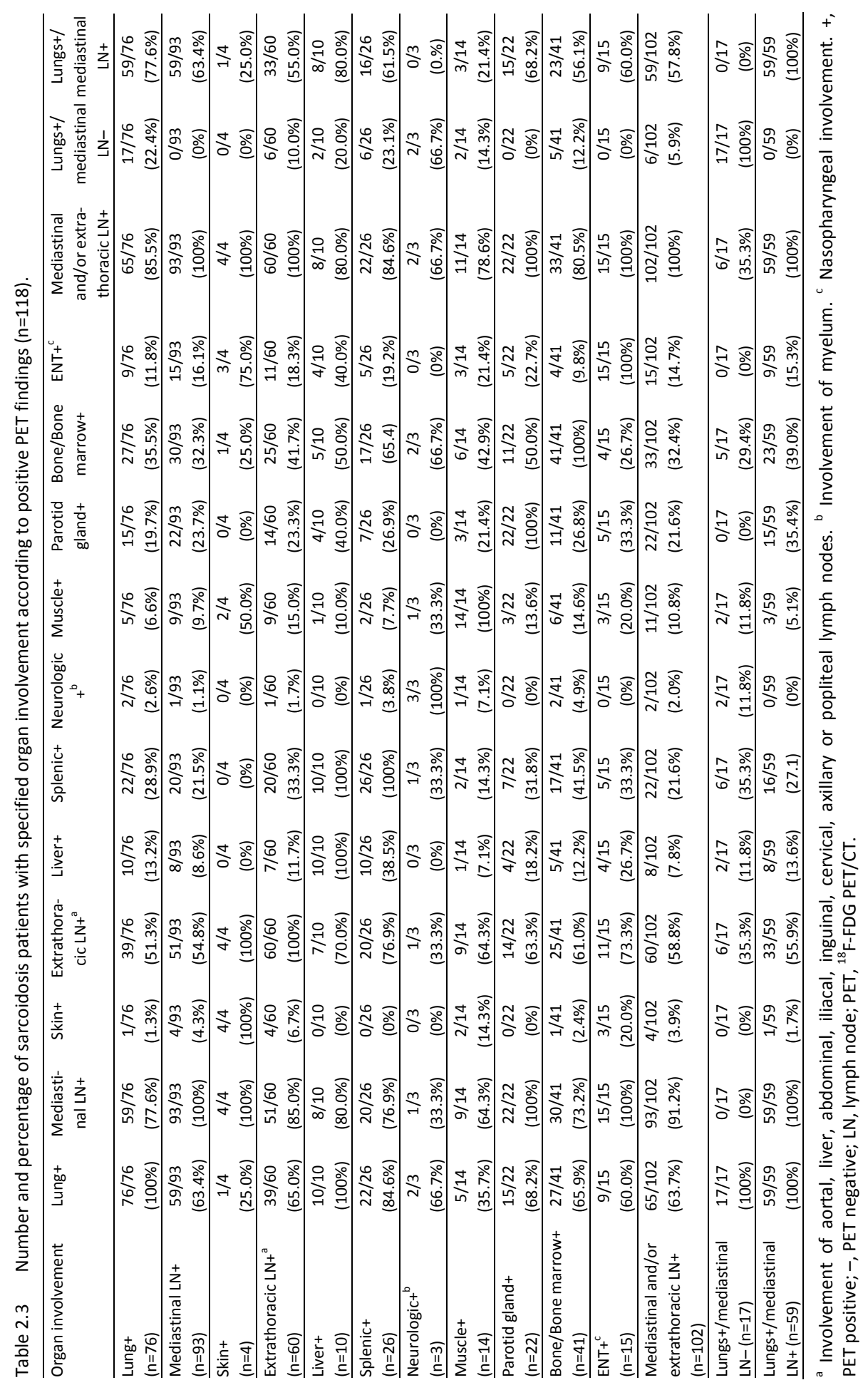


Table 2.4 Respiratory functional impairment in the studied sarcoidosis patients subdivided according to the presence and absence of pulmonary involvement determined by PET (total PET positive group $n=118$, total PET negative group $n=40$ ).

\begin{tabular}{lccc}
\hline & \multicolumn{2}{c}{ PET positive patients } & PET negative patients \\
\cline { 2 - 3 } & PET positive lungs & PET negative lungs & \\
\hline Total number of patients (\%) & $76 / 118(64.4 \%)$ & $42 / 118(35.6 \%)$ & $40 / 158(25.3 \%)$ \\
RFI (n/n measured) & & & \\
Impairment & $57 / 66(86.4 \%)$ & $18 / 31(58.1 \%)$ & $18 / 35(51.4 \%)$ \\
No impairment & $9 / 66(13.6 \%)$ & $13 / 31(41.9 \%)$ & $17 / 35(48.6 \%)$ \\
p value between groups & & $p 1=0.003$ & $p 2=0.005$ \\
RFI not measured & $10 / 76(13.2 \%)$ & $11 / 42(26.2 \%)$ & $5 / 40(12.5 \%)$ \\
\hline
\end{tabular}

p1=PET positive lungs versus PET negative lungs. p2=PET positive patients versus PET negative patients. PET, ${ }^{18}$ F-FDG PET/CT; RFI, respiratory functional impairment; RFI was defined as DLCO $<80 \%$, FVC $<80 \%$, or FEV1 $<80 \%$ (percentage of predicted). ${ }^{25}$

\section{Distribution of organ involvement}

In accordance with earlier results of our group in a smaller population (89 PET positive patients), in the present study in $75 \%$ extrathoracic positivity was found. ${ }^{18}$ Comparing the number of PET positive lesions with the reported organ involvement in the ACCESS study, ${ }^{3,10}$ demonstrated that assessment by PET established a higher rate of involvement of the various organs: peripheral lymph nodes $(51 \%$ and $15 \%$, respectively), bone/bone marrow (35\% and $4 \%$, respectively), spleen $(22 \%$ and $7 \%$, respectively), and parotid gland ( $19 \%$ and $4 \%$, respectively) (Table 2.2 ). These findings confirm that PET is a sensitive method to assess sarcoidosis activity and organ involvement, especially when compared to anamnestic findings, physical examination and laboratory testing. This is in accordance with recent publications. ${ }^{11-21}$ Nevertheless, hepatic and cutaneous involvement were less frequently detected by PET compared to the ACCESS study. A possible explanation could be the higher percentage of black subjects in the ACCESS study population (44\%) compared with the present study (5\%). Black subjects more likely display hepatic and cutaneous involvement due to sarcoidosis. ${ }^{3}$ Furthermore, PET is not a suitable technique to detect cutaneous activity, since FDG-uptake in small cutaneous or subcutaneous sarcoid infiltrations can be below the detection limit, especially when anatomic structures with physiologic or pathologic tracer accumulation are superimposed. ${ }^{12}$ Moreover, cutaneous lesions are usually visible during physical examination and, therefore, PET is usually not performed to assess disease activity in patients with obvious cutaneous manifestations.

\section{Respiratory functional impairment, laboratory abnormalities and PET results}

PET positivity of the lung parenchyma was associated with $\mathrm{RFI}$, which is in accordance with findings of previous studies. ${ }^{19}$ Previously, it was shown that the severity of liver test abnormalities appeared to be related to the degree of fibrosis and extensiveness of 
granulomatous inflammation detected by liver biopsy in hepatic sarcoidosis. ${ }^{26}$ In contrast, PET positivity of the liver parenchyma was not associated with liver test abnormalities. This means that liver test abnormalities are not necessarily present in case of hepatic PET positivity. Signs of decreased haematopoiesis were present in only two patients with bone/bone marrow PET activity (4.9\%) and thrombocytopenia was found in none of the patients with splenic PET activity. The study of Mostard et al., using partly the same population, also showed that bone/bone marrow PET activity is not obviously related to decreased haematopoiesis. ${ }^{22}$ These findings demonstrate that in only a small minority of the patients with extrathoracic PET activity, associated laboratory abnormalities suggestive of specific organ involvement, were present. Hence, PET may be of additional value when assessing the extent of disease to provide an explanation for disabling extrathoracic symptoms.

\section{Value of PET in sarcoidosis}

PET has been shown to be a sensitive method to assess inflammatory activity and the extent of disease in sarcoidosis. ${ }^{11-21}$ However, due to costs and radiation exposure, PET scan should not routinely be performed in the diagnostic work-up of sarcoidosis patients. $^{4,27}$ Recent findings have shown that in specific situations or patient populations PET can be very helpful in disease management and monitoring, even when signs of objective functional organ impairment are absent. ${ }^{14,18,28}$

First of all, PET appears especially helpful in patients with unexplained persistent disabling symptoms in the absence of serological signs of inflammatory activity. ${ }^{16,18}$ Mostard et al. showed that $20 \%$ of patients with persistent disabling symptoms and PET positivity did not have signs of serological inflammatory activity. ${ }^{18}$

In accordance with previous studies, in most of the studied patients pulmonary PET activity was found. ${ }^{11,16,18}$ The severity of pulmonary involvement, assessed by highresolution computed tomography (HRCT) and pulmonary function tests, was found to be associated with PET activity in sarcoidosis. ${ }^{19}$ In patients with radiological signs of fibrosis on chest radiograph or HRCT, PET can be of additional value to detect the presence of ongoing inflammatory activity between the fibrotic elements. ${ }^{19}$

Furthermore, the value of PET to detect cardiac sarcoidosis disease activity is a major subject of recent studies. Detection of cardiac sarcoidosis is important, since it is a major cause of serious morbidity and mortality in sarcoidosis. ${ }^{29}$ PET with cardiac protocol is considered to be a sensitive test for detecting active sarcoid lesions and their response to treatment. ${ }^{20,28,30}$

In addition, PET can have an important role in assessing the extent of organ involvement in an individual patient. Besides the assessment of sarcoidosis activity, depicting disease extent and severity is of great clinical relevance. Evaluation of the extent of disease can be helpful to explain persistent disabling (mainly extrathoracic)

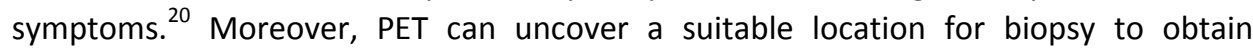
histological evidence for the diagnosis. ${ }^{11,20}$ 
In conclusion, the majority of studied patients appeared to have PET positive findings (75\%), of which, besides intrathoracic positivity (93\%), a high proportion (75\%) displayed extrathoracic activity. Hence, PET can be especially useful in the assessment of extent, distribution and consistency of inflammatory activity in sarcoidosis to provide an explanation for persistent disabling symptoms and/or to provide a suitable location for biopsy.

\section{Acknowledgements}

This study was supported by a research grant from the ild care foundation. 


\section{References}

1. Hunninghake GW, Costabel U, Ando M, Baughman R, Cordier JF, du Bois R, Eklund A, Kitaichi M, Lynch J, Rizzato G, Rose C, Selroos O, Semenzato G, Sharma OP. ATS/ERS/WASOG statement on sarcoidosis. American Thoracic Society/European Respiratory Society/World Association of Sarcoidosis and other Granulomatous Disorders. Sarcoidosis Vasc Diffuse Lung Dis 1999;16:149-173.

2. Iannuzzi MC, Fontana JR. Sarcoidosis: clinical presentation, immunopathogenesis, and therapeutics. JAMA 2011;305:391-399.

3. Baughman RP, Teirstein AS, Judson MA, Rossman MD, Yeager H, Jr., Bresnitz EA, DePalo L, Hunninghake G, lannuzzi MC, Johns CJ, McLennan G, Moller DR, Newman LS, Rabin DL, Rose C, Rybicki B, Weinberger $\mathrm{SE}$, Terrin ML, Knatterud GL, Cherniak R. Clinical characteristics of patients in a case control study of sarcoidosis. Am J Respir Crit Care Med 2001;164:1885-1889.

4. Baughman RP, Culver DA, Judson MA. A concise review of pulmonary sarcoidosis. Am J Respir Crit Care Med 2011;183:573-581.

5. Reich JM. On the nature of sarcoidosis. Eur J Intern Med 2011;23:105-109.

6. Bauer MP, Brouwer PA, Smit VT, Tamsma JT. The challenges of extrapulmonary presentations of sarcoidosis: A case report and review of diagnostic strategies. Eur J Intern Med 2007;18:152-154.

7. Morgenthau AS, lannuzzi MC. Recent advances in sarcoidosis. Chest 2011;139:174-182.

8. Baughman RP, Drent M, Culver DA, Grutters JC, Handa T, Humbert M, Judson MA, Lower EE, Mana J, Pereira CA, Prasse A, Sulica R, Valyere D, Vucinic V, Wells AU. Endpoints for clinical trials of sarcoidosis. Sarcoidosis Vasc Diffuse Lung Dis 2012;29:90-98.

9. Consensus conference: activity of sarcoidosis. Third WASOG meeting, Los Angeles, USA, September 811, 1993. Eur Respir J 1994;7:624-627.

10. Judson MA, Baughman RP, Teirstein AS, Terrin ML, Yeager H Jr. Defining organ involvement in sarcoidosis: the ACCESS proposed instrument. ACCESS Research Group. A Case Control Etiologic Study of Sarcoidosis. Sarcoidosis Vasc Diffuse Lung Dis 1999;16:75-86.

11. Teirstein AS, Machac J, Almeida O, Lu P, Padilla ML, lannuzzi MC. Results of 188 whole-body fluorodeoxyglucose positron emission tomography scans in 137 patients with sarcoidosis. Chest 2007;132:1949-1953.

12. Braun JJ, Kessler R, Constantinesco A, Imperiale A. 18F-FDG PET/CT in sarcoidosis management: review and report of 20 cases. Eur J Nucl Med Mol Imaging 2008;35:1537-1543.

13. Keijsers RG, Grutters JC, Thomeer M, Du Bois RM, Van Buul MM, Lavalaye J, Van Den Bosch JM, Verzijlbergen FJ. Imaging the inflammatory activity of sarcoidosis: sensitivity and inter observer agreement of (67)Ga imaging and (18)F-FDG PET. Q J Nucl Med Mol Imaging 2011;55:66-71.

14. Keijsers RG, Van den Heuvel DA, Grutters JC. Imaging the inflammatory activity of sarcoidosis. Eur Respir J 2012;41:743-751.

15. Treglia G, Taralli S, Giordano A. Emerging role of whole-body 18F-fluorodeoxyglucose positron emission tomography as a marker of disease activity in patients with sarcoidosis: a systematic review. Sarcoidosis Vasc Diffuse Lung Dis 2011;28:87-94.

16. Sobic-Saranovic D, Grozdic I, Videnovic-Ivanov J, Vucinic-Mihailovic V, Artiko V, Saranovic D, DjuricStefanovic A, Masulovic D, Odalovic S, Ilic-Dudvarski A, Popevic S, Pavlovic S, Obradovic V. The Utility of 18F-FDG PET/CT for Diagnosis and Adjustment of Therapy in Patients with Active Chronic Sarcoidosis. J Nucl Med 2012;53:1543-1549.

17. Keijsers RG, Verzijlbergen FJ, Oyen WJ, Van den Bosch JM, Ruven HJ, Van Velzen-Blad H, Grutters JC. 18F-FDG PET, genotype-corrected ACE and SIL-2R in newly diagnosed sarcoidosis. Eur J Nucl Med Mol Imaging 2009;36:1131-1137.

18. Mostard RL, Voo S, Van Kroonenburgh MJ, Verschakelen JA, Wijnen PA, Nelemans PJ, Erckens RJ, Drent M. Inflammatory activity assessment by F18 FDG-PET/CT in persistent symptomatic sarcoidosis. Respir Med 2011;105:1917-1924.

19. Mostard RL, Verschakelen JA, Van Kroonenburgh MJ, Nelemans PJ, Wijnen PA, Voo S, Drent M. Severity of pulmonary involvement and (18)F-FDG PET activity in sarcoidosis. Respir Med 2013;107:439-447.

20. Soussan M, Augier A, Brillet PY, Weinmann P, Valeyre D. Functional Imaging in Extrapulmonary Sarcoidosis: FDG-PET/CT and MR Features. Clin Nucl Med 2013;Epud ahead of print. 
21. Basu S, Saboury B, Werner T, Alavi A. Clinical utility of FDG-PET and PET/CT in non-malignant thoracic disorders. Mol Imaging Biol 2010;13:1051-1060.

22. Mostard RL, Prompers L, Weijers RE, Van Kroonenburgh MJ, Wijnen PA, Geusens PP, Drent M. F-18 FDG $\mathrm{PET} / \mathrm{CT}$ for detecting bone and bone marrow involvement in sarcoidosis patients. Clin Nucl Med 2012;37:21-25.

23. De Vries J, Michielsen H, Van Heck GL, Drent $M$. Measuring fatigue in sarcoidosis: the Fatigue Assessment Scale (FAS). Br J Health Psychol 2004;9:279-291.

24. Hoitsma E, De Vries J, Drent M. The small fiber neuropathy screening list: Construction and crossvalidation in sarcoidosis. Respir Med 2011;105:95-100.

25. Quanjer PH, Tammeling GJ, Cotes JE, Pedersen OF, Peslin R, Yernault JC. Lung volumes and forced ventilatory flows. Report Working Party Standardization of Lung Function Tests, European Community for Steel and Coal. Official Statement of the European Respiratory Society. Eur Respir J Suppl 1993;16:540.

26. Cremers J, Drent M, Driessen A, Nieman F, Wijnen P, Baughman R, Koek G. Liver-test abnormalities in sarcoidosis. Eur J Gastroenterol Hepatol 2012;24:17-24.

27. Mostard RL, Van Kuijk SM, Verschakelen JA, Van Kroonenburgh MJ, Nelemans PJ, Wijnen PA, Drent M. A predictive tool for an effective use of (18)F-FDG PET in assessing activity of sarcoidosis. BMC Pulm Med 2012;12:57.

28. Mc Ardle BA, Leung E, Ohira H, Cocker MS, Dekemp RA, DaSilva J, Birnie D, Beanlands RS, Nery PB. The role of $F(18)$-fluorodeoxyglucose positron emission tomography in guiding diagnosis and management in patients with known or suspected cardiac sarcoidosis. J Nucl Cardiol 2013;20: 297-306.

29. Baughman RP, Lower EE. Who dies from sarcoidosis and why? Am J Respir Crit Care Med 2011;183:1446-1447.

30. Youssef G, Leung E, Mylonas I, Nery P, Williams K, Wisenberg G, Gulenchyn KY, Dekemp RA, Dasilva J, Birnie D, Wells GA, Beanlands RS. The use of 18F-FDG PET in the diagnosis of cardiac sarcoidosis: a systematic review and metaanalysis including the Ontario experience. J Nucl Med 2012;53:241-248. 


\section{Chapter 3}

\section{Body composition profiling in a Dutch sarcoidosis population}

J Cremers, M Drent, M Elfferich, P Nelemans, P Wijnen,

B Witteman, A Schols 


\section{Abstract}

\section{Background}

Muscle atrophy is a common problem in many chronic inflammatory diseases. It may occur as part of a generalized wasting process (cachexia) or be hidden due to preservation of fat mass (sarcopenia, sarcopenic obesity). The aim of this study was to assess the prevalence of cachexia and muscle atrophy in sarcoidosis and their association with disease activity and severity.

\section{Methods}

A cross-sectional study was performed in 423 sarcoidosis patients. Fat-free mass was assessed as an indirect measure of muscle mass by bioelectrical impedance analysis. Patients were stratified based on body mass index (BMI) and fat-free mass index (FFMI). Muscle atrophy was defined as FFMI $<15 \mathrm{~kg} / \mathrm{m}^{2}$ for women and $<17 \mathrm{~kg} / \mathrm{m}^{2}$ for men corresponding to $<10^{\text {th }}$ percentile of current reference values; cachexia as $\mathrm{BMI}<20$ combined with muscle atrophy. Multivariate linear regression models were used to adjust for potential confounders.

\section{Results}

Of the patients examined, $58 \%$ were categorized as overweight $(37 \%)$ or obese $(21 \%)$, whereas $7 \%$ were underweight. Muscle atrophy was present in $25 \%$ and cachexia in $5 \%$. Patients with muscle atrophy showed significantly worse lung function (DLCO, FEV1, FVC, all $p$ values $<0.01$ ) and impaired exercise capacity $\left(\mathrm{VO}_{2} \mathrm{max}, \mathrm{p}<0.001\right)$. The associations were most pronounced in patients with cachexia. Associations remained significant after adjustment for potential confounders.

\section{Conclusion}

Muscle atrophy was present in $25 \%$ of sarcoidosis patients and was associated with more severe pulmonary disease. Prospective studies with longitudinal design are needed to assess the association between muscle atrophy and disease severity in sarcoidosis. 


\section{Introduction}

Sarcoidosis is a multisystemic disease characterized by inflammatory activity with formation of noncaseating granulomas in various organ systems. ${ }^{1,2}$ The etiology is unknown, but immunological, genetic and environmental factors and oxidative stress appear to play a role. ${ }^{2-4}$ The lungs are most commonly affected, but in $50 \%$ of cases extrapulmonary sites can be involved as well. ${ }^{5}$ In severe sarcoidosis, the release of inflammatory mediators causes derangement of organ physiology and finally functional impairment and related symptoms. The disease stabilizes or improves in many cases over the first 2 years, but may worsen and become chronic in others. ${ }^{1}$

Since practically every organ can be involved, patients may present with a wide variety of clinical signs and symptoms. ${ }^{1,2}$ In addition, patients can also suffer from generic disease symptoms, such as fatigue and exercise intolerance, with substantial impact on the quality of life of patients and their families. ${ }^{1,6-14}$ An important determinant of these symptoms in other chronic inflammatory diseases (e.g. chronic obstructive pulmonary disease (COPD) and rheumatoid arthritis (RA)) is skeletal muscle weakness resulting from muscle atrophy, ${ }^{15-20}$ but a detailed profile of body composition in relation to physical functioning is not yet available for sarcoidosis.

Muscle atrophy may occur as part of a generalized wasting process (cachexia) or be hidden due to preservation of fat mass (often referred to as sarcopenia, sarcopenic obesity). According to a recent consensus statement, cachexia is defined as a complex metabolic syndrome associated with underlying illness and characterized by loss of muscle mass with or without loss of fat mass, with the prominent clinical feature of weight loss of at least $5 \%$ during the previous 12 months or a body mass index (BMI) $<20 \mathrm{~kg} / \mathrm{m} .{ }^{21}$ While the disease burden of cachexia is well established, the exact cause and underlying mechanisms of muscle atrophy are still poorly understood, but are likely to be multifactorial. ${ }^{17}$ Putative triggers of muscle wasting are inflammation, oxidative stress, hypoxemia, inactivity, ageing, smoking and endogenous or exogenous glucocorticosteroids. ${ }^{17,20,22,23}$ In contrast to other chronic lung diseases, smoking is not a cause of sarcoidosis, and is even associated with disease protection. ${ }^{24,25}$ Moreover, a low prevalence of smoking is observed among sarcoidosis patients. ${ }^{25}$ Other possible triggers may converge during the clinical course of sarcoidosis. It is especially since inflammation is the most important characteristic of sarcoidosis, with oxidative stress being one of the etiological factors and glucocorticosteroids being the first-line treatment option, that considerable impact on muscle mass status is highly likely. ${ }^{1,2}$ Moreover, hypoxemia and inactivity have been found to be problems in severe sarcoidosis as well. ${ }^{11,26}$ Sarcoidosis patients are relatively young, so the contribution of age-associated muscle mass loss is small. ${ }^{1,5}$

The aim of this study was to investigate the prevalence of different body composition profiles in patients with sarcoidosis and to assess the association of muscle atrophy and cachexia with disease activity and severity. 


\section{Methods}

\section{Study population}

A cross-sectional study was performed among 423 consecutive chronic refractory Caucasian sarcoidosis patients who were referred to the former ild (interstitial lung disease) care team, a tertiary referral centre of the Department of Respiratory Medicine of the Maastricht University Medical Centre+ (MUMC+), between 1 January 2004 and 31 December 2009. The diagnosis of sarcoidosis was based on consistent clinical features and bronchoalveolar lavage fluid analysis, according to the guidelines of the World Association of Sarcoidosis and Other Granulomatous Disorders (WASOG), ${ }_{1}$ with biopsy-proven noncaseating epithelioid cell granulomas confirming sarcoidosis in $74 \%$. Other causes of granulomatous disease were excluded. Six of the patients suffered from glucocorticosteroid-induced diabetes. None of the other patients had relevant medical history or comorbidity. All investigations used in this study were performed during the first visit to the outpatient clinic of the referral centre, and the questionnaire was completed the same day. Other relevant clinical data were obtained from medical records. The study was approved by the Medical Ethics Board of the MUMC+ (METC 11-4-116) and all participants gave their written informed consent.

\section{Body composition}

Body height was measured to the nearest $0.5 \mathrm{~cm}$ while the subjects were standing and barefoot. Body weight was measured with the patients wearing indoor clothing and without shoes on a calibrated beam scale to the nearest $0.1 \mathrm{~kg}$ (model 708, Seca, Hamburg, Germany). Body weight was adjusted for body height by calculating the BMI as weight $(\mathrm{kg}) /$ height $(\mathrm{m})^{2}$.

Fat-free mass (FFM) was assessed as an indirect measure of muscle mass by singlefrequency bioelectrical impedance analysis (BIA; RJL Systems, Detroit, MI, USA) in the supine position with arms and legs abducted and not touching the body. ${ }^{27}$ Patients were in non-fasting condition, but at least 2 hours after their last meal. FFM was calculated from height ${ }^{2} /$ resistance and body weight using the Lukaski formula. ${ }^{28}$ In order to assess the degree of functional tissue depletion, FFM was adjusted for body size by calculating the FFM index (FFMI, FFM/height $\left.{ }^{2}\left(\mathrm{~kg} / \mathrm{m}^{2}\right)\right) .{ }^{27}$ BIA has been extensively validated in COPD and other chronic wasting conditions. FFM correlated well with deuterium dilution as a reference technique. ${ }^{29}$

Muscle atrophy was defined as FFMI $<15 \mathrm{~kg} / \mathrm{m}^{2}$ for women and $<17 \mathrm{~kg} / \mathrm{m}^{2}$ for men corresponding to $<10^{\text {th }}$ percentile of current reference values established in a large Caucasian group of healthy subjects. ${ }^{30}$ Patients were stratified based on BMI and FFMI into six defined categories: cachexia, defined as BMI $<20$ combined with muscle atrophy according to the definition proposed by Evans et al. ${ }^{21}$; underweight, defined as $\mathrm{BMI}<20$ combined with normal muscle mass; hidden muscle atrophy, defined as BMI 20-<25 combined with muscle atrophy; normal body composition, defined as BMI 20- 
$<25$ combined with normal muscle mass; overweight, defined as BMI 25-<30; and obesity, defined as $\mathrm{BMI} \geq 30$.

\section{Questionnaire}

Fatigue was measured with the 10-item fatigue assessment scale (FAS), which indicates both physical and psychological fatigue. Each item has a five-point rating scale, and FAS scores range from 10 to 50 . FAS scores $<22$ indicate non-fatigued persons, scores of $22-$ 34 indicate fatigued persons and scores of $\geq 35$ indicate extremely fatigued persons. ${ }^{31}$ The psychometric properties of the FAS have been found to be good in sarcoidosis. ${ }^{31,32}$

\section{Chest radiography}

The chest radiographs were scored by an experienced thoracic radiologist, blinded to the patient's clinical history. Chest X-ray radiographic abnormalities were classified according to the Scadding radiographic staging system. ${ }^{1}$ Five stages of radiographic abnormality were distinguished: stage 0 (normal chest radiograph), stage I (bilateral hilar lymphadenopathy (BHL)), stage II (BHL and parenchymal abnormalities), stage III (parenchymal abnormalities without $\mathrm{BHL}$ ) and stage IV (end-stage lung fibrosis).

\section{Laboratory tests}

The inflammatory markers angiotensin-converting enzyme (ACE), soluble-interleukin2receptor (sIL2R) and C-reactive protein (CRP) were used to assess sarcoidosis inflammatory activity. ${ }^{33-36}$ Serum ACE was measured by a colorimetric method (cat. no.

FU 116, Fujirebio Inc.). ${ }^{33}$ Serum levels of sIL2R were determined using an IMMULITE Automated Analyzer. ${ }^{33}$ The CRP concentration was measured by a turbidimetric method on a SYNCHRON LX (Beckman Coulter Inc., Fullerton, CA, USA). ${ }^{33}$

\section{Pulmonary function}

The diffusing capacity for carbon monoxide (DLCO) was measured using the singlebreath method (Masterlab, Jaeger, Würzburg, Germany). Forced expiratory volume in 1 second (FEV1) and forced vital capacity (FVC) were measured with a pneumotachograph (Masterlab, Jaeger, Würzburg, Germany). ${ }^{37}$ Pulmonary function tests were performed according to the standards of the European Community of Coal and Steel. ${ }^{37}$ Values were expressed as a percentage of predicted values.

\section{Exercise capacity and muscle strength}

Patients performed a symptom-limited incremental maximal exercise test $(10 \mathrm{~W} / \mathrm{min})$ on an electronically braked cycle ergometer (Cornival 400, Lode, Groningen, The Netherlands) from which maximal oxygen uptake $\left(\mathrm{VO}_{2} \mathrm{max}\right)$ was determined. ${ }^{26}$ This exercise test was performed according to the American Thoracic Society's standards. ${ }^{38}$ 
The 6-minute walk distance (6MWD) was used to assess functional exercise capacity and was performed according to the American Thoracic Society guidelines. ${ }^{11,13,39-41}$ Values were expressed as a percentage of predicted values.

A global impression of muscle strength was obtained by measuring the maximal isometric handgrip force (HGF) of the dominant hand (in kilograms) with the Jamar dynamometer (Jamar, Sammons Preston, Chicago, USA), which is a valid and reliable instrument. ${ }^{42,43}$ Maximal inspiratory pressure (PI,max) was assessed by measuring maximal respiratory mouth pressures using the method of Black and Hyatt. ${ }^{44}$ All tests were performed as reported previously. ${ }^{11}$

\section{Statistical analysis}

Results are presented as means $( \pm S D$ ) for normally distributed continuous variables and as frequencies and percentages for nominal or ordinal variables. The distribution of characteristics and outcome measures of patients with and without muscle atrophy were compared using the Student's t-test or one-way ANOVA test for normally distributed continuous variables and the non-parametric tests Mann-Whitney $U$ or Kruskal-Wallis $\mathrm{H}$ for non-normally distributed variables. Pearson's Chi-squared test was used to assess differences in nominal and ordinal variables. Multivariate linear regression models were used to adjust for potential confounders. A $p$ value $\leq 0.05$ was considered to represent a statistically significant relationship. SPSS-pc version 16.0 (SPSS Inc., Chicago, Illinois, USA) was used for analysis.

\section{Results}

Patient characteristics are summarized in Table 3.1. Twenty-five percent (107/423) of the patients examined showed muscle atrophy. The time since diagnosis varied from 6 months to 37 years prior to the first visit, with a mean value of $4.3( \pm 5.8)$ and a median of 2.0 years. The mean age of the total study group was $43( \pm 11)$ years, $46 \%$ were female and $10.6 \%$ smoked. Fifty-three percent of patients were on pharmacological treatment during data collection: 153 patients used prednisone alone (dose 2.5-60 mg daily, mean dose $11 \mathrm{mg}$ daily); 15 patients methotrexate (MTX) alone (dose 5-15 mg weekly, mean dose $9.0 \mathrm{mg}$ weekly); 29 patients the combination of prednisone (5-30 $\mathrm{mg}$ daily, mean dose $13 \mathrm{mg}$ daily) plus MTX (2.5-15 mg weekly, mean dose $10 \mathrm{mg}$ weekly); and 21 patients were on tumor necrosis factor-alpha (TNF- $\alpha$ ) inhibitor therapy with or without other therapeutics (prednisone or MTX). In patients with muscle athrophy, the presence of extrathoracic sarcoidosis involvement did not differ significantly from patients with normal muscle mass. 
Table 3.1 Summary of patient characteristics.

\begin{tabular}{|c|c|c|c|}
\hline Variable & $\begin{array}{l}\text { Muscle atrophy } \\
\text { (FFMI <15f/17m) }\end{array}$ & $\begin{array}{c}\text { Normal muscle mass } \\
(\mathrm{FFMI} \geq 15 \mathrm{f} / 17 \mathrm{~m})\end{array}$ & Total \\
\hline \multicolumn{4}{|l|}{ Demographics } \\
\hline Number of patients (\%) & $107(25.3 \%)$ & $316(74.7 \%)$ & $423(100 \%)$ \\
\hline Female/male $(\%)^{d}$ & $45.3 / 54.7$ & $47.7 / 52.3$ & $45.9 / 54.1$ \\
\hline Age $(y)^{c}$ & $41.7 \pm 12.0$ & $43.9 \pm 10.8$ & $43.3 \pm 11.1$ \\
\hline Time since diagnosis $(y)^{c}$ & $4.5 \pm 5.4$ & $4.2 \pm 6.0$ & $4.3 \pm 5.8$ \\
\hline Smoking (\%) ${ }^{\mathrm{d}}$ & 11.2 & 10.4 & 10.6 \\
\hline Extrathoracic involvement (\%) ${ }^{d}$ & $75(70.1 \%)$ & $238(75.3 \%)$ & $313(74.0 \%)$ \\
\hline \multicolumn{4}{|l|}{ Body composition } \\
\hline $\mathrm{BMI}\left(\mathrm{kg} / \mathrm{m}^{2}\right)^{\mathrm{c}}$ & $23.1 \pm 3.6^{a}$ & $27.7 \pm 5.0$ & $26.6 \pm 5.1$ \\
\hline Female/male ${ }^{c}$ & $23.6 \pm 3.7 / 22.6 \pm 3.4$ & $28.0 \pm 5.8 / 27.5 \pm 4.1$ & $26.9 \pm 5.7 / 26.3 \pm 4.5$ \\
\hline FFMI $\left(\mathrm{kg} / \mathrm{m}^{2}\right)^{\mathrm{c}}$ & $14.9 \pm 1.3^{\mathrm{a}}$ & $18.3 \pm 2.0$ & $17.4 \pm 2.3$ \\
\hline Female/male ${ }^{c}$ & $14.0 \pm 0.9 / 15.8 \pm 1.0^{b}$ & $17.0 \pm 1.4 / 19.4 \pm 1.6^{\mathrm{b}}$ & $16.2 \pm 1.9 / 18.5 \pm 2.2^{b}$ \\
\hline Pharmacological treatment $(\%)^{d}$ & 56.1 & 52.5 & 53.4 \\
\hline Prednisone use $(\%)^{d}$ & 48.6 & 46.5 & 47.0 \\
\hline Methotrexate use $(\%)^{d}$ & 12.1 & 13.3 & 13 \\
\hline TNF- $\alpha$ inhibitor use $(\%)^{d}$ & 6.5 & 4.4 & 5.0 \\
\hline
\end{tabular}

a Significant difference between the muscle atrophy and normal muscle mass groups, $p<0.05$. ${ }^{b}$ Significant difference between women and men, $p<0.001$. ${ }^{c}$ All values are expressed as mean $\pm S D$ and were tested with one-way ANOVA. ${ }^{d}$ All values are expressed as frequencies and/or percentages and were tested with Pearson's Chi-squared test. BMI, body mass index; f, female; FFMI, fat-free mass index; $m, m a l e ;$ TNF- $\alpha$, tumor necrosis factor-alpha; $y$, years.

The mean BMI was $26.6( \pm 5.1) \mathrm{kg} / \mathrm{m}^{2}$, indicating some excess weight. No significant difference was found between men and women. Mean FFMI was $17.4( \pm 2.3) \mathrm{kg} / \mathrm{m}^{2}$ for the total group and was, as expected, significantly lower in women compared to men $(p<0.001)$; both could, however, be categorized as normal. Apart from BMI and FFMI, patient characteristics did not differ between the muscle atrophy and normal muscle mass groups.

Figure 3.1 shows an overview of the prevalence of the different body composition profiles. Fifty-eight percent of the patients examined were categorized as overweight (37\%) or obese $(21 \%)$, whereas $7 \%$ showed a BMI below normal and $35 \%$ a normal BMI. Of the 107 patients with muscle atrophy, 22 (20\%) were overweight or obese, whereas $21(20 \%)$ had a BMI $<20$ (cachexia, $5 \%$ of the total population). The majority $(n=64$, $60 \%$ ) of patients with muscle atrophy were found to have a normal BMI (hidden muscle atrophy, $15 \%$ of the total population). A total of 82 patients (19\%) had a completely normal body composition (normal BMI and normal FFMI). 


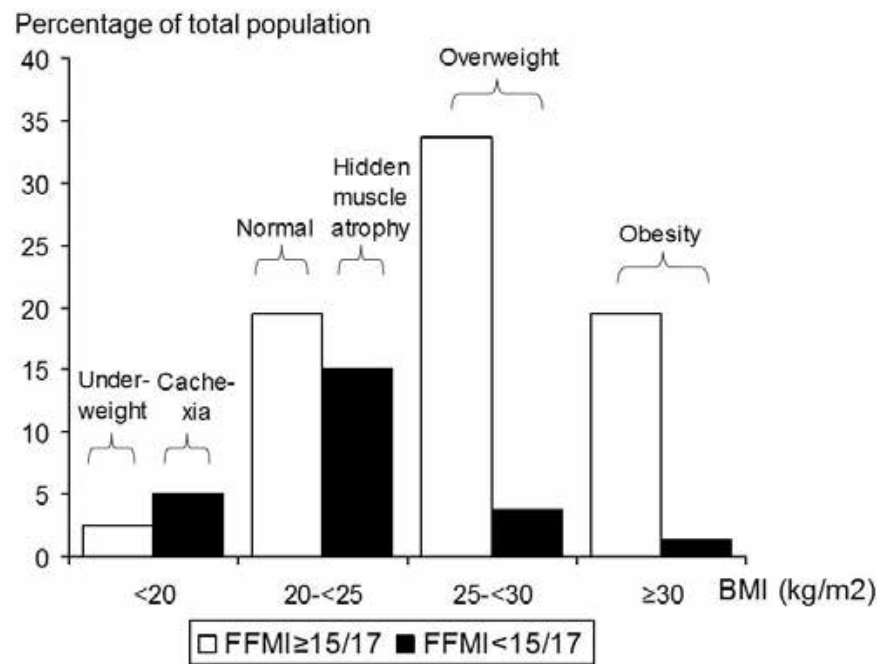

Figure 3.1 Body composition profiles in a sarcoidosis sample.

Stratification of FFMI according to $<10^{\text {th }}$ percentile of current reference values established in a large Caucasian group of healthy subjects. ${ }^{30} \mathrm{BMI}$, body mass index; FFMI, fat-free mass index.

Table 3.2 presents disease parameters for patients with and without muscle atrophy. Fatigue, assessed by the FAS, did not differ between the two groups. The distribution of chest radiograph stages was significantly different in the two groups $(p=0.024)$, with chest radiograph stage IV being more prevalent in muscle atrophic patients (34\%) compared to chest radiograph stages 0-III (24\%). Despite a clear tendency towards higher values of sIL2R in muscle atrophy, sIL2R did not differ significantly between the two groups. This was also true for a subgroup of untreated patients, for whom no difference in sIL2R could be established between the two muscle mass groups (data not shown). The levels of sIL2R were not normally distributed and the range was wide (160-9684 U/ml). The mean values of the other inflammatory parameters ACE and CRP were similar in both groups. The muscle atrophic patients had significantly lower values on lung function test results (DLCO $p<0.001$, FEV1 $p=0.005$, FVC $p<0.001)$ and for exercise capacity $\left(\mathrm{VO}_{2} \max \mathrm{p}<0.001\right)$. A tendency towards lower values of 6MWD, expressed as a percentage of predicted value, was observed in the patients with muscle atrophy, but this tendency did not reach significance $(p=0.165)$. The muscle strength parameters PI, max and HGF of the dominant hand did not differ significantly between the two muscle mass groups, despite a tendency towards lower values of both tests in the muscle atrophy group. 
Table 3.2 Distribution of disease parameters for groups of sarcoidosis patients with and without muscle atrophy.

\begin{tabular}{|c|c|c|c|c|}
\hline Variable & $\begin{array}{l}\text { Muscle atrophy } \\
\text { (FFMI <15f/17m) }\end{array}$ & $\begin{array}{c}\text { Normal muscle mass } \\
(\text { FFMI } \geq 15 \mathrm{f} / 17 \mathrm{~m})\end{array}$ & Total & $p$ value \\
\hline Number of patients (\%) & $107(25.3 \%)$ & $316(74.7 \%)$ & $423(100 \%)$ & - \\
\hline FAS score ${ }^{a}$ & $31.1 \pm 7.1$ & $29.9 \pm 9.0$ & $30.2 \pm 8.5$ & 0.229 \\
\hline $\mathrm{n}$ & 97 & 295 & 392 & \\
\hline Chest radiograph stage & 49.5/2.8/20.6/6.5/ & 41.5/9.8/22.8/12.3/ & 43.5/8.0/22.2/10.9/ & 0.024 \\
\hline 0/I/II/III/IV (\%) & $20.6^{*}$ & 13.6 & 15.4 & \\
\hline \multicolumn{5}{|l|}{ Inflammatory markers } \\
\hline $\operatorname{ACE}(U / I)^{a}$ & $23.2 \pm 16.0$ & $22.0 \pm 11.0$ & $22.3 \pm 12.4$ & 0.410 \\
\hline $\mathrm{n}$ & 105 & 314 & 419 & \\
\hline sIL2R $(U / m l)^{c}$ & $1852 \pm 2297$ & $1391 \pm 1613$ & $1514 \pm 1828$ & 0.440 \\
\hline $\mathrm{n}$ & 86 & 237 & 323 & \\
\hline $\mathrm{CRP}(\mathrm{mg} / \mathrm{l})^{\mathrm{c}}$ & $8.4 \pm 8.3$ & $10.5 \pm 18.8$ & $10.0 \pm 16.8$ & 0.617 \\
\hline $\mathrm{n}$ & 107 & 313 & 420 & \\
\hline \multicolumn{5}{|l|}{ Lung function } \\
\hline DLCO (\% of predicted $)^{a}$ & $76.5 \pm 19.1^{*}$ & $83.6 \pm 16.8$ & $81.8 \pm 17.7$ & $<0.001$ \\
\hline $\mathrm{n}$ & 107 & 313 & 420 & \\
\hline FEV1 (\% of predicted) $)^{a}$ & $83.3 \pm 24.9 *$ & $90.3 \pm 21.3$ & $88.5 \pm 22.4$ & 0.005 \\
\hline $\mathrm{n}$ & 106 & 312 & 418 & \\
\hline FVC (\% of predicted) ${ }^{a}$ & $92.0 \pm 21.8^{*}$ & $99.9 \pm 19.2$ & $97.9 \pm 20.1$ & $<0.001$ \\
\hline $\mathrm{n}$ & 106 & 313 & 419 & \\
\hline \multicolumn{5}{|l|}{ Exercise capacity } \\
\hline $\mathrm{VO}_{2} \max \left(\%\right.$ of predicted) ${ }^{\mathrm{a}}$ & $62.3 \pm 19.7^{*}$ & $81.6 \pm 23.7$ & $77.0 \pm 24.2$ & $<0.001$ \\
\hline $\mathrm{n}$ & 42 & 136 & 178 & \\
\hline $6 \mathrm{MWD}$ (\% of predicted) ${ }^{\mathrm{a}}$ & $64.5 \pm 16.2$ & $68.0 \pm 14.9$ & $67.1 \pm 15.3$ & 0.165 \\
\hline $\mathrm{n}$ & 51 & 140 & 191 & \\
\hline \multicolumn{5}{|l|}{ Muscle strength } \\
\hline $\begin{array}{l}\text { HGF dominant hand (\% of } \\
\text { predicted) }{ }^{\mathrm{a}}\end{array}$ & $87.5 \pm 16.7$ & $94.9 \pm 25.9$ & $93.4 \pm 24.4$ & 0.193 \\
\hline $\mathrm{n}$ & 23 & 90 & 113 & \\
\hline $\mathrm{PI}, \max (\% \text { of predicted })^{\mathrm{a}}$ & $84.6 \pm 26.0$ & $87.9 \pm 30.1$ & $87.0 \pm 29.1$ & 0.325 \\
\hline $\mathrm{n}$ & 100 & 293 & 393 & \\
\hline
\end{tabular}

* Significant difference between the muscle atrophy and normal muscle mass groups, $p<0.05 .{ }^{a}$ All values are expressed as mean $\pm S D$ and were tested with one-way ANOVA. ${ }^{b}$ All values are expressed as frequencies and/or percentages and were tested with Pearson's Chi-squared test. ${ }^{c}$ All values are expressed as mean \pm SD and were tested with Mann-Whitney $U$ test. ACE, angiotensin-converting enzyme; CRP, C-reactive protein; DLCO, diffusing capacity for carbon monoxide; ${ }^{37} \mathrm{f}$, female; FAS, fatigue assessment scale; ${ }^{31}$ FEV1, forced expiratory volume in $1 \mathrm{~s} ;{ }^{37} \mathrm{FFMI}$, fat-free mass index; FVC, forced vital capacity; $;^{37} \mathrm{HGF}$, handgrip force; ${ }^{42,43} \mathrm{~m}$, male; 6MWD, 6 minute walk distance; $;^{13,40,41} \mathrm{PI}$, max, maximal inspiratory pressure; ${ }^{11,44}$ sIL2R, soluble-IL2receptor; $\mathrm{VO}_{2}$ max, maximal oxygen uptake. ${ }^{26,38}$

Table 3.3 shows the between-group differences in mean values of lung function and exercise capacity parameters, with $95 \%$ confidence intervals, before and after adjustment for potential confounders such as gender, age, time since diagnosis, pharmacological treatment status and smoking, based on multivariate regression models. After adjustment, the differences between the groups with and without muscle atrophy remained statistically significant. 
Table 3.3 Differences in mean values of lung function and exercise capacity parameters with $95 \%$ confidence intervals, before and after adjustment for potential confounders, between patients with FFMI $<15 / 17$ and patients with FFMI $\geq 15 / 17$. ${ }^{\text {. }}$

\begin{tabular}{|c|c|c|c|c|c|c|c|c|}
\hline & \multicolumn{4}{|c|}{ Univariate } & \multicolumn{4}{|c|}{ Multivariate } \\
\hline & \multirow[t]{2}{*}{$\mathrm{b}$} & \multirow[t]{2}{*}{$\mathrm{p}$ value } & \multicolumn{2}{|c|}{$95 \% \mathrm{Cl}$ of $\mathrm{b}$} & \multirow[t]{2}{*}{$b$} & \multirow[t]{2}{*}{$p$ value } & \multicolumn{2}{|c|}{$95 \% \mathrm{Cl}$ of $\mathrm{b}$} \\
\hline & & & Lower & Upper & & & Lower & Upper \\
\hline \multicolumn{9}{|l|}{ DLCO\% } \\
\hline FFMI $<15 / 17$ & -7.074 & $<0.001^{*}$ & -10.912 & -3.235 & -6.695 & $0.001^{*}$ & -10.473 & -2.916 \\
\hline \multicolumn{9}{|l|}{ vs. $\geq 15 / 17$} \\
\hline \multicolumn{9}{|l|}{ FEV1\% } \\
\hline FFMI & -7.021 & $0.005^{*}$ & -11.935 & -2.107 & -6.425 & $0,007^{*}$ & -11.057 & $-1,792$ \\
\hline \multicolumn{9}{|l|}{ FVC\% } \\
\hline FFMI & -7.841 & $<0.001 *$ & -12.230 & -3.452 & -6.967 & $0.001^{*}$ & -11.098 & -2.835 \\
\hline \multicolumn{9}{|l|}{ VO2max\% } \\
\hline FFMI & -19.242 & $<0.001^{*}$ & -27.204 & -11.279 & -17.155 & $<0.001^{*}$ & -24.241 & -10.069 \\
\hline
\end{tabular}

${ }^{*} \mathrm{p}<0.05$. ${ }^{a}$ Results from multivariate linear regression models, with adjustment for gender, age, time since diagnosis, pharmacological treatment status and smoking. b, unstandardized regression coefficient; DLCO\%, diffusing capacity for carbon monoxide, percentage of predicted; ${ }^{37}$ FEV $1 \%$, forced expiratory volume in $1 \mathrm{~s}$, percentage of predicted; ${ }^{37}$ FVC\%, forced vital capacity, percentage of predicted; ${ }^{37}$ VO2max $\%$, maximal oxygen uptake, percentage of predicted. ${ }^{26,38}$

Since muscle atrophy was associated with significantly worse disease characteristics, and since it was especially frequent in patients with $\mathrm{BMI}<25$, an additional analysis was performed to investigate a potential difference in risk profile between the cachectic subgroup and the hidden muscle atrophy group. Patients with cachexia demonstrated significantly more impaired lung function and $\mathrm{VO}_{2}$ max test results compared to hidden muscle atrophic patients $(p<0.05)$, as depicted in Figure 3.2. Furthermore, significantly higher values of ACE were detected in patients with cachexia, whereas the other inflammatory parameters were similar for both groups (data not shown). 


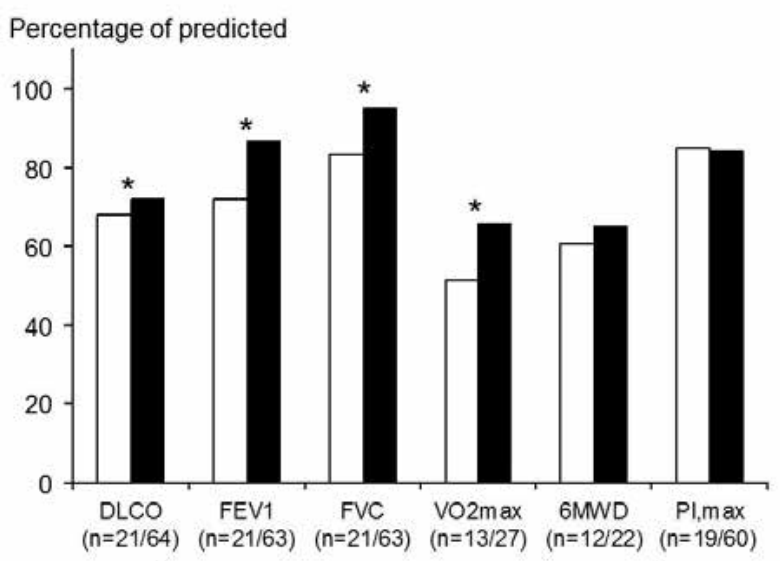

$\square$ Cachexia Hidden muscle atrophy

Figure 3.2 Mean lung function, exercise capacity and muscle strength parameters in cachexia and hidden muscle atrophy.

${ }^{*} p<0.05$ (one-way ANOVA). Cachexia, BMI $<20$ and FFMI $<15$ (f) or $<17$ (m). Hidden muscle atrophy, BMI $20-<25$ and FFMI $<15$ (f) or $<17(\mathrm{~m})$. DLCO, diffusing capacity for carbon monoxide; ${ }^{37} \mathrm{f}$, female; FEV1, forced expiratory volume in $1 \mathrm{~s} ;{ }^{37} \mathrm{FVC}$, forced vital capacity $;^{37} \mathrm{~m}$, male; 6MWD, 6 minute walk distance; ${ }^{13,40,41} \mathrm{VO}_{2} \max$, maximal oxygen uptake; ${ }^{26,38} \mathrm{PI}$, max, maximal inspiratory pressure. ${ }^{11,44}$

\section{Discussion}

This is the first study to demonstrate that muscle atrophy is a substantial problem in sarcoidosis. In our sample of patients with sarcoidosis - a large Dutch cohort - $25 \%$ had muscle atrophy, defined as FFMI $<15$ for women and $<17$ for men. Five percent of patients had cachexia, defined as BMI $<20$ combined with the presence of muscle atrophy. Muscle atrophy in sarcoidosis was associated with worse lung function and more impaired exercise capacity (as indicated by $\mathrm{VO}_{2} \mathrm{max}$ ). These associations were strongest in patients with cachexia.

Sarcoidosis is an intriguing inflammatory disease. ${ }^{2}$ Sarcoidosis patients tend to be relatively young, non-smokers and have only mild or no comorbidity potentially affecting or aggravating muscle atrophy. ${ }^{1,5}$ Furthermore, the presence of extrathoracic sarcoidosis involvement did not differ between the two muscle mass groups. Nevertheless, we found muscle atrophy in sarcoidosis to be clearly more common $(25 \%)$ than in a study of a large healthy Caucasian European population aged 35-54 years $(10 \%)$, which used the same defining criteria as those used in our study. ${ }^{30}$ On the other hand, the prevalence was in agreement with studies showing muscle atrophy percentages of $18-26 \%$ in COPD $^{15,45}$ and of $20 \%$ in RA. ${ }^{18}$ In more severe stages of COPD, percentages of muscle atrophy up to $36-40 \%$ have been found. ${ }^{16,46}$ In line with this, we 
found muscle atrophy in $34 \%$ of the more severe pulmonary sarcoidosis patients with chest X-ray stage IV and more severe respiratory functional impairment (RFI).

Muscle atrophy was associated with significantly impaired lung function and cardiopulmonary exercise test results, expressed as $\mathrm{VO}_{2} \mathrm{max}$, which is in agreement with findings in COPD. ${ }^{15,16}$ However, muscle strength and 6MWD only showed a nonsignificant trend towards lower values in muscle atrophy. The inclusion of leg muscle measurements, besides PI, max and HGF, would be preferable to assess muscle strength. Marcellis et al. ${ }^{11}$ found a trend towards lower levels of FFMI in sarcoidosis patients with reduced leg muscle strength. Another explanation for the non-significant association between muscle mass and strength may be the negative effect of systemic glucocorticosteroid treatment on muscle strength. ${ }^{47,48}$ Moreover, studies in patients with COPD have clearly established that the 6MWD is not only determined by muscle mass, but also by RFI, fatigue and muscle strength. ${ }^{11,13,49,50}$

Fatigue in sarcoidosis has a complex and multifaceted etiology, with systemic inflammation, clinical and psychological factors playing a role. ${ }^{27,51,52}$ Some studies found that patients with peripheral muscle strength impairment were more fatigued than patients with normal muscle strength. ${ }^{11,53}$ The present study showed that fatigue, assessed by the FAS, did not differ between groups stratified according to muscle mass status. However, examining the association between fatigue and muscle mass is difficult, since BIA is only capable of assessing overall FFM, instead of distinguishing appendicular FFM. Furthermore, the FAS examines a subjectively experienced level of fatigue. Studies in patients with COPD have used a more objective tool for the assessment of leg muscle fatigue, by measure electrical activity of the quadriceps, and found that muscle fatigue was linked to the oxidative capacity of the muscle rather than to muscle mass. ${ }^{54,55}$ An important role for oxidative stress and antioxidant capacity in the disease genesis has also been demonstrated in sarcoidosis. ${ }^{3,56}$ Future research into muscle fatigue is warranted to assess the influence of other possible etiological factors, such as decreased oxidative muscle capacity.

The prevalence of cachexia in our study was found to be $5 \%$. Of the more severe pulmonary sarcoidosis patients with chest X-ray stage IV and more RFI, $14 \%$ had cachexia. In COPD, cachexia is described to occur in $11-28 \%$ of patients. ${ }^{16,45,46}$ Many COPD studies were performed in older patient populations with advanced stages of COPD, who had relevant comorbidities and smoking history, whereas the relatively young patient population with sarcoidosis has little or no comorbidity. This might at least partly explain the higher prevalence found in COPD. Just as in COPD, ${ }^{17,57}$ an increased whole body protein turnover in sarcoidosis is associated with increased resting energy expenditure (REE), leading to an energy imbalance enhancing cachexia. ${ }^{27}$ This effect might explain the high prevalence of cachexia in advanced sarcoidosis cases with chest X-ray stage IV.

Cachectic patients in our study showed more impaired lung function and $\mathrm{VO}_{2}$ max compared to those with hidden muscle atrophy. Since cachectic patients are characterized not only by muscle atrophy but also by a low BMI, physicians are more 
likely to be alarmed, whereas patients with hidden muscle atrophy are less likely to be noticed based on their physical appearance. Nevertheless, these patients also had worse lung function and $\mathrm{VO}_{2} \mathrm{max}$, although to a lesser extent than cachectic patients. Since the proportion of patients with hidden muscle atrophy is large, it is important for physicians to be aware of this (see Figure 3.3).
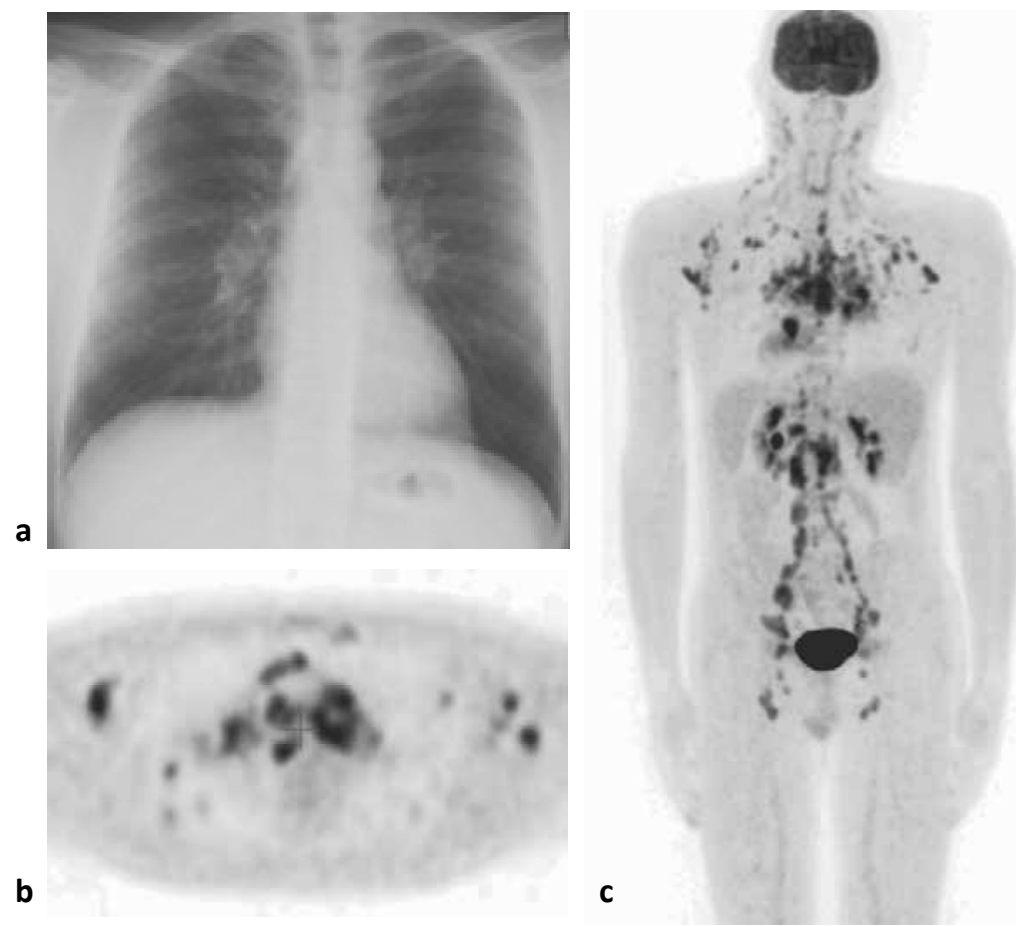

Figure 3.3 Example of a sarcoidosis patient with hidden muscle atrophy.

A 32-year-old man with a history of sarcoidosis of 5 years has a BMI of $21.9 \mathrm{~kg} / \mathrm{m}^{2}$ and a FFMI of $14.9 \mathrm{~kg} / \mathrm{m}^{2}$, indicating hidden muscle atrophy. ACE is $27 \mathrm{U} / \mathrm{l}, \mathrm{sIL} 2 \mathrm{R} 5053 \mathrm{U} / \mathrm{ml}$ and CRP $11 \mathrm{mg} / \mathrm{l}$; elevated sIL2R indicating inflammatory activity. DLCO is $69 \%$, FEV1 $52 \%$ and FVC $62 \%$ of predicted, indicating severe respiratory functional impairment. a. Chest radiograph shows only mild abnormalities consisting of bilateral hilar lymphadenopathy without parenchymal involvement (stage I). b. PET image of the total body shows inflammatory activity indicated by increased FGD uptake in multiple lymph nodes and to a lesser extent in pulmonary parenchyma bilaterally. c. PET image at thoracic level shows mildly increased FDG uptake in the pulmonary parenchyma bilaterally and extensive uptake in axillary and mediastinal lymph nodes. ACE, angiotensin-converting enzyme; BMI, body mass index; CRP, C-reactive protein; DLCO, diffusing capacity for carbon monoxide; ${ }^{37}{ }^{18} \mathrm{FDG}$, fluorine18-fluorodeoxyglucose; FEV1, forced expiratory volume in $1 \mathrm{~s} ;{ }^{37} \mathrm{FFMI}$, fat-free mass index; FVC, forced vital capacity; ${ }^{37} \mathrm{PET},{ }^{18} \mathrm{~F}$-FDG positron emission tomography/computed tomography; sIL2R, soluble-IL2-receptor. 
The use of exogenous glucocorticosteroids, the most frequently used pharmacological therapeutic option in sarcoidosis, can induce an iatrogenic hypercortisolemic state, contributing to muscle wasting. ${ }^{58}$ Hypercortisolemia, the result of endogenous glucocorticosteroid production and consistent with stress during illness including sarcoidosis, represents a persistent catabolic stimulus leading to reduced protein synthesis and increased loss of muscle mass. ${ }^{59}$ This seems, however, to be a less important factor in sarcoidosis, since decreased baseline adreno-corticotropic hormone (ACTH)/cortisol levels as a consequence of the sarcoidosis itself have been demonstrated. ${ }^{60}$ An inappropriate low response to exercise-associated interleukin-6 (IL6 ) increase has also been found, reflecting either a dysfunctional IL-6 induced stimulation of the hypothalamic-pituitary-adrenal axis or an adaptation of this axis to the chronically elevated IL- 6 concentrations in sarcoidosis. ${ }^{61}$

The exact mechanism underlying the transition from flares of inflammation to muscle atrophy remains unresolved. ${ }^{62}$ In both COPD and sarcoidosis, a systemic inflammatory response, reflected by elevated levels of TNF- $\alpha$, presumably contributes to muscle wasting. ${ }^{63,64}$ Our study, however, found similar degrees of inflammation for both muscle mass groups. The cachectic patients had significantly higher values of ACE compared to the hidden muscle atrophic patients, whereas sIL2R and CRP were similar. The upregulation of transient systemic inflammation may only appear during acute flares of disease activity, as has been shown for acute exacerbations in COPD. ${ }^{62,65}$ Muscle nuclear factor-kappa B (NF-kB) activation is thought to play a role as well. ${ }^{62}$ It is likely that flares of systemic inflammatory activity associated with NF-kB activation also contribute to muscle wasting in sarcoidosis.,27,66,67 Moreover, as the inflammatory markers were measured in different conditions in terms of disease duration and activity, an association between inflammation and muscle atrophy may have been missed. Furthermore, the inflammatory capacity of visceral fat is considerably greater than that of subcutaneous fat. ${ }^{68,69}$ Since in sarcopenic obesity, visceral fat increases while subcutaneous fat declines, the contribution of fat-associated inflammatory activity can be expected especially in advanced age groups. ${ }^{68,69}$ Since BIA is not able to establish the precise bodily distribution of fat mass, we could not control for fat mass localization as a possible influencer of systemic inflammation.

\section{Limitations of the study}

A limitation of this cross-sectional study was that patients were included at different time points after diagnosis, so disease conditions varied at inclusion. Furthermore, our study involved a first attempt to assess body composition profiles in sarcoidosis. FFM was assessed as an indirect measure of muscle mass by BIA, a suitable and easy to perform screening instrument. It has been recommended, however, to use a combination of more reliable (deuterium dilution) or specific measuring techniques such as dual energy X-ray absorptiometry (DEXA), magnetic resonance imaging (MRI) or computerized tomography (CT) for more extensive analysis in patients at high risk for 
muscle atrophy. ${ }^{70-73}$ Since DEXA, MRI and CT provide regional assessment of three or even four compartments, it can establish the bodily distribution of muscle and fat mass in more detail, which is not possible by BIA assessment. ${ }^{71-73}$

\section{Directions for future studies}

Prospective longitudinal follow-up studies with uniform measuring conditions at diagnosis and during the course of the disease will be necessary to assess the relations between body composition and systemic inflammation and disease severity in sarcoidosis. A useful approach would be to examine the value of screening for malnutrition using questionnaires, in order to select patients at high risk for muscle atrophy. Another interesting topic of research could be to investigate the effect of pharmacological anti-inflammatory therapeutics on body composition. In addition, the effect on muscle maintenance of a multidisciplinary rehabilitation program, consisting of dietary intervention combined with physical training, needs to be established, along with the potentially different responses between cachectic and non-cachectic patients.

In conclusion, the present study found muscle atrophy and cachexia to be frequent problems in sarcoidosis. Muscle atrophy is associated with worse lung function and exercise capacity compared to normal muscle status, whereas the cachectic patients were the group with the most severe pulmonary disease. Inflammatory status did not discriminate for muscle atrophy. Prospective studies with longitudinal design are needed to investigate the prevalence of cachexia and muscle atrophy and their association with disease activity and severity.

\section{Acknowledgements}

This study was supported by a research grant from the ild care foundation. 


\section{References}

1. Hunninghake GW, Costabel U, Ando M, Baughman R, Cordier JF, du Bois R, Eklund A, Kitaichi M, Lynch J, Rizzato G, Rose C, Selroos O, Semenzato G, Sharma OP. ATS/ERS/WASOG statement on sarcoidosis. American Thoracic Society/European Respiratory Society/World Association of Sarcoidosis and other Granulomatous Disorders. Sarcoidosis Vasc Diffuse Lung Dis 1999;16:149-173.

2. Iannuzzi MC, Fontana JR. Sarcoidosis: clinical presentation, immunopathogenesis, and therapeutics. Jama 2011;305:391-399.

3. Boots AW, Drent M, Swennen EL, Moonen HJ, Bast A, Haenen GR. Antioxidant status associated with inflammation in sarcoidosis: a potential role for antioxidants. Respir Med 2009;103:364-372.

4. $\quad$ Reich JM. On the nature of sarcoidosis. Eur J Intern Med 2012;23:105-109.

5. Baughman RP, Teirstein AS, Judson MA, Rossman MD, Yeager H, Jr., Bresnitz EA, DePalo L, Hunninghake G, lannuzzi MC, Johns CJ, McLennan G, Moller DR, Newman LS, Rabin DL, Rose C, Rybicki B, Weinberger SE, Terrin ML, Knatterud GL, Cherniak R. Clinical characteristics of patients in a case control study of sarcoidosis. Am J Respir Crit Care Med 2001;164:1885-1889.

6. Sharma OP. Fatigue and sarcoidosis. Eur Respir J 1999;13:713-714.

7. Wirnsberger RM, De Vries J, Breteler MH, Van Heck GL, Wouters EF, Drent M. Evaluation of quality of life in sarcoidosis patients. Respir Med 1998;92:750-756.

8. James DG. Complications of sarcoidosis. Chronic fatigue syndrome. Sarcoidosis 1993;10:1-3.

9. Drent M, Lower EE, De Vries J. Sarcoidosis-associated fatigue. Eur Respir J 2012;40:255-263.

10. Wirnsberger RM, De Vries J, Wouters EF, Drent M. Clinical presentation of sarcoidosis in The Netherlands an epidemiological study. Neth J Med 1998;53:53-60.

11. Marcellis RG, Lenssen AF, Elfferich MD, De Vries J, Kassim S, Foerster K, Drent M. Exercise capacity, muscle strength and fatigue in sarcoidosis. Eur Respir J 2011;38:628-634.

12. Alhamad EH. The six-minute walk test in patients with pulmonary sarcoidosis. Ann Thorac Med 2009;4:60-64.

13. Baughman RP, Sparkman BK, Lower EE. Six-minute walk test and health status assessment in sarcoidosis. Chest 2007;132:207-213.

14. Wirnsberger RM, Drent M, Hekelaar N, Breteler MH, Drent S, Wouters EF, Dekhuijzen PN. Relationship between respiratory muscle function and quality of life in sarcoidosis. Eur Respir J 1997;10:1450-1455.

15. Engelen MP, Schols AM, Baken WC, Wesseling GJ, Wouters EF. Nutritional depletion in relation to respiratory and peripheral skeletal muscle function in out-patients with COPD. Eur Respir J 1994;7:1793-1797.

16. Schols AM, Soeters PB, Dingemans AM, Mostert R, Frantzen PJ, Wouters EF. Prevalence and characteristics of nutritional depletion in patients with stable COPD eligible for pulmonary rehabilitation. Am Rev Respir Dis 1993;147:1151-1156.

17. Remels AH, Gosker HR, Langen RC, Schols AM. The mechanisms of cachexia underlying muscle dysfunction in COPD. J Appl Physiol 2013;114:1253-1262.

18. Van Bokhorst-De van der Schueren MA, Konijn NP, Bultink IE, Lems WF, Earthman CP, Van Tuyl LH. Relevance of the new pre-cachexia and cachexia definitions for patients with rheumatoid arthritis. Clin Nutr 2012;31:1008-1010.

19. Rajbhandary R, Khezri A, Panush RS. Rheumatoid cachexia: what is it and why is it important? J Rheumatol 2011;38:406-408.

20. Fanzani A, Conraads VM, Penna F, Martinet W. Molecular and cellular mechanisms of skeletal muscle atrophy: an update. J Cachexia Sarcopenia Muscle 2012;3:163-179.

21. Evans WJ, Morley JE, Argiles J, Bales C, Baracos V, Guttridge D, Jatoi A, Kalantar-Zadeh K, Lochs $H$, Mantovani G, Marks D, Mitch WE, Muscaritoli M, Najand A, Ponikowski P, Rossi Fanelli F, Schambelan M, Schols A, Schuster M, Thomas D, Wolfe R, Anker SD. Cachexia: a new definition. Clin Nutr 2008;27:793-799.

22. Cruz-Jentoft AJ, Baeyens JP, Bauer JM, Boirie Y, Cederholm T, Landi F, Martin FC, Michel JP, Rolland Y, Schneider SM, Topinkova E, Vandewoude M, Zamboni M. Sarcopenia: European consensus on definition and diagnosis: Report of the European Working Group on Sarcopenia in Older People. Age Ageing 2010;39:412-423. 
23. Rom O, Kaisari S, Aizenbud D, Reznick AZ. Sarcopenia and smoking: a possible cellular model of cigarette smoke effects on muscle protein breakdown. Ann N Y Acad Sci 2012;1259:47-53.

24. Valeyre D, Soler P, Clerici C, Pre J, Battesti JP, Georges R, Hance AJ. Smoking and pulmonary sarcoidosis: effect of cigarette smoking on prevalence, clinical manifestations, alveolitis, and evolution of the disease. Thorax 1988;43:516-524.

25. Newman LS, Rose CS, Bresnitz EA, Rossman MD, Barnard J, Frederick M, Terrin ML, Weinberger SE, Moller DR, McLennan G, Hunninghake G, DePalo L, Baughman RP, lannuzzi MC, Judson MA, Knatterud GL, Thompson BW, Teirstein AS, Yeager H, Jr., Johns CJ, Rabin DL, Rybicki BA, Cherniack R. A case control etiologic study of sarcoidosis: environmental and occupational risk factors. Am J Respir Crit Care Med 2004;170:1324-1330.

26. Marcellis RG, Lenssen AF, De Vries GJ, Baughman RP, Van der Grinten CP, Verschakelen JA, De Vries J, Drent $\mathrm{M}$. Is there an added value of cardiopulmonary exercise testing in sarcoidosis patients? Lung 2013;191:43-52.

27. Drent M, Wirnsberger RM, De Vries J, Van Dieijen-Visser MP, Wouters EF, Schols AM. Association of fatigue with an acute phase response in sarcoidosis. Eur Respir J 1999;13:718-722.

28. Lukaski HC, Bolonchuk WW, Hall CB, Siders WA. Validation of tetrapolar bioelectrical impedance method to assess human body composition. J Appl Physiol 1986;60:1327-1332.

29. Schols AM, Wouters EF, Soeters PB, Westerterp KR. Body composition by bioelectrical-impedance analysis compared with deuterium dilution and skinfold anthropometry in patients with chronic obstructive pulmonary disease. Am J Clin Nutr 1991;53:421-424.

30. Schutz Y, Kyle UU, Pichard C. Fat-free mass index and fat mass index percentiles in Caucasians aged 1898 y. Int J Obes Relat Metab Disord 2002;26:953-960.

31. De Vries J, Michielsen H, Van Heck GL, Drent M. Measuring fatigue in sarcoidosis: the Fatigue Assessment Scale (FAS). Br J Health Psychol 2004;9:279-291.

32. Michielsen HJ, De Vries J, Drent M, Peros-Golubicic T. Psychometric qualities of the Fatigue Assessment Scale in Croatian sarcoidosis patients. Sarcoidosis Vasc Diffuse Lung Dis 2005;22:133-138.

33. Rothkrantz-Kos S, Van Dieijen-Visser MP, Mulder PG, Drent M. Potential usefulness of inflammatory markers to monitor respiratory functional impairment in sarcoidosis. Clin Chem 2003;49:1510-1517.

34. Agostini C, Trentin L, Facco M, Sancetta R, Cerutti A, Tassinari C, Cimarosto L, Adami F, Cipriani A, Zambello R, Semenzato G. Role of IL-15, IL-2, and their receptors in the development of T cell alveolitis in pulmonary sarcoidosis. J Immunol 1996;157:910-918.

35. Hunninghake GW, Bedell GN, Zavala DC, Monick M, Brady M. Role of interleukin-2 release by lung Tcells in active pulmonary sarcoidosis. Am Rev Respir Dis 1983;128:634-638.

36. Muller-Quernheim J. Serum markers for the staging of disease activity of sarcoidosis and other interstitial lung diseases of unknown etiology. Sarcoidosis Vasc Diffuse Lung Dis 1998;15:22-37.

37. Quanjer PH, Tammeling GJ, Cotes JE, Pedersen OF, Peslin R, Yernault JC. Lung volumes and forced ventilatory flows. Report Working Party Standardization of Lung Function Tests, European Community for Steel and Coal. Official Statement of the European Respiratory Society. Eur Respir J Suppl 1993;16: $5-40$.

38. ATS/ACCP Statement on cardiopulmonary exercise testing. American Thoracic Society/American College of Chest Physicians. Am J Respir Crit Care Med 2003;167:211-277.

39. ATS statement: guidelines for the six-minute walk test. American Thoracic Society. Am J Respir Crit Care Med 2002;166:111-117.

40. $\quad$ Enright PL. The six-minute walk test. Respir Care 2003;48:783-785.

41. Enright PL, Sherrill DL. Reference equations for the six-minute walk in healthy adults. Am J Respir Crit Care Med 1998;158:1384-1387.

42. Werle S, Goldhahn J, Drerup S, Simmen BR, Sprott H, Herren DB. Age- and gender-specific normative data of grip and pinch strength in a healthy adult Swiss population. J Hand Surg Eur Vol 2009;34: 76-84.

43. Mathiowetz V, Kashman N, Volland G, Weber K, Dowe M, Rogers S. Grip and pinch strength: normative data for adults. Arch Phys Med Rehabil 1985;66:69-74.

44. Black LF, Hyatt RE. Maximal respiratory pressures: normal values and relationship to age and sex. Am Rev Respir Dis 1969;99:696-702.

45. Vermeeren MA, Creutzberg EC, Schols AM, Postma DS, Pieters WR, Roldaan AC, Wouters EF. Prevalence of nutritional depletion in a large out-patient population of patients with COPD. Respir Med 2006;100:1349-1355. 
46. Schols AM, Broekhuizen R, Weling-Scheepers CA, Wouters EF. Body composition and mortality in chronic obstructive pulmonary disease. Am J Clin Nutr 2005;82:53-59.

47. Decramer M, Lacquet LM, Fagard R, Rogiers P. Corticosteroids contribute to muscle weakness in chronic airflow obstruction. Am J Respir Crit Care Med 1994;150:11-16.

48. Bernard S, LeBlanc P, Whittom F, Carrier G, Jobin J, Belleau R, Maltais F. Peripheral muscle weakness in patients with chronic obstructive pulmonary disease. Am J Respir Crit Care Med 1998;158:629-634.

49. Waatevik M, Johannessen A, Hardie JA, Bjordal JM, Aukrust P, Bakke PS, Eagan TM. Different COPD disease characteristics are related to different outcomes in the 6-minute walk test. Copd 2012;9: 227-234.

50. Hillman CM, Heinecke EL, Hii JW, Cecins NM, Jenkins SC, Eastwood PR. Relationship between body composition, peripheral muscle strength and functional exercise capacity in patients with severe chronic obstructive pulmonary disease. Intern Med J 2012;42:578-581.

51. De Kleijn WP, De Vries J, Lower EE, Elfferich MD, Baughman RP, Drent M. Fatigue in sarcoidosis: a systematic review. Curr Opin Pulm Med 2009;15:499-506.

52. De Vries J, Rothkrantz-Kos S, Van Dieijen-Visser MP, Drent M. The relationship between fatigue and clinical parameters in pulmonary sarcoidosis. Sarcoidosis Vasc Diffuse Lung Dis 2004;21:127-136.

53. Spruit MA, Thomeer MJ, Gosselink R, Troosters T, Kasran A, Debrock AJ, Demedts MG, Decramer M. Skeletal muscle weakness in patients with sarcoidosis and its relationship with exercise intolerance and reduced health status. Thorax 2005;60:32-38.

54. Allaire J, Maltais F, Doyon JF, Noel M, LeBlanc P, Carrier G, Simard C, Jobin J. Peripheral muscle endurance and the oxidative profile of the quadriceps in patients with COPD. Thorax 2004;59: 673-678.

55. Serres I, Gautier V, Varray A, Prefaut C. Impaired skeletal muscle endurance related to physical inactivity and altered lung function in COPD patients. Chest 1998;113:900-905.

56. Boots AW, Drent M, De Boer VC, Bast A, Haenen GR. Quercetin reduces markers of oxidative stress and inflammation in sarcoidosis. Clin Nutr 2011;30:506-512.

57. Kao CC, Hsu JW, Bandi V, Hanania NA, Kheradmand F, Jahoor F. Resting energy expenditure and protein turnover are increased in patients with severe chronic obstructive pulmonary disease. Metabolism 2011;60:1449-1455.

58. Grutters JC, Van den Bosch JM. Corticosteroid treatment in sarcoidosis. Eur Respir J 2006;28:627-636.

59. Paddon-Jones D, Sheffield-Moore M, Cree MG, Hewlings SJ, Aarsland A, Wolfe RR, Ferrando AA. Atrophy and impaired muscle protein synthesis during prolonged inactivity and stress. J Clin Endocrinol Metab 2006;91:4836-4841.

60. Korenromp IH, Grutters JC, Van den Bosch JM, Heijnen CJ. Post-inflammatory fatigue in sarcoidosis: personality profiles, psychological symptoms and stress hormones. J Psychosom Res 2012;72:97-102.

61. Mastorakos G, Paltoglou G, Greene M, Ilias I, Papamichalopoulos A, Dimopoulos S, Pouliou E, Fatouros IG, Nanas S. Inappropriately normal plasma ACTH and cortisol concentrations in the face of increased circulating interleukin-6 concentration in exercise in patients with sarcoidosis. Stress 2013;16:202-210.

62. Langen RC, Haegens A, Vernooy JH, Wouters EF, De Winther MP, Carlsen H, Steele C, Shoelson SE, Schols AM. NF-kappaB activation is required for the transition of pulmonary inflammation to muscle atrophy. Am J Respir Cell Mol Biol 2012;47:288-297.

63. Zoico $E$, Roubenoff $R$. The role of cytokines in regulating protein metabolism and muscle function. Nutr $\operatorname{Rev} 2002 ; 60: 39-51$

64. Langen RC, Schols AM, Kelders MC, Van der Velden JL, Wouters EF, Janssen-Heininger YM. Muscle wasting and impaired muscle regeneration in a murine model of chronic pulmonary inflammation. $\mathrm{Am} \mathrm{J}$ Respir Cell Mol Biol 2006;35:689-696.

65. Wouters EF, Groenewegen KH, Dentener MA, Vernooy JH. Systemic inflammation in chronic obstructive pulmonary disease: the role of exacerbations. Proc Am Thorac Soc 2007;4:626-634.

66. Drent M, Van den Berg R, Haenen GR, Van den Berg H, Wouters EF, Bast A. NF-kappaB activation in sarcoidosis. Sarcoidosis Vasc Diffuse Lung Dis 2001;18:50-56.

67. Rahman I. Oxidative stress, transcription factors and chromatin remodelling in lung inflammation. Biochem Pharmacol 2002;64:935-942.

68. Van den Borst B, Gosker HR, Schols AM. Central fat and peripheral muscle: partners in crime in chronic obstructive pulmonary disease. Am J Respir Crit Care Med 2013;187:8-13.

69. Zafon C. Fat and aging: a tale of two tissues. Curr Aging Sci 2009;2:83-94. 
70. Fuller NJ, Jebb SA, Laskey MA, Coward WA, Elia M. Four-component model for the assessment of body composition in humans: comparison with alternative methods, and evaluation of the density and hydration of fat-free mass. Clin Sci (Lond) 1992;82:687-693.

71. Van Loan MD. Is dual-energy X-ray absorptiometry ready for prime time in the clinical evaluation of body composition? Am J Clin Nutr 1998;68:1155-1156.

72. Wilson JP, Mulligan K, Fan B, Sherman JL, Murphy EJ, Tai VW, Powers CL, Marquez L, Ruiz-Barros V, Shepherd JA. Dual-energy X-ray absorptiometry-based body volume measurement for 4-compartment body composition. Am J Clin Nutr 2012;95:25-31.

73. Pahor M, Manini T, Cesari M. Sarcopenia: clinical evaluation, biological markers and other evaluation tools. J Nutr Health Aging 2009;13:724-728. 



\section{Chapter 4}

Liver test abnormalities in sarcoidosis

J Cremers, M Drent, A Driessen, F Nieman, P Wijnen,

R Baughman, G Koek

Eur J Gastroenterol Hepatol 2012;24:17-24 


\section{Abstract}

\section{Background}

Sarcoidosis is a multisystemic inflammatory granulomatous disease. The prevalence of hepatic involvement is not clear. The aim of this study was to establish the presence and severity of liver test abnormalities in sarcoidosis.

\section{Methods}

Retrospectively, patients with confirmed sarcoidosis $(n=837)$ presenting with the liver test abnormalities (alkaline phosphatase, $\gamma$-glutamyl transferase, alanine aminotransferase or aspartate aminotransferase $>1.5$ times the upper limit of normal (ULN)) who were classified according to severity into mild (zero liver tests $\geq 3$ times the ULN), moderate (one or two liver tests $\geq 3$ times the ULN) and severe (three or four liver tests $\geq 3$ times the ULN) were evaluated. Moreover, the relationship between severity of liver tests and histology was examined.

\section{Results}

Liver test abnormalities were found in 204 of 837 patients with chronic sarcoidosis $(24.4 \%)$, among which 127 (15.2\%) were suspected of having hepatic sarcoidosis (79 of 127 males, 111 Caucasian, eight African-American). In 22 of 127 patients (17.3\%), a liver biopsy was obtained; 21 were compatible with hepatic sarcoidosis. In these 21 patients, severity of liver test abnormalities was significantly associated with extensiveness of granulomatous inflammation $(\rho=0.58, p=0.006)$ and degree of fibrosis $(\rho=0.64, p=0.002)$. These results remained in the multiple regression analysis when controlled for treatment status, sex, genetics, ethnicity and age.

\section{Conclusion}

Liver test abnormalities were present in $24 \%$ of the studied patients; in $15 \%$ highly because of hepatic involvement of sarcoidosis. Moderate and severe liver test abnormalities seemed to be associated with more advanced histopathological disease. Therefore, in the management of sarcoidosis, for patients with moderate or severe liver test abnormalities a liver biopsy is recommended. 


\section{Introduction}

Sarcoidosis is a multisystemic inflammatory granulomatous disease of unknown etiology. ${ }^{1}$ Typical for sarcoidosis is the presence of non-necrotizing granulomas, affecting lung and lymph nodes in more than $90 \%$ of the cases, but it can involve almost every organ system. ${ }^{2-5}$ The prevalence of sarcoidosis is estimated at 1 to 40 cases per 100 000, with an age-adjusted annual incidence in the USA of 35.5 per 100000 for African-Americans and 10.9 per 100000 for Caucasians. ${ }^{1}$

Extrapulmonary sites, including the liver, are involved in $50 \%$ of cases. ${ }^{4,6,7}$ Hepatic sarcoidosis mostly affects young individuals between 20 and 40 years old, and is twice as common in African-Americans as in Caucasians. ${ }^{6-12}$ Hepatic sarcoidosis is usually asymptomatic. ${ }^{4,8,13}$ Only $5-30 \%$ of the patients present with atypical clinical signs and symptoms such as nausea, vomiting, abdominal pain in de right upper quadrant, a painful liver during palpation and/or hepatomegaly. ${ }^{3,8,10-12,14-21}$ In a minority of patients, hepatic sarcoidosis can be a serious and rapid progressive disease with the occurrence of complications as cirrhosis, portal hypertension, chronic cholestasis and Budd-Chiari syndrome. $3,4,8,10,13,14,17,21-24$ Because symptomatic hepatic sarcoidosis is uncommon, studies to investigate the natural history and the diagnostic approach are scarce.

Diagnosis of hepatic sarcoidosis is established when clinicoradiological findings are supported by a compatible histological picture of a biopsy obtained from another organ and/or the liver, after the exclusion of other causes of hepatic granulomas. ${ }^{1}$ Guidelines with recommendations for the assessment of hepatic involvement in patients with sarcoidosis presenting with liver test abnormalities are not yet available. Moreover, diagnosis is considered to be a clinical challenge, because of the wide spectrum of disease presentation and course with the absence of specific symptoms, signs and radiological findings. ${ }^{3,8,10-12,14-21,25}$ Furthermore, liver test abnormalities can be found in hepatic sarcoidosis; however, the clinical relevance of the severity of these abnormalities is uncertain. ${ }^{10-12,16,18,19,26}$ Therefore, the aim of this study was to establish the presence and severity of the liver test abnormalities in a Dutch sarcoidosis population and additionally, to evaluate the relationship between severity of liver test abnormalities and histopathological abnormalities in hepatic sarcoidosis.

\section{Methods}

\section{Study design and selection of patients}

In this retrospective study, we analysed the data of patients with the established diagnosis sarcoidosis ( $n=837$ ) who, between 2000 and 2009, visited the ild care centre (interstitial lung diseases including sarcoidosis management and research) of the Maastricht University Medical Centre+ (MUMC+), a tertiary referral centre for the Netherlands. 
Of the studied sarcoidosis patients, in 570 (68.1\%) a biopsy was obtained: 269 of the lung; 112 of the skin; 145 of a lymph node; 44 of other organs of which 22 of the liver. In patients with typical features of the Löfgren's syndrome and characteristic features of the bronchoalveolar lavage fluid analysis results, no biopsy was obtained. This policy is consistent with the World Association of Sarcoidosis and Other Granulomatous Diseases guidelines. ${ }^{1,27}$

Liver involvement was suspected if one of the following liver tests exceeded the level of the upper limit of normal (ULN) 1.5 times: alanine aminotransferase more than $67.5 \mathrm{U} / \mathrm{l}$ for men and more than $52.5 \mathrm{U} / \mathrm{I}$ for women, aspartate aminotransferase more than $52.5 \mathrm{U} / \mathrm{I}$ for men and more than $45 \mathrm{U} / \mathrm{I}$ for women, alkaline phosphatase (ALP) more than $210 \mathrm{U} / \mathrm{I}$ for both men and women, $\mathrm{v}$-glutamyl transferase more than $75 \mathrm{U} / \mathrm{I}$ for men and more than $60 \mathrm{U} / \mathrm{I}$ for women. All available histological liver biopsies from the histopathologic department of the MUMC+ were examined to cross-check and supplement the list of patients suspected of hepatic sarcoidosis.

Patients with liver test abnormalities that were attributable to drug use $(n=12)$ or other (liver) diseases $(n=10)$ were excluded.

\section{Collection of clinical data}

For each patient suspected of hepatic sarcoidosis, we reviewed Mirador, the electronic database of MUMC+, in detail to gather the following items: general information, data concerning the diagnostic process (laboratory abnormalities, radiological findings, liver biopsies) and treatment status. Because of the absence of a standard grading system, we classified the liver test abnormalities according to severity into mild (zero liver tests $\geq 3$ times the ULN), moderate (one or two liver tests $\geq 3$ times the ULN) and severe (three or four liver tests $\geq 3$ times the ULN). Ultrasonographic findings were defined positive (i.e. suggestive for hepatic sarcoidosis) in the presence of hyperechogenic or hypoechogenic spots. ${ }^{13}$ Treatment status was established for the distinction between patients treated and patients not treated during the liver biopsy. All data were recorded within 6 months from the time the liver biopsy was performed. For missing follow-up data we contacted the medical practitioners of the secondary care centre where the patient had been treated originally.

\section{Histopathologic examination}

Histological examination was performed on formalin-fixed paraffin-embedded material. A panel of histochemical stains was used: haematoxylin and eosin (H/E), Sirius red, reticulin, Periodic Acid-Schiff diastase reaction and Ziehl Nielsen. The aim of these stains was to evaluate the architecture of the liver, the presence and degree of inflammation, steatosis and fibrosis and the distribution of the granulomas. In the granulomas we looked for necrosis, Schaumann's bodies and asteroid bodies. An immunohistochemical analysis was restricted to a cytokeratin 7-stain in order to evaluate the presence of bile ducts, and their possible loss (ductopenia). Polarization of 
the liver biopsy was conducted to detect birefringent material. According to a classification modified from Kahi et al., ${ }^{17}$ the extent of granulomatous inflammation was graded. Based on the percentage of liver sample occupied by granulomas the liver biopsies were classified into three groups: $0-25,26-50$, more than $50 \%$. The degree of inflammation was subtyped into mild (no or minimal periportal inflammation), moderate (periportal and minimal lobular inflammation) and severe (periportal and lobular inflammation). ${ }^{28}$ Fibrosis was classified according to the classification proprosed by Desmet et al. ${ }^{28}$ : grade 1 (periportal fibrous expansion without septa formation), grade 2 (porto-portal septa with intact architecture), grade 3 (portocentral septa with architectural distortion) and grade 4 (cirrhosis). The level of steatosis was determined according to the classification proposed by Kleiner et al. ${ }^{29}$ : stage 0 , less than $5 \%$; stage 1 , more than 5-33\%; stage 2, more than $33-66 \%$ and stage 3 , more than $66 \%$ of parenchyma involved by steatosis.

\section{Statistical analysis}

For univariate normally distributed variates means and SDs were used. For nonnormally distributed variates score minima and maxima were given. For univariate nominal or ordinal variables frequencies and percentages were used. To examine and test associations between ordinal diagnostic scales (liver test abnormalities and histopathology), log-likelihood chi-squares $\left(X_{L}{ }^{2}\right)$ and Spearman's rank-correlation coefficient (Spearman's $\rho$ ) were used. Despite the low statistical power, an attempt was made to use multiple regression analysis to adjust this relationship for other confounding variables (treatment status, age, sex, genetics and ethnicity). Forward selection was used to find a final regression model containing only statistically significant effects. A p value less than 0.05 was considered to represent a statistically significant relationship. SPSS-pc version 16.0 (SPSS Inc., Chicago, Illinois, USA) was used for analysis.

\section{Results}

\section{Selection process}

A total of 837 patients with a confirmed diagnosis of sarcoidosis visited the ild care centre of the MUMC+ (Figure 4.1). Liver test abnormalities were present in 204 patients (24.4\%). Among these, 77 patients were excluded: 55 because of minimal liver test abnormalities ( $<1.5$ times ULN), 12 because of suspected medication induced liver test abnormalities (among others methotrexate, azathioprine and antibiotics), two because of development of colorectal carcinoma with hepatic metastases during sarcoidosis disease course, five because of other liver diseases (viral hepatitis, alcohol induced liver damage and cholelithiasis) and three patients because of liver test abnormalities as a 
consequence of pulmonary hypertension due to pulmonary sarcoidosis with resultant cardiac congestion. The remaining 127 patients were included with the suspected diagnosis of hepatic sarcoidosis. In 22 out of 127 patients with liver test abnormalities (17.3\%) a liver biopsy was performed. Twenty-one out of 22 biopsies showed granulomas compatible with hepatic sarcoidosis. These 21 biopsies were used for the comparison between severity of liver test abnormalities and histological findings. One liver biopsy was small and fragmented and showed no granulomas, possibly because of a sampling error.

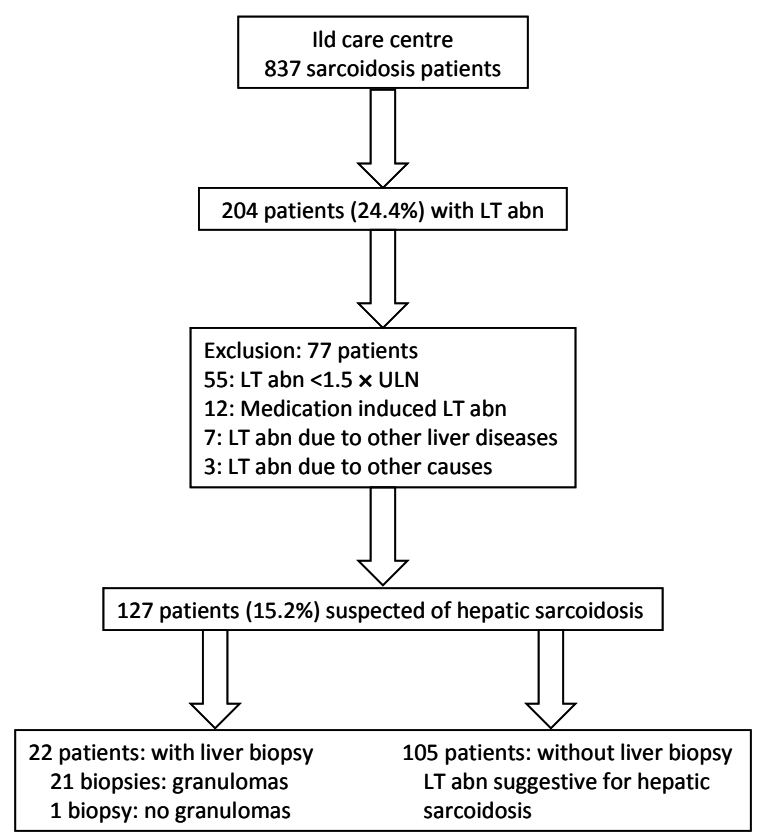

Figure 4.1 Flow diagram inclusion and exclusion of patients. LT abn, liver test abnormalities; ULN, upper limit of normal.

\section{Baseline characteristics}

Finally, 127 patients (79 men, 48 women) were suspected of hepatic sarcoidosis. Baseline characteristics are summarized in Table 4.1. The prevalence of suspected symptomatic liver involvement in patients with the confirmed diagnosis sarcoidosis in this group of patients was estimated at 1:7 (15.2\%). Mean age of patients with suspected symptomatic hepatic sarcoidosis was 50.5 years ( \pm 11.39 ). Familial involvement was reported in $7.9 \%$ of patients and African-American descent in $6.3 \%$. 
Liver test abnormalities were in $43.3 \%$ cases of cholestatic origin, in $22.8 \%$ parenchymatous and in $33.9 \%$ combined.

Table 4.1 Baseline characteristics of patients suspected of hepatic sarcoidosis ( $n=127)$.

\begin{tabular}{|c|c|}
\hline Baseline characteristics & \\
\hline Age (years) ${ }^{a}$ & $50.5( \pm 11.39,28-83)$ \\
\hline \multicolumn{2}{|l|}{ Sex ${ }^{b}$} \\
\hline Male & $79 / 127$ (62.2\%) \\
\hline Female & $48 / 127$ (37.8\%) \\
\hline \multicolumn{2}{|l|}{ Race $^{b}$} \\
\hline Caucasian & $111 / 126(88.1 \%)$ \\
\hline African-American & $8 / 126(6.3 \%)$ \\
\hline Other & $7 / 126(5.6 \%)$ \\
\hline Average disease duration (years) ${ }^{a}$ & $7.93( \pm 5.45,1-29)$ \\
\hline Familial involvement ${ }^{b}$ & $10 / 126(7.9 \%)$ \\
\hline Smoking ${ }^{\mathrm{b}}$ & $15 / 124(12.1 \%)$ \\
\hline \multicolumn{2}{|l|}{ Liver test abnormalities ${ }^{b, c}$} \\
\hline Mild & $36 / 127$ (28.3\%) \\
\hline Moderate & $85 / 127$ (67.0\%) \\
\hline Severe & $6 / 127(4.7 \%)$ \\
\hline \multicolumn{2}{|l|}{ Liver test abnormalities $^{\mathrm{b}}$} \\
\hline Cholestatic & $55 / 127$ (43.3\%) \\
\hline Parenchymatous & $29 / 127(22.8 \%)$ \\
\hline Combined & 43/127 (33.9\%) \\
\hline
\end{tabular}

${ }^{a}$ Data are presented as means \pm SD with range. ${ }^{b}$ Data are presented as absolute numbers with percentages. ${ }^{c}$ Liver test abnormalities on the basis of severity: mild, $1.5 \times$ ULN $<$ LTs $\geq 3 \times$ ULN; moderate, 1 or 2 LTs $\geq 3 \times$ ULN; severe, 3 or 4 LTs $\geq 3 \times$ ULN. LT abn, liver test abnormalities; ULN, upper limit of normal.

\section{Histopathological findings}

In $17.3 \%$ (22 of 127 patients) a liver biopsy was obtained, of which 21 were compatible with hepatic sarcoidosis. Baseline characteristics and the results of histopathological assessment for this subpopulation are summarized in Table 4.2. The percentage of biopsy area occupied by granulomas was estimated to be less than $50 \%$ in $71 \%$ of the liver biopsies, with granulomas located predominantly mixed portal and parenchymatous (Figure 4.2a and 4.2b). Inflammation was present in all cases, often periportal, but involving the liver parenchyma to a variable degree in 12 patients $(57 \%)$. In one patient asteroid bodies were found in giant cells situated in granulomas, as illustrated in Figure 4.2c. Ductopenia was present in 33\% of cases. Birefringent material was made visible during polarization in a total of six granulomas (Figure $4.2 \mathrm{~d}$ ). Fibrosis grade 3 was noted in five biopsies (24\%). 
Table 4.2 Baseline characteristics and histopathological findings $(n=21)$.

\begin{tabular}{|c|c|c|}
\hline \multicolumn{3}{|l|}{ Baseline characteristics } \\
\hline Mean age (years) ${ }^{a}$ & & $48( \pm 13,28-73)$ \\
\hline \multirow[t]{2}{*}{ Sex ${ }^{b}$} & Male & $12(57 \%)$ \\
\hline & Female & $9(43 \%)$ \\
\hline \multirow[t]{2}{*}{ Race $^{b}$} & Caucasian & $19(90 \%)$ \\
\hline & African-American & $2(10 \%)$ \\
\hline \multirow[t]{3}{*}{ Liver test abnormalities ${ }^{b, c}$} & Mild & $5(24 \%)$ \\
\hline & Moderate & $12(57 \%)$ \\
\hline & Severe & $4(19 \%)$ \\
\hline \multicolumn{3}{|l|}{ Histological features } \\
\hline \multirow[t]{3}{*}{ Area of liver samples occupied by granulomas ${ }^{b}$} & $0-25 \%$ & $10(48 \%)$ \\
\hline & $26-50 \%$ & $5(24 \%)$ \\
\hline & $>50 \%$ & $6(29 \%)$ \\
\hline Non-necrotizing granulomas ${ }^{b}$ & & $21(100 \%)$ \\
\hline \multirow[t]{3}{*}{ Location granulomas $^{\mathrm{b}}$} & Portal & $4(19 \%)$ \\
\hline & Parenchymatous & $4(19 \%)$ \\
\hline & Mixed & $13(62 \%)$ \\
\hline Asteroid bodies ${ }^{b}$ & & $1(5 \%)$ \\
\hline Schaumann's bodies ${ }^{b}$ & & $0(0 \%)$ \\
\hline Ductopenia $^{\mathrm{b}}$ & & $7(33 \%)$ \\
\hline Sinusoidal dilatation $^{\mathrm{b}}$ & & $5(24 \%)$ \\
\hline Birefringent material on polarization ${ }^{d}$ & & 6 granulomas \\
\hline Cholestatic changes $^{\mathrm{b}}$ & & $4(19 \%)$ \\
\hline \multirow[t]{3}{*}{ Degree of inflammation ${ }^{\text {b,e }}$} & Mild & $9(43 \%)$ \\
\hline & Moderate & $10(48 \%)$ \\
\hline & Severe & $2(10 \%)$ \\
\hline \multirow[t]{5}{*}{ Degree of fibrosis ${ }^{b, f}$} & Stage 0 & $5(24 \%)$ \\
\hline & Stage 1 & $9(43 \%)$ \\
\hline & Stage 2 & $2(10 \%)$ \\
\hline & Stage 3 & $5(24 \%)$ \\
\hline & Stage 4 & $0(0 \%)$ \\
\hline \multirow[t]{4}{*}{ Degree of steatosis ${ }^{b}$} & Stage $0:<5 \%$ & $12(57 \%)$ \\
\hline & Stage 1: 5-33\% & $6(29 \%)$ \\
\hline & Stage 2: 34-66\% & $2(10 \%)$ \\
\hline & Stage 3: >66\% & $1(5 \%)$ \\
\hline
\end{tabular}

${ }^{a}$ Data are presented as means \pm SD with range. ${ }^{b}$ Data are presented as absolute numbers with percentages. ${ }^{c}$ Liver test abnormalities on the basis of severity: mild, $1.5 \times$ ULN $<$ LTs $\geq 3 \times$ ULN; moderate, 1 or 2 LTs $\geq 3 \times$ ULN; severe, 3 or 4 LTs $\geq 3 \times$ ULN. ${ }^{d}$ Using a polarizing microscope revealed birefringent material, that is, the presence of foreign body material. ${ }^{e}$ Degree of inflammation: mild, no or minimal periportal inflammation; moderate, periportal and minimal lobular inflammation; severe, periportal and lobular inflammation. ${ }^{28 \mathrm{f}}$ Degree of fibrosis: stage 0, no fibrosis; stage 1, periportal fibrous expansion without septa formation; grade 2, porto-portal septa with intact architecture; grade 3, portocentral septa with architectured distortion; grade 4, cirrhosis. $^{28}$ LT, liver test; ULN, upper limit of normal.

For the 21 available liver biopsies, we examined the association between the three main outcome histopathological features and the severity of liver test abnormalities. Severity of liver test abnormalities was significantly and positively associated with the percentage of biopsy area occupied by granulomas (Spearman's $\rho=0.58, p=0.006$ ) and degree of fibrosis (Spearman's $\rho=0.64, p=0.002$ ). After control for the possible 
confounding variables treatment status, sex, genetics, ethnicity and age by multiple regression analysis, severity of liver tests was still significantly associated with extensiveness of granulomatous inflammation (moderate vs. mild beta $=0.53, p=0.02$; severe vs. mild beta $=0.66, p=0.005$ ) and degree of fibrosis (beta $=0.22, p=0.24$ and beta=0.87, $p<0.001$, Table 4.3). Sex appeared to be significantly associated with extent of granulomatous inflammation as well (beta $=0.39, p=0.04$ ): in females more advanced stages of granulomatous inflammation can be observed. After statistical correction for possible confounders, severity of liver test abnormalities appeared not to be associated with degree of inflammation, but with age and race.
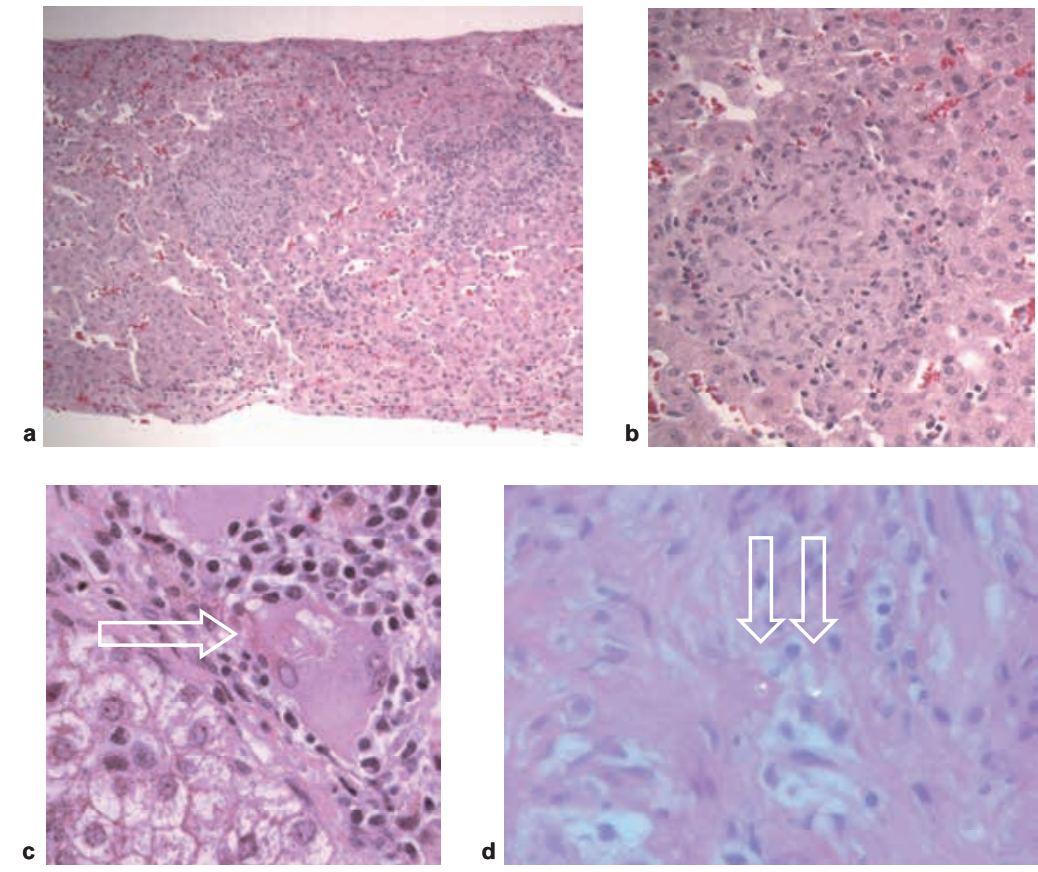

Figure 4.2 Liver biopsy sections from patients diagnosed with hepatic sarcoidosis. a. Granulomas located in portal fields and liver parenchyma (H/E, magnification 10x). b. Non-necrotizing granuloma consisting of epithelioid histiocytes and giant cells surrounded by a rim of lymphocytes (H/E, magnification 20x). c. Asteroid body in a giant cell (H/E, magnification 40x). d. Birefringent material during polarization, pointing towards foreign exogenous material as a possible cause for granuloma formation (H/E, magnification 63x). H/E, haematoxylin and eosin.

When the liver biopsy was performed, four patients were pharmacologically treated: two patients with prednisone because of extrahepatic sarcoidosis activity and two patients because of suspected hepatic sarcoidosis (one patient used prednisone and one ursodeoxycholic acid). In multiple regression analysis, treatment status did not appear to disturb the association between liver tests and histology. 
Table 4.3 Results of the three final regression analysis models $(n=21)$.

\begin{tabular}{|c|c|c|c|c|c|c|}
\hline & \multirow[t]{2}{*}{$\mathrm{b}$} & \multirow[t]{2}{*}{ SE } & \multirow[t]{2}{*}{$\beta$} & \multirow[t]{2}{*}{$p$ value } & \multicolumn{2}{|c|}{$95 \% \mathrm{Cl}$ of $\mathrm{b}$} \\
\hline & & & & & Lower & Upper \\
\hline \multicolumn{7}{|c|}{ 1. Area of liver sample occupied by granulomas; variance explained $=0.50$} \\
\hline Constant & 0.73 & 0.32 & - & 0.04 & 0.05 & 1.41 \\
\hline \multicolumn{7}{|l|}{ Severity LT abn ${ }^{c}$} \\
\hline Moderate vs. mild & 0.91 & 0.36 & 0.53 & $0.02 *$ & 0.15 & 1.66 \\
\hline Severe vs. mild & 1.43 & 0.45 & 0.66 & $0.005^{*}$ & 0.48 & 2.38 \\
\hline \multicolumn{7}{|l|}{ Sex } \\
\hline Female vs. male & 0.67 & 0.30 & 0.39 & $0.04 *$ & 0.04 & 1.29 \\
\hline \multicolumn{7}{|c|}{ 2. Degree of inflammation; variance explained $=0.62^{\mathrm{a}}$} \\
\hline Constant & 0.03 & 0.36 & - & 0.95 & -0.73 & 0.78 \\
\hline Age & 0.03 & 0.01 & 0.66 & $<0.001^{*}$ & 0.02 & 0.05 \\
\hline \multicolumn{7}{|l|}{ Ethnicity } \\
\hline Afr-Am vs. Cauc & 0.85 & 0.32 & 0.39 & $0.02 *$ & 0.18 & 1.53 \\
\hline \multicolumn{7}{|c|}{ 3. Degree of fibrosis, variance explained $=0.59^{b}$} \\
\hline Constant & 0.60 & 0.34 & - & 0.09 & -0.10 & 1.30 \\
\hline \multicolumn{7}{|l|}{ Severity LT abn ${ }^{c}$} \\
\hline Moderate vs. mild & 0.48 & 0.40 & 0.22 & 0.24 & -0.36 & 1.32 \\
\hline Severe vs. mild & 2.40 & 0.50 & 0.87 & $<0.001^{*}$ & 1.34 & 3.46 \\
\hline
\end{tabular}

* Statistically significant at $\mathrm{p}<0.05$. $^{\mathrm{a}}$ Degree of inflammation: mild, no or minimal periportal inflammation; moderate, periportal and minimal lobular inflammation; severe, periportal and lobular inflammation. ${ }^{28}$ ${ }^{b}$ Degree of fibrosis: stage 0, no fibrosis; stage 1, periportal fibrous expansion without septa formation; grade 2, porto-portal septa with intact architecture; grade 3, portocentral septa with architectured distortion; grade 4 , cirrhosis. $^{28 \text { c }}$ Liver test abnormalities on the basis of severity: mild, $1.5 \times$ ULN < LTs $\geq 3 \times$ ULN; moderate, 1 or 2 LTs $\geq 3 \times$ ULN; severe, 3 or 4 LTs $\geq 3 \times$ ULN. b, unstandardized regression coefficient; Cl, confidence interval; LT abn, liver test abnormalities; SE, standard error for $b$; ULN, upper limit of normal; $\beta$, standardized regression coefficient.

\section{Radiological findings}

Liver ultrasound evaluation in 13 patients with histological confirmed hepatic sarcoidosis, revealed positive results in six cases (sensitivity $46.2 \%$ ).

\section{Discussion}

To the best of our knowledge, this was the first study demonstrating that severity of liver test abnormalities was significantly related with the degree of fibrosis and extensiveness of the granulomatous inflammation in sarcoidosis. Diagnosis of hepatic sarcoidosis is difficult, as diagnostic criteria are lacking and guidelines with recommendations for diagnosis and follow-up of patients suspected of hepatic sarcoidosis are not available. However, because hepatic sarcoidosis can be a serious and rapid progressive disease, a correct diagnosis without delay is important.

There has been conflicting evidence to both support and refute the rationale that liver test abnormalities are associated with the extent of the severity of liver involvement. In patients with asymptomatic hepatic sarcoidosis, Lebacq and Heller ${ }^{26}$ 
found ALP to be more reliable than y-glutamyl transferase in predicting sarcoid liver involvement. Baughman et al. ${ }^{30}$ found higher levels of various liver tests, especially ALP, in patients with liver sarcoidosis. In patients with abnormal liver tests, hepatic granulomas were more often seen compared to patients with normal liver tests. ${ }^{19}$ In contrast, others did not find this relationship. ${ }^{11}$ However, liver parameters were not classified according to severity and the study group was small in the latter study $(n=15) .{ }^{12}$ In 20 patients with advanced inflammatory changes, higher levels of ALP, transaminases and fibrosis around hepatic granulomas in the liver were reported. However, this study did not grade liver tests and remained descriptive. ${ }^{10}$

Every physician managing patients with sarcoidosis should be alert about the possibility of the development of hepatobiliary disorders. On the bases of the results of the present study, we made a first attempt for a diagnostic algorithm in the diagnosis and follow-up of patients with sarcoidosis presenting with liver test abnormalities (Figure 4.3). In patients with liver test abnormalities above 1.5 times the ULN for more than 3 months, a careful follow-up is recommended. Unfortunately, studies with arguments for follow-up of liver tests in patients with different degrees of liver test abnormalities are lacking.

For the classification of severity of liver test abnormalities in our study we found no distinction between cholestatic and parenchymatous liver tests.

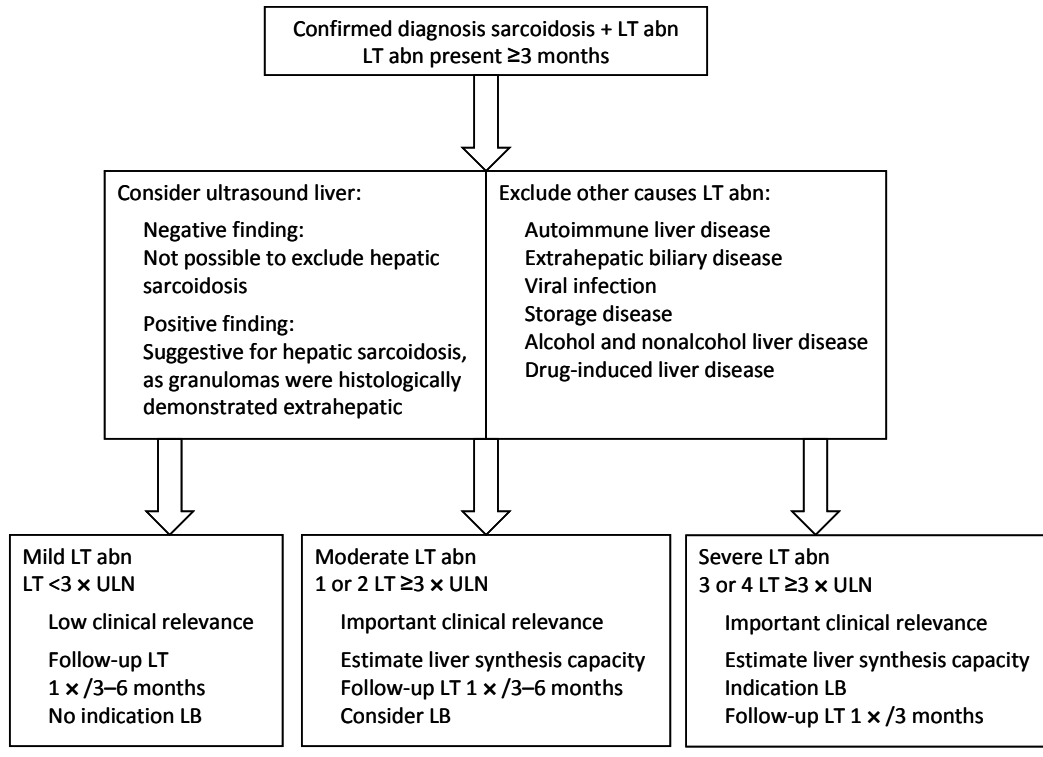

Figure 4.3 Diagnostic algorithm sarcoidosis patients with liver test abnormalities. LB, liver biopsy; LT, liver tests; LT abn, liver test abnormalities. 
Although liver biopsy might be useful in diagnosing hepatic sarcoidosis, there are some major disadvantages. First of all, percutaneous liver biopsy is an invasive procedure with the risk of major complications (among others haemorrhage, perforation of gall-bladder or colon, pneumothorax and biliary peritonitis) estimated to occur in $0.09 \%-3.1 \%$ of cases. ${ }^{31-33}$ Moreover, liver biopsy might be accompanied with a lot of anxiety and postbiopsy discomfort. ${ }^{31}$ Furthermore, as a biopsy specimen represents as few as 1 in 50.000 of the total mass of the liver, ${ }^{34}$ sampling error may be a possible consequence. However, Hercules and Bethlem ${ }^{11}$ demonstrated that falsenegative results in liver biopsy were unlikely.

Whether radiological examination might be an alternative for detection of hepatic sarcoidosis is not clear. In the present study, a sensitivity of $46.2 \%$ was found for liver ultrasound. This implicates that it is not useful in the exclusion of hepatic sarcoidosis in the case of an absence of hyperechogenic or hypoechogenic spots. Positive findings of liver ultrasound were suggestive for hepatic sarcoidosis, especially when signs of extrahepatic granulomas consistent with sarcoidosis were found. In line with the previous studies in which a sensitivity of 53-59.2\% for conventional liver ultrasound in the detection of general hepatic lesions was shown, it appeared of limited value in the confirmation of hepatic sarcoidosis. 35,36

In sarcoidosis patients with severe liver test abnormalities during a minimum of 3 months, advanced stages of fibrosis must be suspected. In addition, in patients with moderate liver test abnormalities during a minimum of 3 months, advanced stages of fibrosis cannot be excluded. A liver biopsy to assess the disease severity to guide a more or less aggressive pharmacological approach is recommended. The occurrence of hepatic complications because of advanced stages of fibrosis (stage 3 and 4) in our study was estimated at almost $25 \%$, which is in accordance with the finding of bridging fibrosis and cirrhosis in $8-26 \%$ of cases in previous studies. ${ }^{4,14,17}$ If liver test abnormalities progress to advanced stages, it is recommended to adjust the diagnostic approach according to Figure 4.3.

One of the major limitations of this study is the small number of liver biopsies. Prospective studies are warranted to establish liver sarcoidosis in a respectable number of patients.

Furthermore, although the studied patient population was gathered in a tertiary referral centre, the severity mainly refers to the chronicity of the sarcoidosis patients. Hence this study appears to be representative for chronic Dutch sarcoidosis patients. However, conclusions must be interpreted with caution.

In conclusion, in the studied Dutch chronic sarcoidosis population liver test abnormalities were present in $24 \%$ of patients; in $15 \%$ highly likely because of hepatic involvement of sarcoidosis. Severity of liver test abnormalities appeared to be related to the degree of fibrosis and extensiveness of granulomatous inflammation in hepatic sarcoidosis. In the management of sarcoidosis patients presenting with severe liver test abnormalities, a liver biopsy is strongly recommended, whereas, in patients with moderate liver test abnormalities a liver biopsy should be considered. 


\section{References}

1. Statement on sarcoidosis. Joint Statement of the American Thoracic Society (ATS), the European Respiratory Society (ERS) and the World Association of Sarcoidosis and Other Granulomatous Disorders (WASOG) adopted by the ATS Board of Directors and by the ERS Executive Committee, February 1999. Am J Respir Crit Care Med 1999;160:736-755.

2. Rosen Y. Pathology of sarcoidosis. Semin Respir Crit Care Med 2007;28:36-52.

3. Mueller S, Boehme MW, Hofmann WJ, Stremmel W. Extrapulmonary sarcoidosis primarily diagnosed in the liver. Scand J Gastroenterol 2000;35:1003-1008.

4. Kennedy PT, Zakaria N, Modawi SB, Papadopoulou AM, Murray-Lyon I, du Bois RM, Jervoise NAH, Devlin J. Natural history of hepatic sarcoidosis and its response to treatment. Eur J Gastroenterol Hepatol 2006;18:721-726.

5. Ebert EC, Kierson M, Hagspiel KD. Gastrointestinal and hepatic manifestations of sarcoidosis. Am J Gastroenterol 2008;103:3184-3192; quiz 3193.

6. Baughman RP, Teirstein AS, Judson MA, Rossman MD, Yeager H, Jr., Bresnitz EA, DePalo L, Hunninghake G, lannuzzi MC, Johns CJ, McLennan G, Moller DR, Newman LS, Rabin DL, Rose C, Rybicki B, Weinberger SE, Terrin ML, Knatterud GL, Cherniak R. Clinical characteristics of patients in a case control study of sarcoidosis. Am J Respir Crit Care Med 2001;164:1885-1889.

7. Ayyala US, Padilla ML. Diagnosis and treatment of hepatic sarcoidosis. Curr Treat Options Gastroenterol 2006;9:475-483.

8. Judson MA. Hepatic, splenic, and gastrointestinal involvement with sarcoidosis. Semin Respir Crit Care Med 2002;23:529-541.

9. Costabel U. Sarcoidosis: clinical update. Eur Respir J Supp/ 2001;32:56s-68s.

10. Maddrey WC, Johns CJ, Boitnott JK, Iber FL. Sarcoidosis and chronic hepatic disease: a clinical and pathologic study of 20 patients. Medicine (Baltimore) 1970;49:375-395.

11. Hercules HD, Bethlem NM. Value of liver biopsy in sarcoidosis. Arch Pathol Lab Med 1984;108: 831-834.

12. Klatskin G, Yesner R. Hepatic manifestations of sarcoidosis and other granulomatous diseases; a study based on histological examination of tissue obtained by needle biopsy of the liver. Yale J Biol Med 1950;23:207-248.

13. Valla DC, Benhamou JP. Hepatic granulomas and hepatic sarcoidosis. Clin Liver Dis 2000;4:269-285, ix-x.

14. Devaney K, Goodman ZD, Epstein MS, Zimmerman HJ, Ishak KG. Hepatic sarcoidosis. Clinicopathologic features in 100 patients. Am J Surg Pathol 1993;17:1272-1280.

15. Bilir M, Mert A, Ozaras R, Yanardag H, Karayel T, Senturk H, Tahan V, Ozbay G, Sonsuz A. Hepatic sarcoidosis: clinicopathologic features in thirty-seven patients. J Clin Gastroenterol 2000;31:337-338.

16. Vatti R, Sharma OP. Course of asymptomatic liver involvement in sarcoidosis: role of therapy in selected cases. Sarcoidosis Vasc Diffuse Lung Dis 1997;14:73-76.

17. Kahi CJ, Saxena R, Temkit M, Canlas K, Roberts S, Knox K, Wilkes D, Kwo PY. Hepatobiliary disease in sarcoidosis. Sarcoidosis Vasc Diffuse Lung Dis 2006;23:117-123.

18. Israel HL, Margolis ML, Rose LJ. Hepatic granulomatosis and sarcoidosis. Further observations. Dig Dis Sci 1984;29:353-356.

19. Lehmuskallio E, Hannuksela M, Halme H. The liver in sarcoidosis. Acta Med Scand 1977;202:289-293.

20. Zimmerman HJ. The clinical importance of hepatic involvement in sarcoidosis. Stanford Med Bull 1953;11:173-178.

21. Ishak KG. Sarcoidosis of the liver and bile ducts. Mayo Clin Proc 1998;73:467-472.

22. Adler M, Burroughs A, Beynon H. Gastrointestinal sarcoidosis. A review. Sarcoidosis Vasc Diffuse Lung Dis 2007;24:3-11.

23. Blich M, Edoute Y. Clinical manifestations of sarcoid liver disease. J Gastroenterol Hepatol 2004;19: 732-737.

24. Karagiannidis A, Karavalaki M, Koulaouzidis A. Hepatic sarcoidosis. Ann Hepatol 2006;5:251-256.

25. Koyama T, Ueda H, Togashi K, Umeoka S, Kataoka M, Nagai S. Radiologic manifestations of sarcoidosis in various organs. Radiographics 2004;24:87-104.

26. Lebacq EG, Heller F. LP-X test in sarcoidosis patients with liver involvement: comparison with other liver function tests. Ann N Y Acad Sci 1976;278:439-444. 
27. Wijnen PA, Nelemans PJ, Verschakelen JA, Bekers O, Voorter CE, Drent M. The role of tumor necrosis factor alpha G-308A polymorphisms in the course of pulmonary sarcoidosis. Tissue Antigens 2010; 75:262-268.

28. Desmet VJ, Gerber M, Hoofnagle JH, Manns M, Scheuer PJ. Classification of chronic hepatitis: diagnosis, grading and staging. Hepatology 1994;19:1513-1520.

29. Kleiner DE BE, Natta Van M, Behling C, Contos MJ, Cummings OW, Ferrell LD, Liu YC, Torbenson MS, Unalp-Arida A, Yeh M, McCullough AJ and Sanyal AJ for the Nonalcoholic Steatohepatitis Clinical Research Network. Design and validation of a histological scoring system for non alcoholic fatty liver disease. Hepatology 2005:1313-1321.

30. Baughman RP, Koehler A, Bejarano PA, Lower EE, Weber FL, Jr. Role of liver function tests in detecting methotrexate-induced liver damage in sarcoidosis. Arch Intern Med 2003;163:615-620.

31. Al Knawy B, Shiffman M. Percutaneous liver biopsy in clinical practice. Liver Int 2007;27:1166-1173.

32. Poynard T, Ratziu V, Bedossa P. Appropriateness of liver biopsy. Can J Gastroenterol 2000;14:543-548.

33. Adams T JL. Percutaneous liver biopsy. Clin Perspectives Gastroenterol 2002;2:117-121.

34. Sporea I, Popescu A, Sirli R. Why, who and how should perform liver biopsy in chronic liver diseases. World J Gastroenterol 2008;14:3396-3402.

35. Trillaud H, Bruel JM, Valette PJ, Vilgrain V, Schmutz G, Oyen R, Jakubowski W, Danes J, Valek V, Greis C. Characterization of focal liver lesions with SonoVue-enhanced sonography: international multicenterstudy in comparison to CT and MRI. World J Gastroenterol 2009;15:3748-3756.

36. Tranquart F, Bleuzen A, Kissel A. Value of combined conventional and contrast enhanced sonography in the evaluation of hepatic disorders. J Radiol 2004;85:755-762. 


\section{Chapter 5}

Therapeutic approach of hepatic sarcoidosis

J Cremers, M Drent, R Baughman, P Wijnen, G Koek

Curr Opin Pulm Med 2012;18:472-482 


\section{Abstract}

\section{Purpose of review}

Surveillance of hepatic involvement in sarcoidosis has not been standardized. Therefore, management of hepatic involvement is a clinical challenge. This review analyses published data on the pharmacological treatment of hepatic sarcoidosis.

\section{Recent findings}

Only $5-30 \%$ of patients with hepatic sarcoidosis display symptoms. Occasionally, hepatic sarcoidosis has a rapid progressive course with serious complications, stressing an appropriate and carefully timed therapeutic approach. Because symptomatic hepatic involvement is uncommon, therapeutic studies are scarce. Answers to the questions when to initiate which treatment are lacking. Case reports describe beneficial effects of glucocorticosteroids and the augmentation of cytotoxic and anti-tumor necrosis factor-alpha (TNF- $\alpha$ ) therapy. However, because of small sample sizes, no meaningful conclusions could be drawn. In symptomatic hepatic sarcoidosis patients, it is recommended to start to treat the sarcoidosis with glucocorticosteroids, preceded by ursodeoxycholic acid when signs of cholestasis are present. Furthermore, antioxidants can be considered. In refractory cases or when glucocorticosteroids weaning is impossible, cytotoxic drugs or TNF- $\alpha$ inhibitor therapy should be started.

\section{Summary}

This review illustrates the importance of an appropriate therapeutic approach of sarcoidosis patients with hepatic involvement. It emphasizes the need for future studies to evaluate treatment options to avoid disease progression and hepatic complications. 


\section{Introduction}

Sarcoidosis is a systemic inflammatory granulomatous disease of unknown etiology that is characterized by a highly variable pattern of disease presentation, involving more than one organ of the body, and by a wide range of disease severity. ${ }^{1}$ The lung is the most commonly affected organ. The degree of impairment ranges from minimal disease to life-threatening fibrosis with the risk of pulmonary hypertension. ${ }^{2}$ In many cases, lung involvement stabilizes or improves over the first 2 years, but may worsen and become chronic. ${ }^{3}$ Devastating extrapulmonary complications may become apparent. 4

Estimates of liver involvement in sarcoidosis vary from 11 to $80 \%$ of cases, with lower rates based on symptomatic disease, whereas higher rates reported in studies performing random liver biopsies..$^{5-10}$ In one study of 736 newly diagnosed sarcoidosis patients, liver disease was more frequent in women and African-Americans. ${ }^{11}$ However, in a retrospective review of over 1400 patients, liver disease was more common in men. ${ }^{12}$ Most individuals with liver disease present asymptomatically with evidence of hepatomegaly, increased liver tests, or computed tomography (CT) scan abnormalities. $^{6,10,13-15}$ Nonspecific symptoms, including abdominal pain, fever, and weight loss are common in sarcoidosis liver disease, although patients may also present with pruritis, jaundice and chronic cholestasis. Cirrhosis, portal hypertension, BuddChiari syndrome, and variceal bleeding occur rarely. In cases of known sarcoidosis, a probable diagnosis of liver disease may be established on the basis of increased alkaline phosphatase, or transaminases, or CT findings with characteristic nodules consisting of low-attenuating lesions of varied but usually small size. ${ }^{14-16}$ Occasionally, a liver biopsy may be obtained, although this is usually not necessary to confirm liver sarcoidosis. ${ }^{14}$ Ultrasound may be obtained to assess portal hypertension and to exclude other causes of liver disease. In general, a diagnosis of hepatic sarcoidosis must be confirmed and other causes of liver disease must be excluded. ${ }^{14}$

Because symptomatic hepatic sarcoidosis is uncommon, studies investigating course, progression, and response to treatment of this sarcoidosis manifestation are limited. Hence, management of sarcoidosis patients with liver involvement is mainly empirical. A protocol with recommendations for when treatment should be initiated, drug choice, dosage, and appropriate duration of the therapy does not exist. Therefore, the purpose of this review is to analyse published data on the effectiveness of pharmacological treatment and to combine these data into recommendations for the therapeutic approach of hepatic sarcoidosis.

\section{Methods}

A computerized search of the literature from 1965 until 2012 was performed using the search terms 'sarcoidosis', 'liver' or 'hepatic', and 'therapy' or 'treatment'. 
Unfortunately, few hits were identified. Reference lists of relevant studies were checked to identify additional research not found by database search.

\section{Selection criteria}

Studies included for evaluation met the following criteria: the objective was to evaluate the effect of pharmacological treatment on disease course, progression, and complications; the population consisted of sarcoidosis patients with (among others) liver involvement; and the study was published in English.

\section{Results}

Most hepatic sarcoidosis patients do not require therapy as spontaneous remission is seen in the majority of cases. ${ }^{14,17}$ However, as mentioned previously, in some patients hepatic sarcoidosis can be a rapid progressive disease with the occurrence of complications in which timely implemented therapy might lead to preservation of liver function and restriction or avoidance of hepatic complications. ${ }^{5,6,10,12,13,18-22}$ In a retrospective study by Cremers et al. ${ }^{23}$ liver test abnormalities were present in 204 of the 837 (24.4\%) studied patients, among which 127 (15.2\%) were suspected of having hepatic sarcoidosis. Moderate and severe liver test abnormalities seemed to be associated with more advanced histopathological disease. ${ }^{12,18,23,24}$ For patients with moderate or severe liver test abnormalities, a liver biopsy may be useful.

\section{Pathogenesis}

Sarcoidosis appears to be a multifactorial disease in which immunological, genetic, environmental, and oxidative stress factors play a role. ${ }^{1,2,5,25}$ Several immunological factors are involved in granuloma formation: after contact with antigenic material, predominant T helper 1 (Th1) cytokines and chemokines are released leading to the expression of, among others, tumor necrosis factor-alpha (TNF- $\alpha$ ), facilitating granuloma formation. $^{20,22}$ The formed granuloma can resolve spontaneously, but may persist and lead to a chronic inflammatory status. ${ }^{20,22}$ Genetic factors are likely to be involved in the pathogenesis. ${ }^{26-29}$ The nature of the antigens that stimulate the Th1 response are thought to be possibly infectious, although there is no definite evidence for specific micro-organisms. ${ }^{8,20,22,30}$ Oxidative stress, caused by reactive oxygen species (ROS) and low endogenous antioxidant levels, is suggested to be involved in initiating and mediating the inflammatory process in sarcoidosis. ${ }^{25,31,32}$ ROS are able to promote inflammation by activating transcription factors that induce pro-inflammatory cytokines and chemokines. ${ }^{25,32-34}$ 


\section{Pharmacological treatment}

First, the sarcoidosis should be treated adequately. In general, that is enough to ensure the liver test abnormalities improve as well. Pharmacological treatment options when progressive granulomatous liver disease is present, include antioxidants, ursodeoxycholic acid (UDCA), and glucocorticosteroids. ${ }^{22,25,35}$ Glucocorticosteroids are considered first-line treatment option. ${ }^{22}$ In case of steroid-resistant sarcoidosis (disease progression during glucocorticosteroid treatment), second-line treatment options involve azathioprine (AZA), methotrexate (MTX), cyclosporine, cyclophosphamide, pentoxifylline (POF), thalidomide, or TNF- $\alpha$ inhibitors. Second-line agents can be used as steroid-sparing treatment as well. ${ }^{36}$

\section{Antioxidants}

Recent studies suggest a beneficial effect of the antioxidant quercetin in patients with sarcoidosis of the lungs. ${ }^{32}$ It has been suggested that ROS play a crucial role in the chronic inflammation causing fibrosis in interstitial lung diseases, by the indirect evidence that two antioxidants are protective. ${ }^{37}$ We noticed an improvement of liver test abnormalities with glutathione $600 \mathrm{mg} 3$ times a day, but these observations should be tested in a larger cohort of patients.

\section{Ursodeoxycholic acid}

Hepatic sarcoidosis can be associated with chronic cholestasis. The mechanism of UDCA in cholestasis includes inhibition of intestinal absorption and increasing biliary secretion of cholic and chenodeoxycholic acids, and immune response modulation with decreased cytokine and immunoglobulin production. ${ }^{38-40}$ UDCA also decreases human leukocyte antigen (HLA) class I antigen on hepatic surfaces and HLA class II antigen on cell membranes of biliary duct epithelial cells. ${ }^{38,41-43}$ Some case reports showed a beneficial effect of UDCA in sarcoidosis (Table 5.1). ${ }^{5,6,38,41,44-54}$ No improvement was seen histologically, but because of absence of progression of liver disease, UDCA may delay complications. UDCA should be administered at $10 \mathrm{mg} / \mathrm{kg}$ per day (300 $\mathrm{mg}$ orally twice daily). ${ }^{17}$ Reported side-effects are shown in Table 5.2. ${ }^{20,55}$ 


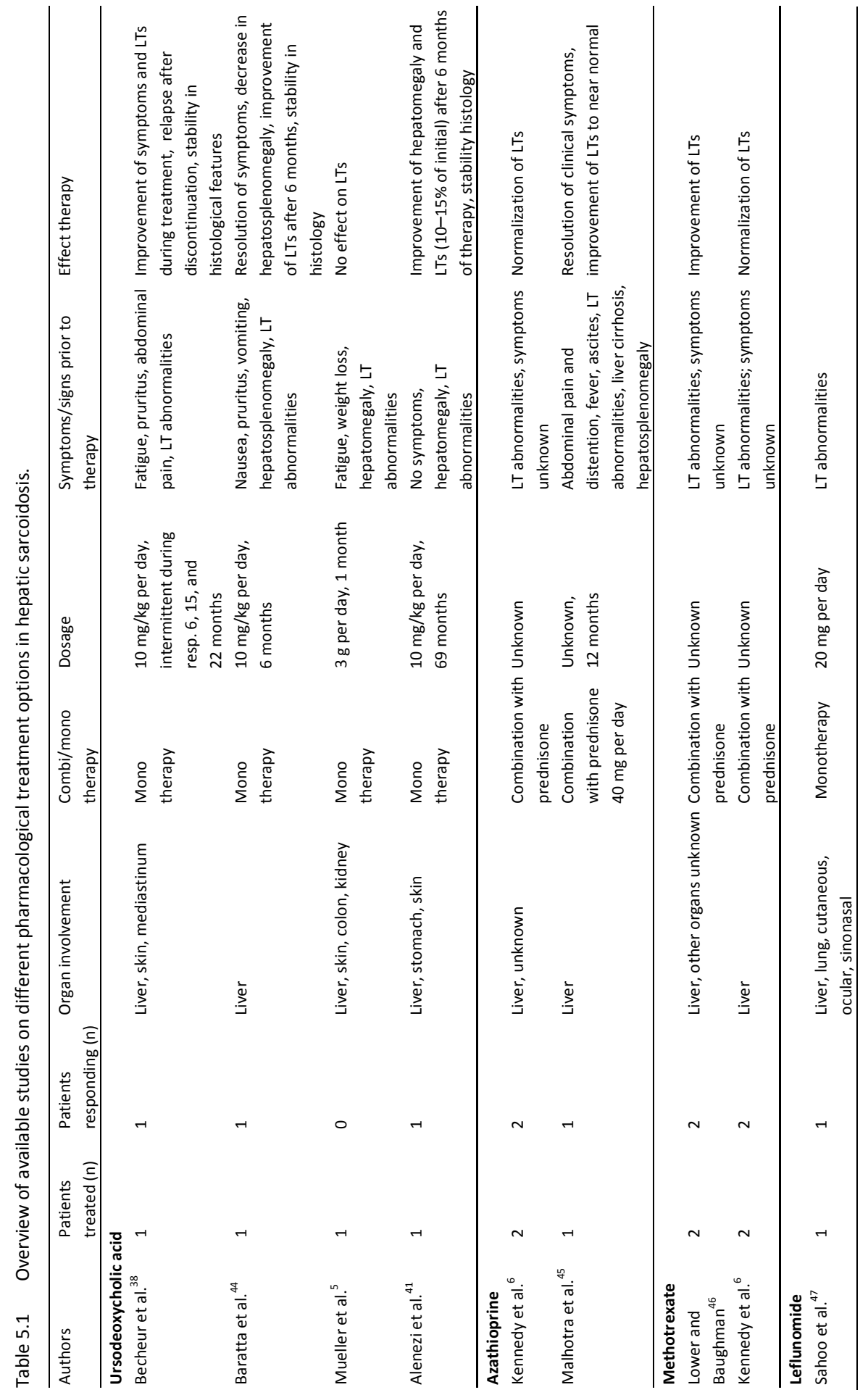




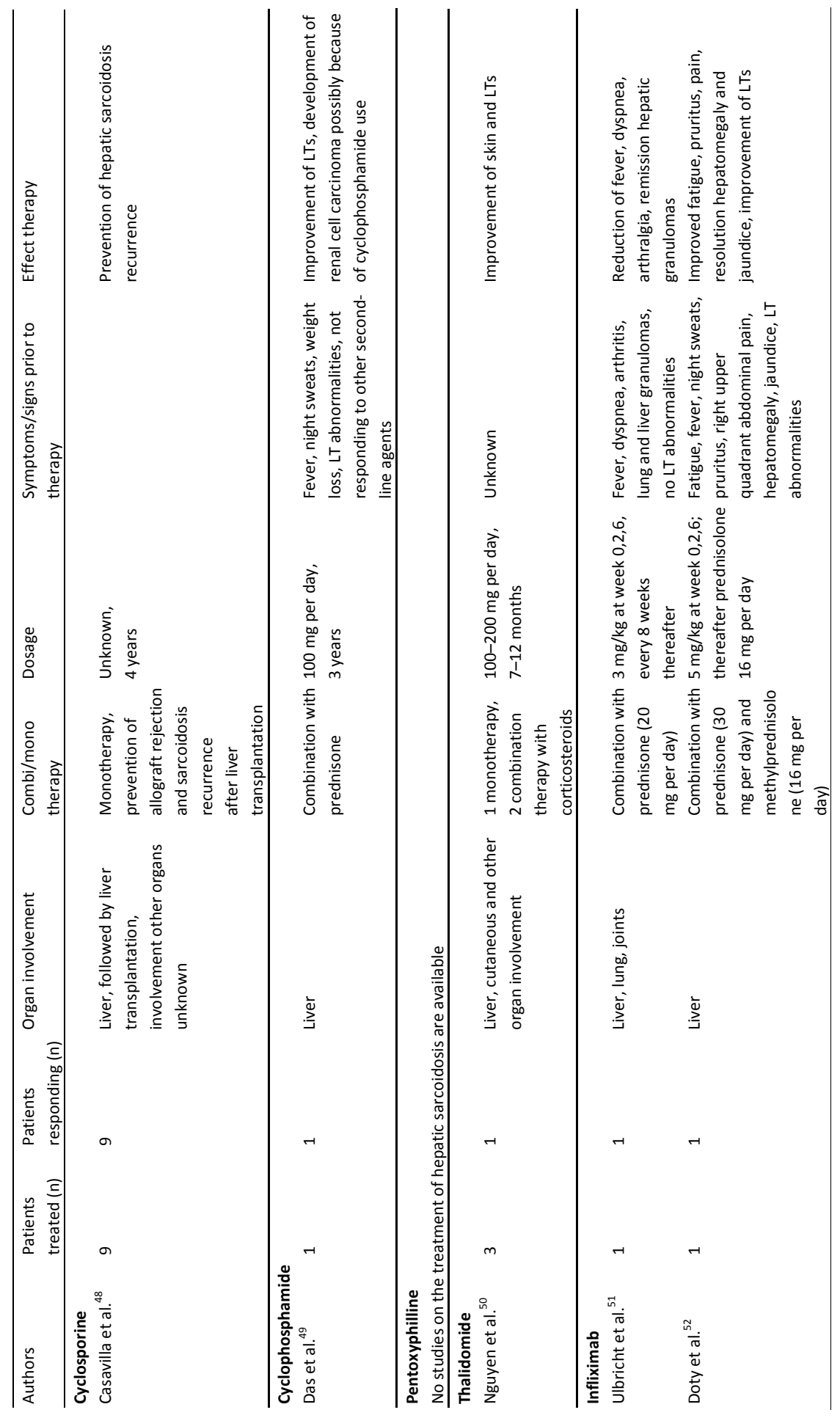




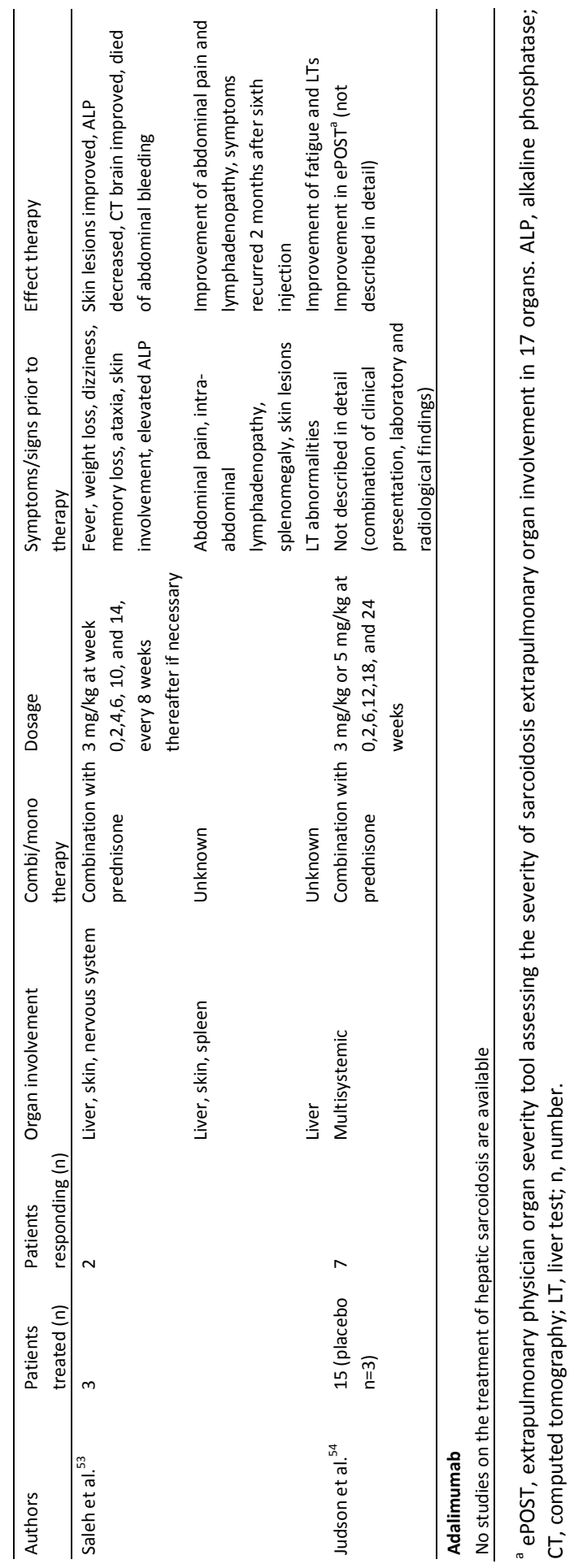




\section{Glucocorticosteroids}

The mechanism by which glucocorticosteroids lead to suppression of the granulomatous inflammation is not completely understood. Steroids might have an anti-inflammatory effect on $\mathrm{T}$ cells, macrophages, and granulocytes, and might enhance transforming growth factor-beta (TGF- $\beta$ ) expression by T cells. ${ }^{22}$ Glucocorticosteroids are the first-choice in the treatment of pulmonary sarcoidosis. ${ }^{5,36,56}$ Only a few case reports described the use of steroids in hepatic sarcoidosis. ${ }^{5}$ Improvements in clinical symptoms, normalization of liver tests, and reduction of hepatomegaly have been demonstrated. ${ }^{7,10}$ However, serial biopsies demonstrate that corticosteroids rarely lead to total resolution of hepatic sarcoidosis and do not prevent hepatic progression. ${ }^{5,7,36}$ In line with this, Kennedy et al. ${ }^{6}$ showed that treatment with glucocorticosteroids may improve liver tests without benefit to liver histology. In this study, $67 \%$ of patients showed clinical response after steroid therapy, with one-third showing complete response. Maddrey et al. ${ }^{24}$ reported that patients with cirrhosis from sarcoidosis had little response to glucocorticosteroids. On the other hand, patients with biliary obstruction due to porta hepatis adenopathy may have total resolution of their hyperbilirubinemia with steroid therapy. ${ }^{57,58}$ Dosage of prednisone is usually 20-40 $\mathrm{mg} /$ day for the first 4-6 weeks. Dose reduction can be achieved by $5-10 \mathrm{mg}$ decrements every 4-8 weeks. The maintenance dose is the lowest effective dose. ${ }^{17,36,59}$ Relapse can occur after discontinuation of steroids. ${ }^{17,36}$

Because of the significant toxic side-effects (Table 5.2), the use of glucocorticosteroids cannot be justified in asymptomatic patients or patients with mild disease that may spontaneously remit. ${ }^{20,36}$ Although steroids usually are the first-choice therapy, up to a third of patients may not respond. When no response to glucocorticosteroids is noted, cytotoxic agents are a good alternative. ${ }^{60}$

\section{Azathioprine}

AZA is a purine analogue and is hydrolysed in the blood to 6-mercaptopurine by the enzyme thiopurine S-methyltransferase (TPMT). ${ }^{22,61}$ AZA inhibits nucleotide synthesis by feedback inhibition in the early stages of purine metabolism and it prevents $T$ cell and B cell proliferation. ${ }^{22}$ The experience with AZA as treatment option in hepatic sarcoidosis is limited. Kennedy et al. ${ }^{6}$ reported normalization of liver tests in two patients and Malhotra et al. ${ }^{45}$ reported one patient with improvement in symptoms and liver tests after treatment (Table 5.1). AZA dosage is $50-150 \mathrm{mg} / \mathrm{day}$, starting at a relatively low dose. ${ }^{62}$ Blood counts must be checked before increasing the dose. ${ }^{62}$ Possible toxicity is shown in Table 5.2. Long-term monitoring of complete blood count and hepatic function should be done every 2 months. ${ }^{62}$ Because of genetic mutations, in up to 6 in 1000 people TPMT deficiency is present, with potentially life-threatening bone marrow toxicity when treated with conventional doses of AZA. Measuring TPMT enzyme activity should be considered in all patients starting on AZA. ${ }^{61,63}$ 


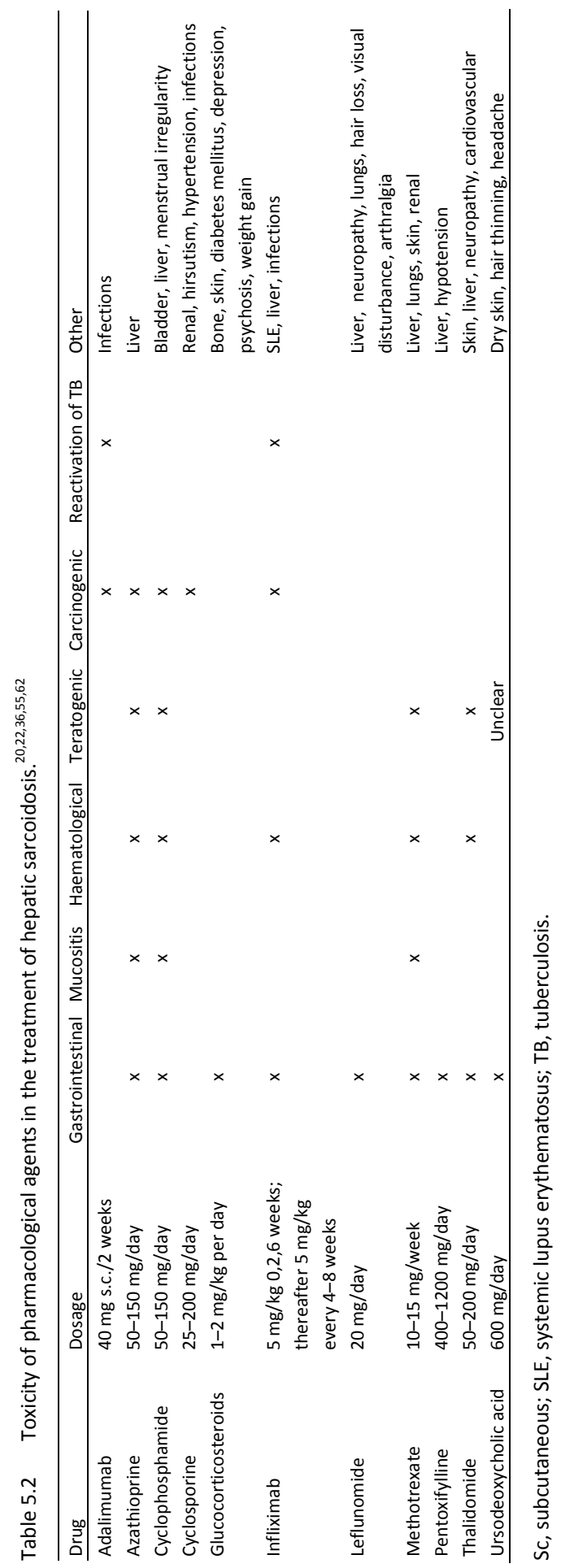


AZA can cause an acute hepatitis, which usually responds to withdrawal of the drug, but may also require glucocorticosteroid therapy. Therefore, acute worsening of liver tests in a hepatic sarcoidosis patient on AZA should lead to withdrawal of the drug.

\section{Methotrexate}

MTX is a folic acid analogue inhibiting dihydrofolate reductase, which leads to the depletion of tetrahydrofolate and inhibition of thymidylate synthesis, a step that is required for DNA replication in actively dividing cells. ${ }^{64} \mathrm{MTX}$ suppresses TNF, interleukin (IL)-6, and IL-8 release from macrophages, ROS and TNF release from neutrophils, and it suppresses lymphocyte proliferation. ${ }^{64}$

Four cases of successful treatment of hepatic sarcoidosis with MTX have been described (Table 5.1). ${ }^{6,46}$ Relapses are frequent after discontinuation, which suggests that MTX suppresses but does not cure the disease. ${ }^{36}$ MTX has to be administered once a week at an initial dosage of $10 \mathrm{mg}$ with a maximum dose of $15 \mathrm{mg}$. ${ }^{22}$ Toxic side-effects are listed in Table 5.2. Because of bone marrow and renal toxicity risks, a complete blood count with renal function tests should be performed every 1-3 months. ${ }^{22,62}$ Furthermore, MTX has the potential for hepatic toxicity with the development of severe cirrhosis in about $14 \%$ of sarcoidosis patients. ${ }^{22,55}$ Toxicity of MTX can be reduced by the use of folic acid. ${ }^{22}$

In using MTX for rheumatoid arthritis or psoriasis, liver test monitoring is recommended every 1-3 months to control for MTX toxicity. Patients with persistent transaminase elevation should be considered for drug withdrawal or liver biopsy. ${ }^{55}$ In sarcoidosis, liver test abnormalities may be due to the underlying sarcoidosis or MTX. In a study of 100 liver biopsies performed on sarcoidosis patients undergoing MTX treatment, 47 had granulomatous disease due to sarcoidosis and 14 had changes consistent with MTX toxicity. ${ }^{55}$ Transaminase levels were higher for those with hepatic sarcoidosis than those with MTX toxicity. ${ }^{55}$ For sarcoidosis patients being treated with MTX, serial liver test monitoring is recommended. A rise in transaminase levels should lead to either MTX withdrawal or a liver biopsy to evaluate for MTX toxicity. ${ }^{65}$

Figure 5.1 demonstrates an fluorine18-fluorodeoxyglucose positron emission tomography $\left({ }^{18} \mathrm{~F}-\mathrm{FGD}\right.$ PET) scan before and after MTX therapy. The marked reduction of uptake associated with treatment supports the effectiveness of MTX in treating this patient's liver and extrahepatic disease. Besides the assessment of inflammation, serial PET scanning has recently been demonstrated to be useful in follow-up. ${ }^{66-69}$

\section{Chlorambucil}

Chlorambucil has been reported by one group as useful in treating hepatic sarcoidosis. ${ }^{43}$ Given the increased malignancy risk of chlorambucil compared with other cytotoxic agents, it has been replaced by other agents. 

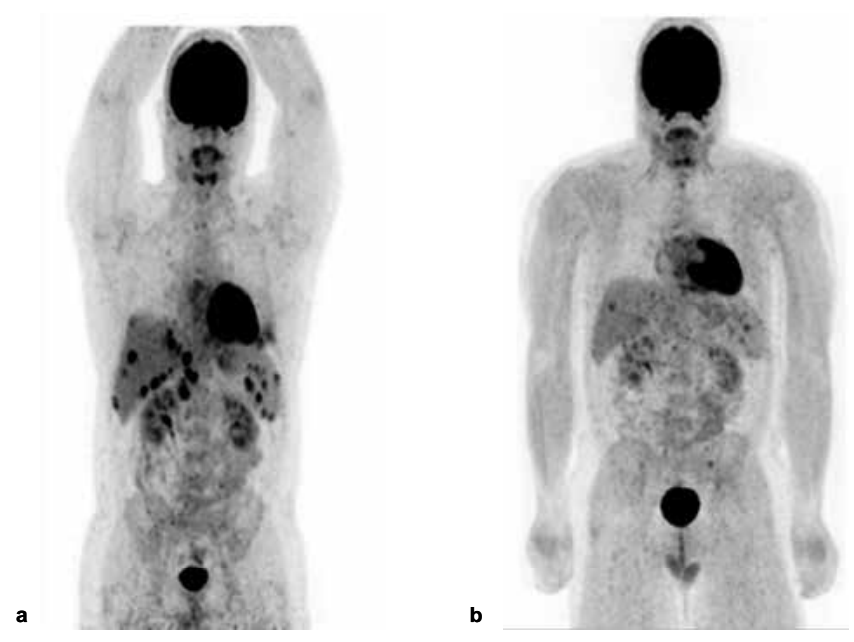

Figure $5.1 \quad{ }^{18}$ F-FGD PET scans of a patient with mainly liver and splenic sarcoidosis involvement. The scans are before (a) and after (b) 6 months of treatment with methotrexate $12.5 \mathrm{mg}$ once a week, 5 $\mathrm{mg}$ folic acid once a week and $10 \mathrm{mg}$ prednisone once a day orally. Enhanced activity (nodules) was seen in liver, spleen, and porta hepatis lymph nodes prior to therapy. The liver, spleen, and lymph node lesions have significantly less activity after therapy.

\section{Cyclosporine}

Cyclosporine is a fungal peptide that suppresses $\mathrm{T}$ cell activation. ${ }^{22}$ Casavilla et al. ${ }^{48}$ showed cyclosporine to be effective for the prevention of allograft rejection and sarcoidosis recurrence in patients who underwent liver transplantation (Table 5.1). Because of the unknown effectiveness, the major adverse effects and an increased malignancy risk, cyclosporine should be restricted to the most serious cases (Table 5.2). ${ }^{22}$ Recommended dosage is $25-200 \mathrm{mg} /$ day.

\section{Cyclophosphamide}

Cyclophosphamide is metabolized in the liver into active alkylating metabolites, which inhibit lymphocyte proliferation with consequent anti-inflammatory effects. ${ }^{22}$ Das et al. ${ }^{49}$ showed one case report with improvement in liver test abnormalities after therapy with glucocorticosteroids in combination with cyclophosphamide (Table 5.1). Dosage is 50-150 mg/day. ${ }^{62}$ Use of intermittent, intravenous bolus cyclophosphamide at 500$1500 \mathrm{mg}$ every 2-4 weeks has also been reported as useful for refractory sarcoidosis with less toxicity than daily oral dosing. ${ }^{70,71}$ Cyclophosphamide is associated with, among others, bone marrow suppression, bladder carcinoma, and hepatotoxicity (Table $5.2)^{62}$ 


\section{Thalidomide}

Thalidomide is a synthetic derivate of glutamic acid and has several molecular targets. ${ }^{72}$ The most important function in sarcoidosis is the inhibition of TNF- $\alpha$ production. ${ }^{22}$ Nguyen et al. ${ }^{50}$ showed effectiveness of thalidomide in a patient with cutaneous and hepatic sarcoidosis (Table 5.1). Because of major side-effects, its use is limited to a second- or third-line therapy (Table 5.2). Recommended dosage is 50-200 mg/day. ${ }^{22}$

\section{Pentoxifylline}

POF is a methylxanthine derivative that inhibits a number of pro-inflammatory cytokines including TNF- $\alpha$. There is evidence supportive of a potential role for POF in sarcoidosis. ${ }^{60,73}$ In addition, POF may have hepatoprotective effects. Zein et al. ${ }^{74}$ demonstrated that POF improves nonalcoholic steatohepatitis (NASH) and reduces progression of liver fibrosis in NASH.

\section{Infliximab}

Infliximab is a biological chimeric 'humanized' monoclonal antibody that binds to free TNF- $\alpha$, blocking its interaction with the TNF-receptor, and sometimes to cell surface TNF- $\alpha{ }^{22}$

Two double-blinded randomized controlled trials are available, which evaluate the use of infliximab in chronic sarcoidosis. The study of Baughman et al. ${ }^{75}$ showed a small benefit of infliximab on forced vital capacity and chest radiograph scores after 24 weeks. Judson et al. $^{54}$ used an extrapulmonary physician organ severity tool for evaluation of specific organ involvement in sarcoidosis. Although the sample size was low, their results suggest that infliximab may be beneficial in extrapulmonary sarcoidosis including liver involvement.

In Table 5.1, an overview of reports on the treatment of hepatic sarcoidosis with infliximab is shown. Ulbricht et al. ${ }^{51}$ showed remission of hepatic granulomas and other clinical features of sarcoidosis during treatment with prednisone and infliximab. Doty et al. ${ }^{52}$ reported improvement of 10 patients resistant to conventional therapy, including one with hepatic sarcoidosis. Saleh et al. ${ }^{53}$ showed improvement of three patients with hepatic sarcoidosis. However, in one patient, symptoms recurred 2 months after the sixth injection.

The induction treatment is $5 \mathrm{mg} / \mathrm{kg}$ at weeks 0,2 , and 6 , and then maintenance of $5 \mathrm{mg} / \mathrm{kg}$ every 4 weeks. $^{36}$ The main risk of infliximab is reactivation of tuberculosis, which could be mistaken as worsening of sarcoidosis (Table 5.2). ${ }^{36}$ Infliximab can generate antimurine antibody immune reactions that limit its use and require MTX comedication. $^{76,77}$ 


\section{Adalimumab}

Adalimumab is a recombinant fully human monoclonal antibody against TNF- $\alpha{ }^{78}$ No information is available about its effectiveness in hepatic sarcoidosis. Adalimumab has also been associated with reactivation of tuberculosis (Table 5.2). ${ }^{36}$

\section{Transplantation}

Organ transplantation can be the final treatment option in complicated hepatic sarcoidosis. ${ }^{6,79}$ Liver transplantation because of sarcoidosis accounts for $0.01 \%$ of total liver transplantations. ${ }^{17}$ Rates of graft and patient survival were equivalent between hepatic sarcoidosis and other causes of liver failure. ${ }^{79,80}$ However, recurrence of disease in the allograft has been documented in a few case reports. ${ }^{79,81,82}$

\section{Discussion}

Data are scarce and there are no controlled trials evaluating liver involvement in sarcoidosis specifically. There are similarities with NASH or non-alcoholic fatty liver disease (NAFLD). ${ }^{83}$ Like in sarcoidosis, cytokines including TNF- $\alpha$ are believed to play an important role in hepatocellular damage, inflammation, and fibrogenesis in NASH. ${ }^{84,85}$ As there are no controlled trials, recommendations in sarcoidosis are based on clinical experience, retrospective case series, and both NASH and NAFLD treatment recommendations, including lifestyle interventions. ${ }^{60,83,84}$

The first advice is to assess sarcoidosis in general to determine whether there is a need for therapeutic intervention. The majority of patients with hepatic sarcoidosis do not require therapy. These include patients with asymptomatic disease and mildly elevated liver tests, no evidence of cholestasis (normal bilirubin), and normal liver synthetic function (e.g., prothrombin time (PT)), or without hepatomegaly noted on physical examination and/or without radiographic abnormalities. These individuals should be followed using liver function tests to determine whether they develop evidence of cholestasis or abnormal PT, which would be considered reasons for starting systemic therapy. Liver test abnormalities may resolve spontaneously over time or with treatment aimed at other organ involvement (e.g., lung disease).

On the basis of information gathered from the literature, a therapeutic approach of patients with hepatic sarcoidosis is proposed (see Figure 5.2). Hepatic sarcoidosis can be subdivided into symptomatic and asymptomatic disease. In asymptomatic disease (absence of clinical signs and symptoms and absence of cholestasis with a low risk of developing hepatic complications), no treatment is needed, but a regular follow-up of liver tests (every 3-6 months) is recommended. As previous studies showed that severity of liver test abnormalities is associated with severity of histopathological disease, worsening of liver test abnormalities or abnormal synthetic liver function is an important reason to start pharmacological therapy. ${ }^{23}$ 


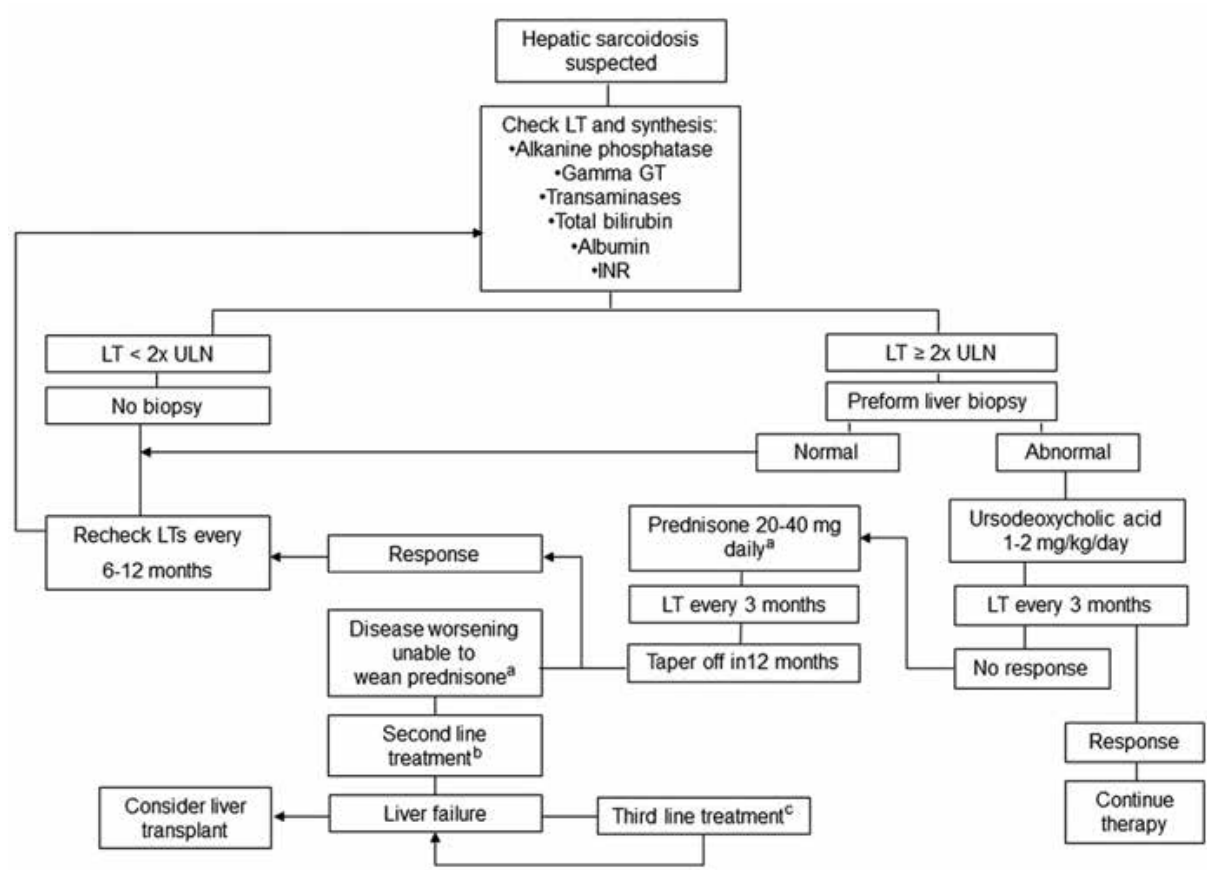

Figure 5.2 Decision flowchart. ${ }^{\text {a }}$ Where prednisone is indicated, an equivalent dose of glucocortico-steroids (i.e., methylprednisolone) could also be used. ${ }^{b}$ Cytostatic drug, including azathioprine, methotrexate, and leflunomide. 'Anti-TNF- $\alpha$ treatment. GT, glutamyl trans-ferase; INR, international normalized ratio; LT, liver test; TNF- $\alpha$, tumor necrosis factor-alpha; ULN, upper limit of normal.

In symptomatic liver involvement (presence of clinical signs and symptoms or presence of cholestasis characteristics with a high risk of developing hepatic complications), pharmacological treatment is recommended. ${ }^{40,74,86,87}$ In cases of jaundice, cholestasis, or pruritis, UDCA must be considered as first treatment option. In absence of response or when non-cholestasis symptoms are present, prednisone should be considered (20-40 mg/day). Dosage must be tapered off when stable disease or recovery is seen, after which regular follow-up of liver tests is recommended. Cytotoxic drugs or TNF- $\alpha$ inhibitors can be considered in cases of disease worsening or impossibility of tapering off glucocorticosteroids. Finally, liver transplantation can be the only therapeutic option in cases of liver failure. 


\section{Conclusion}

The cornerstone of sarcoidosis disease management involves careful baseline assessment of disease distribution and severity by organ, with emphasis on vital target organs. Because the clinical course can be unpredictable, regular monitoring for signs of disease progression in known organs of involvement and disease development in other organs is necessary. Because hepatic sarcoidosis can be rapidly progressive with the occurrence of serious complications, an appropriate therapeutic approach is important. However, therapeutic studies are rare. It is recommended to treat symptomatic hepatic sarcoidosis with glucocorticosteroids, preceded by UDCA when cholestasis is present. Furthermore, antioxidants can be considered. Cytotoxic drugs or TNF- $\alpha$ inhibitor therapy should be started when disease worsening or impossibility of weaning from glucocorticosteroids is present. Future randomized controlled studies are really necessary to assess the effect of treatment on disease progression and complications. Moreover, there is need for a more individualized process that addresses each individual's requirements with no redundancy of investigation and, probably more importantly, no unnecessary treatment with its risk of adverse events. 


\section{References}

1. Statement on sarcoidosis. Joint Statement of the American Thoracic Society (ATS), the European Respiratory Society (ERS) and the World Association of Sarcoidosis and Other Granulomatous Disorders (WASOG) adopted by the ATS Board of Directors and by the ERS Executive Committee, February 1999. Am J Respir Crit Care Med 1999;160:736-755.

2. Baughman RP, Culver DA, Judson MA. A concise review of pulmonary sarcoidosis. Am J Respir Crit Care Med 2011;183:573-581.

3. Gottlieb JE, Israel HL, Steiner RM, Triolo J, Patrick H. Outcome in sarcoidosis. The relationship of relapse to corticosteroid therapy. Chest 1997;111:623-631.

4. Oswald-Richter KA, Drake WP. The etiologic role of infectious antigens in sarcoidosis pathogenesis. Semin Respir Crit Care Med 2010;31:375-379.

5. Mueller S, Boehme MW, Hofmann WJ, Stremmel W. Extrapulmonary sarcoidosis primarily diagnosed in the liver. Scand J Gastroenterol 2000;35:1003-1008.

6. Kennedy PT, Zakaria N, Modawi SB, Papadopoulou AM, Murray-Lyon I, du Bois RM, Jervoise NAH, Devlin J. Natural history of hepatic sarcoidosis and its response to treatment. Eur J Gastroenterol Hepatol 2006;18:721-726.

7. Ebert EC, Kierson M, Hagspiel KD. Gastrointestinal and hepatic manifestations of sarcoidosis. Am J Gastroenterol 2008;103:3184-3192; quiz 3193.

8. Rosen Y. Pathology of sarcoidosis. Semin Respir Crit Care Med 2007;28:36-52.

9. Rose AS, Tielker MA, Knox KS. Hepatic, ocular, and cutaneous sarcoidosis. Clin Chest Med 2008;29: 509524,ix.

10. Judson MA. Hepatic, splenic, and gastrointestinal involvement with sarcoidosis. Semin Respir Crit Care Med 2002;23:529-541.

11. Baughman RP, Teirstein AS, Judson MA, Rossman MD, Yeager H Jr, Bresnitz EA, DePalo L, Hunninghake G, lannuzzi MC, Johns CJ, McLennan G, Moller DR, Newman LS, Rabin DL, Rose C, Rybicki B, Weinberger SE, Terrin ML, Knatterud GL, Cherniak R; Case Control Etiologic Study of Sarcoidosis (ACCESS) research group. Clinical characteristics of patients in a case control study of sarcoidosis. Am J Respir Crit Care Med 2001;164:1885-1889.

12. Kahi CJ, Saxena R, Temkit M, Canlas K, Roberts S, Knox K, Wilkes D, Kwo PY. Hepatobiliary disease in sarcoidosis. Sarcoidosis Vasc Diffuse Lung Dis 2006;23:117-123.

13. Valla DC, Benhamou JP. Hepatic granulomas and hepatic sarcoidosis. Clin Liver Dis 2000;4:269-285, ix-x.

14. Dulai PS, Rothstein RI. Disseminated Sarcoidosis Presenting as Granulomatous Gastritis: A Clinical Review of the Gastrointestinal and Hepatic Manifestations of Sarcoidosis. J Clin Gastroenterol 2012;46:367-374.

15. Vardhanabhuti V, Venkatanarasimha N, Bhatnagar G, Maviki M, lyengar S, Adams WM, Suresh P. Extrapulmonary manifestations of sarcoidosis. Clin Radiol 2012;67:263-276.

16. Warshauer DM, Molina PL, Hamman SM, Koehler RE, Paulson EK, Bechtold RE, Perlmutter ML, Hiken JN, Francis IR, Cooper CJ. Nodular sarcoidosis of the liver and spleen: analysis of 32 cases. Radiology 1995;195:757-762.

17. Ayyala US, Padilla ML. Diagnosis and treatment of hepatic sarcoidosis. Curr Treat Options Gastroenterol 2006;9:475-483.

18. Devaney K, Goodman ZD, Epstein MS, Zimmerman HJ, Ishak KG. Hepatic sarcoidosis. Clinicopathologic features in 100 patients. Am J Surg Pathol 1993;17:1272-1280.

19. Bilir M, Mert A, Ozaras R, Yanardag H, Karayel T, Senturk H, Tahan V, Ozbay G, Sonsuz A. Hepatic sarcoidosis: clinicopathologic features in thirty-seven patients. J Clin Gastroenterol 2000;31:337-338.

20. Costabel U. Sarcoidosis: clinical update. Eur Respir J Suppl 2001;32:56s-68s.

21. Vatti R, Sharma OP. Course of asymptomatic liver involvement in sarcoidosis: role of therapy in selected cases. Sarcoidosis Vasc Diffuse Lung Dis 1997;14:73-76.

22. Moller DR. Treatment of sarcoidosis -- from a basic science point of view. J Intern Med 2003;253: 31-40.

23. Cremers J, Drent M, Driessen A, Nieman F, Wijnen P, Baughman R, Koek G. Liver-test abnormalities in sarcoidosis. Eur J Gastroenterol Hepatol 2012;24:17-24.

24. Maddrey WC, Johns CJ, Boitnott JK, Iber FL. Sarcoidosis and chronic hepatic disease: a clinical and pathologic study of 20 patients. Medicine 1970;49:375-395. 
25. Boots AW, Drent M, Swennen EL, Moonen HJ, Bast A, Haenen GR. Antioxidant status associated with inflammation in sarcoidosis: a potential role for antioxidants. Respir Med 2009;103:364-372.

26. Wijnen PA, Voorter CE, Nelemans PJ, Verschakelen JA, Bekers O, Drent M. Butyrophilin-like 2 in pulmonary sarcoidosis: a factor for susceptibility and progression? Hum Immunol 2011;72:342-347.

27. Wijnen PA, Nelemans PJ, Verschakelen JA, Bekers O, Voorter CE, Drent M. The role of tumor necrosis factor alpha G-308A polymorphisms in the course of pulmonary sarcoidosis. Tissue antigens 2010;75: 262-268.

28. Rybicki BA, Walewski JL, Maliarik MJ, Kian H, lannuzzi MC. The BTNL2 gene and sarcoidosis susceptibility in African Americans and Whites. Am J Hum Genet 2005;77:491-499.

29. Judson MA, Hirst K, lyengar SK, Rybicki BA, El-Ghormli L, Baughman RP, Donohue JF, Elston RC, Kavuru MS, Moller DR, Newman LS, Rabin DL, Rossman MD, Teirstein AS, lannuzzi MC. Comparison of sarcoidosis phenotypes among affected African-American siblings. Chest 2006;130:855-862.

30. Moller DR. Potential etiologic agents in sarcoidosis. Proc Am Thorac Soc 2007; 4:465-468.

31. Uzun H, Yanardag H, Gelisgen R, Genc H, Uygun S, Vehid S, Karter Y, Demirci S. Levels of paraoxonase, an index of antioxidant defense, in patients with active sarcoidosis. Curr Med Res Opin 2008;24: 1651-1657.

32. Boots AW, Drent M, De Boer VC, Bast A, Haenen GR. Quercetin reduces markers of oxidative stress and inflammation in sarcoidosis. Clin Nutr 2011;30:506-512.

33. Rahman I. Oxidative stress, transcription factors and chromatin remodelling in lung inflammation. Biochem Pharmacol 2002;64:935-942.

34. MacNee W. Oxidative stress and lung inflammation in airways disease. Eur J Pharmacol 2001;429: 195-207.

35. Adler M, Burroughs A, Beynon H. Gastrointestinal sarcoidosis. A review. Sarcoidosis Vasc Diffuse Lung Dis 2007;24:3-11.

36. Denys BG, Bogaerts Y, Coenegrachts KL, De Vriese AS. Steroid-resistant sarcoidosis: is antagonism of TNF-alpha the answer? Clin Sci (Lond) 2007;112:281-289.

37. Bast A, Weseler AR, Haenen GR, den Hartog GJ. Oxidative stress and antioxidants in interstitial lung disease. Curr Opin Pulm Med 2010;16:516-520.

38. Becheur H, Dall'osto H, Chatellier G, Charton-Bain MC, Aubertin JM, Attar A, Bloch F, Petite JP. Effect of ursodeoxycholic acid on chronic intrahepatic cholestasis due to sarcoidosis. Dig Dis Sci 1997;42: 789-791.

39. Moreno-Merlo F, Wanless IR, Shimamatsu K, Sherman M, Greig P, Chiasson D. The role of granulomatous phlebitis and thrombosis in the pathogenesis of cirrhosis and portal hypertension in sarcoidosis. Hepatology 1997;26:554-560.

40. Ratziu V, De Ledinghen V, Oberti F, Mathurin P, Wartelle-Bladou C, Renou C, Sogni P, Maynard M, Larrey D, Serfaty L, Bonnefont-Rousselot D, Bastard JP, Riviere M, Spenard J. A randomized controlled trial of high-dose ursodesoxycholic acid for nonalcoholic steatohepatitis. J Hepatol 2011;54: 1011-1019.

41. Alenezi B, Lamoureux E, Alpert L, Szilagyi A. Effect of ursodeoxycholic acid on granulomatous liver disease due to sarcoidosis. Dig Dis Sci 2005;50:196-200.

42. Galwankar S, Vyas M, Desai D, Udwadia ZF. Hepatic sarcoidosis responding to chloroquine as steroidsparing drug. Indian J Gastroenterol 1999;18:177-178.

43. Hughes GS, Jr., Kataria YP, O'Brien TF, Jr. Sarcoidosis presenting as biliary cirrhosis: treatment with chlorambucil. South Med J 1983;76:1440-1442.

44. Baratta L, Cascino A, Delfino M, Giorgino F, Vitolo D, Lagana B, Urani C, Rossi Fanelli F. Ursodeoxycholic acid treatment in abdominal sarcoidosis. Dig Dis Sci 2000;45:1559-1562.

45. Malhotra A, Naniwadekar A, Sood G. Hepatobiliary and pancreatic: cirrhosis secondary to hepatic sarcoidosis. J Gastroenterol Hepatol 2008;23:1942.

46. Lower EE, Baughman RP. The use of low dose methotrexate in refractory sarcoidosis. Am J Med Sci 1990;299:153-157.

47. Sahoo DH, Bandyopadhyay D, Xu M, Pearson K, Parambil JG, Lazar CA, Chapman JT, Culver DA. Effectiveness and safety of leflunomide for pulmonary and extrapulmonary sarcoidosis. Eur Respir $J$ 2011;38:1145-1150.

48. Casavilla FA, Gordon R, Wright HI, Gavaler JS, Starzl TE, Van Thiel DH. Clinical course after liver transplantation in patients with sarcoidosis. Ann Intern Med 1993;118:865-866. 
49. Das D, Smith A, Warnes TW. Hepatic sarcoidosis and renal carcinoma. J Clin Gastroenterol 1999;28: 61-63.

50. Nguyen YT, Dupuy A, Cordoliani F, Vignon-Pennamen MD, Lebbe C, Morel P, Rybojad M. Treatment of cutaneous sarcoidosis with thalidomide. J Am Acad Dermatol 2004;50:235-241.

51. Ulbricht KU, Stoll M, Bierwirth J, Witte T, Schmidt RE. Successful tumor necrosis factor alpha blockade treatment in therapy-resistant sarcoidosis. Arthritis Rheum 2003;48:3542-3543.

52. Doty JD, Mazur JE, Judson MA. Treatment of sarcoidosis with infliximab. Chest 2005;127:1064-1071.

53. Saleh S, Ghodsian S, Yakimova V, Henderson J, Sharma OP. Effectiveness of infliximab in treating selected patients with sarcoidosis. Respir Med 2006;100:2053-2059.

54. Judson MA, Baughman RP, Costabel U, Flavin S, Lo KH, Kavuru MS, Drent M. Efficacy of infliximab in extrapulmonary sarcoidosis: results from a randomised trial. Eur Respir J 2008;31:1189-1196.

55. Baughman RP, Koehler A, Bejarano PA, Lower EE, Weber FL, Jr. Role of liver function tests in detecting methotrexate-induced liver damage in sarcoidosis. Arch Intern Med 2003;163:615-620.

56. Baughman RP. Pulmonary sarcoidosis. Clin Chest Med 2004;25:521-530,vi.

57. Baughman RP. Sarcoidosis. Usual and unusual manifestations. Chest 1988;94:165-170.

58. Bloom R, Sybert A, Mascatello VJ. Granulomatous biliary tract obstruction due to sarcoidosis. Report of a case and review of the literature. Am J Respir Dis 1978;117:783-787.

59. Wu JJ, Schiff KR. Sarcoidosis. Am Fam Physician 2004;70:312-322.

60. Lazar CA, Culver DA. Treatment of sarcoidosis. Semin Respir Crit Care Med 2010;31:501-518.

61. Wan Y. TPMT testing before azathioprine therapy? Drug Ther Bull 2009;47:9-12.

62. Baughman RP, Lynch JP. Difficult treatment issues in sarcoidosis. J Intern Med 2003;253:41-45.

63. Hagaman JT, Kinder BW, Eckman MH. Thiopurine S- methyltransferase [corrected] testing in idiopathic pulmonary fibrosis: a pharmacogenetic cost-effectiveness analysis. Lung 2010;188:125-132.

64. Cronstein B. How does methotrexate suppress inflammation? Clin Exp Rheumatol 2010;28:S21-23.

65. Whiting-O'Keefe QE, Fye KH, Sack KD. Methotrexate and histologic hepatic abnormalities: a metaanalysis. Am J Med 1991;90:711-716.

66. Mostard RL, Voo S, Van Kroonenburgh MJ, Verschakelen JA, Wijnen PA, Nelemans PJ, Erckens RJ, Drent M. Inflammatory activity assessment by F18 FDG-PET/CT in persistent symptomatic sarcoidosis. Respiratory medicine 2011;105:1917-1924.

67. Keijsers RG, Verzijlbergen JF, Van Diepen DM, Van den Bosch JM, Grutters JC. 18F-FDG PET in sarcoidosis: an observational study in 12 patients treated with infliximab. Sarcoidosis Vasc Diffuse Lung Dis 2008;25:143-149.

68. Milman N, Graudal N, Loft A, Mortensen J, Larsen J, Baslund B. Effect of the TNF-alpha inhibitor adalimumab in patients with recalcitrant sarcoidosis: a prospective observational study using FDG-PET. Clin Respir J 2011;6:238-247.

69. Treglia G, Taralli S, Giordano A. Emerging role of whole-body 18F-fluorodeoxyglucose positron emission tomography as a marker of disease activity in patients with sarcoidosis: a systematic review. Sarcoidosis Vasc Diffuse Lung Dis 2011;28:87-94.

70. Lower EE, Broderick JP, Brott TG, Baughman RP. Diagnosis and management of neurological sarcoidosis. Arch Intern Med 1997; 157:1864-1868.

71. Doty JD, Mazur JE, Judson MA. Treatment of corticosteroid-resistant neurosarcoidosis with a shortcourse cyclophosphamide regimen. Chest 2003;124:2023-2026.

72. Dimopoulos MA, Eleutherakis-Papaiakovou V. Adverse effects of thalidomide administration in patients with neoplastic diseases. Am J Med 2004;117:508-515.

73. Park MK, Fontana, Jr., Babaali H, Gilbert-McClain LI, Stylianou M, Joo J, Moss J, Manganiello VC. Steroidsparing effects of pentoxifylline in pulmonary sarcoidosis. Sarcoidosis Vasc Diffuse Lung Dis 2009;26:121-131.

74. Zein CO, Yerian LM, Gogate P, Lopez R, Kirwan JP, Feldstein AE, McCullough AJ. Pentoxifylline improves nonalcoholic steatohepatitis: a randomized placebo-controlled trial. Hepatology 2011; 54:1610-1619.

75. Baughman RP, Drent M, Kavuru M, Judson MA, Costabel U, du Bois R, Albera C, Brutsche M, Davis G, Donohue JF, Muller-Quernheim J, Schlenker-Herceg R, Flavin S, Lo KH, Oemar B, Barnathan ES. Infliximab therapy in patients with chronic sarcoidosis and pulmonary involvement. Am J Respir Crit Care Med 2006;174:795-802.

76. Baughman RP, Lower EE, Drent M. Inhibitors of tumor necrosis factor (TNF) in sarcoidosis: who, what, and how to use them. Sarcoidosis Vasc Diffuse Lung Dis 2008;25:76-89. 
77. Kavanaugh A, St Clair EW, McCune WJ, Braakman T, Lipsky P. Chimeric anti-tumor necrosis factor-alpha monoclonal antibody treatment of patients with rheumatoid arthritis receiving methotrexate therapy. $J$ Rheumatol 2000;27:841-850.

78. Baughman RP, Lower EE. Novel therapies for sarcoidosis. Semin Respir Crit Care Med 2007;28: 128-133.

79. Vanatta JM, Modanlou KA, Dean AG, Nezakatgoo N, Campos L, Nair S, Eason JD. Outcomes of orthotopic liver transplantation for hepatic sarcoidosis: an analysis of the United Network for Organ Sharing/Organ Procurement and Transplantation Network data files for a comparative study with cholestatic liver diseases. Liver Transp/ 2011;17:1027-1034.

80. Lipson EJ, Fiel MI, Florman SS, Korenblat KM. Patient and graft outcomes following liver transplantation for sarcoidosis. Clin Transplant 2005;19:487-491.

81. Cengiz C, Rodriguez-Davalos M, deBoccardo G, Fiel MI, Rodriguez-Laiz G, Kovacevic M, Emre S, Schiano T. Recurrent hepatic sarcoidosis post-liver transplantation manifesting with severe hypercalcemia: a case report and review of the literature. Liver Transp/ 2005;11:1611-1614.

82. Hunt J, Gordon FD, Jenkins RL, Lewis WD, Khettry U. Sarcoidosis with selective involvement of a second liver allograft: report of a case and review of the literature. Mod Pathol 1999;12:325-328.

83. Polyzos SA, Kountouras J, Zavos C, Deretzi G. Nonalcoholic Fatty Liver Disease: Multimodal Treatment Options for a Pathogenetically Multiple-hit Disease. J Clin Gastroenterol 2012;46:272-284.

84. Antoniu SA. Targeting the TNF-alpha pathway in sarcoidosis. Expert Opin Ther Targets 2010;14:21-29.

85. Ratziu V, Bellentani S, Cortez-Pinto H, Day C, Marchesini G. A position statement on NAFLD/NASH based on the EASL 2009 special conference. J Hepatol 2010;53:372-384.

86. Singal AK, Jampana SC, Weinman SA. Antioxidants as therapeutic agents for liver disease. Liver Int 2011;31:1432-1448.

87. Musso G, Cassader M, Rosina F, Gambino R. Impact of current treatments on liver disease, glucose metabolism and cardiovascular risk in non-alcoholic fatty liver disease (NAFLD): a systematic review and meta-analysis of randomised trials. Diabetologia 2012. 


\section{Chapter 6}

Multinational evidence-based World

Association of Sarcoidosis and

Other Granulomatous Disorders

recommendations for the use of

methotrexate in sarcoidosis: integrating

systematic literature research and expert

opinion of sarcoidologists worldwide

J Cremers, M Drent, A Bast, H Shigemitsu, R Baughman, D Valeyre,

$N$ Sweiss, T Jansen 


\section{Abstract}

\section{Background}

Although glucocorticosteroids are considered the first-line treatment in sarcoidosis, refractory cases require alternatives, such as methotrexate (MTX). The aim of this study was to develop, on behalf of the World Association of Sarcoidosis and Other Granulomatous Disorders (WASOG), multinational evidence-based recommendations for the use of MTX in sarcoidosis for routine clinical practice.

\section{Methods}

A systematic literature search was conducted and combined with the opinions of sarcoidosis experts worldwide to formulate the recommendations. An online survey concerning 10 clinical questions was sent through the WASOG newsletter to sarcoidosis experts. Agreement about the recommendations among the world's leading sarcoidologists was evaluated.

\section{Results}

A total of 237 articles were identified, 43 of which were included. Randomized controlled trial evidence supporting the use of MTX in sarcoidosis was limited. Forty-five per cent (113 of 250) of the sarcoidosis experts contacted completed the survey (Europe 55\%, North America 26\%, and Asia 12\%). Ten recommendations were formulated concerning the indications for use, starting dose, folic acid, work-up, contraindications, monitoring, administration options in case of adverse gastrointestinal effects, hepatotoxicity, long-term safety and use during pregnancy and breast feeding.

\section{Conclusion}

Ten multinational evidence-based recommendations for the use of MTX in sarcoidosis were developed, which are supported by the world's foremost sarcoidosis experts. 


\section{Introduction}

Sarcoidosis is a multisystemic disease of unknown cause, characterized by inflammatory activity with noncaseating granulomas commonly developing in the lungs, but in other organ systems as well. ${ }^{1-3}$ In severe sarcoidosis, the release of inflammatory mediators causes derangement of organ physiology and ultimately functional impairment and related symptoms. The disease stabilizes or improves in many cases over the first 2 years, but may worsen and become chronic in others. ${ }^{1}$ As virtually any organ can be involved, patients may present with a wide variety of clinical signs and symptoms, ${ }^{1,2}$ and may first present to any one of a variety of organ specialists. As high-quality care and patients' expectations may not be covered by an individual specialist's expertise, recommendations for practical use can be expected to provide added value to optimize expertise in the field of sarcoidosis treatment.

Traditionally, glucocorticosteroids are considered the first-line treatment option in serious systemic sarcoidosis, but alternative treatment options have expanded tremendously. ${ }^{4,5}$ Refractory cases, with steroid resistance or steroid-induced adverse effects, require alternatives to glucocorticosteroids, ${ }^{6,7}$ for which we propose to introduce the term disease-modifying antisarcoid drugs (DMASDs). One option to be considered is that of potentiators of glucocorticosteroids, such as methotrexate (MTX) and azathioprine (AZA). Other DMASDs that may also play a role in controlling chronic granulomatous inflammation include leflunomide, mycophenolate mofetil, (hydroxy) chloroquine, cyclosporine, cyclophosphamide and pentoxifylline. ${ }^{6-9}$ If traditional cytotoxic DMASDs fail, new immunomodulating biological treatment modalities, such as tumor necrosis factor-alpha (TNF- $\alpha$ ) inhibitors, are available, providing elegant therapeutic options for refractory sarcoidosis patients. ${ }^{10,11}$ In view of these promising results, a trend seems to be emerging amongst the healthcare providers towards a low threshold for switching from other second-line treatment options to biologicals. However, one of the drawbacks of using biologicals is their considerable costs. ${ }^{12}$ It is important to optimize the utilization of less expensive, but effective disease-modifying therapeutics for granulomatous inflammation, in order to keep the healthcare system affordable and accessible to all.

MTX is often considered the first-choice DMASD used for patients with sarcoidosis, with $80 \%$ of physicians reporting MTX as their preferred second-line option. ${ }^{13,14}$ MTX has proved to be a cornerstone therapeutic agent in a large group of immune-mediated diseases, such as rheumatoid arthritis (RA) and polymyositis. ${ }^{15,16}$ The anti-inflammatory action of MTX can be attributed to the release of adenosine which elicits its effect via adenosine $\mathrm{A}_{2 \mathrm{~A}}$ receptors. ${ }^{17}$ This action differs from the mode of action of steroids in inflammation. ${ }^{18}$ Unfortunately, evidence for the use of MTX in sarcoidosis is limited, and evidence-based recommendations for its use in clinical practice are lacking.

On behalf of the World Association of Sarcoidosis and Other Granulomatous Disorders (WASOG), we aimed to develop practical recommendations for the use of 
MTX in sarcoidosis by integrating the evidence obtained through a systematic literature review and the opinions of sarcoidosis experts worldwide.

\section{Methods}

The new recommendations for the use of MTX in sarcoidosis on behalf of the WASOG were developed in four phases. First, we conducted a review of scientific evidence to create an evidence report on the use of MTX in sarcoidosis. The second phase comprised an evaluation of the experience with MTX amongst sarcoidosis experts around the world by means of an online web-based questionnaire. In the third phase, evidence obtained during phases 1 and 2 was combined to design 10 multinational recommendations. Finally, the recommendations were submitted to the world's leading sarcoidosis experts to assess whether they agreed with them and to evaluate how the recommendations would influence clinical practice.

\section{Systematic review of the literature}

The literature search was carried out by five experienced sarcoidologists (M.D., H.S., R.B., D.V. and N.S.) from three countries, one rheumatologist (T.J.), and one internal medicine resident and PhD student (J.C.). The computerized literature search for MTX relied predominantly on PubMed (articles from December 1968 to 28 March 2013). Reference lists of relevant review studies were checked to identify additional studies not found by the database search.

The terms 'sarcoidosis' and 'methotrexate' were entered as MeSH terms and free text. The search was limited to original research involving humans and published in English. Review articles were excluded from the systematic search, but were examined later to find other references. Data specifically relating to sarcoidosis were supplemented with data obtained from important studies on other inflammatory diseases, with specific emphasis on rheumatic disorders, in view of the wide availability of evidence in this field.

\section{Establishing expert opinion of sarcoidologists worldwide}

In view of the lack of sufficient high-quality studies on the use of MTX in sarcoidosis, the available evidence was supplemented with the expert opinion obtained from sarcoidologists worldwide. An online questionnaire was sent by e-mail through the WASOG newsletter to 250 experts around the world. The questionnaire addressed the following aspects: indications for use, starting dose, prescription of folic acid to reduce MTX toxicity, work-up prior to the start of MTX, contraindications, monitoring during use, administration options in case of adverse effects, hepatotoxicity, long-term safety, and use during pregnancy and breast feeding. Questions concerning the experts' clinical 
experience, specialty, the continent where they worked and the type of hospital were added as well. Experience with MTX in the treatment of sarcoidosis was assessed by the frequency of prescription: respondents prescribing MTX to more than five patients a year were defined as experienced and experts treating less than five patients a year with MTX as less experienced. Differences in response between experienced and less experienced specialists were examined using the Pearson's chi-squared test. When recapitulating the expert opinion based on the answers, the opinions of experienced sarcoidologists were given greater weight than those of less experienced respondents.

\section{Establishing World Association of Sarcoidosis and Other Granulomatous Disorders recommendations}

The above-mentioned investigators (J.C., M.D., T.J., R.B., H.S., D.V. and N.S.) combined the information gathered during phases 1 and 2 to formulate the 10 WASOG recommendations. Proposals were discussed via e-mail, phone and videoconference to finalize each of the recommendations.

The level of evidence for each recommendation was determined from the methodological quality of available studies in sarcoidosis, according to the levels of evidence of the Oxford Centre for Evidence-Based Medicine. ${ }^{19}$ The grade of recommendation for each item was defined according to the Oxford Level of Evidence. ${ }^{19}$ The authors focussed on formulating the recommendations in such a way so as to ensure their practical value to clinicians with less MTX prescription experience in sarcoidosis.

\section{Evaluation of experts' agreement}

During the last phase of this study, the proposed set of recommendations was evaluated by 17 of the world's leading sarcoidologists, who answered three questions for every recommendation. Experts were asked to indicate whether they agreed with the recommendation; their level of agreement was measured on a 10-point visual analogue scale $\left(1\right.$, no agreement to 10 , full agreement); ${ }^{20}$ and the potential impact amongst the participants was assessed using three statements: 'This recommendation will change my practice'; 'I'm already working in accordance with this recommendation' and 'I will not change my practice with regard to this aspect'.

The total set of recommendations was also evaluated using these three questions, plus two additional queries: 'Do you think that these recommendations should be implemented in general clinical practice?' and 'Would you encourage your fellow physicians to implement these recommendations?'. 


\section{Results}

The results of every phase were combined to develop the recommendations, which will be discussed subsequently.

\section{Findings of the literature review}

The literature search identified 237 citations of potential interest. We screened each title and abstract for relevance resulting in the exclusion of 194 articles, as MTX had been used for non-sarcoidosis conditions (40 articles) or MTX had not been used as a pharmacological treatment option but in a different context (78 articles). Review articles were excluded as well (76 articles). After this exclusion process, 43 articles were retrieved and considered further for full review. Checking the references in review articles yielded no additional original studies. Included were one randomized controlled trial (RCT), 10 case series involving more than 10 patients and 32 case reports involving fewer than 10 patients, examining the effectiveness of MTX in sarcoidosis. Study characteristics and results for each included article are summarized in Appendix 1. Summarizing the available studies, it can be said that RCT evidence supporting the use of MTX in sarcoidosis was very limited, as only one RCT was available ${ }^{21}$ and most of the published data were observational case series. ${ }^{22-63}$ A Cochrane review for DMASDs in pulmonary sarcoidosis found no data on MTX available for meta-analysis. ${ }^{7}$

\section{Findings regarding expert opinion}

A total of 113 of 250 (45\%) experts completed the questionnaire. Characteristics of the respondents are presented in Table 6.1. The questionnaire was completed mainly by pulmonologists, rheumatologists and neurologists, working in countries all over the world (55\% Europe, $26 \%$ North America, and $12 \%$ Asia). Almost $60 \%$ of respondents could be classified as experienced with regard to MTX prescription for sarcoidosis. Eleven per cent of the respondents did not prescribe MTX at all in sarcoidosis patients, $70 \%$ of them quoting fear of toxicity as their reason for not doing so. Other reasons were 'too little experience' (42\%) and 'no indication for MTX as sarcoidosis cases were not severe enough' (25\%) (multiple options could be selected). The number of respondents experienced in MTX prescription for sarcoidosis was significantly higher in specialized sarcoidosis clinics and university hospitals than in general hospitals $(p=0.001)$ (data not shown). 
Table 6.1 Summary of characteristics of sarcoidosis experts who participated in this study.

\section{Number of respondents}

Pulmonologist/rheumatologist/neurologist/other

Type of hospital: general/university/sarcoidosis clinic

Continent: Europe/North America/Asia/other

Working experience: $0-10 / 10-20 />20$ years

Average number of sarcoidosis patients treated with methotrexate:

none/1-5/5-25/>25 a year

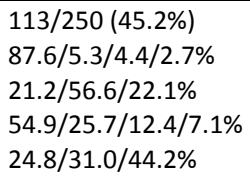

$24.8 / 31.0 / 44.2 \%$

Table 6.2 summarizes the results of the online questionnaire for each recommendation. Glucocorticosteroid monotherapy was by far the most commonly prescribed first-line treatment option, although MTX monotherapy was sometimes used as first-line therapy. Experienced respondents were significantly more likely to prescribe steroid/MTX combination therapy as the first-choice treatment option than the less experienced respondents $(p=0.003)$. Furthermore, experienced respondents were significantly more likely to use the parenteral administration mode of MTX in cases complicated by gastrointestinal side-effects (including mucositis), whereas less experienced specialists were more likely to split the oral MTX dose as an alternative option $(p=0.005)$. Hepatic disease was significantly more often quoted as a contraindication for starting MTX by experienced participants $(p=0.013)$. No other significant differences between experienced and less experienced respondents were found. A small subgroup of sarcoidosis experts $(n=14)$ reported a $10 \%$ discontinuation rate of MTX, with the most important reported reasons for discontinuation including gastrointestinal (30\% of cases), liver $(27 \%)$ and haematological $(17 \%)$ toxicity (data not shown). The results of the questionnaire were processed to formulate the recommendations.

Table 6.2 Expert opinion amongst sarcoidologists, based on questionnaire answers, for each recommendation and level of methotrexate experience. ${ }^{a}$

\begin{tabular}{lllll}
\hline & $\begin{array}{l}\text { MTX prescription to } \\
1-5 \text { patients a year }\end{array}$ & $\begin{array}{l}\text { MTX prescription to } \\
>5 \text { patients a year }\end{array}$ & Total & p value \\
\hline Number of respondents & $35(34.7 \%)$ & $66(65.3 \%)$ & $101(100 \%)$ & -
\end{tabular}

\section{Recommendation 1}

First-choice treatment option

(often/sometimes/never in \%)

- Steroid monotherapy

$97.1 / 2.9 / 0 \%$

- MTX monotherapy

$0 / 38.2 / 61.8 \%$

- Steroid/MTX combination therapy

\section{Recommendation 2}

Starting dosage of MTX

- 0-5 mg weekly

- 5-10 mg weekly

- 10-15 mg weekly

$0 / 61.8 / 38.2 \%$
$87.0 / 12.0 / 1.0 \%$

$1.0 / 51.0 / 48.0 \%$

$12.0 / 65.0 / 23.0 \%$
0.098

0.123

$0.003^{*}$

- >15 mg weekly

$\begin{array}{ll}4(12.1 \%) & 10(15.4 \%) \\ 20(60.6 \%) & 34(52.3 \%) \\ 8(24.2 \%) & 21(32.3 \%) \\ 1(3.0 \%) & 0(0 \%)\end{array}$




\begin{tabular}{lllll}
\hline & $\begin{array}{l}\text { MTX prescription to } \\
1-5 \text { patients a year }\end{array}$ & $\begin{array}{l}\text { MTX prescription to } \\
>5 \text { patients a year }\end{array}$ & Total & p value \\
\hline $\begin{array}{l}\text { Maintenance dosage of MTX } \\
-0-5 \text { mg weekly }\end{array}$ & $2(6.1 \%)$ & $0(0 \%)$ & $2(2.0 \%)$ & 0.068 \\
$-5-10$ mg weekly & $12(36.4 \%)$ & $14(21.5 \%)$ & $26(26.5 \%)$ & $58(59.2 \%)$ \\
$-10-15$ mg weekly & $16(48.5 \%)$ & $42(64.6 \%)$ & $12(12.2 \%)$ & \\
$->15$ mg weekly & $3(9.1 \%)$ & $9(13.8 \%)$ & &
\end{tabular}

\section{Recommendation 3}

Mean folic acid dosage

- $1 \mathrm{mg}$ daily

$7(21.9 \%)$
$19(59.4 \%)$
$2(6.3 \%)$
$1(3.1 \%)$
$3(9.4 \%)$

$22(33.8 \%)$
$18(27.7 \%)$
$7(10.8 \%)$
$6(9.2 \%)$
$12(18.5 \%)$

- 5 mg once weekly

$3(9.4 \%)$

- Depending on MTX dosage

$12(18.5 \%)$

0.052

\section{Recommendation 4}

Work-up before start of MTX

- AST

$30(85.7 \%)$

$62(93.9 \%)$

$63(95.5 \%)$

- ALT

$31(88.6 \%)$

$59(89.4 \%)$

$33(94.3 \%)$

$65(98.5 \%)$

- CBC

$27(77.1 \%)$

55 (83.3\%)

$15(15.5 \%)$

- Creatinine

\section{Recommendation 5}

Contraindications

- Renal disease

- Hepatic disease

- Pulmonary disease

- Leucocytopenia

- Thrombocytopenia

- Anaemia

$23(65.7 \%)$

$28(80.0 \%)$

$13(37.1 \%)$

$28(80.0 \%)$

$27(77.1 \%)$

$16(45.7 \%)$

- Infection acute/chronic

$28(80.0 \%)$

- Alcohol/drugs use (current or 19 (54.3\%) past)

Contraindicating creatinine clearance

- Stage 2 (GFR 60-89)

- Stage 3 (GFR 30-59)

$2(8.7 \%)$

$11(47.8 \%)$

$3(6.3 \%)$

$48(72.7 \%)$

$63(95.5 \%)$

$13(19.7 \%)$

$52(78.8 \%)$

$45(68.2 \%)$

$33(50.0 \%)$

$53(80.3 \%)$

34 (51.5\%)

92 (91.1\%)

0.167

$94(93.1 \%)$

0.195

$84(83.2 \%)$

$0.022^{*}$

$98(97.0 \%)$

0.237

$82(81.2 \%)$

0.449

- Stage 4-5 (GFR <29)

$10(43.5 \%)$

$19(39.6 \%)$

5 (7.0\%)

0.427

Contraindicating WBC level

$-<2.0 \times 10^{9} / 1$

$-<1.5 \times 10^{9} / /$

$23(92.0 \%)$
$1(4.0 \%)$
$1(4.0 \%)$

$32(72.7 \%)$

$10(22.7 \%)$

$71(70.3 \%)$

0.463

$91(90.1 \%)$

$0.013^{*}$

$26(25.7 \%)$

0.056

$80(79.2 \%)$

0.886

$72(71.3 \%)$

0.344

$49(48.5 \%)$

0.682

$81(80.2 \%)$

0.971

$53(52.5 \%)$

0.791

$-<1.0 \times 10^{9} / /$

2 (4.5\%)

$55(79.7 \%)$

0.119

Contraindicating platelet count number

$$
-<200 \times 10^{9} / /
$$

$-<100 \times 10^{9} / 1$ 


\begin{tabular}{lllll}
\hline & $\begin{array}{l}\text { MTX prescription to } \\
1-5 \text { patients a year }\end{array}$ & $\begin{array}{l}\text { MTX prescription to } \\
>5 \text { patients a year }\end{array}$ & Total & p value \\
\hline $\begin{array}{l}\text { Contraindicating anaemia level } \\
-<6 \mathrm{mmol} / \mathrm{l}\end{array}$ & $8(44.4 \%)$ & $17(45.9 \%)$ & $25(45.5 \%)$ & 0.995 \\
$-<5 \mathrm{mmol} / \mathrm{l}$ & $7(38.9 \%)$ & $14(37.8 \%)$ & $21(38.2 \%)$ & $9(16.4 \%)$ \\
$-<4 \mathrm{mmol} / \mathrm{l}$ & $3(16.7 \%)$ & $6(16.2 \%)$ &
\end{tabular}

\section{Recommendation 6}

Blood monitoring interval after start of MTX

- Once after 2-3 weeks

$$
\begin{aligned}
& 12(38.7 \%) \\
& 13(41.9 \%) \\
& 5(16.1 \%) \\
& 1(3.2 \%)
\end{aligned}
$$

$21(32.3 \%)$

$24(36.9 \%)$

$33(34.4 \%)$

$37(38.5 \%)$

$15(23.1 \%)$

$20(20.8 \%)$

- Every 2-3 months

$5(7.7 \%)$

$6(6.3 \%)$

Blood monitoring interval after stable MTX dose

- Every month

- Every 2 months

$13(41.9 \%)$

$6(19.4 \%)$

$15(23.1 \%)$

$28(29.2 \%)$

$15(23.1 \%)$

$21(21.9 \%)$

$11(35.5 \%)$

$32(49.2 \%)$

$43(44.8 \%)$

- Every 6 months

$1(3.2 \%)$

$3(4.6 \%)$

$4(4.2 \%)$

\section{Recommendation 7}

Alternative administration modes in case of MTX-induced gastrointestinal side-effects

- Parenteral administration

- Splitting oral dose

$0(0 \%)$

$14(45.2 \%)$

$8(25.8 \%)$

$9(29.0 \%)$

- None

\section{Recommendation 8}

First action when LT >4 x ULN

- Check for alcohol/NSAID

- Increase folic acid dosage

- Decrease MTX dosage

- Parenteral MTX

- Discontinue MTX

- Start UDCA/antioxidants

Level of LT abnormalities

requiring MTX discontinuation

$\begin{array}{ll}\text { - }>2 \times \text { ULN } & 9(29.0 \%) \\ ->3 \times \text { ULN } & 15(48.4 \%) \\ \text { - >4 x ULN } & 7(22.6 \%) \\ \text { - No discontinuation } & 0(0 \%)\end{array}$

\section{Recommendation 9}

Long-term MTX use

- Unaltered continuation

- Discontinuation

After 1 year

After 2 years

After $>2$ years

$18 / 35(51.4 \%)$
$4 / 35(11.4 \%)$
$7 / 35(20.0 \%)$
$1 / 35(2.9 \%)$
$25 / 35(71.4 \%)$
$7 / 35(20.0 \%)$

$29 / 66(43.9 \%)$
$6 / 66(9.1 \%)$
$20 / 66(30.3 \%)$
$1 / 66(1.5 \%)$
$49 / 66(74.2 \%)$
$5 / 66(7.6 \%)$

47/101 (46.5\%)

$10 / 101$ (9.9\%)

$27 / 101(26.7 \%)$

2/101 (2.0\%)

$74 / 101(73.3 \%)$

$12 / 101(11.9 \%)$

0.473

0.708

0.266

0.645

0.761

0.066

20 (30.8\%)

$30(46.2 \%)$

14 (21.5\%)

1 (1.5\%)

$29(30.2 \%)$
$45(46.9 \%)$
$21(21.9 \%)$
$1(1.0 \%)$

0.912

$44 / 65(67.7 \%)$
$21 / 65(32.3 \%)$
$5 / 21(23.8 \%)$
$11 / 21(52.4 \%)$
$5 / 21(23.8 \%)$

$63 / 96$ (65.6\%)

0.537

$33 / 96$ (34.4\%)

9/33 (27.3\%)

$17 / 33$ (51.5\%)

$7 / 33(21.2 \%)$
0.800 


\begin{tabular}{lllll}
\hline & $\begin{array}{l}\text { MTX prescription to } \\
1-5 \text { patients a year }\end{array}$ & $\begin{array}{l}\text { MTX prescription to } \\
>5 \text { patients a year }\end{array}$ & Total & p value \\
\hline $\begin{array}{l}\text { Recommendation } 10 \\
\text { Establishing pregnancy wish }\end{array}$ & $29 / 31(93.5 \%)$ & $64 / 65(98.5 \%)$ & $93 / 96(96.9 \%)$ & 0.196 \\
- In women & $18 / 31(58.1 \%)$ & $46 / 65(70.8 \%)$ & $64 / 96(66.7 \%)$ & 0.217 \\
- In men & & & & \\
& & & & \\
Discontinuation of MTX if & & & & \\
pregnancy wish & $29 / 31(93.5 \%)$ & $64 / 65(98.5 \%)$ & $93 / 96(96.9 \%)$ & 0.196 \\
- In women & $22 / 31(71.0 \%)$ & $45 / 65(69.2 \%)$ & $67 / 96(69.8 \%)$ & 0.862 \\
- In men &
\end{tabular}

${ }^{a}$ Values are expressed as frequencies and/or percentages, and were tested with Pearson's chi-squared test. * $p<0.05$, significant difference between the experienced and less experienced respondents. ALP, alkaline phosphatase; ALT, alanine aminotransferase; $A S T$, aspartate aminotransferase; $C B C$, complete blood count; GFR, glomerular filtration rate expressed as $\mathrm{ml} / \mathrm{min}$ and normalized to an average surface area (size) of 1.73 $\mathrm{m}^{2}$; LT, liver tests; MTX, methotrexate; NSAID, nonsteroidal anti-inflammatory drug; UDCA, ursodeoxycholic acid; ULN, upper limit of normal; WBC, white blood cell.

\section{Recommendations}

The 10 key WASOG recommendations are listed in Table 6.3, with the corresponding level of evidence and grade of recommendation. The mean level of agreement for the total set of recommendations amongst the 17 leading sarcoidologists was 8.7 (range 8.0-10). The percentage of sarcoidologists who indicated that they would change their clinical practice in accordance with each of the recommendations is shown in Table 6.4. Twelve per cent of the sarcoidologists reported that the total set of recommendations would change their clinical practice; the other experts reported that they were already working according to the recommendations. All sarcoidologists were in favour of implementing these recommendations in general clinical practice and would encourage fellow physicians to use these recommendations.

\section{Recommendation 1}

The indications for MTX in sarcoidosis consist of its use as a second-line treatment option in steroid-refractory cases, in the presence of steroid-associated adverse effects or as a steroid-sparing agent; or as a first-line treatment option as a MTX/steroid combination therapy or monotherapy in exceptional situations.

The evidence to support MTX as a steroid-sparing agent or alternative agent is scarce. One small $(n=24)$ but high-quality RCT showed that sarcoidosis patients without previous treatment who took MTX $10 \mathrm{mg}$ weekly required significantly lower doses of glucocorticosteroids than patients taking placebo, after 12 months of treatment (median $8.3 \mathrm{mg}$ daily (0.83-21.7) and $16 \mathrm{mg}$ daily, respectively, $\mathrm{p}<0.001$ ); at 6 months, there was no significant difference between the groups. ${ }^{21} \mathrm{~A}$ recent retrospective cohort study comparing the DMASDs MTX and AZA in sarcoidosis showed a significant steroidsparing potency, without a difference between the two groups. ${ }^{22}$ The steroid-sparing potency of MTX was also found in several case series. ${ }^{24,26,28,46,51,52,54,56,57,63}$ Moreover, 
MTX has been proven effective and is recommended as a steroid-sparing agent in other inflammatory diseases, such as RA, giant-cell arteritis and polymyalgia rheumatica, and can also be considered in systemic lupus erythematosus or (juvenile) dermatomyositis. ${ }^{64}$

Table 6.3 Multinational recommendations for the use of methotrexate in sarcoidosis.

\begin{tabular}{|c|c|c|c|c|}
\hline \multicolumn{2}{|c|}{ Recommendation } & \multirow{2}{*}{$\begin{array}{l}\text { Level of } \\
\text { evidence }^{19} \\
2 \mathrm{~b}\end{array}$} & \multirow{2}{*}{$\begin{array}{l}\text { Grade of } \\
\text { recommen } \\
\text { dation }^{19} \\
\text { B }\end{array}$} & \multirow{2}{*}{$\begin{array}{l}\text { Agreement } \\
\text { mean } \\
( \pm S D)^{a} \\
8.9( \pm 1.1)\end{array}$} \\
\hline 1 & $\begin{array}{l}\text { The indications for MTX in sarcoidosis consist of its use as a } \\
\text { second-line treatment option in steroid-refractory cases, in the } \\
\text { presence of steroid-associated adverse effects or as a steroid- } \\
\text { sparing agent; or as a first-line treatment option as a MTX/steroid } \\
\text { combination therapy or monotherapy in exceptional situations. }\end{array}$ & & & \\
\hline 2 & The recommended initial dosage of oral MTX is $5-15 \mathrm{mg}$ weekly. & 4 & $\mathrm{C}$ & $9.0( \pm 1.6)$ \\
\hline 3 & $\begin{array}{l}\text { Prescription of folic acid with MTX therapy is recommended, at } \\
\text { least } 5 \mathrm{mg} \text { weekly or } 1 \mathrm{mg} \text { daily. }\end{array}$ & 5 & $\mathrm{~B}^{\mathrm{b}}$ & $9.6( \pm 1.1)$ \\
\hline 4 & $\begin{array}{l}\text { The preadministration work-up for patients starting MTX should } \\
\text { include aspartate aminotransferase (AST), alanine } \\
\text { aminotransferase (ALT), alkaline phosphatase (ALP), bilirubin, } \\
\text { complete blood count (CBC), creatinine, and when indicated, } \\
\text { serology for HIV, hepatitis B/C and IGRA test for Mycobacterium } \\
\text { tuberculosis infection. }\end{array}$ & 5 & $\mathrm{D}$ & $9.1( \pm 1.1)$ \\
\hline 5 & $\begin{array}{l}\text { Before starting MTX, some contraindications should be } \\
\text { considered: significant renal disease, significant hepatic disease } \\
\text { other than sarcoidosis, bone marrow depression and acute or } \\
\text { chronic infection. }\end{array}$ & 5 & $\mathrm{D}$ & $9.3( \pm 1.2)$ \\
\hline 6 & $\begin{array}{l}\text { When starting MTX or increasing the dose, ALT with or without } \\
\text { AST, creatinine and CBC should be monitored every } 3-6 \text { weeks } \\
\text { until a stable dose is reached, and every } 1-3 \text { months thereafter; } \\
\text { after stabilization the monitoring interval can be extended to } \\
\text { every } 6 \text { months. }\end{array}$ & 5 & $\mathrm{D}$ & $8.9( \pm 1.3)$ \\
\hline 7 & $\begin{array}{l}\text { In case of MTX-induced gastrointestinal side-effects, including } \\
\text { mucositis, splitting the oral dose should be considered, provided } \\
\text { the total MTX dose is ingested within a 12-h period. Parenteral } \\
\text { administration or an alternative immunosuppressive drug should } \\
\text { be considered in case of persistent intolerance. }\end{array}$ & 5 & $\mathrm{D}$ & $8.3( \pm 2.0)$ \\
\hline 8 & $\begin{array}{l}\text { Caution is warranted if there is a confirmed increase in ALT/AST. If } \\
\text { there are no other causes, it should lead to either MTX dose } \\
\text { reduction or withdrawal, liver biopsy to evaluate for MTX toxicity } \\
\text { or additional folic acid supplementation; consider an alternative } \\
\text { immunosuppressive drug after normalization. }\end{array}$ & 4 & $\mathrm{C}$ & $9.0( \pm 1.4)$ \\
\hline 9 & $\begin{array}{l}\text { Based on its acceptable safety profile, MTX is appropriate for } \\
\text { long-term use. }\end{array}$ & 5 & $C^{b}$ & $9.3( \pm 1.1)$ \\
\hline 10 & $\begin{array}{l}\text { MTX should not be used by men or women for at least } 3 \text { months } \\
\text { before planned pregnancy, and should not be used during } \\
\text { pregnancy or breast feeding (absolute contraindication). }\end{array}$ & 5 & $D$ & $9.5( \pm 0.9)$ \\
\hline
\end{tabular}

${ }^{a}$ The level of agreement was measured on a 10-point visual analogue scale (1, no agreement; 10 , full agreement). ${ }^{b}$ Upgraded level of recommendation based on evidence derived from rheumatoid arthritis studies. ALP, alkaline phosphatase; ALT, alanine aminotransferase; AST, aspartate aminotransferase; CBC, complete blood count; IGRA, interferon-gamma release assay; MTX, methotrexate. 
Table 6.4 Evaluation of recommendations, with the percentage of sarcoidologists who indicated that each of the recommendations would change their clinical practice or not.

\begin{tabular}{llcc}
\hline Recommendation & $\begin{array}{c}\text { The recommendation } \\
\text { will change my practice } \\
(\%)\end{array}$ & $\begin{array}{c}\text { Already working } \\
\text { according to this } \\
\text { recommendation (\%) }\end{array}$ & $\begin{array}{c}\text { I will not change my } \\
\text { practice in this respect } \\
\text { (\%) }\end{array}$ \\
\hline 1. $\quad$ Indications for use & 5.9 & 94.1 & 0 \\
2. Starting dosage & 0 & 88.2 & 11.8 \\
3. Folic acid & 11.8 & 88.2 & 0 \\
4. Preadministration work-up & 5.9 & 88.2 & 5.9 \\
5. Contraindications & 11.8 & 88.2 & 0 \\
6. Monitoring & 0 & 94.1 & 5.9 \\
7. Adverse effects and & 17.6 & 64.7 & 17.6 \\
8. Hepatotoxicity & & & 5.9 \\
9. Long-term safety & 0 & 94.1 & 0 \\
10. Pregnancy & 0 & 100 & 0 \\
\hline
\end{tabular}

Several case series are available for pulmonary and extrapulmonary sarcoidosis, and showed a $60-80 \%$ response to MTX in steroid-refractory cases or in the presence of steroid-associated adverse effects. ${ }^{22-63}$ MTX appeared to take 6 months to be effective. The previously described retrospective cohort study comparing MTX and AZA found a positive effect of MTX on lung function. ${ }^{22}$ Lower and Baughman ${ }^{28}$ showed that 33 of 50 patients using MTX for 2 years saw their vital capacity improve by more than $15 \%$ or showed improvement in other organs. Vucinic ${ }^{24}$ showed an improvement in forced expiratory volume in 1 second (FEV1) in $80 \%$ and in diffusing capacity for carbon monoxide (DLCO) in 65\% of 91 sarcoidosis patients using MTX for 6 months. The only available RCT did not find a significant effect of MTX on lung function (vital capacity), symptoms or adverse events compared to placebo. However, the study may not have been adequately powered to demonstrate the true effect of MTX because of the small number of patients enrolled in the study. ${ }^{21}$

Some exceptional manifestations of sarcoidosis might respond better to nonsteroidal drugs. In these cases, MTX/steroid combination or MTX monotherapy can be considered as the first-line treatment option. However, this recommendation is mostly based on expert opinion rather than evidence. Experienced sarcoidologists in particular seemed to consider MTX as a first-choice therapy in such cases (Table 6.2). For example, first-line systemic MTX therapy, whether or not combined with glucocorticosteroids, has been reported as beneficial in uveitis after topical steroid application failed. ${ }^{23,26}$ MTX has been proposed as a first-choice immunosuppressant in neurosarcoidosis. ${ }^{65}$ An MTX/glucocorticosteroid combination has been reported to be beneficial as a first-line treatment option in neurosarcoidosis, ${ }^{27,36,40,46,61}$ as many neurosarcoidosis manifestations are usually chronic and MTX appears to show increased efficacy at lower levels of morbidity. ${ }^{27}$ Another indication is cardiac involvement, in which a first-line MTX/glucocorticosteroid combination therapy should be considered to avoid aneurysm formation because of high doses of 
glucocorticosteroids. ${ }^{66}$ Starting MTX with low-dosed glucocorticosteroids might also be beneficial for patients suffering from diabetes or overweight whose steroid dose should be kept as low as possible, as the required cumulative glucocorticosteroids dose with MTX is several milligrams lower than without MTX. ${ }^{21}$

\section{Recommendation 2}

The recommended initial dosage of oral MTX is 5-15 mg weekly.

The single available RCT demonstrated that an initial oral MTX dosage of $10 \mathrm{mg}$ weekly had steroid-sparing efficacy, ${ }^{21}$ whereas case series showing effectiveness of MTX used dosages of 5-20 mg weekly. ${ }^{22-63}$ The safety profile of MTX in these cases was acceptable (see Appendix 1). Most research experience has been in the initial dosage range of 10-15 mg weekly. Eighty-five per cent of sarcoidologists reported using starting dosages of 5-15 mg weekly (Table 6.2). A lower initial MTX dosage is advisable in case of suspected bone marrow involvement in the sarcoidosis process, as evidenced by cytopenia. ${ }^{67,68}$

Studies comparing different MTX dosages in sarcoidosis are not available, and there is a need for future studies to compare higher and lower dosages of MTX to provide the best treatment effect with acceptable safety profile. Studies comparing different doseescalation methods are not available for sarcoidosis either, but in RA the results of three RCTs directly comparing different dosages of oral MTX showed dose-dependent efficacy and toxicity. ${ }^{64,69-71}$ The higher starting doses (12.5-25 mg weekly) were clearly more effective in RA patients than the lower doses (5-15 mg weekly), but were accompanied by more adverse effects. ${ }^{69,70}$ Rapid dose escalation by $5 \mathrm{mg}$ monthly was associated not only with higher effectiveness, but also with more adverse events, in comparison with escalation of 5 mg every 3 months. ${ }^{71}$ Table 6.2 shows that $86 \%$ of the sarcoidologists recommended a maintenance dosage of MTX for sarcoidosis of 5-15 mg weekly, but $12 \%$ reported that higher dosages of up to $20 \mathrm{mg}$ weekly may be warranted in individual cases. As the treatment effect and safety profile for higher dosages of MTX in sarcoidosis have not been determined, increasing the dose of MTX for sarcoidosis beyond $20 \mathrm{mg}$ weekly is probably not advisable without appropriate safety studies. Evidence regarding the best escalation method in sarcoidosis is not available, but in the case of insufficient response and an acceptable safety profile we recommend considering escalation after 8 weeks to $10-15 \mathrm{mg}$ weekly with a maximum of $20 \mathrm{mg}$ weekly in individual cases.

\section{Recommendation 3}

Prescription of folic acid with MTX therapy is recommended, at least $5 \mathrm{mg}$ weekly or 1 mg daily.

No studies on the prescription of folic acid with MTX therapy for sarcoidosis are available. A meta-analysis of nine studies in RA, including 788 patients, suggested that folic acid supplementation reduces the gastrointestinal and liver toxicity of MTX, 
without reducing its efficacy. ${ }^{64,72}$ High dosages of folic acid (>5 mg weekly) led to a significant reduction in gastrointestinal side-effects (odds ratio (OR) 0.42; 95\% confidence interval (Cl) $0.21-0.85),{ }^{73-76}$ whereas dosages of less than $5 \mathrm{mg}$ weekly showed only a trend towards reducing gastrointestinal side-effects. ${ }^{74}$ After further stratification, however, the protective effect of folic acid on gastrointestinal toxicity proved only significant in the studies that used MTX at weekly doses of less than $10 \mathrm{mg}^{74,75}$ The studies analysing hepatotoxicity showed a significant protective effect of $1 \mathrm{mg}$ folic acid daily or $7 \mathrm{mg}$ weekly (OR $0.17 ; 95 \% \mathrm{Cl} 0.09-0.32$ ). ${ }^{73,75,76}$ The effect of folic acid supplementation on haematological adverse effects could not be accurately assessed because of a low incidence of events in the samples studied. ${ }^{77}$ Almost $70 \%$ of the sarcoidologists recommended prescribing folic acid at $1 \mathrm{mg}$ daily or $5 \mathrm{mg}$ weekly, whereas $17 \%$ reported prescribing higher dosages.

At least $5 \mathrm{mg}$ folic acid weekly is recommended for RA, taking into account the potential need for higher dosages if MTX is given in higher doses. ${ }^{64}$ Similar prophylaxis is recommended in sarcoidosis, as data on the prescription of folic acid or data supporting the need for higher dosages to provide adequate prophylaxis in sarcoidosis are not yet available.

\section{Recommendation 4}

The preadministration work-up for patients starting MTX should include aspartate aminotransferase (AST), alanine aminotransferase (ALT), alkaline phosphatase (ALP), bilirubin, complete blood count $(C B C)$, creatinine, and when indicated, serology for HIV, hepatitis $B / C$ and interferon-gamma release assay (IGRA) test for Mycobacterium tuberculosis infection.

The work-up information needed to decide whether to start a patient with sarcoidosis on MTX can be extrapolated from data on MTX-induced toxicity. Studies investigating the risk factors for severe toxicity in sarcoidosis are lacking, but data on RA suggested that an estimated creatinine clearance less than $79 \mathrm{ml} / \mathrm{min}$ increases the risk of severe pulmonary toxicity. ${ }^{64,78}$ Furthermore, lung abnormalities on radiograph, but not pulmonary function tests, proved predictive of MTX-induced pneumonitis. ${ }^{64,79-81}$ Exacerbation of hepatic disease was an additional risk in obesity, diabetes and viral/alcoholic hepatitis. ${ }^{64,82-85}$

Recommendations in Europe and the USA about the preadministration work-up for arthritis patients all suggest $C B C$, creatinine, AST, ALT with or without bilirubin and ALP. ${ }^{86,87}$ Hepatitis B/C serology, serology for HIV and chest radiographs have also been suggested as part of the pretreatment work-up. ${ }^{64,87,88}$ Table 6.2 shows that $83-99 \%$ of the sarcoidosis experts reported AST, ALT, ALP, bilirubin, CBC and creatinine to be part of their preadministration work-up. A chest radiograph is usually available in sarcoidosis patients, as the lungs are commonly involved in the sarcoidosis process. ${ }^{1,2}$ An additional chest radiograph as part of the preadministration work-up does not offer added value, and we therefore do not recommend routine chest radiographs. Only in cases with suspected pulmonary infection, established during clinical evaluation before the start of 
MTX, an additional chest radiograph is recommended to determine a change in the features (based on expert opinion).

Sarcoidosis and tuberculosis (TB) have comparable clinical and histopathological features, both being granulomatous diseases frequently affecting the lungs. A well known feature is the increased risk of reactivating a latent TB infection or worsening of an active TB infection caused by immunosuppressive TNF- $\alpha$ inhibitors. ${ }^{89}$ Therefore, screening for TB is recommended before starting TNF- $\alpha$ inhibitors. However, no evidence is available on the screening methods for TB in patients on MTX. One retrospective study concluded that MTX treatment was probably not associated with an increased incidence of TB in rheumatic diseases. ${ }^{90}$ Recommendations in RA stated that screening should therefore be similar to that in the general population. ${ }^{91}$ However, some case reports showed the occurrence of active TB in patients on long-term MTX treatment. $^{92}$ Furthermore, the American College of Rheumatology (ACR) recommended that MTX should not be initiated in the presence of active TB or latent TB infection prior to starting preventive therapy. ${ }^{87}$ Combining the available evidence, we recommend excluding mycobacterial infection in selected sarcoidosis cases using an IGRA test such as QuantiFERON-TB Gold In-Tube (QFT-GIT) assay or T-SPOT.TB assay, which seem to be accurate methods given the presence of anergy to tuberculin in sarcoidosis, prior to initiating further immunosuppressive treatment with MTX. ${ }^{93,94}$

The evidence available for RA was combined with the expert opinion among sarcoidologists and processed into recommendation 4 . Contraindications that should be considered before the start of MTX in sarcoidosis are discussed in more detail at recommendation 5 .

\section{Recommendation 5}

Before starting MTX, some contraindications should be considered: significant renal disease, significant hepatic disease other than sarcoidosis, bone marrow depression and acute or chronic infection.

There is no evidence regarding any contraindications that should be considered before the start of MTX in sarcoidosis. Contraindications that should be considered according to rheumatology experts include significant renal disease with glomerular filtration rate (GFR) less than $30 \mathrm{ml} / \mathrm{min}$, hepatic disorders, leucocytopenia less than 3.0 $\times 10^{9} /$, thrombocytopenia less than $50 \times 10^{9} /$, inadequate contraception, pregnancy, history of drug or alcohol abuse, acute or chronic infection and pulmonary disease. ${ }^{87}$ Renal and hepatic diseases, leucocytopenia, thrombocytopenia and infections were considered contraindications by $70-96 \%$ of the sarcoidologists in our survey, whereas pulmonary disease, anaemia and a history of alcohol/drugs use were less often mentioned (20-52\%) (Table 6.2). In addition, GFR less than $30 \mathrm{ml} / \mathrm{min}$ was considered a contraindication by $54 \%$, white blood cell (WBC) count of less than $2.0 \times 10^{9} / 1$ by $73 \%$, platelet count of less than $100 \times 10^{9} /$ by $64 \%$ and haemoglobin $(\mathrm{Hb})$ level of less than 5-6 mmol// by $84 \%$ (Table 6.2). In general, sarcoidologists seem to take a more cautious approach than the rheumatology guidelines. 
MTX is considered contraindicated by significant renal disease, as MTX is mainly cleared by the kidney. ${ }^{95}$ Kidney involvement from sarcoidosis is rare, having been reported in $7-22 \%$ of sarcoidosis patients at autopsy, but sometimes leads to kidney failure. ${ }^{96}$ Furthermore, renal failure can also be the consequence of hypercalcaemia and hypercalciuria, which are both frequent manifestations of sarcoidosis. ${ }^{96}$ In these cases, AZA is recommended as the first-choice glucocorticosteroid-sparing immunomodulator (based on expert opinion).

Involvement of the liver often occurs in sarcoidosis, with liver biopsy demonstrating granulomatous disease in half of the patients. ${ }^{97-101}$ Liver test abnormalities are seen in one-fourth to one half of sarcoidosis patients before the start of MTX; these can be the result of sarcoidosis or other liver diseases. ${ }^{47,97}$ Treatment with MTX is not contraindicated when liver test abnormalities are the consequence of sarcoidosis

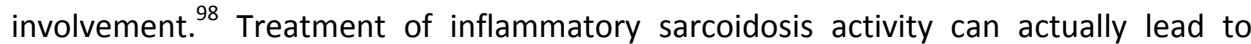
improvement of liver tests. ${ }^{98}$ A study of baseline liver test abnormalities in rheumatology patients found that values were only mildly elevated and were rarely a contraindication for starting MTX. ${ }^{86}$ Liver test abnormalities at baseline are more common in sarcoidosis, because of liver disease from the sarcoidosis itself. ${ }^{47,97}$ In patients with severe liver test abnormalities prior to starting MTX, one should consider a liver biopsy or radiological examination to distinguish between sarcoidosis and other liver diseases. ${ }^{97}$ Acute and chronic hepatitis $B$ and $C$ infections are considered to represent contraindications. ${ }^{87}$

Rheumatology guidelines consider pulmonary diseases, especially interstitial lung diseases of unknown cause, to represent contraindications, ${ }^{87}$ as pre-existing lung disease may be a risk factor for the development of MTX-induced pneumonitis. ${ }^{79}$ In sarcoidosis, however, the main reasons for MTX prescription are pulmonary disease and respiratory functional impairment, which can be successfully treated with MTX. The presence of pulmonary disease in sarcoidosis as such is therefore not considered a contraindication to treatment with MTX, which is also reflected in the very low percentage of sarcoidologists $(20 \%)$ considering pulmonary disease a contraindication (Table 6.2). Figure 6.1 shows an example of substantial improvement of parenchymal pulmonary lesions from sarcoidosis after treatment with MTX. ${ }^{102}$ In cases of suspected or confirmed other pulmonary disease, such as acute or chronic infections, however, MTX should be considered contraindicated (based on expert opinion).

\section{Recommendation 6}

When starting MTX or increasing the dose, ALT with or without AST, creatinine and CBC should be monitored every 3-6 weeks until a stable dose is reached, and every 1-3 months thereafter; after stabilization the monitoring interval can be extended to every 6 months.

No studies evaluating the frequency of monitoring have been done for sarcoidosis, and the recommended frequency of monitoring in RA is largely based on expert opinion. ${ }^{87}$ The limited available evidence suggests an optimal interval to detect liver 
test abnormalities of 30-60 days and a decreasing incidence of MTX-induced liver damage in the first months of therapy. ${ }^{64} \mathrm{~A}$ total of $60 \%$ of the sarcoidosis experts suggested a monitoring interval of 2-6 weeks, whereas $95 \%$ suggested an interval of $1-$ 3 months after a stable dosage has been reached (Table 6.2).
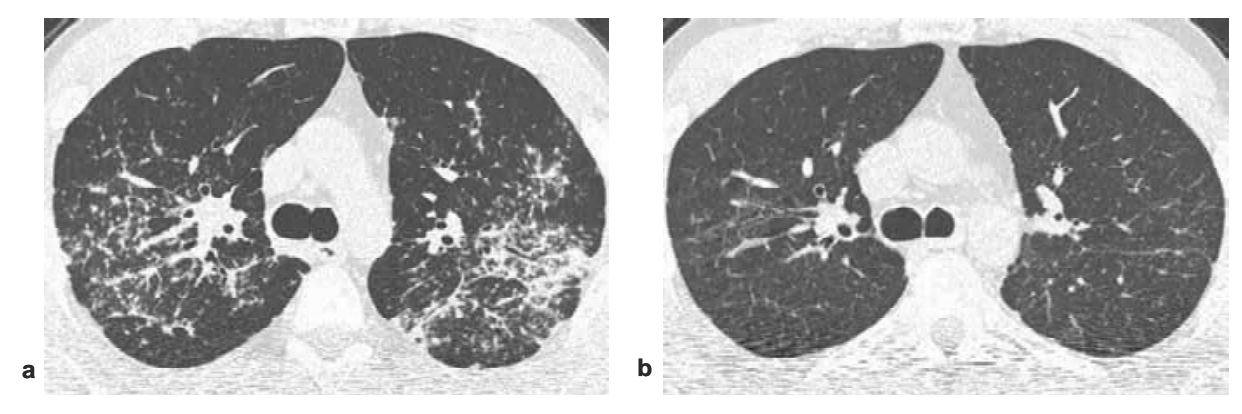

Figure 6.1 High-resolution computed tomography (HRCT) studies from a 36-year-old man with a history of 5 years of biopsy-proven sarcoidosis. Because of respiratory functional impairment, he had been previously treated with prednisone, starting at $40 \mathrm{mg}$ daily. This was tapered off because of side-effects to $20 \mathrm{mg}$ daily. No improvement was achieved, so treatment with methotrexate (MTX) was started. a. HRCT before treatment with MTX, showing multiple intraparenchymal nodules, focal pleural thickening, septal and nonseptal lines, and thickening or irregularity of the bronchovascular bundle. ${ }^{102}$ b. HRCT after 6 months of treatment with $12.5 \mathrm{mg}$ MTX weekly and $5 \mathrm{mg}$ folic acid once a week orally, together with $10 \mathrm{mg}$ prednisone daily, showing substantial improvement.

AST and ALT have been reported to correlate with the histological grades of liver disease in RA. ${ }^{64,103-107}$ Creatinine should also be monitored, as renal dysfunction is associated with increased risk of pulmonary toxicity. $A C B C$ is required to monitor bone marrow toxicity. ${ }^{64,78} \mathrm{~A}$ baseline WBC count at the time of starting or increasing the dosage of MTX may be helpful to determine the follow-up interval for CBC: if baseline WBC count is low, a follow-up $C B C$ should be performed at shorter intervals than with higher WBC count at baseline.

The 2008 ACR guidelines suggest monitoring every 1-3 months, with more frequent assessments initially. ${ }^{87}$ As evidence regarding monitoring frequency in sarcoidosis is lacking, we have combined the recommendations extrapolated from RA with expert opinion to recommend a monitoring frequency of 3-6 weeks until a stable dose is reached and every 1-3 months thereafter. After stabilization, the monitoring interval can be extended to 6 months. Despite the observations that MTX hepatotoxicity is rarer in RA than in sarcoidosis, which can probably be explained by the underlying liver disease from the sarcoidosis itself, $28,83,84,101,107,108$ we recommend a similar frequency pattern of liver testing in sarcoidosis. Severe liver disease as a result of MTX in sarcoidosis is rare. ${ }^{101}$ 


\section{Recommendation 7}

In case of MTX-induced gastrointestinal side-effects, including mucositis, splitting the oral dose should be considered, provided the total MTX dose is ingested within a 12-h period. Parenteral administration or an alternative immunosuppressive drug should be considered in case of persistent intolerance.

No studies are available comparing different administration modes in sarcoidosis. Recommendations for RA patients indicate a preference for the oral route when starting MTX treatment. ${ }^{64,109}$ The bioavailability of MTX at higher oral doses (25-35 mg weekly) is decreased in RA patients, most probably because of limited absorption from the gastrointestinal tract, and can be improved by splitting the oral dose. ${ }^{110,111}$ No studies are available investigating the effectiveness of splitting the oral dose in terms of reducing the gastrointestinal side-effects. Almost half of the sarcoidosis experts in our survey, however, reported using splitting of the oral dose with ingestion of the total dose within a 12-h period as an alternative administration option in case of MTXinduced gastrointestinal side-effects (Table 6.2); they reported regularly observing the disappearance of inconvenient symptoms.

Retrospective studies in RA suggest higher efficacy and less gastrointestinal toxicity with parenteral versus oral administration of MTX, which can be explained by a higher bioavailability of the parenteral form. ${ }^{112-114}$ The efficacy and safety of routes of administration were evaluated in open-label studies, which found a significant reduction in disease activity scores following the switch from oral to parenteral administration. ${ }^{109,115,116}$ This leads to a recommendation for RA patients to switch to subcutaneous or intramuscular administration in case of gastrointestinal side-effects, poor compliance or inadequate effectiveness. ${ }^{109}$ The variable bioavailability of high oral MTX dosages forms another argument to consider changing to parenteral administration. ${ }^{114}$ Almost half of the sarcoidologists in our survey reported prescribing parenteral MTX as an alternative administration route in case of MTX-induced gastrointestinal side-effects (Table 6.2).

As evidence regarding the best administration routes of MTX in sarcoidosis is lacking, evidence extrapolated from RA, combined with expert opinion, resulted in the recommendation to split the oral dose, changing to parenteral administration routes or considering an alternative immunosuppressive drug in case of gastrointestinal intolerance.

\section{Recommendation 8}

Caution is warranted if there is a confirmed increase in ALT/AST. If there are no other causes, it should lead to either MTX dose reduction or withdrawal, liver biopsy to evaluate for MTX toxicity or additional folic acid supplementation; consider an alternative immunosuppressive drug after normalization.

Sarcoidosis commonly affects the liver ${ }^{97,99-101}$ and liver test abnormalities during MTX use may thus be due to the underlying sarcoidosis, but also due to MTX use or 
some other cause. ${ }^{101}$ Studies among RA patients have found a relatively low rate of MTX hepatotoxicity, with a reported 3-5\% incidence of advanced pathological changes on liver biopsy. ${ }^{83,84,107,108}$ Studies found that only patients with persistently elevated transaminase levels or decreased albumin levels had a toxic reaction to MTX. ${ }^{103-107}$ Therefore, RA guidelines rely on the use of serial liver function testing to identify patients with a toxic reaction to MTX. ${ }^{64}$ Studies amongst sarcoidosis patients found a 9\% incidence rate of MTX-associated toxic effects established by liver biopsy after 1 year of MTX therapy and a 14\% incidence rate after 2 years of therapy. ${ }^{28,101}$ However, no sarcoidosis patients were reported to have severe liver disease as a result of MTX therapy. ${ }^{101}$ The higher incidence of hepatotoxicity in sarcoidosis compared to RA may be because of the underlying liver disease from the sarcoidosis itself. ${ }^{28,101}$ As half of the patients showed changes in their liver biopsy results that were attributed to sarcoidosis, the associated inflammatory and fibrotic changes may overlap with the changes seen in toxic reactions to MTX and could therefore have led to overestimation of MTX toxicity. ${ }^{101}$ In sarcoidosis, the ALP level at the time of biopsy ${ }^{28,101}$ and the number of times the AST was elevated in the year before the biopsy ${ }^{101}$ correlated with the severity of the toxic effect of MTX. However, patients with hepatic sarcoidosis showed higher levels of various liver tests as well. ${ }^{28,101}$ Therefore, the absolute liver test results or the number of abnormal tests are not clinically useful for predicting either liver sarcoid involvement or MTX hepatotoxicity. ${ }^{28,101}$ Nevertheless, as serial liver testing is a noninvasive safe way to trace liver disease including MTX toxicity, it is recommended for sarcoidosis patients on MTX therapy. Baughman et al. ${ }^{101}$ also claimed an important role for liver biopsy in screening for toxic reactions.

Studies investigating how to deal with the liver test abnormalities in sarcoidosis patients using MTX, or the level of liver test abnormalities at which MTX should be discontinued, have been scarce. Forty-six per cent of the sarcoidologists in our survey reported discontinuing MTX when liver test results exceeded the level of 3 times the upper limit of normal (ULN), whereas the remaining experts reported that they discontinued MTX at liver test results more than 2 times the ULN or more than 4 times the ULN (Table 6.2). Studies in RA recommended MTX withdrawal if there is a confirmed increase in ALT/AST of more than 3 times the ULN. ${ }^{64}$ The majority of sarcoidologists reported discontinuing or decreasing the dosage of MTX when liver test results exceed the level of 4 times the ULN, after checking for other causes of liver test abnormalities, such as alcohol or nonsteroidal anti-inflammatory drugs use (Table 6.2). Checking for other causes is important, as, for example, RA patients on MTX treatment who are heavy drinkers are more likely to show advanced changes on liver biopsy. ${ }^{108}$ Rheumatology experts emphasize that other causal factors, including nonsteroidal antiinflammatory drugs, obesity with nonalcoholic steatohepatitis and alcohol, should be considered in case of persistently elevated liver tests after discontinuation of MTX. ${ }^{64}$ Only $10 \%$ of the sarcoidosis experts reported that they first increased the dosage of folic acid to decrease the hepatotoxic effects of MTX (Table 6.2). However, no literature is available on the value of raising the folic acid dosage when liver test abnormalities 
increase during MTX use. Expert opinion, however, suggests some beneficial effects. Furthermore, the sarcoidologists did not agree with the recommendation by rheumatology experts to reinstitute MTX at a lower dose following normalization of liver tests, ${ }^{64}$ but suggested considering an alternative immunosuppressive drug after normalization.

As there is no definite evidence regarding how to deal with an increase in liver test abnormalities during MTX treatment of sarcoidosis patients, we combined recommendations extrapolated from RA with sarcoidosis expert opinion to formulate recommendation 8 .

\section{Recommendation 9}

Based on its acceptable safety profile, MTX is appropriate for long-term use.

There have been no studies with long-term follow-up data to conclusively determine the long-term safety profile of MTX for sarcoidosis patients. Adverse effects because of MTX are listed in Appendix 1. As described above, gastrointestinal and liver toxicity were most frequently reported by the sarcoidologists as the reason to discontinue MTX, which was necessary in $10 \%$ of cases. However, Baughman et al. and Vucinic reported lower discontinuation rates of $0-4 \% .{ }^{23,24}$ Sixty-eight per cent of the experienced sarcoidologists reported continuing MTX unaltered in the long term (Table 6.2). Compared with AZA, MTX has comparable side-effects in sarcoidosis patients, except for a higher infection rate during AZA use. ${ }^{22}$ Leflunomide has been proposed to have a more favourable safety profile compared with $\mathrm{MTX}^{117,118}$ but studies directly comparing MTX and leflunomide are lacking.

A large 6-year study found that RA patients on MTX had a lower mortality rate and reduced cardiovascular mortality. ${ }^{64,119}$ Furthermore, discontinuation of MTX because of toxicity in RA patients is unusual ${ }^{120}$ and MTX is less frequently discontinued than other disease-modifying antirheumatic drugs. ${ }^{64,121}$ Long-term MTX use by RA patients was not associated with an increased risk of serious infections. ${ }^{64,122}$ Whether MTX in RA patients is associated with a low risk of developing lymphoma has not been fully elucidated. ${ }^{64,123,124}$

Despite the limited available evidence, the overall safety profile of MTX in the short term seems to be acceptable. As studies to determine the long-term safety profile of MTX in sarcoidosis patients are lacking, we surmise that the safety profile will be reasonably similar to that found for RA patients.

\section{Recommendation 10}

MTX should not be used by men or women for at least 3 months before planned pregnancy, and should not be used during pregnancy or breast feeding labsolute contraindication).

No studies are available assessing the outcome of continued MTX therapy before or during pregnancy in sarcoidosis patients. A total of $99 \%$ of the experts in our survey 
asked female patients whether they had a pregnancy wish, and $71 \%$ did so with male patients. A total of $99 \%$ discontinued MTX if female patients wanted to become pregnant and $70 \%$ did the same for male patients (Table 6.2).

Six studies amongst RA patients assessed the outcome of continued MTX therapy before or during pregnancy $(n=101)$ : they reported $24 \%$ miscarriages and $6 \%$ congenital malformations, ${ }^{64,125-130}$ whereas lower percentages of miscarriages and congenital malformations were found in healthy women not using MTX. ${ }^{131}$ No studies amongst RA patients have evaluated the effect of MTX use by men on pregnancy or fertility. Nevertheless, the recommendation for both male and female RA patients is to discontinue MTX at least 3 months before planned pregnancy. ${ }^{64}$ For sarcoidosis patients, similar incompatibility of MTX with planned or actual pregnancy and breast feeding is indisputable, so MTX should be discontinued by both men and women at least 3 months before planned pregnancy, and should not be used during pregnancy or breast feeding.

\section{Conclusion}

Ten multinational WASOG recommendations for the practical use of MTX in sarcoidosis were developed by integrating evidence from both a systematic literature search and the expert opinions of sarcoidologists worldwide, and were shown by an evaluation study to be supported by all leading sarcoidosis experts.

This is the first study addressing evidence-based recommendations for the optimized use of MTX in sarcoidosis. A unique feature was the involvement of 113 sarcoidosis experts from all over the world in the development of the recommendations, which allowed approaches to frequently encountered issues on the use of MTX in sarcoidosis in daily practice to be collected. The broad range of participants, involving all the leading international sarcoidosis experts, should enhance the implementation of these recommendations in sarcoidosis practice worldwide.

Our systematic literature search showed that RCT evidence supporting the use of MTX in sarcoidosis was very limited. Most of the published data were derived from observational case series, some of them including a large number of patients but most including only a small sample. A Cochrane review on DMASDs in pulmonary sarcoidosis found no data on MTX available for meta-analysis. ${ }^{7}$ Furthermore, no long-term followup data were available, which is actually crucial in determining the long-term benefits, given the recurring nature of sarcoidosis. For most aspects, little or no evidence was found specifically relating to sarcoidosis, which limits the strength of the proposed recommendations. On the other hand, evidence on these aspects in RA was available from several RCTs and high-quality cohort studies. We extrapolated evidence from these studies to help develop the recommendations for MTX in sarcoidosis, especially where data for sarcoidosis were lacking. As the clinical problems encountered in sarcoidosis show many similarities with those in RA, lessons learned from the use of MTX in RA are extremely valuable. Nevertheless, certain scenarios and clinical 
challenges are unique to sarcoidosis, and should be considered separate from the evidence gained amongst RA patients. It is especially in these cases, therefore, that the expert opinion of sarcoidologists from all over the world was important. Moreover, the world's leading sarcoidosis experts reported a high level of agreement with the proposed recommendations, which strengthens their value.

Optimization of treatment with MTX and other glucocorticosteroid-sparing immunomodulators in sarcoidosis is important to avoid overprescription of more expensive treatment modalities, such as TNF- $\alpha$ inhibitors. Optimized utilization of less expensive, but effective treatment modalities is important to keep the healthcare system affordable. MTX has proved to be the cornerstone of therapy in many immunemediated diseases, ${ }^{15,16}$ and a survey found that $80 \%$ of physicians reported MTX to be their preferred second-line treatment option for sarcoidosis. ${ }^{13,14}$ Therefore, the proposed evidence-based recommendations may serve to help optimize the prescription of MTX in clinical practice. We think these recommendations will be useful for both experienced and less experienced MTX prescribers.

As studies investigating the use of MTX in sarcoidosis have been scarce, there is a need for RCTs looking into the effect of MTX on various well defined outcome measures in sarcoidosis with a reasonable duration of follow-up. In addition, side-effects and safety must be well documented. When patients fail to respond to MTX or develop severe toxicity symptoms necessitating MTX withdrawal, alternative treatment options such as AZA $^{22}$, leflunomide ${ }^{118}$ or biologicals ${ }^{10}$ should be considered. However, specific guidelines for these treatment modalities are currently lacking. Future research should focus on establishing useful recommendations in clinical practice for these therapeutics as well.

In conclusion, we developed multinational WASOG recommendations for the use of MTX amongst sarcoidosis patients in routine clinical practice, by combining a systematic literature search with expert opinion, with the aim of promoting both evidence-based and patient-based medicine.

\section{Mobile application}

A mobile application (app) was developed for smartphone or tablet with the recommendations and useful clinical sarcoidosis cases. The app 'MTX in sarcoidosis' can be downloaded for free from the Apple Store or Google Play Store (Appendix 2).

\section{Acknowledgements}

The efforts of the sarcoidosis experts who participated in this study by completing the questionnaires are greatly appreciated. This study was supported by an educational grant from the ild care foundation and TEVA The Netherlands. 


\section{References}

1. Hunninghake GW, Costabel U, Ando M, Baughman R, Cordier JF, du Bois R, Eklund A, Kitaichi M, Lynch J, Rizzato G, Rose C, Selroos O, Semenzato G, Sharma OP. ATS/ERS/WASOG statement on sarcoidosis. American Thoracic Society/European Respiratory Society/World Association of Sarcoidosis and other Granulomatous Disorders. Sarcoidosis Vasc Diffuse Lung Dis 1999;16:149-173.

2. Iannuzzi MC, Fontana JR. Sarcoidosis: clinical presentation, immunopathogenesis, and therapeutics. JAMA 2011;305:391-399.

3. Baughman RP, Teirstein AS, Judson MA, Rossman MD, Yeager H, Jr., Bresnitz EA, DePalo L, Hunninghake G, lannuzzi MC, Johns CJ, McLennan G, Moller DR, Newman LS, Rabin DL, Rose C, Rybicki B, Weinberger $\mathrm{SE}$, Terrin ML, Knatterud GL, Cherniak R. Clinical characteristics of patients in a case control study of sarcoidosis. Am J Respir Crit Care Med 2001;164:1885-1889.

4. Paramothayan NS, Lasserson TJ, Jones PW. Corticosteroids for pulmonary sarcoidosis. Cochrane Database Syst Rev 2005:CD001114.

5. Grutters JC, Van den Bosch JM. Corticosteroid treatment in sarcoidosis. Eur Respir J 2006;28:627-636.

6. Paramothayan S, Lasserson T. Treatments for pulmonary sarcoidosis. Respir Med 2008;102:1-9.

7. Paramothayan S, Lasserson TJ, Walters EH. Immunosuppressive and cytotoxic therapy for pulmonary sarcoidosis. Cochrane Database Syst Rev 2006:CD003536.

8. Lazar CA, Culver DA. Treatment of sarcoidosis. Semin Respir Crit Care Med 2010;31:501-518.

9. Baughman RP, Nunes H, Sweiss NJ, Lower EE. Established and experimental medical therapy of pulmonary sarcoidosis. Eur Respir J 2013;41:1424-1438.

10. Baughman RP, Drent M, Kavuru M, Judson MA, Costabel U, du Bois R, Albera C, Brutsche M, Davis G, Donohue JF, Muller-Quernheim J, Schlenker-Herceg R, Flavin S, Lo KH, Oemar B, Barnathan ES. Infliximab therapy in patients with chronic sarcoidosis and pulmonary involvement. Am J Respir Crit Care Med 2006;174:795-802.

11. Judson MA, Baughman RP, Costabel U, Flavin S, Lo KH, Kavuru MS, Drent M. Efficacy of infliximab in extrapulmonary sarcoidosis: results from a randomised trial. Eur Respir J 2008;31:1189-1196.

12. Liu Y, Wu EQ, Bensimon AG, Fan CP, Bao Y, Ganguli A, Yang M, Cifaldi M, Mulani P. Cost per responder associated with biologic therapies for Crohn's disease, psoriasis, and rheumatoid arthritis. Adv Ther 2012;29:620-634.

13. Baughman RP, Nunes H. Therapy for sarcoidosis: evidence-based recommendations. Expert Rev Clin Immunol 2012;8:95-103.

14. Schutt AC, Bullington WM, Judson MA. Pharmacotherapy for pulmonary sarcoidosis: a Delphi consensus study. Respir Med 2010;104:717-723.

15. Suarez-Almazor ME, Belseck E, Shea B, Wells G, Tugwell P. Methotrexate for rheumatoid arthritis. Cochrane Database Syst Rev 2000:CD000957.

16. Gordon PA, Winer JB, Hoogendijk JE, Choy EH. Immunosuppressant and immunomodulatory treatment for dermatomyositis and polymyositis. Cochrane Database Syst Rev 2012;8:CD003643.

17. Chan ES, Cronstein BN. Methotrexate--how does it really work? Nat Rev Rheumatol 2010;6:175-178.

18. Barnes PJ. Corticosteroid resistance in patients with asthma and chronic obstructive pulmonary disease. J Allergy Clin Immunol 2013;131:636-645.

19. Oxford Centre for Evidence-Based Medicine. Levels of evidence (March 2009). http://wwwcebmnet/ indexaspx?o=1025.

20. Roddy E, Zhang W, Doherty M, Arden NK, Barlow J, Birrell F, Carr A, Chakravarty K, Dickson J, Hay E, Hosie G, Hurley M, Jordan KM, McCarthy C, McMurdo M, Mockett S, O'Reilly S, Peat G, Pendleton A, Richards S. Evidence-based clinical guidelines: a new system to better determine true strength of recommendation. J Eval Clin Pract 2006;12:347-352.

21. Baughman RP, Winget DB, Lower EE. Methotrexate is steroid sparing in acute sarcoidosis: results of a double blind, randomized trial. Sarcoidosis Vasc Diffuse Lung Dis 2000;17:60-66.

22. Vorselaars AD, Wuyts WA, Vorselaars VM, Zanen $P$, Deneer VH, Veltkamp M, Thomeer M, Van Moorsel $\mathrm{CH}$, Grutters JC. Methotrexate versus azathioprine in second line therapy of sarcoidosis. Chest 2013;144:805-812.

23. Baughman RP, Lower EE, Ingledue R, Kaufman AH. Management of ocular sarcoidosis. Sarcoidosis Vasc Diffuse Lung Dis 2012;29:26-33. 
24. Vucinic VM. What is the future of methotrexate in sarcoidosis? A study and review. Curr Opin Pulm Med 2002;8:470-476.

25. Zeitlin JF, Tami TA, Baughman R, Winget D. Nasal and sinus manifestations of sarcoidosis. Am J Rhinol 2000;14:157-161.

26. Dev S, McCallum RM, Jaffe GJ. Methotrexate treatment for sarcoid-associated panuveitis. Ophthalmology 1999;106:111-118.

27. Lower EE, Broderick JP, Brott TG, Baughman RP. Diagnosis and management of neurological sarcoidosis. Arch Intern Med 1997;157:1864-1868.

28. Lower EE, Baughman RP. Prolonged use of methotrexate for sarcoidosis. Arch Intern Med 1995; 155:846-851.

29. Baughman RP, Lower EE. The effect of corticosteroid or methotrexate therapy on lung lymphocytes and macrophages in sarcoidosis. Am Rev Respir Dis 1990;142:1268-1271.

30. Lower EE, Baughman RP. The use of low dose methotrexate in refractory sarcoidosis. Am J Med Sci 1990;299:153-157.

31. Veien NK, Brodthagen H. Cutaneous sarcoidosis treated with methotrexate. Br J Dermatol 1977;97: 213-216.

32. Sakellariou GT, Anastasilakis AD, Karanikolas D, Vounotrypidis P, Berberidis C. Central skeletal sarcoidosis: a case report with sustained remission only on methotrexate, and a literature review on the imaging approach, treatment, and assessment of disease activity. Mod Rheumatol 2013;23: 175-181.

33. Alemdaroglu E, Erturk A, Eroglu AG. A sarcoidosis patient with hand involvement and large pulmonary lymph nodes: results of 1-year treatment with methotrexate. Clin Rheumatol 2013;32(suppl):S71-73.

34. Bouaziz A, Le Scanff J, Chapelon-Abric C, Varron L, Khenifer S, Gleizal A, Bentz MH, Barthel A, Valeyre D, Seve P. Oral involvement in sarcoidosis: report of 12 cases. Qjm 2012;105:755-767.

35. Delmonte L, Zamo A, Cantini M, De Franceschi L. An unusual case of sarcoidosis in an adult patient with sickle cell disease: Management with methotrexate and low dose of steroid. Am J Hematol 2012; $88: 243$.

36. Sakushima K, Yabe I, Nakano F, Yoshida K, Tajima Y, Houzen H, Maruo Y, Sasaki H. Clinical features of spinal cord sarcoidosis: analysis of 17 neurosarcoidosis patients. J Neurol 2011;258:2163-2167.

37. Bargagli E, Olivieri C, Penza F, Bertelli P, Gonnelli S, Volterrani L, Rottoli P. Rare localizations of bone sarcoidosis: two case reports and review of the literature. Rheumatol Int 2011;31:1503-1506.

38. Gautam M, Patil S, Munde P. Skin as a marker of internal disease: a case of sarcoidosis. Indian J Dermatol 2011;56:439-441.

39. Lambert L, Riemer EC, Judson MA. Rapid development of sarcoid tenosynovitis. J Clin Rheumatol 2011;17:201-203.

40. Kimball MM, Wind JJ, Codispoti KE, Jones RV, Leiphart JW. Neurosarcoidosis presenting as an isolated intrasellar mass: case report and review of the literature. Clin Neuropathol 2010;29:156-162.

41. Kalajian AH, Van Meter JR, Callen JP. Sarcoidal anemia and leukopenia treated with methotrexate and mycophenolate mofetil. Arch Dermatol 2009;145:905-909.

42. Mannam P, Boselli JM, Schulman ES. Successful treatment of chylous ascites secondary to sarcoidosis with methotrexate. Hosp Pract (Minneap) 2009;37:144-146.

43. Varron L, Broussolle C, Candessanche JP, Marignier R, Rousset H, Ninet J, Seve P. Spinal cord sarcoidosis: report of seven cases. Eur J Neurol 2009;16:289-296.

44. Suarez Zambrano GA, Hutton GJ. Heart-shaped lesion secondary to neurosarcoidosis. Arch Neurol 2008;65:1388-1389.

45. Morgan SS, Aslam MB, Mukkanna KS, Ampat G. A rare presentation of sarcoidosis, back pain and spondylolisthesis. J Bone Joint Surg Br 2008;90:240-242.

46. Bradley DA, Lower EE, Baughman RP. Diagnosis and management of spinal cord sarcoidosis. Sarcoidosis Vasc Diffuse Lung Dis 2006;23:58-65.

47. Kennedy PT, Zakaria N, Modawi SB, Papadopoulou AM, Murray-Lyon I, du Bois RM, Jervoise NAH, Devlin J. Natural history of hepatic sarcoidosis and its response to treatment. Eur J Gastroenterol Hepatol 2006;18:721-726.

48. Chong WS, Tan HH, Tan SH. Cutaneous sarcoidosis in Asians: a report of 25 patients from Singapore. Clin Exp Dermatol 2005;30:120-124. 
49. Gardner GC, Hunter JC. Clinical images: Radiographic healing of osseous sarcoidosis. Arthritis Rheum 2005;52:2225.

50. Braun JJ, Gentine A, Pauli G. Sinonasal sarcoidosis: review and report of fifteen cases. Laryngoscope 2004;114:1960-1963.

51. Maust HA, Foroozan R, Sergott RC, Niazi S, Weibel S, Savino PJ. Use of methotrexate in sarcoidassociated optic neuropathy. Ophthalmology 2003;110:559-563.

52. Moin M, Kersten RC, Bernardini F, Kulwin DR. Destructive eyelid lesions in sarcoidosis. Ophthal Plast Reconstr Surg 2001;17:123-125.

53. Scola RH, Werneck LC, Prevedello DM, Greboge P, Iwamoto FM. Symptomatic muscle involvement in neurosarcoidosis: a clinicopathological study of 5 cases. Arq Neuropsiquiatr 2001;59:347-352.

54. Diri E, Espinoza CG, Espinoza LR. Spinal cord granulomatous vasculitis: an unusual clinical presentation of sarcoidosis. J Rheumatol 1999;26:1408-1410.

55. Mana J, Gomez-Vaquero C, Dorca J, Pujol R. Vertebral and rib sarcoidosis: long-term clinical remission with methotrexate. Clin Rheumatol 1999;18:492-494.

56. Gedalia A, Molina JF, Ellis GS, Jr., Galen W, Moore C, Espinoza LR. Low-dose methotrexate therapy for childhood sarcoidosis. J Pediatr 1997;130:25-29.

57. Kaye O, Palazzo E, Grossin M, Bourgeois P, Kahn MF, Malaise MG. Low-dose methotrexate: an effective corticosteroid-sparing agent in the musculoskeletal manifestations of sarcoidosis. $\mathrm{Br} J$ Rheumatol 1995;34:642-644.

58. Henderson CA, Ilchyshyn A, Curry AR. Laryngeal and cutaneous sarcoidosis treated with methotrexate. $J$ $R$ Soc Med 1994;87:632-633.

59. Suda T, Sato A, Toyoshima M, Imokawa S, Yoshitomi A, Tamura R, Suganuma H, Yagi T, Hayakawa H, Shirai M, Chida K. Weekly low-dose methotrexate therapy for sarcoidosis. Intern Med 1994;33:437-440.

60. Webster GF, Razsi LK, Sanchez M, Shupack JL. Weekly low-dose methotrexate therapy for cutaneous sarcoidosis. J Am Acad Dermatol 1991;24:451-454.

61. Soriano FG, Caramelli P, Nitrini R, Rocha AS. Neurosarcoidosis: therapeutic success with methotrexate. Postgrad Med J 1990;66:142-143.

62. Webster GF, Razsi LK, Sanchez M, Shupack JR. Methotrexate therapy in cutaneous sarcoidosis. Ann Intern Med 1989;111:538-539.

63. Lacher MJ. Spontaneous remission or response to methotrexate in sarcoidosis. Ann Intern Med 1968;69:1247-1248.

64. Visser K, Katchamart W, Loza E, Martinez-Lopez JA, Salliot C, Trudeau J, Bombardier C, Carmona L, Van der Heijde D, Bijlsma JW, Boumpas DT, Canhao H, Edwards CJ, Hamuryudan V, Kvien TK, Leeb BF, Martin-Mola EM, Mielants H, Muller-Ladner U, Murphy G, Ostergaard M, Pereira IA, Ramos-Remus C, Valentini G, Zochling J, Dougados M. Multinational evidence-based recommendations for the use of methotrexate in rheumatic disorders with a focus on rheumatoid arthritis: integrating systematic literature research and expert opinion of a broad international panel of rheumatologists in the $3 \mathrm{E}$ Initiative. Ann Rheum Dis 2009;68:1086-1093.

65. Hoitsma E, Faber CG, Drent M, Sharma OP. Neurosarcoidosis: a clinical dilemma. Lancet Neurol 2004;3:397-407.

66. Baughman RP, Ohmichi M, Lower EE. Combination therapy for sarcoidosis. Sarcoidosis Vasc Diffuse Lung Dis 2001;18:133-137.

67. Browne PM, Sharma OP, Salkin D. Bone marrow sarcoidosis. Jama 1978;240:2654-2655.

68. Lower EE, Smith JT, Martelo OJ, Baughman RP. The anemia of sarcoidosis. Sarcoidosis 1988;5:51-55.

69. Furst DE, Koehnke R, Burmeister LF, Kohler J, Cargill I. Increasing methotrexate effect with increasing dose in the treatment of resistant rheumatoid arthritis. J Rheumatol 1989;16:313-320.

70. Schnabel A, Reinhold-Keller E, Willmann V, Gross WL. Tolerability of methotrexate starting with 15 or $25 \mathrm{mg} /$ week for rheumatoid arthritis. Rheumatol Int 1994;14:33-38.

71. Verstappen SM, Jacobs JW, Van der Veen MJ, Heurkens AH, Schenk Y, ter Borg EJ, Blaauw AA, Bijlsma JW. Intensive treatment with methotrexate in early rheumatoid arthritis: aiming for remission. Computer Assisted Management in Early Rheumatoid Arthritis (CAMERA, an open-label strategy trial). Ann Rheum Dis 2007;66:1443-1449.

72. Shea B, Swinden MV, Tanjong Ghogomu E, Ortiz Z, Katchamart W, Rader T, Bombardier C, Wells GA, Tugwell P. Folic acid and folinic acid for reducing side effects in patients receiving methotrexate for rheumatoid arthritis. Cochrane Database Syst Rev 2013; 5:CD000951. 
73. Van Ede AE, Laan RF, Rood MJ, Huizinga TW, Van de Laar MA, Van Denderen CJ, Westgeest TA, Romme TC, De Rooij DJ, Jacobs MJ, De Boo TM, Van der Wilt GJ, Severens JL, Hartman M, Krabbe PF, Dijkmans BA, Breedveld FC, Van de Putte LB. Effect of folic or folinic acid supplementation on the toxicity and efficacy of methotrexate in rheumatoid arthritis: a forty-eight week, multicenter, randomized, doubleblind, placebo-controlled study. Arthritis Rheum 2001;44:1515-1524.

74. Morgan SL, Baggott JE, Vaughn WH, Austin JS, Veitch TA, Lee JY, Koopman WJ, Krumdieck CL, Alarcon GS. Supplementation with folic acid during methotrexate therapy for rheumatoid arthritis. A doubleblind, placebo-controlled trial. Ann Intern Med 1994;121:833-841.

75. Morgan SL, Baggott JE, Vaughn WH, Young PK, Austin JV, Krumdieck CL, Alarcon GS. The effect of folic acid supplementation on the toxicity of low-dose methotrexate in patients with rheumatoid arthritis. Arthritis Rheum 1990;33:9-18.

76. Griffith SM, Fisher J, Clarke S, Montgomery B, Jones PW, Saklatvala J, Dawes PT, Shadforth MF, Hothersall TE, Hassell AB, Hay EM. Do patients with rheumatoid arthritis established on methotrexate and folic acid $5 \mathrm{mg}$ daily need to continue folic acid supplements long term? Rheumatology (Oxford) 2000;39:1102-1109.

77. Prey S, Paul C. Effect of folic or folinic acid supplementation on methotrexate-associated safety and efficacy in inflammatory disease: a systematic review. Br J Dermatol 2009;160:622-628.

78. The effect of age and renal function on the efficacy and toxicity of methotrexate in rheumatoid arthritis. Rheumatoid Arthritis Clinical Trial Archive Group. J Rheumatol 1995;22:218-223.

79. Golden MR, Katz RS, Balk RA, Golden HE. The relationship of preexisting lung disease to the development of methotrexate pneumonitis in patients with rheumatoid arthritis. I Rheumatol 1995;22:1043-1047.

80. Cottin V, Tebib J, Massonnet B, Souquet PJ, Bernard JP. Pulmonary function in patients receiving longterm low-dose methotrexate. Chest 1996;109:933-938.

81. Beyeler C, Jordi B, Gerber NJ, Im Hof V. Pulmonary function in rheumatoid arthritis treated with lowdose methotrexate: a longitudinal study. Br J Rheumatol 1996;35:446-452.

82. Hagiyama H, Kubota T, Komano $\mathrm{Y}$, Kurosaki M, Watanabe M, Miyasaka N. Fulminant hepatitis in an asymptomatic chronic carrier of hepatitis B virus mutant after withdrawal of low-dose methotrexate therapy for rheumatoid arthritis. Clin Exp Rheumatol 2004;22:375-376.

83. Shergy WJ, Polisson RP, Caldwell DS, Rice JR, Pisetsky DS, Allen NB. Methotrexate-associated hepatotoxicity: retrospective analysis of 210 patients with rheumatoid arthritis. Am J Med 1988;85:771774.

84. Phillips CA, Cera PJ, Mangan TF, Newman ED. Clinical liver disease in patients with rheumatoid arthritis taking methotrexate. J Rheumatol 1992;19:229-233.

85. Minocha A, Dean HA, Pittsley RA. Liver cirrhosis in rheumatoid arthritis patients treated with long-term methotrexate. Vet Hum Toxicol 1993;35:45-48.

86. Le Boedec M, Marhadour T, Devauchelle-Pensec V, Jousse-Joulin S, Binard A, Fautrel B, Marc Flipo R, Le Loet X, Francois Menard J, Saraux A. Baseline laboratory test abnormalities are common in early arthritis but rarely contraindicate methotrexate: Study of three cohorts (ESPOIR, VErA, and Brittany). Semin Arthritis Rheum 2013;42:474-481.

87. Saag KG, Teng GG, Patkar NM, Anuntiyo J, Finney C, Curtis JR, Paulus HE, Mudano A, Pisu M, ElkinsMelton M, Outman R, Allison JJ, Suarez Almazor M, Bridges SL, Jr., Chatham WW, Hochberg M, MacLean C, Mikuls T, Moreland LW, O'Dell J, Turkiewicz AM, Furst DE. American College of Rheumatology 2008 recommendations for the use of nonbiologic and biologic disease-modifying antirheumatic drugs in rheumatoid arthritis. Arthritis Rheum 2008;59:762-784.

88. Guidelines for monitoring drug therapy in rheumatoid arthritis. American College of Rheumatology Ad Hoc Committee on Clinical Guidelines. Arthritis Rheum 1996;39:723-731.

89. Rubbert-Roth A. Assessing the safety of biologic agents in patients with rheumatoid arthritis. Rheumatology (Oxford) 2012;51 Suppl 5:v38-47.

90. Vadillo Font C, Hernandez-Garcia C, Pato E, Morado IC, Salido M, Judez E, Macarron P, FernandezGutierrez B, Abasolo L, Jover JA. [Incidence and characteristics of tuberculosis in patients with autoimmune rheumatic diseases]. Rev Clin Esp 2003;203:178-182.

91. Bogas M, Machado P, Mourao AF, Costa L, Santos MJ, Fonseca JE, Silva JA, Canhao H. Methotrexate treatment in rheumatoid arthritis: management in clinical remission, common infection and tuberculosis. Results from a systematic literature review. Clin Rheumatol 2010;29:629-635. 
92. Maejima H, Watarai A, Nakano T, Katayama C, Nishiyama H, Katsuoka K. Adverse effects of methotrexate in three psoriatic arthritis patients. Rheumatol Int 2012; Epub ahead of print.

93. Gupta D, Kumar S, Aggarwal AN, Verma I, Agarwal R. Interferon gamma release assay (QuantiFERON-TB Gold In Tube) in patients of sarcoidosis from a population with high prevalence of tuberculosis infection. Sarcoidosis Vasc Diffuse Lung Dis 2011;28:95-101.

94. Redelman-Sidi G, Sepkowitz KA. Interferon Gamma Release Assays in the Diagnosis of Latent Tuberculosis Infection Among Immunocompromised Adults. Am J Respir Crit Care Med 2013;188: 422-431.

95. Bannwarth B, Pehourcq F, Schaeverbeke T, Dehais J. Clinical pharmacokinetics of low-dose pulse methotrexate in rheumatoid arthritis. Clin Pharmacokinet 1996;30:194-210.

96. Holmes J, Lazarus A. Sarcoidosis: extrathoracic manifestations. Dis Mon 2009;55:675-692.

97. Cremers J, Drent M, Driessen A, Nieman F, Wijnen P, Baughman R, Koek G. Liver-test abnormalities in sarcoidosis. Eur J Gastroenterol Hepatol 2012;24:17-24.

98. Cremers JP, Drent M, Baughman RP, Wijnen PA, Koek GH. Therapeutic approach of hepatic sarcoidosis. Curr Opin Pulm Med 2012;18:472-482.

99. Hercules HD, Bethlem NM. Value of liver biopsy in sarcoidosis. Arch Pathol Lab Med 1984;108: 831-834.

100. Devaney K, Goodman ZD, Epstein MS, Zimmerman HJ, Ishak KG. Hepatic sarcoidosis. Clinicopathologic features in 100 patients. Am J Surg Pathol 1993;17:1272-1280.

101. Baughman RP, Koehler A, Bejarano PA, Lower EE, Weber FL, Jr. Role of liver function tests in detecting methotrexate-induced liver damage in sarcoidosis. Arch Intern Med 2003;163:615-620.

102. Drent M, De Vries J, Lenters M, Lamers RJ, Rothkranz-Kos S, Wouters EF, Van Dieijen-Visser MP, Verschakelen JA. Sarcoidosis: assessment of disease severity using HRCT. Eur Radiol 2003;13: 2462-2471.

103. Kremer JM, Lee RG, Tolman KG. Liver histology in rheumatoid arthritis patients receiving long-term methotrexate therapy. A prospective study with baseline and sequential biopsy samples. Arthritis Rheum 1989;32:121-127.

104. Kremer JM, Furst DE, Weinblatt ME, Blotner SD. Significant changes in serum AST across hepatic histological biopsy grades: prospective analysis of 3 cohorts receiving methotrexate therapy for rheumatoid arthritis. J Rheumatol 1996;23:459-461.

105. Tolman KG, Clegg DO, Lee RG, Ward JR. Methotrexate and the liver. J Rheumatol Supp/ 1985;12 Suppl 12:29-34.

106. Willkens RF, Leonard PA, Clegg DO, Tolman KG, Ward JR, Marks CR, Greene ML, Roth GJ, Jackson CG, Cannon GW, Lee RG. Liver histology in patients receiving low dose pulse methotrexate for the treatment of rheumatoid arthritis. Ann Rheum Dis 1990;49:591-593.

107. Kremer JM, Lee JK. The safety and efficacy of the use of methotrexate in long-term therapy for rheumatoid arthritis. Arthritis Rheum 1986;29:822-831.

108. Whiting-O'Keefe QE, Fye KH, Sack KD. Methotrexate and histologic hepatic abnormalities: a metaanalysis. Am J Med 1991;90:711-716.

109. Pavy S, Constantin A, Pham T, Gossec L, Maillefert JF, Cantagrel A, Combe B, Flipo RM, Goupille P, Le Loet X, Mariette X, Puechal X, Schaeverbeke T, Sibilia J, Tebib J, Wendling D, Dougados M. Methotrexate therapy for rheumatoid arthritis: clinical practice guidelines based on published evidence and expert opinion. Joint Bone Spine 2006;73:388-395.

110. Hoekstra M, Haagsma C, Neef C, Proost J, Knuif A, Van de Laar M. Splitting high-dose oral methotrexate improves bioavailability: a pharmacokinetic study in patients with rheumatoid arthritis. I Rheumatol 2006;33:481-485.

111. Van Roon EN, Van de Laar MA. Methotrexate bioavailability. Clin Exp Rheumatol 2010;28:S27-32.

112. Rozin A, Schapira D, Balbir-Gurman A, Braun-Moscovici Y, Markovits D, Militianu D, Nahir MA. Relapse of rheumatoid arthritis after substitution of oral for parenteral administration of methotrexate. Ann Rheum Dis 2002;61:756-757.

113. Jundt JW, Browne BA, Fiocco GP, Steele AD, Mock D. A comparison of low dose methotrexate bioavailability: oral solution, oral tablet, subcutaneous and intramuscular dosing. J Rheumatol 1993;20:1845-1849.

114. Hoekstra M, Haagsma C, Neef C, Proost J, Knuif A, Van de Laar M. Bioavailability of higher dose methotrexate comparing oral and subcutaneous administration in patients with rheumatoid arthritis. $J$ Rheumatol 2004;31:645-648. 
115. Lambert CM, Sandhu S, Lochhead A, Hurst NP, McRorie E, Dhillon V. Dose escalation of parenteral methotrexate in active rheumatoid arthritis that has been unresponsive to conventional doses of methotrexate: a randomized, controlled trial. Arthritis Rheum 2004;50:364-371.

116. Bingham SJ, Buch MH, Lindsay S, Pollard A, White J, Emery P. Parenteral methotrexate should be given before biological therapy. Rheumatology (Oxford) 2003;42:1009-1010.

117. Baughman RP, Lower EE. Leflunomide for chronic sarcoidosis. Sarcoidosis Vasc Diffuse Lung Dis 2004;21:43-48.

118. Sahoo DH, Bandyopadhyay D, Xu M, Pearson K, Parambil JG, Lazar CA, Chapman JT, Culver DA. Effectiveness and safety of leflunomide for pulmonary and extrapulmonary sarcoidosis. Eur Respir J 2011;38:1145-1150.

119. Choi HK, Hernan MA, Seeger JD, Robins JM, Wolfe F. Methotrexate and mortality in patients with rheumatoid arthritis: a prospective study. Lancet 2002;359:1173-1177.

120. Yazici Y, Sokka T, Kautiainen H, Swearingen C, Kulman I, Pincus T. Long term safety of methotrexate in routine clinical care: discontinuation is unusual and rarely the result of laboratory abnormalities. Ann Rheum Dis 2005;64:207-211.

121. Salliot C, Van der Heijde D. Long-term safety of methotrexate monotherapy in patients with rheumatoid arthritis: a systematic literature research. Ann Rheum Dis 2009;68:1100-1104.

122. Doran MF, Crowson CS, Pond GR, O'Fallon WM, Gabriel SE. Predictors of infection in rheumatoid arthritis. Arthritis Rheum 2002;46:2294-2300.

123. Wolfe F, Michaud K. Lymphoma in rheumatoid arthritis: the effect of methotrexate and anti-tumor necrosis factor therapy in 18,572 patients. Arthritis Rheum 2004;50:1740-1751.

124. Mariette X, Cazals-Hatem D, Warszawki J, Liote F, Balandraud N, Sibilia J. Lymphomas in rheumatoid arthritis patients treated with methotrexate: a 3-year prospective study in France. Blood 2002;99:39093915.

125. Ostensen $M$, von Esebeck M, Villiger PM. Therapy with immunosuppressive drugs and biological agents and use of contraception in patients with rheumatic disease. J Rheumatol 2007;34:1266-1269.

126. Ostensen $\mathrm{M}$, Hartmann $\mathrm{H}$, Salvesen K. Low dose weekly methotrexate in early pregnancy. A case series and review of the literature. J Rheumatol 2000;27:1872-1875.

127. Lewden B, Vial T, Elefant E, Nelva A, Carlier P, Descotes J. Low dose methotrexate in the first trimester of pregnancy: results of a French collaborative study. J Rheumatol 2004;31:2360-2365.

128. Kozlowski RD, Steinbrunner JV, MacKenzie AH, Clough JD, Wilke WS, Segal AM. Outcome of firsttrimester exposure to low-dose methotrexate in eight patients with rheumatic disease. Am J Med 1990;88:589-592.

129. Donnenfeld AE, Pastuszak A, Noah JS, Schick B, Rose NC, Koren G. Methotrexate exposure prior to and during pregnancy. Teratology 1994;49:79-81.

130. Chakravarty EF, Sanchez-Yamamoto D, Bush TM. The use of disease modifying antirheumatic drugs in women with rheumatoid arthritis of childbearing age: a survey of practice patterns and pregnancy outcomes. J Rheumatol 2003;30:241-246.

131. Regan L, Rai R. Epidemiology and the medical causes of miscarriage. Baillieres Best Pract Res Clin Obstet Gynaecol 2000;14:839-854. 


\title{
Chapter 7
}

Practical eminence and experience-based recommendations for use of TNF- $\alpha$ inhibitors in sarcoidosis

\author{
M Drent, J Cremers, T Jansen, R Baughman
}

Sarcoidosis Vasc Diffuse Lung Dis 2014; accepted for publication 


\section{Abstract}

\section{Background}

In severe refractory sarcoidosis cases not responding to conventional immunosuppressive treatment, the third-line tumor necrosis factor-alpha (TNF- $\alpha$ ) inhibitors infliximab and adalimumab might be an alternative. However, appropriate studies to guide the clinician are lacking. The aim of this study was to establish practical recommendations for the use of TNF- $\alpha$ inhibitors in the management of refractory sarcoidosis patients.

\section{Methods}

Based on a literature search and the opinion of sarcoidosis experts worldwide, the recommendations were established. Studies conducted in sarcoidosis were supplemented with data obtained from relevant studies in other inflammatory diseases. A Delphi method of polling, using an online survey addressing 12 clinical questions, was performed amongst 20 of the world's leading sarcoidologists to investigate consensus in case of inadequate data to determine an objective answer.

\section{Results}

Of the 256 papers found, 101 were included. Randomized controlled trial studies about the use of TNF- $\alpha$ inhibitors in sarcoidosis are limited. Ninety-five percent (19 of 20) of the sarcoidologists contacted, completed the questionnaire (Europe 68\%, North America 32\%). Nine recommendations were formulated concerning general aspects of TNF- $\alpha$ inhibitor use; Specific sarcoidosis related items, including indications, starting and maintenance dosage, interval of treatment, treatment duration, and discontinuation regimen of infliximab and adalimumab, were addressed.

\section{Conclusion}

Based on earlier studies and consensus amongst world's leading sarcoidologists, practical recommendations for the use of TNF- $\alpha$ inhibitors in sarcoidosis were established. These recommendations, with emphasis on indications, dosage and discontinuation regimens, have been developed to support the clinician in the management of refractory sarcoidosis patients. 


\section{Introduction}

Sarcoidosis is a multiorgan disease of unknown cause, characterized by inflammatory activity with formation of noncaseating granulomas in various organ systems. ${ }^{1}$ It primarily affects the lungs, but virtually any organ system can be involved. ${ }^{1}$ The presentation and the course of sarcoidosis are highly variable. ${ }^{1,2}$ Sarcoidosis activity can lead to a wide range of disease severity, varying from an acute disease course with minimal involvement to chronic disease with derangement of organ physiology and functional impairment. ${ }^{1-3}$ Therefore, especially in severe sarcoidosis cases, a timely implementation of a potent individual treatment regimen is important. ${ }^{1}$ Since sarcoidosis patients can present to any one of a variety of organ specialists, the therapeutic strategy followed is dependent on the experience of an individual specialist.

When systemic immunosuppressive therapy is indicated, glucocorticosteroids are in general considered the first-line therapy. ${ }^{4-6}$ However, prolonged use is associated with significant side-effects, making glucocorticosteroids undesirable for chronic disease management. ${ }^{5,7}$ In steroid-refractory cases and in the presence of steroidassociated side-effects, second-line disease-modifying antisarcoid drugs (DMASDs), with usually steroid-sparing potency, are available. ${ }^{4,5,8,9}$ Methotrexate (MTX) is considered the first-choice DMASD. ${ }^{10,11}$ Optimized use of these drugs should be pursued. ${ }^{10}$ Nevertheless, in some sarcoidosis patients the available first- and secondline therapeutics do not provide the optimal result. The potent pro-inflammatory tumor necrosis factor-alpha (TNF- $\alpha$ ) plays a critical role in the immunopathogenesis of sarcoidosis. $^{2,12-15}$ In refractory sarcoidosis cases, biological TNF- $\alpha$ inhibitors have been introduced as third-line treatment option. ${ }^{4,5}$

The TNF- $\alpha$ inhibitors infliximab and adalimumab have been widely used for the treatment of inflammatory diseases, such as rheumatoid arthritis and Crohn's disease. ${ }^{16-18}$ Until now, only a few studies in sarcoidosis were conducted, demonstrating promising results. ${ }^{12,19-22}$ Hence the costs are considerable and substantial side-effects are reported, optimal use of these agents in sarcoidosis is important. ${ }^{23-25}$ In general, sarcoidosis patients are treated by pulmonologists, who usually have less experience with the use of TNF- $\alpha$ inhibitors. Further complicating the use, evidence-based recommendations for infliximab and adalimumab therapy in sarcoidosis clinical practice are lacking.

The aim of this study was to establish practical recommendations for the use of TNF- $\alpha$ inhibitors in the management of refractory sarcoidosis patients by integrating the evidence obtained through a systematic literature review and the results of a Delphi study amongst sarcoidosis experts worldwide. 


\section{Methods}

The methods used in this study have been described previously by our group. ${ }^{10}$ The recommendations for the use of TNF- $\alpha$ inhibitors in sarcoidosis were developed in three phases.

\section{Systematic review of the literature}

The computerized literature search relied predominantly on PubMed (articles from 1989 to October 2013). The terms 'sarcoidosis' and 'anti-TNF', 'anti-TNF-alpha', 'TNFalpha inhibitors', 'infliximab' or 'adalimumab' were entered as MeSH terms and free text. Only original research published in English was reviewed. Review papers were used to identify additional studies missed by the database search. Data specifically relating to sarcoidosis were supplemented with the data obtained from relevant studies in other inflammatory diseases, with specific emphasis on rheumatic disorders and inflammatory bowel disease (IBD).

\section{Delphi study amongst sarcoidologists worldwide}

As sufficient high-quality studies on the use of infliximab and adalimumab in sarcoidosis are scarce, a Delphi method of polling was used to investigate consensus in situations where there are inadequate data to determine an objective answer. An online webbased questionnaire was sent by e-mail to 20 of the world's leading sarcoidosis experts. The questionnaire addressed some aspects specifically related to sarcoidosis, including indications for use, starting and maintenance dosage, interval of treatment, treatment duration, and discontinuation regimen of infliximab and adalimumab, and general aspects, including work-up and contra-indications prior to the start of the TNF- $\alpha$ inhibitors, use during pregnancy and breast feeding, prevention of antidrug antibody formation, management of infusion reactions, monitoring during use, vaccination and traveling. Questions concerning the experts' clinical experience with both infliximab and adalimumab were addressed as well. Consensus was considered to be achieved when at least $70 \%$ of respondents agreed to an answer. ${ }^{26}$

\section{Establishing the recommendations}

The information gathered during phases 1 and 2 was combined to formulate the recommendations. They were divided into recommendations for the use of TNF- $\alpha$ inhibitors specifically targeting sarcoidosis and for general use. Proposals were discussed via e-mail, phone and videoconference to reach agreement and finalize each of the recommendations. 


\section{Results}

\section{Findings of the literature review}

The literature search identified 256 citations of potential interest. We screened each title and abstract for relevance resulting in the exclusion of 93 papers, as the TNF- $\alpha$ inhibitors had been used for non-sarcoidosis conditions (24 papers) or the TNF- $\alpha$ inhibitors had been used in a different context (69 papers). Sixty-two studies were review papers, whereas 101 original papers were retrieved and considered further for full review. Checking the references in review papers yielded no additional original studies. Included were four randomized controlled trials (RCTs), two discontinuation studies, one polymorphism study, 12 case series involving 10 or more patients and 82 case reports involving fewer than 10 patients, examining the effectiveness of TNF- $\alpha$ inhibitor treatment in sarcoidosis. Study characteristics and results for the most relevant studies are presented in Appendix 3. Summarizing the available studies, it can be concluded that the number of RCTs supporting the use of TNF- $\alpha$ inhibitors in sarcoidosis is limited and most of the published data were observational case series.

\section{Findings of Delphi study}

A total of 19 of 20 (95\%) of the world's leading sarcoidologists completed the questionnaire. Characteristics of the respondents are presented in Table 7.1. Most experts are working as pulmonologists or rheumatologists in countries in Europe $(68 \%$ of respondents) and North America (32\%). All sarcoidologists have experience with TNF- $\alpha$ inhibitors in the management of refractory sarcoidosis patients, $77 \%$ of them prescribing TNF- $\alpha$ inhibitors to five or more sarcoidosis patients a year. Experts reported to prescribe infliximab as an immunosuppressant in $7.2 \%$ (mean, range 0$25 \%$ ) and adalimumab in $4.2 \%$ (mean, range $0-25 \%$ ) of their total sarcoidosis population treated.

Table 7.1 Summary of characteristics of sarcoidosis experts who participated in this study.

Number of respondents

Pulmonologist/rheumatologist/internist

Continent: Europe/North America

Working experience: $0-10 / 10-20 />20$ years

Average number of sarcoidosis patients treated with TNF- $\alpha$ inhibitor:

none/1-5/5-25/>25 a year

\section{$19 / 20$ (95.0\%)}

$84.2 / 10.5 / 5.3 \%$

$68.4 / 31.6 \%$

$26.3 / 31.6 / 42.1 \%$

$0 / 26.3 / 42.1 / 31.6 \%$

TNF- $\alpha$, tumor necrosis factor-alpha. 
Specific sarcoidosis related items gathered from the experts are summarized in Table 7.2. Seventeen sarcoidologists (89\%) had experience with infliximab prescription and 17 experts (89\%) with adalimumab. The majority of experienced experts (83\%) used an infliximab dosage of $5 \mathrm{mg} / \mathrm{kg}$. All reported to use the 0-2-6 weeks induction regimen and $77 \%$ used a maintenance dosing frequency of every 4 or 6 weeks, with a predominance for the 4 weeks interval. The mean response rate for infliximab, reported by the experts, administered every 4 weeks was 78\% (range $70-85 \%$ ), and administered every 6 weeks 68\% (range 65-75\%).

Table 7.2 Expert opinion amongst sarcoidologists, based on questionnaire answers, for recommendations specifically targeting sarcoidosis.

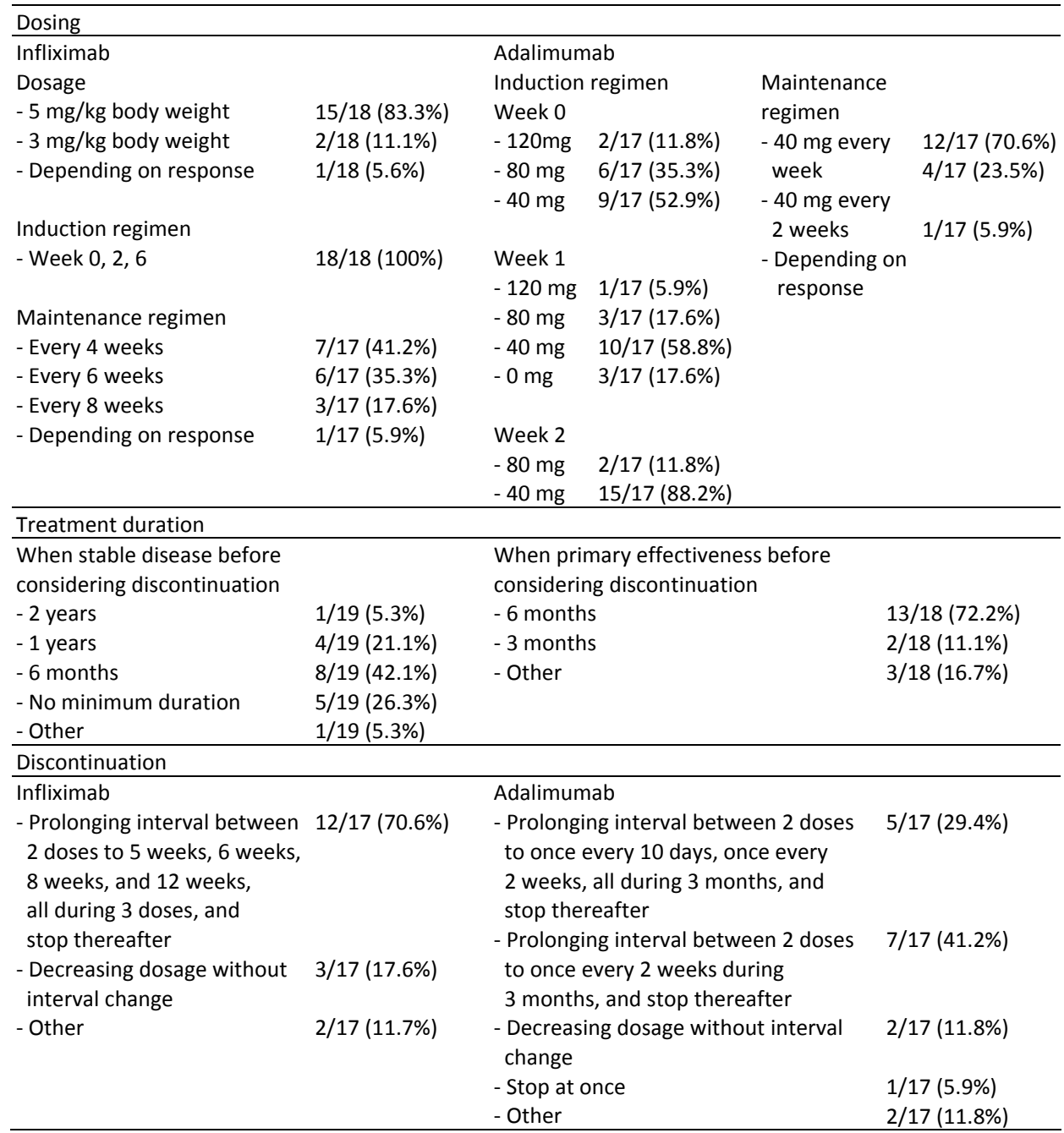


The induction regimen for adalimumab dosing used by the experienced experts was very divers. However, a preference seemed to be present for a dosage of $40-80 \mathrm{mg}$ in week $0,40 \mathrm{mg}$ in week 1 and $40 \mathrm{mg}$ in week 2 . The majority (71\%) of the respondents reported to use a maintenance schedule of adalimumab of $40 \mathrm{mg}$ once every week, whereas most remaining experts used the $40 \mathrm{mg}$ every other week regimen. The mean reported response rate for adalimumab used in a frequency once every week was 63.8\% (range 50-75\%), whereas the mean response rate for an administration frequency of once every 2 weeks was $46.7 \%$ (range 30-60\%). With regard to the discontinuation regimen of infliximab, the majority of experts (71\%) agreed with the gradual prolongation of the dosing interval, while continuing the dosage unchanged. Seventy-one percent applied gradual prolongation of the interval when discontinuing adalimumab, using either a one- or two-step tapering regimen.

Table 7.3 Expert opinion amongst sarcoidologists, based on questionnaire answers, for the general recommendations.

\begin{tabular}{|c|c|c|c|}
\hline \multicolumn{2}{|l|}{ Pre-administration work-up } & \multicolumn{2}{|l|}{ Vaccination } \\
\hline - IGRA test & $19 / 19(100 \%)$ & - Vaccines made of live, attenuated & $17 / 18(94.4 \%)$ \\
\hline - Chest radiograph & $19 / 19(100 \%)$ & microorganisms discouraged & \\
\hline - Treatment TB after positive & $14 / 19(73.7 \%)$ & - Influenza vaccination & $12 / 18(66.7 \%)$ \\
\hline screening & & - Pneumococcal vaccination & $8 / 18(44.4 \%)$ \\
\hline - Hepatitis B serology & $16 / 19(84.2 \%)$ & - Hepatitis B vaccination & $5 / 18(27.8 \%)$ \\
\hline - Hepatitis C serology & $12 / 19(63.2 \%)$ & & \\
\hline - HIV serology & $7 / 19(36.8 \%)$ & & \\
\hline - Malignancy screening & $7 / 19(36.8 \%)$ & & \\
\hline Contraindications & & Treatment infusion reaction & \\
\hline - TB infection & $16 / 19(84.2 \%)$ & - Mild: decreasing infusion velocity & $14 / 18(77.7 \%)$ \\
\hline - Opportunistic infection & $18 / 19(94.7 \%)$ & - Hydrocortisone, paracetamol/ & $10 / 18(55.6 \%)$ \\
\hline $\begin{array}{l}\text { - Serious bacterial infection or } \\
\text { treated with antibiotics }\end{array}$ & $19 / 19(100 \%)$ & $\begin{array}{l}\text { acetaminophen, clemastine, and } \\
\text { when indicated adrenaline }\end{array}$ & \\
\hline - Upper airway infection & $11 / 19(57.9 \%)$ & - Permanent discontinuation & $12 / 18(66.7 \%)$ \\
\hline - Non-healing ulcer of the skin & $8 / 19(42.1 \%)$ & TNF- $\alpha$ inhibitor & \\
\hline - Active fungus infection & $19 / 19(100 \%)$ & - Premedication for next infusion & $11 / 18(61.1 \%)$ \\
\hline - Active Herpes Zoster infection & $18 / 19(94.7 \%)$ & - Maintenance dosage of GC & $2 / 18(11.1 \%)$ \\
\hline - Hepatitis B & $15 / 19(78.9 \%)$ & & \\
\hline - Hepatitis C & $13 / 19(68.4 \%)$ & & \\
\hline - Heart failure NYHA class III/IV & 15/19 (78.9\%) & & \\
\hline - Malignancy $\leq 5$ years ago & $15 / 19(78.9 \%)$ & & \\
\hline - Malignancy at present & $19 / 19(100 \%)$ & & \\
\hline $\begin{array}{l}\text { Contraindication in (planned) } \\
\text { pregnancy }\end{array}$ & & Monitoring & \\
\hline - In women & $18 / 19(94.7 \%)$ & - Every 1-3 months after start & $18 / 18(100 \%)$ \\
\hline- In men & $10 / 19(52.6 \%)$ & - Every 3-6 months thereafter & $15 / 18(83.3 \%)$ \\
\hline $\begin{array}{l}\text { Prevention of antidrug antibody } \\
\text { formation }\end{array}$ & & Traveling abroad & \\
\hline - Use of MTX & $17 / 18(94.4 \%)$ & - Discouraged to countries without & $16 / 18(88.9 \%)$ \\
\hline - Use of GC & $9 / 18(50.0 \%)$ & medical/sanitary supplies & \\
\hline
\end{tabular}

GC, glucocorticosteroids; IGRA, interferon-gamma release assay; MTX, methotrexate; NYHA, New York Heart Association; TB, mycobacterium tuberculosis; TNF- $\alpha$, tumor necrosis factor-alpha. 
Table 7.3 indicates the questionnaire answers concerning the general items. There was at least $70 \%$ agreement amongst experts for most issues in general clinical practice. However, less agreement was found regarding the use of preventive vaccinations, the method of treatment of infusion reactions, and on the consideration of planned pregnancy being a contraindication for TNF- $\alpha$ inhibitor therapy in men. To prevent antidrug antibody formation, MTX was more frequently used compared with glucocorticosteroids.

\section{Discussion}

Based on earlier studies and the results of a Delphi study amongst the world's leading sarcoidologists, practical recommendations for the use of TNF- $\alpha$ inhibitors in sarcoidosis were established. These recommendations are summarized in Table 7.4 and 7.5 and have been developed to support the clinician in the management of refractory sarcoidosis patients.

\section{Recommendations with an approach specific for sarcoidosis}

\section{Effectiveness}

In Crohn's disease and rheumatoid arthritis, both infliximab and adalimumab have been proven efficacious in inducing short-term clinical remission. ${ }^{27-32}$ Timely introduction of TNF- $\alpha$ inhibitor treatment can lead to a greater likelihood of control of symptoms and prevention of serious organ damage resulting in a more favorable outcome. ${ }^{27-29,33}$ The short-term efficacy of TNF- $\alpha$ inhibitor treatment in severe refractory sarcoidosis cases has been proven (Appendix 3). ${ }^{12,19-22,34-77}$ Also in these cases, timely implementation of an effective therapeutic regimen, if necessary consisting of TNF- $\alpha$ inhibitors, should be pursued to obtain low disease activity and a better outcome. Effectiveness of infliximab and adalimumab in maintaining long-term clinical remission has been shown in Crohn's disease and rheumatoid arthritis. ${ }^{27,28,32,78}$ One study in sarcoidosis showed maintained efficacy with prolonged infliximab treatment (mean treatment duration 46 months). ${ }^{79}$ However, another study found only 10 of 25 patients with sarcoid eyes involvement successfully maintained on long-term TNF- $\alpha$ inhibitor treatment. ${ }^{42}$ Future studies are necessary to establish if TNF- $\alpha$ inhibitors are effective by bridging in active disease in order to aim for long-term remission in sarcoidosis as well. 
Table 7.4 Recommendations for the use of TNF- $\alpha$ inhibitors specifically targeting sarcoidosis. ${ }^{\text {a }}$

\section{Recommendation}

\section{Dosage}

- Infliximab:

Intravenous infusion of a dosage of $5 \mathrm{mg} / \mathrm{kg}$ at week $0,2,6$ and every 4 weeks thereafter is recommended; consider other maintenance dosages depending on disease activity.

- Adalimumab:

Subcutaneous administration at a dosage of 80-160 mg at week 0, $40 \mathrm{mg}$ at week 1, and $40 \mathrm{mg}$ once every week thereafter, is recommended; consider other maintenance dosages depending on disease activity.

\section{Discontinuation}

In case of severe uncontrolled side-effects; primary ineffectiveness during 3-6 months of treatment; secondary ineffectiveness due to antibody formation; or stable disease during treatment with a TNF- $\alpha$ inhibitor for at least 6-12 months, discontinuation should be considered.

- Infliximab:

When discontinuing infliximab because of stable sarcoidosis, gradually prolonging the interval between 2 doses to 5 weeks (during 3 doses), 6 weeks (during 3 doses), 8 weeks (during 3 doses), 12 weeks (during 3 doses) and stop thereafter, while continuing the dosage unchanged, is recommended.

- Adalimumab:

When discontinuing adalimumab because of stable sarcoidosis, prolonging the interval between 2 doses to once in every 10 days (during 3 months), once in every 2 weeks (during 3 months), and stop thereafter, while continuing the dosage unchanged, is recommended.

a All recommendations apply to general situations; for every individual case, patient and disease characteristics should be taken into account. TNF- $\alpha$, tumor necrosis factor-alpha.

Table 7.5 General recommendations for the use of TNF- $\alpha$ inhibitors.

\section{Recommendation}

1 Before starting TNF- $\alpha$ inhibitors, active or latent TB infection (positive IGRA test), serious opportunistic infections, serious bacterial infections, infections treated with antibiotics, upper airway infections with fever, active fungus infection, active herpes zoster infection, hepatitis B/C infection, heart failure NYHA class III/IV, malignancy $\leq 5$ years ago in medical history, and malignancy at present, should be excluded.

2 TNF- $\alpha$ inhibitors should not be used by women for at least 2-3 months before planned pregnancy; a recommendation for the use by men is not possible because of lack of evidence. TNF- $\alpha$ inhibitors should not be used during pregnancy or breast feeding; in individual cases, use during pregnancy can be considered.

3 Before every administration of the TNF- $\alpha$ inhibitor, a current infection should be excluded. ${ }^{\text {a }}$

4 Elective surgeries or interventions and dentist visits should be planned in consultation with the treating physician.

5 To prevent antidrug antibody formation, TNF- $\alpha$ inhibitors should be combined with low doses methotrexate and/or glucocorticosteroids.

6 Mild infusion reactions occurring during treatment with a TNF- $\alpha$ inhibitor should be treated by decreasing the infusion velocity; serious infusion reactions with hydrocortisone, paracetamol/ acetaminophen, clemastine, and when indicated adrenaline; permanent discontinuation of the TNF- $\alpha$ inhibitor should be considered. To prevent future infusion reactions, premedication for the next infusion is recommended.

7 After the start of TNF- $\alpha$ inhibitors, regular monitoring is recommended every 1-3 months and once the dosage is stable every 3-6 months.

8 The use of vaccines made of live, attenuated microorganisms is discouraged, but vaccines made of killed microorganisms can be used safely during anti-TNF- $\alpha$ therapy; preventive influenza, pneumococcal, and hepatitis B vaccinations before or during TNF- $\alpha$ inhibitors can be considered.

9 In general, traveling to countries without decent medical and sanitary supplies or for which administration of vaccines made of live, attenuated microorganisms is necessary, is discouraged. When traveling to countries without sufficient medical supplies, the patient should take antibiotics along. During travel, adalimumab should be transported and preserved in a cooled environment.

\footnotetext{
${ }^{a}$ In case of an infection, the TNF- $\alpha$ inhibitor should at least temporarily be discontinued until all signs of the infection have disappeared. IGRA, interferon-gamma release assay; NYHA, New York Heart Association; TB, mycobacterium tuberculosis; TNF- $\alpha$, tumor necrosis factor-alpha.
} 


\section{Indications}

The indications for TNF- $\alpha$ inhibitor treatment in sarcoidosis consist of its use as a thirdline treatment option in refractory cases with inadequate response to or in the presence of unacceptable side-effects from first-line glucocorticosteroids and secondline DMASDs. ${ }^{80}$ Infliximab is the most widely studied TNF- $\alpha$ inhibitor in sarcoidosis. It is shown to be effective in pulmonary sarcoidosis, ${ }^{12,20,35-38,79}$ but its use has also been described for skin, ${ }^{19,36,38,39,47,49,79}$ neurological, ${ }^{19,39,45,48,51-55,57,60,61,64,66-68,70,79}$ liver, $^{19,38,39,75,79}$ kidney, $^{19,76,77,79}$ muscle, $^{19,39,79}$ bone, ${ }^{19,38,39,74,79}$ and eye (uveitis) $^{19,36,38,42,58,59,65,69,79}$ involvement, hypercalcaemia, ${ }^{50}$ small fiber neuropathy, ${ }^{46,63}$ and extreme devastating fatigue. ${ }^{43}$ Its value in cardiac sarcoidosis is also shown in case reports. $^{19,35,56,62,69}$

The use of adalimumab has especially been shown for eye involvement (consisting of uveitis, choroidal involvement, papillitis and macula edema). ${ }^{22,71}$ Beneficial effects have been described for patients with symptomatic lung, ${ }^{22}$ skin, $^{21}$ bone, ${ }^{74}$ and bone marrow $^{73}$ involvement and sarcoidosis associated fatigue. ${ }^{22,43,72}$

To date, etanercept is not used in sarcoidosis disease management. In an open label trial of pulmonary sarcoidosis, etanercept was associated with treatment failure. ${ }^{81}$ Furthermore, the drug failed in an RCT investigating patients with refractory sarcoidosis uveitis. $^{82}$ These results are in line with observations in Crohn's disease. ${ }^{83}$

\section{Cardiac sarcoidosis}

Initial observations suggested that inhibition of TNF- $\alpha$ may favorably modify the course of heart failure. ${ }^{84}$ However, based on the subsequent findings, heart failure New York Heart Association (NYHA) class III and IV is currently considered a contraindication for the use of TNF- $\alpha$ inhibitors, ${ }^{30,31}$ which is supported by almost $80 \%$ of the participating sarcoidosis experts. Chung et al. ${ }^{85}$ evaluated the efficacy and safety of infliximab in 150 patients with stable NYHA class III or IV heart failure and showed that TNF- $\alpha$ inhibition adversely affected the clinical condition of these patients. Mann et al. ${ }^{86}$ ruled out a positive effect of etanercept on death or hospitalization due to chronic heart failure (NYHA class II-IV). Furthermore, the occurrence of symptomatic cardiac arrhythmias associated with the use of infliximab has been reported. ${ }^{87,88}$

What to do with TNF- $\alpha$ inhibitors in patients with cardiac sarcoidosis, either with or without consequent heart failure? In the presence of active cardiac sarcoidosis without signs of heart failure class III or IV and without responsiveness to conventional treatment, we recommend considering infliximab. In case reports, infliximab is demonstrated to have beneficial effects in cardiac sarcoidosis. ${ }^{19,35,56,62,69}$ Furthermore, $84 \%$ of sarcoidosis experts stated to use TNF- $\alpha$ inhibitors in selected cases of cardiac involvement. In the presence of active cardiac sarcoidosis with heart failure NYHA class III or IV, more caution is warranted. The decision to either implement or refrain from TNF- $\alpha$ inhibitors should be based on the patients' individual circumstances. If cardiac sarcoidosis activity is the only cause for heart failure, infliximab can be considered (for 
instance young sarcoidosis patient without relevant comorbidity or co-medication). If besides cardiac sarcoidosis activity other causes for heart failure are present, infliximab should be considered contraindicated.

\section{Dosing}

No guidelines are available concerning dosing of infliximab or adalimumab in sarcoidosis. Only one randomized controlled trial compared different dosages of intravenous infliximab in sarcoidosis (placebo vs. $3 \mathrm{mg} / \mathrm{kg}$ body weight vs. $5 \mathrm{mg} / \mathrm{kg}$, $\mathrm{n}=138) .{ }^{12}$ No significant difference in the change from baseline in the percentage of predicted forced vital capacity (FVC\%) between the $3 \mathrm{mg} / \mathrm{kg}$ and $5 \mathrm{mg} / \mathrm{kg}$ group was found, whereas the combined infliximab group had a significant increase in the FVC\% compared with no change in placebo-treated patients $(p=0.038)$. Other studies and case series used either dosages of $5 \mathrm{mg} / \mathrm{kg}$ or $3 \mathrm{mg} / \mathrm{kg}$, but a preference for infliximab 5 $\mathrm{mg} / \mathrm{kg}$ seemed to be present (Appendix 3). ${ }^{20,34-39,41-43,45-47,49-70,74-77,89,90}$ The majority of sarcoidosis experts reported using an infliximab dosage of $5 \mathrm{mg} / \mathrm{kg}$. Guidelines and consensus statements recommend an infliximab dosage of $5 \mathrm{mg} / \mathrm{kg}$ in IBD, ankylosing spondylitis, psoriatric arthritis and psoriasis, and of $3 \mathrm{mg} / \mathrm{kg}$ in rheumatoid arthritis. ${ }^{91}$ Combining the available evidence, infliximab infusion using a dosage of $5 \mathrm{mg} / \mathrm{kg}$ is recommended in sarcoidosis.

The induction regimen most frequently used in sarcoidosis literature consisted of infliximab administration in week 0,2 and 6 , which was also supported by all sarcoidosis experts (Appendix 3). ${ }^{12,19,20,34,36,37,39,42,43,47,50-58,60-70,89}$ Guidelines and consensus statements in IBD, rheumatoid arthritis, ankylosing spondylitis, psoriatric arthritis and psoriasis, all recommended a $0-2-6$-weeks induction regimen. ${ }^{91}$ Maintenance dosages used in the literature varied from every 4 to 8 weeks (Appendix 3 ), whereas three fourth of experts used a dosing frequency of every 4 or 6 weeks .12,19,20,34-39,41-43,45-70,74-77,89,90 A predominance for the 4 weeks interval was present. The mean reported response rate for infliximab administered every 4 weeks was higher when compared to the 6 weeks interval. In IBD and rheumatoid arthritis, a maintenance dosing every 8 weeks is advised, whereas in ankylosing spondylitis, psoriatric arthritis and psoriasis maintenance treatment every 6-8 weeks is recommended. ${ }^{91}$ Given the better reported results in sarcoidosis when using the 4 weeks maintenance interval, an infliximab induction regime at week $0,2,6$, followed by maintenance dosing every 4 weeks is recommended. ${ }^{3}$ 
The induction regimen used in week 0 until 2 for subcutaneous adalimumab was very diverse, but most sarcoidosis experts were in favor of weekly dosing of relatively low dosages. In Crohn's disease a loading dose of 160/80 mg was advised at week $0 /$ week 2 to achieve early disease control, whereas in rheumatic inflammatory diseases a loading dose was not advised. ${ }^{18,29,32}$ Results in Crohn's disease show that initiating TNF- $\alpha$ inhibitors early in the disease course at sufficient dosage levels, might prevent serious organ damage and result in a more favorable outcome. ${ }^{33,92}$ Following the experience in Crohn's disease, loading dosages of 80-160 mg at week 0 , with at least 40 $\mathrm{mg}$ at week 1 and 2, respectively, should be considered in sarcoidosis.

The number of sarcoidosis studies using an adalimumab maintenance dosage of 40 mg every week versus every other week is equal (Appendix 3). ${ }^{21,22,34,40-43,72-74}$ Experienced sarcoidosis experts were more likely to use the weekly dosing interval. The mean reported response rate was in favor of the weekly administration compared to the every other week administration. This was also reported in an expert review on TNF- $\alpha$ inhibitor use in sarcoidosis. ${ }^{80}$ Guidelines in Crohn's disease, recommending the $40 \mathrm{mg}$ every other week maintenance therapy regimen, are difficult to compare with sarcoidosis, given the higher induction dosages used. ${ }^{29}$ In accordance with infliximab practice and given the opinion of experienced sarcoidologists, we suggest using an adalimumab maintenance dosage of $40 \mathrm{mg}$ once a week in sarcoidosis. To create a better evidence-based foundation for dosing recommendations, future research is necessary.

\section{Discontinuation}

In case of supposedly primary ineffectiveness, TNF- $\alpha$ inhibitors should be continued for at least 3-6 months before discontinuation can be considered, which is supported by more than $80 \%$ of sarcoidosis experts. In rheumatic inflammatory diseases and IBD, response is most frequently seen in the first month of treatment, but it can also be achieved after longer treatment duration. ${ }^{29,32}$ In primary non-responding patients, adjustment of dosage or administration interval or a biological agent with another mode of action should be considered. ${ }^{91}$ In rheumatoid arthritis, it is shown that these patients are less likely to respond to a second TNF- $\alpha$ inhibitor. ${ }^{32}$ In case of secondary ineffectiveness, switch from one TNF- $\alpha$ inhibitor to another or a biological agent from another class can be successful. ${ }^{32}$ In sarcoidosis, promising results have been shown for rituximab, a chimeric monoclonal antibody that targets CD-20 cells with reduction of circulating mature B lymphocytes. ${ }^{93,94}$

An issue clinicians are struggling with is in which sarcoidosis patients and after what treatment duration, maintenance of clinical remission is likely when tapering off TNF- $\alpha$ inhibitors. Studies in rheumatoid arthritis have been investigating this issue aiming 'biological free remission' (BFR), i.e. sustainability of remission after a biological agent is discontinued. ${ }^{95,96}$ The first difficulty is the identification of patients with stabilization of sarcoidosis disease, i.e. patients who might be possible candidates for sustained BFR after tapering down TNF- $\alpha$ inhibitor treatment. To identify these patients, a definition 
of response is needed. ${ }^{97}$ Since sarcoidosis is a disease which can affect almost every organ system and which has a fluctuating disease course, defining exact response criteria is difficult. Wijnen et al. $^{34}$ made a first attempt how to define treatment response in sarcoidosis and assessed possible predictors of response. Other studies did not use standardized criteria, but determined treatment effect based on evaluation by the treating physician. Prospective studies are needed to establish criteria for the identification of responders and non-responders when evaluating pharmacological treatment. Another question is: which period is long enough before successful withdrawal of TNF- $\alpha$ inhibitors is reasonable and which indicators can be used to establish this period? Vorselaars et al. ${ }^{89}$ showed that the majority of sarcoidosis patients (29 of 47 patients, 62\%) relapsed after discontinuation of infliximab after a mean treatment duration of 8.5 months with a median time to relapse of 11.1 months. Panselinas et al. ${ }^{98}$ showed deterioration in 12 of 14 patients (86\%) after discontinuation of infliximab after a mean treatment duration of 4.4 months. These results suggest that successful discontinuation only is probable after stable disease has been reached. Sixtythree percent of sarcoidosis experts reported that stable disease has to be present for at least 6 to 12 months of treatment before they considered discontinuation. In rheumatoid arthritis, recommendations suggest that a discontinuation attempt should be considered in case of low disease activity or remission for at least 6 months. ${ }^{99}$ Future research is necessary to establish in which sarcoidosis patients and after what optimal TNF- $\alpha$ inhibitor treatment duration, sustained BFR can be achieved.

In sarcoidosis or other chronic inflammatory diseases, no recommendations are available for the best stepwise discontinuation regimen of TNF- $\alpha$ inhibitors. When discontinuing infliximab in stable sarcoidosis disease, we recommend, based on the expert opinion, gradually prolonging of the interval between 2 doses to 5 weeks (during 3 doses), 6 weeks (during 3 doses), 8 weeks (during 3 doses), 12 weeks (during 3 doses) and stop thereafter, while continuing the dosage unchanged. When discontinuing adalimumab, prolonging the interval between 2 doses to once in every 10 days (during 3 months), once in every 2 weeks (during 3 months), and stop thereafter, while continuing the dosage unchanged, is recommended. There is a risk of relapse after discontinuation, often necessitating reinstitution of treatment. ${ }^{80}$ When TNF- $\alpha$ inhibitor treatment is resumed, the risk of antidrug antibody formation is possibly higher, with consequent higher risk for loss of response and allergic reactions during infusion. ${ }^{80} \mathrm{~A}$ careful tapering method might trace a threatening relapse while gradually prolonging the interval. Prompt reinstitution of the original dosing regimen can avoid the occurrence of a relapse in most cases. 


\section{General recommendations}

The general recommendations are based on guidelines and consensus statements in other chronic inflammatory diseases, mainly IBD and rheumatoid arthritis. ${ }^{18,30-33,78,92,100}$ The recommendations presented do not differ from the general attitude towards the use of TNF- $\alpha$ inhibitors and are according to the clinical practice already followed by the participating experts.

\section{Infection prevention}

Every patient should be screened for the possibility of (latent) TB. ${ }^{31,32,92,101}$ The use of live attenuated vaccines is contraindicated during TNF- $\alpha$ inhibitor treatment, according to available guidelines. ${ }^{18,30-33,92}$ Discussion exists on the use of preventive vaccinations in patients on TNF- $\alpha$ inhibitors. Two third of sarcoidosis experts stated to prescribe yearly influenza vaccination (killed vaccine) in patients treated with TNF- $\alpha$ inhibitors. However, only $44 \%$ indicated that they routinely administer pneumococcal vaccinations (killed vaccine) and $28 \%$ reported the completion of hepatitis B series (killed vaccine) in patients at risk. Rheumatology and IBD guidelines recommended annual influenza vaccination and periodic pneumococcal vaccination for all patients receiving biological agents. ${ }^{30-33,92}$ The immune response to influenza and pneumococcal vaccinations in patients receiving biologic therapies may be attenuated, although serological protection is adequate in most cases. ${ }^{30-32}$ The completion of hepatitis $B$ vaccination series was also recommended in case of risk factors, such as a history of intravenous drug abuse or in healthcare professionals. ${ }^{30-32}$ Some recently updated guidelines also advise vaccination for human papillomavirus (recombinant vaccine) before or during biological therapy and herpes zoster vaccination (live vaccine) before starting a TNF- $\alpha$ inhibitor, based on age and risk. . $^{30,32,100}$

\section{Other issues}

Regular monitoring every 1-3 months after the start of TNF- $\alpha$ inhibitors is recommended; and once the use is stable every 3-6 months. Given the risk of rare instances of pancytopenia, aplastic anaemia or abnormal liver transaminases during TNF- $\alpha$ inhibitor use, monitoring of complete blood count and liver transaminases is recommended. $^{30,32}$ The frequency should be established by the patient's concomitant drugs use, conditions and risk factors. To prevent antidrug antibody formation during TNF- $\alpha$ inhibitor treatment, concomitant immunosuppressive therapy (MTX, azathioprine or glucocorticosteroids) is recommended. ${ }^{91} \mathrm{~A}$ recent study in RA shows that adalimumab levels are influenced by concomitant MTX use: patients on adalimumab monotherapy had a median adalimumab level of $4.1 \mu \mathrm{g} / \mathrm{mL}$ (IQR 1.3-7.7), whereas patients concomitantly taking MTX had a median level of $7.4 \mu \mathrm{g} / \mathrm{mL}$ (IQR 5.310.6, $\mathrm{p}<0.001) .{ }^{102} \mathrm{~A}$ better clinical response was present for patients using both adalimumab and MTX. ${ }^{102}$ A possible explanation is that patients with concomitant MTX are less prone to antibody formation. ${ }^{102}$ 


\section{Conclusion}

Based on earlier studies and the results of a Delphi study amongst world's leading sarcoidologists, practical recommendations for the use of TNF- $\alpha$ inhibitors in sarcoidosis were established. These recommendations with emphasis on indications, dosage and discontinuation regimens have been developed to support the clinician in the management of refractory sarcoidosis patients.

\section{Acknowledgements}

The efforts of the sarcoidosis experts who participated in this study by completing the survey are greatly appreciated. This study was supported by a research grant from the ild care foundation. 


\section{References}

1. Hunninghake GW, Costabel U, Ando M, Baughman R, Cordier JF, du Bois R, Eklund A, Kitaichi M, Lynch J, Rizzato G, Rose C, Selroos O, Semenzato G, Sharma OP. ATS/ERS/WASOG statement on sarcoidosis. American Thoracic Society/European Respiratory Society/World Association of Sarcoidosis and other Granulomatous Disorders. Sarcoidosis Vasc Diffuse Lung Dis 1999;16:149-173.

2. Iannuzzi MC, Fontana JR. Sarcoidosis: clinical presentation, immunopathogenesis, and therapeutics. JAMA 2011;305:391-399.

3. Baughman RP, Culver DA, Judson MA. A concise review of pulmonary sarcoidosis. Am J Respir Crit Care Med 2011;183:573-581.

4. Baughman RP, Nunes H, Sweiss NJ, Lower EE. Established and experimental medical therapy of pulmonary sarcoidosis. Eur Respir J 2013;41:1424-1438.

5. Korsten P, Mirsaeidi M, Sweiss NJ. Nonsteroidal therapy of sarcoidosis. Curr Opin Pulm Med 2013;19: 516-523.

6. Grutters JC, Van den Bosch JM. Corticosteroid treatment in sarcoidosis. Eur Respir J 2006;28:627-636.

7. Baughman RP. Pulmonary sarcoidosis. Clin Chest Med 2004;25:521-530,vi.

8. Paramothayan S, Lasserson T. Treatments for pulmonary sarcoidosis. Respir Med 2008;102:1-9.

9. Paramothayan S, Lasserson TJ, Walters EH. Immunosuppressive and cytotoxic therapy for pulmonary sarcoidosis. Cochrane Database Syst Rev 2006:CD003536.

10. Cremers JP, Drent M, Bast A, Shigemitsu H, Baughman RP, Valeyre D, Sweiss NJ, Jansen TL. Multinational evidence-based World Association of Sarcoidosis and Other Granulomatous Disorders recommendations for the use of methotrexate in sarcoidosis: integrating systematic literature research and expert opinion of sarcoidologists worldwide. Curr Opin Pulm Med 2013;19:545-561.

11. Schutt AC, Bullington WM, Judson MA. Pharmacotherapy for pulmonary sarcoidosis: a Delphi consensus study. Respir Med 2010;104:717-723.

12. Baughman RP, Drent M, Kavuru M, Judson MA, Costabel U, du Bois R, Albera C, Brutsche M, Davis G, Donohue JF, Muller-Quernheim J, Schlenker-Herceg R, Flavin S, Lo KH, Oemar B, Barnathan ES. Infliximab therapy in patients with chronic sarcoidosis and pulmonary involvement. Am J Respir Crit Care Med 2006;174:795-802.

13. Ziegenhagen MW, Rothe ME, Zissel G, Muller-Quernheim J. Exaggerated TNFalpha release of alveolar macrophages in corticosteroid resistant sarcoidosis. Sarcoidosis Vasc Diffuse Lung Dis 2002;19: 185-190.

14. Antoniu SA. Targeting the TNF-alpha pathway in sarcoidosis. Expert Opin Ther Targets 2010;14:21-29.

15. Loza MJ, Brodmerkel C, Du Bois RM, Judson MA, Costabel U, Drent M, Kavuru M, Flavin S, Lo KH, Barnathan ES, Baughman RP. Inflammatory profile and response to anti-tumor necrosis factor therapy in patients with chronic pulmonary sarcoidosis. Clin Vaccine Immunol 2011;18:931-939.

16. Aaltonen KJ, Virkki LM, Malmivaara A, Konttinen YT, Nordstrom DC, Blom M. Systematic review and meta-analysis of the efficacy and safety of existing TNF blocking agents in treatment of rheumatoid arthritis. PLoS One 2012;7:e30275.

17. Osterman MT, Haynes K, Delzell E, Zhang J, Bewtra M, Brensinger C, Chen L, Xie F, Curtis JR, Lewis JD. Comparative Effectiveness of Infliximab and Adalimumab for Crohn's Disease. Clin Gastroenterol Hepatol 2013;Epub ahead of print.

18. Thomson AB, Gupta M, Freeman HJ. Use of the tumor necrosis factor-blockers for Crohn's disease. World J Gastroenterol 2012;18:4823-4854.

19. Judson MA, Baughman RP, Costabel U, Flavin S, Lo KH, Kavuru MS, Drent M. Efficacy of infliximab in extrapulmonary sarcoidosis: results from a randomised trial. Eur Respir J 2008;31:1189-1196.

20. Rossman MD, Newman LS, Baughman RP, Teirstein A, Weinberger SE, Miller W, Jr., Sands BE. A doubleblinded, randomized, placebo-controlled trial of infliximab in subjects with active pulmonary sarcoidosis. Sarcoidosis Vasc Diffuse Lung Dis 2006;23:201-208.

21. Pariser RJ, Paul J, Hirano S, Torosky C, Smith M. A double-blind, randomized, placebo-controlled trial of adalimumab in the treatment of cutaneous sarcoidosis. J Am Acad Dermatol 2013;68:765-773.

22. Erckens RJ, Mostard RL, Wijnen PA, Schouten JS, Drent M. Adalimumab successful in sarcoidosis patients with refractory chronic non-infectious uveitis. Graefes Arch Clin Exp Ophthalmol 2012;250: 713-720. 
23. Liu Y, Wu EQ, Bensimon AG, Fan CP, Bao Y, Ganguli A, Yang M, Cifaldi M, Mulani P. Cost per responder associated with biologic therapies for Crohn's disease, psoriasis, and rheumatoid arthritis. Adv Ther 2012;29:620-634.

24. Rosenblum H, Amital H. Anti-TNF therapy: safety aspects of taking the risk. Autoimmun Rev 2011;10:563-568.

25. Singh JA, Wells GA, Christensen R, Tanjong Ghogomu E, Maxwell L, Macdonald JK, Filippini G, Skoetz N, Francis D, Lopes LC, Guyatt GH, Schmitt J, La Mantia L, Weberschock T, Roos JF, Siebert H, Hershan S, Lunn MP, Tugwell P, Buchbinder R. Adverse effects of biologics: a network meta-analysis and Cochrane overview. Cochrane Database Syst Rev 2011:CD008794.

26. De Meyrick J. The Delphi method and health research. Health Educ 2003;103:7-16.

27. Denmark VK, Mayer L. Current status of monoclonal antibody therapy for the treatment of inflammatory bowel disease: an update. Expert Rev Clin Immunol 2013;9:77-92.

28. Smolen JS, Landewe R, Breedveld FC, Buch M, Burmester G, Dougados M, Emery P, Gaujoux-Viala C, Gossec L, Nam J, Ramiro S, Winthrop K, De Wit M, Aletaha D, Betteridge N, Bijlsma JW, Boers M, Buttgereit F, Combe B, Cutolo M, Damjanov N, Hazes JM, Kouloumas M, Kvien TK, Mariette X, Pavelka K, Van Riel PL, Rubbert-Roth A, Scholte-Voshaar M, Scott DL, Sokka-Isler T, Wong JB, Van der Heijde D. EULAR recommendations for the management of rheumatoid arthritis with synthetic and biological disease-modifying antirheumatic drugs: 2013 update. Ann Rheum Dis 2013;Epub ahead of print.

29. Rubin DT, Panaccione R, Chao J, Robinson AM. A practical, evidence-based guide to the use of adalimumab in Crohn's disease. Curr Med Res Opin 2011;27:1803-1813.

30. Saag KG, Teng GG, Patkar NM, Anuntiyo J, Finney C, Curtis JR, Paulus HE, Mudano A, Pisu M, ElkinsMelton M, Outman R, Allison JJ, Suarez Almazor M, Bridges SL, Jr., Chatham WW, Hochberg $M$, MacLean C, Mikuls T, Moreland LW, O'Dell J, Turkiewicz AM, Furst DE. American College of Rheumatology 2008 recommendations for the use of nonbiologic and biologic disease-modifying antirheumatic drugs in rheumatoid arthritis. Arthritis Rheum 2008;59:762-784.

31. Singh JA, Furst DE, Bharat A, Curtis JR, Kavanaugh AF, Kremer JM, Moreland LW, O'Dell J, Winthrop KL, Beukelman T, Bridges SL, Jr., Chatham WW, Paulus HE, Suarez-Almazor M, Bombardier C, Dougados M, Khanna D, King CM, Leong AL, Matteson EL, Schousboe JT, Moynihan E, Kolba KS, Jain A, Volkmann ER, Agrawal H, Bae S, Mudano AS, Patkar NM, Saag KG. 2012 update of the 2008 American College of Rheumatology recommendations for the use of disease-modifying antirheumatic drugs and biologic agents in the treatment of rheumatoid arthritis. Arthritis Care Res (Hoboken) 2012;64: 625-639.

32. Furst DE, Keystone EC, So AK, Braun J, Breedveld FC, Burmester GR, De Benedetti F, Dorner T, Emery P, Fleischmann R, Gibofsky A, Kalden JR, Kavanaugh A, Kirkham B, Mease P, Rubbert-Roth A, Sieper J, Singer NG, Smolen JS, Van Riel PL, Weisman MH, Winthrop KL. Updated consensus statement on biological agents for the treatment of rheumatic diseases, 2012. Ann Rheum Dis 2013;72 Suppl 2:ii2-34.

33. D'Haens GR, Panaccione R, Higgins PD, Vermeire S, Gassull M, Chowers $Y$, Hanauer SB, Herfarth $H$, Hommes DW, Kamm M, Lofberg R, Quary A, Sands B, Sood A, Watermeyer G, Lashner B, Lemann M, Plevy S, Reinisch W, Schreiber S, Siegel C, Targan S, Watanabe M, Feagan B, Sandborn WJ, Colombel JF, Travis S. The London Position Statement of the World Congress of Gastroenterology on Biological Therapy for IBD with the European Crohn's and Colitis Organization: when to start, when to stop, which drug to choose, and how to predict response? Am J Gastroenterol 2011;106:199-212;quiz 213.

34. Wijnen PA, Cremers JP, Nelemans PJ, Erckens RJ, Hoitsma E, Jansen TL, Bekers O, Drent M. Association of the TNF- $\alpha$ G-308A polymorphism with TNF-inhibitor response in sarcoidosis. Eur Respir J 2014; In press.

35. Hostettler KE, Studler U, Tamm M, Brutsche MH. Long-term treatment with infliximab in patients with sarcoidosis. Respiration 2012;83:218-224.

36. Orum M, Hilberg $\mathrm{O}$, Krag S, Bendstrup E. Beneficial effect of infliximab on refractory sarcoidosis. Dan Med J 2012;59:A4535.

37. Keijsers RG, Verzijlbergen JF, Van Diepen DM, Van den Bosch JM, Grutters JC. 18F-FDG PET in sarcoidosis: an observational study in 12 patients treated with infliximab. Sarcoidosis Vasc Diffuse Lung Dis 2008;25:143-149.

38. Saleh S, Ghodsian S, Yakimova V, Henderson J, Sharma OP. Effectiveness of infliximab in treating selected patients with sarcoidosis. Respir Med 2006;100:2053-2059.

39. Doty JD, Mazur JE, Judson MA. Treatment of sarcoidosis with infliximab. Chest 2005;127:1064-1071. 
40. Milman N, Graudal N, Loft A, Mortensen J, Larsen J, Baslund B. Effect of the TNF-alpha inhibitor adalimumab in patients with recalcitrant sarcoidosis: a prospective observational study using FDG-PET. Clin Respir J 2012;6:238-247.

41. Banse C, Bisson-Vaivre A, Kozyreff-Meurice M, Vittecoq O, Goeb V. No impact of tumor necrosis-factor antagonists on the joint manifestations of sarcoidosis. Int J Gen Med 2013;6:605-611.

42. Baughman RP, Lower EE, Ingledue R, Kaufman AH. Management of ocular sarcoidosis. Sarcoidosis Vasc Diffuse Lung Dis 2012;29:26-33.

43. Elfferich MD, Nelemans PJ, Ponds RW, De Vries J, Wijnen PA, Drent M. Everyday cognitive failure in sarcoidosis: the prevalence and the effect of anti-TNF-alpha treatment. Respiration 2010;80:212-219.

44. Baughman R. Tumor necrosis factor inhibition in treating sarcoidosis: the American experience. Rev Port de Pneumologia 2007;8:S47-S50.

45. Goenka N, Venna N. Teaching Neurolmages: Sarcoidosis presenting as longitudinally extensive myelitis: Excellent response to infliximab. Neurology 2013;81:e61.

46. Vorselaars AD, Sjogren EV, Van Moorsel CH, Grutters JC. Bilateral Vocal Cord Carcinoma in a Sarcoidosis Patient during Infliximab Therapy. Case Rep Pulmonol 2013;2013:308092.

47. Tu J, Chan J. Cutaneous sarcoidosis and infliximab: evidence for efficacy in refractory disease. Australas J Dermatol 2013; Epub ahead of print.

48. O'Reilly MW, Sexton DJ, Dennedy MC, Counihan TJ, Finucane FM, O'Brien T, O'Regan AW. Radiological remission and recovery of thirst appreciation after infliximab therapy in adipsic diabetes insipidus secondary to neurosarcoidosis. Qjm 2013; Epub ahead of print.

49. Vorselaars AD, Keijsers RG, Grutters JC. Earlobe sarcoidosis. Sarcoidosis Vasc Diffuse Lung Dis 2012; 29:55-57.

50. Huffstutter JG, Huffstutter JE. Hypercalcemia from sarcoidosis successfully treated with infliximab. Sarcoidosis Vasc Diffuse Lung Dis 2012;29:51-52.

51. Chintamaneni S, Patel AM, Pegram SB, Patel H, Roppelt H. Dramatic response to infliximab in refractory neurosarcoidosis. Ann Indian Acad Neurol 2010;13:207-210.

52. Pereira J, Anderson NE, McAuley D, Bergin P, Kilfoyle D, Fink J. Medically refractory neurosarcoidosis treated with infliximab. Intern Med J 2011;41:354-357.

53. Santos E, Shaunak S, Renowden S, Scolding NJ. Treatment of refractory neurosarcoidosis with Infliximab. J Neurol Neurosurg Psychiatry 2010;81:241-246.

54. Moravan M, Segal BM. Treatment of CNS sarcoidosis with infliximab and mycophenolate mofetil. Neurology 2009;72:337-340.

55. Sodhi M, Pearson K, White ES, Culver DA. Infliximab therapy rescues cyclophosphamide failure in severe central nervous system sarcoidosis. Respir Med 2009;103:268-273.

56. Barnabe C, McMeekin J, Howarth A, Martin L. Successful treatment of cardiac sarcoidosis with infliximab. J Rheumatol 2008;35:1686-1687.

57. Dolhun R, Sriram S. Neurosarcoidosis presenting as longitudinally extensive transverse myelitis. J Clin Neurosci 2009;16:595-597.

58. Petropoulos IK, Vaudaux JD, Guex-Crosier Y. Anti-TNF-alpha therapy in patients with chronic noninfectious uveitis: the experience of Jules Gonin Eye Hospital. Klin Monbl Augenheilkd 2008;225: 457-461.

59. Baughman RP, Bradley DA, Lower EE. Infliximab in chronic ocular inflammation. Int J Clin Pharmacol Ther 2005;43:7-11.

60. Kumar G, Kang CA, Giannini C. Neurosarcoidosis presenting as a cerebellar mass. J Gen Intern Med 2007;22:1373-1376.

61. Toth C, Martin L, Morrish W, Coutts S, Parney I. Dramatic MRI improvement with refractory neurosarcoidosis treated with infliximab. Acta Neurol Scand 2007;116:259-262.

62. Uthman I, Touma Z, Khoury M. Cardiac sarcoidosis responding to monotherapy with infliximab. Clin Rheumatol 2007;26:2001-2003.

63. Hoitsma E, Faber CG, Van Santen-Hoeufft M, De Vries J, Reulen JP, Drent M. Improvement of small fiber neuropathy in a sarcoidosis patient after treatment with infliximab. Sarcoidosis Vasc Diffuse Lung Dis 2006;23:73-77.

64. Salama B, Gicquel JJ, Lenoble P, Dighiero PL. Optic neuropathy in refractory neurosarcoidosis treated with TNF-alpha antagonist. Can J Ophthalmol 2006;41:766-768. 
65. Benitez-del-Castillo JM, Martinez-de-la-Casa JM, Pato-Cour E, Mendez-Fernandez R, Lopez-Abad C, Matilla M, Garcia-Sanchez J. Long-term treatment of refractory posterior uveitis with anti-TNFalpha (infliximab). Eye (Lond) 2005;19:841-845.

66. Carter JD, Valeriano J, Vasey FB, Bognar B. Refractory neurosarcoidosis: a dramatic response to infliximab. Am J Med 2004;117:277-279.

67. Sollberger M, Fluri F, Baumann T, Sonnet S, Tamm M, Steck AJ, Brutsche M. Successful treatment of steroid-refractory neurosarcoidosis with infliximab. J Neurol 2004;251:760-761.

68. Katz JM, Bruno MK, Winterkorn JM, Nealon N. The pathogenesis and treatment of optic disc swelling in neurosarcoidosis: a unique therapeutic response to infliximab. Arch Neurol 2003;60:426-430.

69. Roberts SD, Wilkes DS, Burgett RA, Knox KS. Refractory sarcoidosis responding to infliximab. Chest 2003;124:2028-2031.

70. Pettersen JA, Zochodne DW, Bell RB, Martin L, Hill MD. Refractory neurosarcoidosis responding to infliximab. Neurology 2002;59:1660-1661.

71. Dragnev D, Barr D, Kulshrestha M, Shanmugalingam S. Sarcoid panuveitis associated with etanercept treatment, resolving with adalimumab. BMJ Case Rep 2013;Epub ahead of print.

72. Kamphuis LS, Lam-Tse WK, Dik WA, Van Daele PL, Van Biezen P, Kwekkeboom DJ, Kuijpers RW, Hooijkaas H, Van Laar JA, Bastiaans J, Baarsma GS, Van Hagen PM. Efficacy of adalimumab in chronically active and symptomatic patients with sarcoidosis. Am J Respir Crit Care Med 2011;184:1214-1216.

73. Patel SR. Systemic sarcoidosis with bone marrow involvement responding to therapy with adalimumab: a case report. J Med Case Rep 2009;3:8573.

74. Hasni SA, Kunz D, Finzel K, Gruber BL. Osseous sarcoidosis treated with tumor necrosis factor-inhibitors: case report and review of the literature. Spine (Phila Pa 1976) 2010;35:E904-907.

75. Te HS, Campbell L, Chohan S. Infliximab therapy for hepatic and intestinal sarcoidosis. Gastroenterol Hepatol (N Y) 2007;3:447-452.

76. Ahmed MM, Mubashir E, Dossabhoy NR. Isolated renal sarcoidosis: a rare presentation of a rare disease treated with infliximab. Clin Rheumatol 2007;26:1346-1349.

77. Thumfart J, Muller D, Rudolph B, Zimmering M, Querfeld U, Haffner D. Isolated sarcoid granulomatous interstitial nephritis responding to infliximab therapy. Am J Kidney Dis 2005;45: 411-414.

78. Hommes DW, Oldenburg B, Van Bodegraven AA, Van Hogezand RA, De Jong DJ, Romberg-Camps MJ, Van der Woude J, Dijkstra G. Guidelines for treatment with infliximab for Crohn's disease. Neth J Med 2006;64:219-229.

79. Russell E, Luk F, Manocha S, Ho T, O'Connor C, Hussain H. Long term follow-up of infliximab efficacy in pulmonary and extra-pulmonary sarcoidosis refractory to conventional therapy. Semin Arthritis Rheum 2013;43:119-124.

80. Baughman RP, Lower EE, Drent M. Inhibitors of tumor necrosis factor (TNF) in sarcoidosis: who, what, and how to use them. Sarcoidosis Vasc Diffuse Lung Dis 2008;25:76-89.

81. Utz JP, Limper AH, Kalra S, Specks U, Scott JP, Vuk-Pavlovic Z, Schroeder DR. Etanercept for the treatment of stage II and III progressive pulmonary sarcoidosis. Chest 2003;124:177-185.

82. Baughman RP, Lower EE, Bradley DA, Raymond LA, Kaufman A. Etanercept for refractory ocular sarcoidosis: results of a double-blind randomized trial. Chest 2005;128:1062-1047.

83. Osterman MT, Lichtenstein GR. Current and Future Anti-TNF Therapy for Inflammatory Bowel Disease. Curr Treat Options Gastroenterol 2007;10:195-207.

84. Bozkurt B, Torre-Amione G, Warren MS, Whitmore J, Soran OZ, Feldman AM, Mann DL. Results of targeted anti-tumor necrosis factor therapy with etanercept (ENBREL) in patients with advanced heart failure. Circulation 2001;103:1044-1047.

85. Chung ES, Packer M, Lo KH, Fasanmade AA, Willerson JT. Randomized, double-blind, placebocontrolled, pilot trial of infliximab, a chimeric monoclonal antibody to tumor necrosis factor-alpha, in patients with moderate-to-severe heart failure: results of the anti-TNF Therapy Against Congestive Heart Failure (ATTACH) trial. Circulation 2003;107:3133-3140.

86. Mann DL, McMurray JJ, Packer M, Swedberg K, Borer JS, Colucci WS, Djian J, Drexler H, Feldman A, Kober L, Krum H, Liu P, Nieminen M, Tavazzi L, Van Veldhuisen DJ, Waldenstrom A, Warren M, Westheim A, Zannad F, Fleming T. Targeted anticytokine therapy in patients with chronic heart failure: results of the Randomized Etanercept Worldwide Evaluation (RENEWAL). Circulation 2004;109: 1594-1602. 
87. Sood A, Midha V. Symptomatic sinus bradycardia with infliximab. Indian J Gastroenterol 2004;23: 118-119.

88. Sote Y, Green S, Maddison P. Complete heart block after infliximab therapy. Rheumatology (Oxford) 2008;47:227-228.

89. Vorselaars AD, Verwoerd A, Van Moorsel CH, Keijsers RG, Rijkers GT, Grutters JC. Prediction of relapse after discontinuation of infliximab therapy in severe sarcoidosis. Eur Respir J 2013; Epub ahead of print.

90. Dasilva V, Breuil V, Chevallier P, Euller-Ziegler L. Relapse of severe sarcoidosis with an uncommon peritoneal location after TNFalpha blockade. Efficacy of rituximab, report of a single case. Joint Bone Spine 2010;77:82-83.

91. De Vries HS, Van Oijen MG, Driessen RJ, De Jong EM, Creemers MC, Kievit W, De Jong DJ. Appropriate infliximab infusion dosage and monitoring: results of a panel meeting of rheumatologists, dermatologists and gastroenterologists. Br J Clin Pharmacol 2011;71:7-19.

92. Orlando A, Armuzzi A, Papi C, Annese V, Ardizzone S, Biancone L, Bortoli A, Castiglione F, D'Inca R, Gionchetti P, Kohn A, Poggioli G, Rizzello F, Vecchi M, Cottone M. The Italian Society of Gastroenterology (SIGE) and the Italian Group for the study of Inflammatory Bowel Disease (IG-IBD) Clinical Practice Guidelines: The use of tumor necrosis factor-alpha antagonist therapy in inflammatory bowel disease. Dig Liver Dis 2011;43:1-20.

93. Lower EE, Baughman RP, Kaufman AH. Rituximab for refractory granulomatous eye disease. Clin Ophthalmol 2012;6:1613-1618.

94. Beccastrini E, Vannozzi L, Bacherini D, Squatrito D, Emmi L. Successful treatment of ocular sarcoidosis with rituximab. Ocul Immunol Inflamm 2013;21:244-246.

95. Kavanaugh A, Smolen JS. The when and how of biologic agent withdrawal in rheumatoid arthritis: learning from large randomised controlled trials. Clin Exp Rheumatol 2013;31:S19-21.

96. Tanaka Y, Hirata S, Saleem B, Emery P. Discontinuation of biologics in patients with rheumatoid arthritis. Clin Exp Rheumatol 2013;31:S22-27.

97. Baughman RP, Drent M, Culver DA, Grutters JC, Handa T, Humbert M, Judson MA, Lower EE, Mana J, Pereira CA, Prasse A, Sulica R, Valyere D, Vucinic V, Wells AU. Endpoints for clinical trials of sarcoidosis. Sarcoidosis Vasc Diffuse Lung Dis 2012;29:90-98.

98. Panselinas E, Rodgers JK, Judson MA. Clinical outcomes in sarcoidosis after cessation of infliximab treatment. Respirology 2009;14:522-528.

99. Van den Broek M, Lems WF, Allaart CF. Do we need guidelines to stop as well as to start biological therapies for rheumatoid arthritis? Clin Exp Rheumatol 2012;30:S21-26.

100. Papa A, Mocci G, Bonizzi M, Felice C, Andrisani G, De Vitis I, Guidi L, Gasbarrini A. Use of infliximab in particular clinical settings: management based on current evidence. Am J Gastroenterol 2009;104: 1575-1586.

101. Redelman-Sidi G, Sepkowitz KA. IFN-gamma release assays in the diagnosis of latent tuberculosis infection among immunocompromised adults. Am J Respir Crit Care Med 2013;188:422-431.

102. Pouw MF, Krieckaert CL, Nurmohamed MT, Van der Kleij D, Aarden L, Rispens T, Wolbink G. Key findings towards optimising adalimumab treatment: the concentration-effect curve. Ann Rheum Dis 2013; Epub ahead of print. 


\section{Chapter 8}

\section{Association of the TNF- $\alpha$ G-308A polymorphism with TNF-inhibitor response in sarcoidosis}

P Wijnen, J Cremers, P Nelemans, R Erckens, E Hoitsma, T Jansen, O Bekers, M Drent 


\section{Abstract}

\section{Background}

Responsiveness to tumor necrosis factor-alpha (TNF- $\alpha$ ) inhibitors has been associated with the $T N F-\alpha$ G-308A polymorphism in rheumatoid arthritis. The aim of this study was to examine the association between the presence of this polymorphism and the response to TNF- $\alpha$ inhibitors in patients with refractory sarcoidosis.

\section{Methods}

Patients ( $n=111$ ) who started TNF- $\alpha$ inhibitor treatment (76 infliximab, 35 adalimumab) were followed for at least 1 year. Main symptoms in these patients were fatigue $(n=100,90.1 \%)$, small fiber neuropathy $(n=91 ; 82.0 \%)$, pulmonary involvement $(n=69 ; 62.2 \%)$, and/or uveitis $(n=31$; 27.9\%). Patients were additionally genotyped for the presence of the TNF- $\alpha$ G-308A polymorphism. Treatment response was assessed using clinical outcome measures and questionnaires.

\section{Results}

Three-quarters $(n=83 ; 74.8 \%)$ of the patients responded well. Of the patients without the variant A-allele $93.6 \%(73 / 78 ; p<0.001)$ improved, while $30.3 \%(10 / 33)$ of variant A-allele carriers responded favorably to TNF- $\alpha$ inhibitors. For patients with the GG-genotype, the probability of improving compared with remaining stable or deteriorating was three times higher (risk ratio=3.09; 95\% confidence interval 1.84-5.20).

\section{Conclusion}

Sarcoidosis patients without the TNF- $\alpha$-308A variant allele (GG-genotype) had a three-fold higher response to TNF- $\alpha$ inhibitors (adalimumab or infliximab). Further research is needed to evaluate the value of genotyping for the TNF- $\alpha$ G-308A polymorphism in order to tailor TNF- $\alpha$ inhibitor treatment. 


\section{Introduction}

Sarcoidosis is a multisystem disease characterized by inflammatory activity with the formation of noncaseating granulomas that commonly affect the lungs, although other organ systems can also be involved. ${ }^{1,2}$ Clinical presentation and outcome vary greatly and therapeutic options range from no treatment to a variety of pharmacological agents. $^{2}$

Although the exact etiology is still unknown, tumor necrosis factor-alpha (TNF- $\alpha$ ) is known to play a crucial role in the granuloma formation. ${ }^{2}$ The production of this cytokine by alveolar macrophages is substantially elevated, and TNF- $\alpha$ elevation has been shown to correlate with sarcoid disease activity and progression. ${ }^{3}$ In severe sarcoidosis, the release of inflammatory mediators causes derangement of organ physiology and ultimately irreversible organ damage. ${ }^{1}$ Timely implementation of an appropriate potent individual treatment regimen is especially important for patients with a severe disease course and poor prognosis. ${ }^{4,5}$

Glucocorticosteroids are traditionally considered first-line treatment, but their long-term use can be impaired by failure or intolerance, with serious adverse effects such as weight gain/obesity, diabetes or osteoporosis., ${ }^{6,7}$ In case of intolerable sideeffects or steroid resistance, second-line treatment options should be considered, such as methotrexate (MTX), azathioprine or leflunomide, but these therapies may also be subject to failure or intolerance. ${ }^{8-10}$ Another option to consider is TNF- $\alpha$ inhibitors, which inhibit the potent pro-inflammatory TNF- $\alpha$, often a predominant problem in patients with refractory sarcoidosis, and these have shown promising results. ${ }^{11-14}$ However, a drawback of TNF- $\alpha$ inhibitors is considerable treatment costs. ${ }^{15}$ Therefore, the ideal situation would involve identification of patients likely to respond to TNF- $\alpha$ inhibitors before starting treatment.

When considering the natural course of sarcoidosis, polymorphisms seem to make an important contribution to the clinical phenotype. ${ }^{16}$ Genetic analysis has previously revealed a number of polymorphisms in genes coding for TNF- $\alpha$, with potential functional consequences. ${ }^{17}$ The presence of the TNF- $\alpha$ - 308A variant allele, which has been associated with variations in TNF- $\alpha$ production, proved to be associated with a favorable prognosis. ${ }^{16-18}$ In rheumatoid arthritis, the TNF- $\alpha$ G-308A polymorphism has been studied in relation to TNF- $\alpha$ inhibitors. Patients without the TNF- $\alpha-308 \mathrm{~A}$ variant allele were found to be better responders. ${ }^{19,20}$ However, studies assessing such an association in sarcoidosis are currently lacking.

The aim of the present study was to assess the association between the presence of the TNF- $\alpha$ G-308A polymorphism and the response to TNF- $\alpha$ inhibitors among patients with refractory sarcoidosis. 


\section{Methods}

\section{Study population}

Dutch Caucasian patients with refractory sarcoidosis $(n=118)$ with various manifestations despite conventional treatment were started on TNF- $\alpha$ inhibitors during a 4-year period (2007-2011) and followed for at least 1 year. Patients were diagnosed with sarcoidosis in accordance with the guidelines of the World Association of Sarcoidosis and Other Granulomatous diseases, as previously reported. ${ }^{1,18}$

All patients were given prednisone as a first-line treatment. When this treatment failed or when serious side-effects occurred, a combination of prednisone and MTX was given. Finally, TNF- $\alpha$ inhibitor treatment was started if combination treatment did not achieve clinical improvement. Failure of therapy was determined by a pulmonologist, neurologist and/or ophthalmologist and defined as either clinical or symptomatic progression of disease despite conventional therapy.

If treatment was discontinued within 1 year, patients were regarded as drop-outs. Of the initial 118 patients, seven discontinued treatment within 1 year, leaving 111 for the analyses. Pulmonary and extrapulmonary (i.e. ocular, cutaneous, lymphatic, musculoskeletal, and neurologic) data were collected. Patients were treated with infliximab $(n=76)$ or adalimumab $(n=35)$.

The study was performed in accordance with the Declaration of Helsinki and its amendments. Written informed consent for participation was obtained from all patients and the protocol was approved by the Medical Ethics Board of Maastricht University Medical Centre+, Maastricht, The Netherlands (METC 11-4-116).

\section{Clinical response rate}

Responses to TNF- $\alpha$ inhibitors were defined. A patient's individual clinical response was graded 1 year after starting TNF- $\alpha$ inhibitors, based on documented objective data. Each organ with documented sarcoid involvement or symptoms or inflammation was graded in a systematic manner before and after 1 year of TNF- $\alpha$ inhibitor treatment, as described below. We carefully documented whether a patient improved, was stable or deteriorated.

Improvement was defined as an increase or decrease in at least one of the parameters, values or scores of $\geq 10 \%$ of the original value. Any change, whether an increase or a reduction, of $<10 \%$ was regarded as stable disease and a decrease or increase, when appropriate, of $\geq 10 \%$ as deterioration.

\section{Evaluation of pulmonary involvement}

All chest radiographs were graded, at inclusion and after 1 year of treatment, by a single observer, who was blinded to the genetic test results. Radiographic abnormalities were classified into five stages (0 to IV), as described previously. ${ }^{18}$ 
Forced vital capacity (FVC), forced expiratory volume in 1 second (FEV1), and diffusing capacity for carbon monoxide (DLCO) were measured. ${ }^{18}$ Values were expressed as a percentage of the predicted values. The cut-off value for DLCO, FEV1 and FVC was $<80 \%$ of predicted ( $\geq 80 \%$ was considered normal). ${ }^{21}$ Respiratory functional impairment (RFI) was defined as DLCO $<80 \%$, FVC $<80 \%$ or FEV $1<80 \%$. Patients without RFI were those for whom all three indices were normal. ${ }^{22}$ Patients with pulmonary sarcoidosis should have RFI and/or abnormal chest radiographs (Stage II or higher; Figure 8.1).
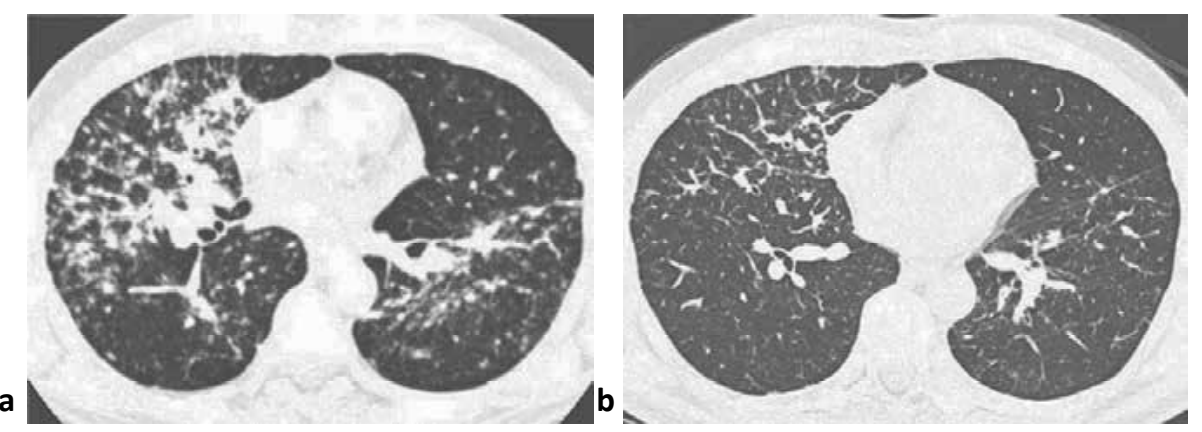

Figure 8.1 An example of a patient with respiratory functional impairment with substantial improvement after 1 year of treatment with infliximab. The original value of the diffusing capacity for carbon monoxide improved by $\geq 10 \%$ from $67 \%$ to $78 \%$ of predicted, while the forced vital capacity changed from $77 \%$ to $83 \%$, and the forced expiratory volume in one second from $90 \%$ to $92 \%$. a. High-resolution computed tomography (HRCT) scan before treatment with infliximab; b. HRCT scan after treatment with infliximab showing a decrease of the parenchymal lesions.

\section{Evaluation of uveitis}

All patients with eye problems due to sarcoidosis were evaluated by the same ophthalmologist, who was blinded to the genetic test results. The patients were screened for the presence of uveitis, as described previously. ${ }^{23}$ In addition, fluorescein angiography or optical coherence tomography was performed to detect the presence of vasculitis, papillitis, or macular edema, as described previously (Figure 8.2). ${ }^{23}$

The overall outcome of intraocular inflammatory signs was scored as improvement if at least one of the inflammatory signs scored showed complete clearance or if at least one of the inflammatory signs scored improved in the absence of deterioration of other inflammatory signs. It was scored as stabilization if all inflammatory signs remained unchanged, and as deterioration if at least one of the inflammatory signs increased. ${ }^{23}$ 

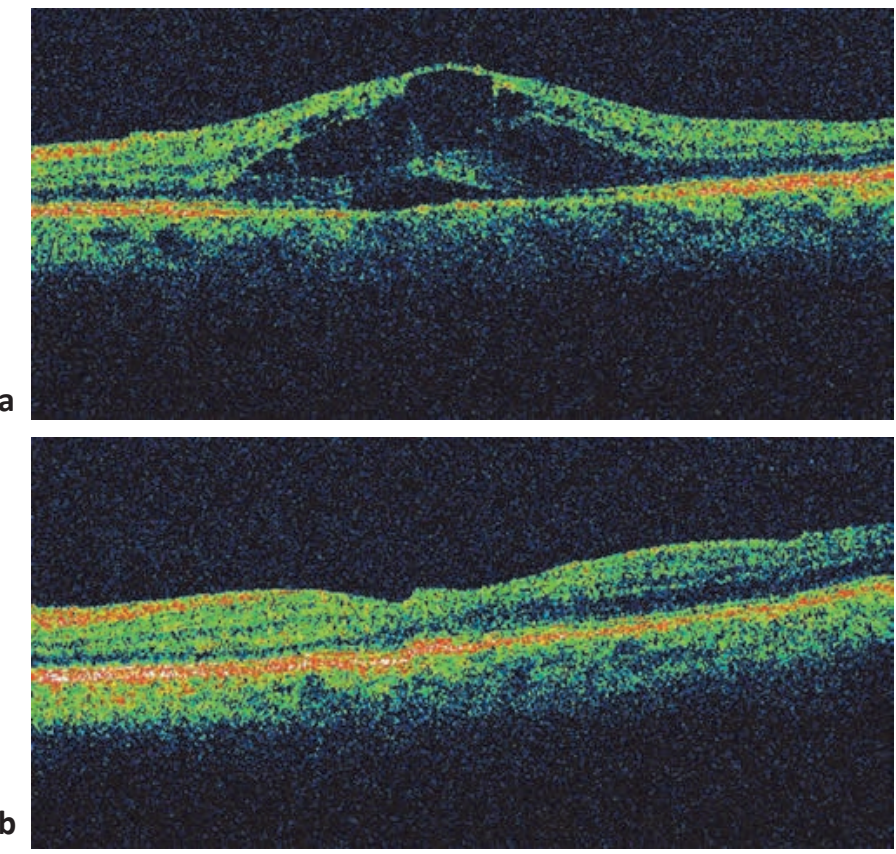

Figure 8.2 a. Optical coherence tomography scan in a patient with uveitis before treatment with adalimumab; and $\mathbf{b}$. after 1 year of treatment with adalimumab, showing reduction of macular edema.

\section{Evaluation of small fiber neuropathy}

The presence of small fiber neuropathy (SFN) symptoms was assessed using the small fiber neuropathy screenings list (SFNSL). It is a practical, brief and easy to use tool to screen for the presence of SFN-related symptoms with high scores indicating more severe SFN-related symptoms. ${ }^{24}$

Temperature threshold testing was used to support the presence of SFN. This test was used to assess the function of small caliber sensory fibers by measuring temperature sensation thresholds, as described previously. ${ }^{25}$

\section{Evaluation of fatigue}

One of the most important patient-reported outcome measures is fatigue, which was assessed by means of the fatigue assessment scale (FAS). The FAS contains 10 specific fatigue questions that have been validated for sarcoidosis patients, with high scores indicating more fatigue. The minimal clinically important difference has been established, and a change of $\geq 4$ points or $10 \%$ change in FAS score was found to be clinically significant. $^{26}$ 


\section{Evaluation of inflammation}

Serum levels of angiotensin-converting enzyme (ACE, reference interval: 9-25 U/l; measured by a colorimetric method (cat. no. FU 116; Fujirebio Inc., Tokyo, Japan)) and soluble-interleukin2-receptor (sIL2R, levels considered elevated if >3154 pg/ml; analysed in commercially available Diaclone ELISA kits (Sanquin, Amsterdam, The Netherlands)) were measured according to manufacturer's instructions.

\section{Other manifestations}

Neurosarcoidosis was evaluated by a neurologist based on the results of magnetic resonance imaging scans (Figure 8.3). Photographs of skin lesions prior to and after treatment were used as the main outcome measures for skin lesions.
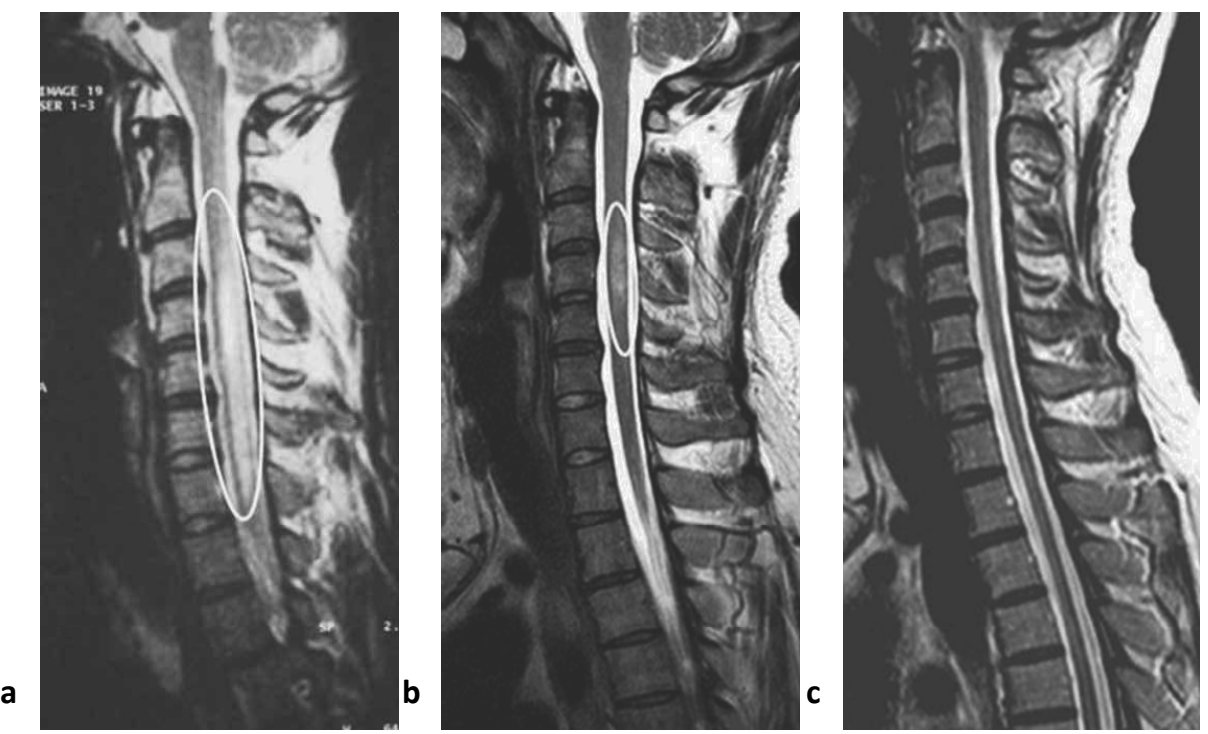

Figure 8.3 Sagittal T2 weighted magnetic resonance images. a. Before treatment showing an extensive spinal cord lesion; b. After 1 year of treatment with infliximab, with only a minor lesion left; $\mathbf{c}$. After 3 years, showing complete remission of the spinal cord lesion.

\section{Evaluation of response rates}

The overall response rate was calculated by scoring improvement, stable disease or deterioration of disease manifestations of sarcoidosis. Response was defined as improvement of at least one of the following if it was the main reason for treatment: RFI, SFN symptoms, uveitis, skin lesions or neurosarcoidosis, without deterioration of any other disease manifestation. Stable was defined as no improvement or no deterioration of at least the major reason for treatment without deterioration of any other disease manifestation. Deterioration was defined as deterioration of at least the major disease manifestation. 


\section{Genotyping}

DNA was obtained using venous EDTA anti-coagulated blood and isolated, according to the manufacturer's instructions. All patients were genotyped for the TNF- $\alpha$ G-308A promoter polymorphism using a real-time PCR Fluorescence Resonance Energy Transfer assay (TIB MOLBIOL, Berlin, Germany), as described previously. ${ }^{18}$ The person who performed the analyses was blinded to the clinical data and response to therapy.

\section{Statistical analysis}

Statistical analyses were performed with SPSS 20.0 (SPSS Inc., Chicago, IL, USA) for Windows. Cross tables were used to compare the percentages of patients with response according to each genotype. Relative risk (RR) with $95 \%$ confidence interval (CI) was calculated to evaluate strength of association. Multivariate logistic regression analyses were used to adjust for relevant baseline differences between genotype groups. The Chi-square test was used to test for statistically significant differences between groups and to calculate deviations from the Hardy-Weinberg equilibrium. A p value of $<0.05$ (two-sided) was considered to indicate statistical significance.

\section{Results}

Characteristics of patients in our sarcoidosis sample and the main reasons for initiating TNF- $\alpha$ inhibitors are summarized in Table 8.1.

Patients suffered from one or more disabling problems: 91 (82.0\%) out of 111 suffered from SFN (SFNSL >11), with 38 (34.2\%) having severe symptoms (SFNSL >37); $69(62.2 \%)$ out of 111 suffered from pulmonary sarcoidosis (Figure 8.1 ); 31 (27.9\%) out of 111 from uveitis; six (5.4\%) out of 111 from skin lesions; one (0.9\%) out of 111 from spinal cord involvement; and one (0.9\%) out of 111 from kidney failure. In addition, the majority of the patients (100 (90.1\%) out of 111 ) also suffered from fatigue (FAS $\geq 22$ ), with 59 (59.0\%) out of 100 having severe fatigue (FAS >34).

Responders were identified based on the following criteria: in 39 (56.5\%) out of the 69 patients with RFI at least one lung function test parameter improved by more than $10 \%$. Of the 31 patients with eye involvement, 23 (74.2\%) improved substantially according to the criteria used by the ophthalmologist (Figure 8.2). Neurological symptoms improved in $49(53.8 \%)$ out of 91 patients, in 17 of whom this appeared to be the only improving primary endpoint. All six patients with skin lesions responded, as well as the patient suffering from neurosarcoidosis (spinal cord involvement; Figure 8.3) and the patient with kidney problems. Signs of activity and inflammation improved in $75(67.6 \%)$ out of 111 patients, and fatigue improved in 60 (60.0\%) out of 100 patients. None of the responders showed deterioration in any of the other manifestations of sarcoidosis that were present. 
Table 8.1 Characteristics of the study population. ${ }^{a}$

\begin{tabular}{|c|c|c|c|c|}
\hline & Total population & Lung involvement & SFN symptoms & Eye involvement \\
\hline Number & 111 & 69 & 32 & 10 \\
\hline Age (y) & $45.0 \pm 10.6$ & $44.5 \pm 10.8$ & $46.6 \pm 9.8$ & $43.0 \pm 11.6$ \\
\hline Female/male & $46 / 65$ & $30 / 39$ & $10 / 22$ & $6 / 4$ \\
\hline CXR stage: $0+1 / I I+I I I / I V$ & $54 / 43 / 14$ & $21 / 34 / 14^{*}$ & $24 / 8 / 0$ & $9 / 1 / 0$ \\
\hline FEV1 \% predicted & $85.7 \pm 24.2$ & $75.2 \pm 22.7^{*}$ & $104.5 \pm 12.1$ & $105.4 \pm 13.4$ \\
\hline FVC $\%$ predicted & $96.6 \pm 19.2$ & $88.6 \pm 17.7^{*}$ & $110.6 \pm 13.1$ & $111.7 \pm 12.9$ \\
\hline DLCO $\%$ predicted & $77.1 \pm 17.2$ & $68.3 \pm 12.9 *$ & $92.2 \pm 11.8$ & $95.8 \pm 11.3$ \\
\hline RFI & $69(62.2)$ & 69 (100) & $0(0)$ & $0(0)$ \\
\hline ACE U/I & $20.7 \pm 12.9$ & $21.5 \pm 14.2$ & $19.0 \pm 10.1$ & $20.0 \pm 9.6$ \\
\hline slL2R pg/ml & $3073 \pm 3120$ & $3530 \pm 3645$ & $2337 \pm 1460$ & $1719 \pm 1190$ \\
\hline FAS & $33.0 \pm 8.5$ & $33.5 \pm 8.4$ & $33.6 \pm 17.9$ & $27.6 \pm 8.1$ \\
\hline Fatigue reported & $100(90.1)$ & $63(91.3)$ & $29(90.6)$ & $8(80.0)$ \\
\hline SFNSL & $32.5 \pm 19.3$ & $32.0 \pm 20.0$ & $37.6 \pm 18.0$ & $18.8 \pm 9.1 * *$ \\
\hline SFN symptoms & $91(82.0)$ & $54(78.3)$ & $32(100)$ & $5(50.0)$ \\
\hline Eye involvement & 31 (27.9) & $16(23.2)^{*}$ & $5(15.6)$ & $10(100)$ \\
\hline Adalimumab & 35 & 23 & 5 & 7 \\
\hline $\mathrm{mg} /$ dose sc & $45.9 \pm 15.5$ & $47.2 \pm 17.2$ & $48.0 \pm 17.9$ & $40.0 \pm 0.0$ \\
\hline dose interval, weeks & 1 & 1 & 1 & 1 \\
\hline Infliximab & 76 & 46 & 27 & 3 \\
\hline $\mathrm{mg} /$ dose intravenously & $404.1 \pm 25.5$ & $404.5 \pm 28.1$ & $403.7 \pm 19.2$ & $400.0 \pm 0.0$ \\
\hline dose interval, weeks & $4.5 \pm 0.6$ & $4.5 \pm 0.5$ & $4.6 \pm 0.6$ & $4.0 \pm 0.0$ \\
\hline \multicolumn{5}{|l|}{ Co-medication } \\
\hline no prednisone, no MTX & 40 & 15 & 16 & 9 \\
\hline prednisone alone & 14 & 10 & 1 & 3 \\
\hline $\mathrm{mg} /$ day, orally \pm range & $14.3 \pm 10.7$ & $15.4 \pm 11.7$ & $15.0 \pm 0.0$ & $8.8 \pm 8.8$ \\
\hline prednisone $+\mathrm{MTX}$ & 28 & 19 & 7 & 2 \\
\hline pred mg/day, orally & $9.3 \pm 5.2$ & $8.6 \pm 3.7$ & $12.9 \pm 8.1$ & $5.0 \pm 0.0$ \\
\hline MTX mg/week, orally & $9.1 \pm 2.9$ & $9.6 \pm 3.1$ & $7.9 \pm 1.0$ & $8.5 \pm 5.3$ \\
\hline MTX alone & 29 & 18 & 8 & 3 \\
\hline mg/week, orally & $7.5 \pm 1.4$ & $7.5 \pm 0.8$ & $7.5 \pm 5.5$ & $7.5 \pm 0.0$ \\
\hline
\end{tabular}

${ }^{*} \mathrm{p}<0.001$ lung involvement versus SFN and eye involvement. ${ }^{* *} \mathrm{p}<0.01$ eye involvement versus lung involvement and SFN. ${ }^{a}$ All values presented are absolute numbers with percentages in parentheses if applicable and means $\pm S D$ if appropriate. ACE, angiotensin-converting enzyme (reference range: 9.0-25.0 $\mathrm{U} / \mathrm{I})$; CXR, chest radiograph; DLCO, carbon monoxide diffusing capacity; FAS, fatigue assessment scale; FEV1, forced expiratory volume in 1 second; FVC, forced vital capacity; MTX, methotrexate, RFI, respiratory functional impairment defined as DLCO $<80 \%$, FVC $<80 \%$ or FEV1 $<80 \%$ (percentage of predicted); sc, subcutaneous; SFN, small fiber neuropathy; SFNSL, small fiber neuropathy screenings list; sIL2R, solubleinterleukin2-receptor (reference range: $<3154 \mathrm{pg} / \mathrm{ml}$ ); y, years.

Overall, 83 (74.8\%) of the 111 included patients with refractory sarcoidosis had a positive response. Improvement was achieved in 119 (59.8\%) of the 199 organs assessed. The choice of TNF- $\alpha$ inhibitor had no influence on outcome, as both infliximab and adalimumab resulted in $25 \%$ non-responders. Allele frequencies were $84.2 \%$ for the G-allele and $15.8 \%$ for the A-allele. The frequency distribution is in agreement with the Hardy-Weinberg equilibrium. There were no significant differences in TNF- $\alpha$ G-308A polymorphism distribution between the various disease manifestations. 
Of the patients without the A-allele, $73(93.6 \%)$ out of $78(p<0.001)$ had a positive response to TNF- $\alpha$ inhibitors, compared with 10 (30.3\%) out of the 33 patients with the variant A-allele. For patients possessing the GG-genotype, the probability of improving was three times higher than that of remaining stable or deteriorating $(\mathrm{RR}=3.09 ; 95 \% \mathrm{Cl}$ 1.84-5.20), as shown in Table 8.2.

Table 8.2 Disease course in relation to TNF- $\alpha$ G-308A polymorphism. ${ }^{2}$

\begin{tabular}{lccccc}
\hline TNF-308 & Total & Improved & Stabilized/worsened & RR (95\% Cl) & p value \\
\hline GG & 78 & $73(93.6)$ & $5(6.4)$ & $3.09(1.84-5.20)$ & $<0.001$ \\
GA & 31 & $9(29.0)$ & $22(71.0)$ & 1 & \\
AA & 2 & $1(50.0)$ & $1(50.0)$ & & \\
\hline
\end{tabular}

${ }^{a}$ Absolute numbers with percentages or range in parentheses. $95 \% \mathrm{Cl}, 95 \%$ confidence interval; RR, relative risk; TNF-308, TNF- $\alpha$ G-308A genotype; GG, wild type; GA, heterozygote; AA, homozygote variant.

The different genotype groups (GG 70.3\%, GA 27.9\%, and AA 1.8\%) were similar with respect to distribution of therapy (infliximab versus adalimumab) and comedication, but the group with the GG-genotype had a higher mean age and proportion of female patients (Table 8.3). Multivariate logistic regression analysis to adjust for baseline differences in age and gender between the genotype groups resulted in an adjusted odds ratio of 39.7 (95\% $\mathrm{Cl} 11.1-142.3)$, which was slightly higher than the unadjusted odds ratio of 33.6 (95\% Cl 10.4-108.3).

Table 8.3 Demographic and medication characteristics of the sarcoidosis sample according to genotype.

\begin{tabular}{llccc}
\hline & & GG & GA/AA & p value \\
& & $\mathrm{n}=78$ & $\mathrm{n}=33$ & \\
\hline Gender & female & $35(44.9)$ & $11(33.3)$ & 0.30 \\
Age at diagnosis & male & $43(55.1)$ & $22(66.7)$ & \\
Therapy & year \pm SD & $45.7 \pm 10.3$ & $42.6 \pm 10.8$ & 0.15 \\
& infliximab $(\mathrm{n}=76)$ & $52(66.7)$ & $24(72.7)$ & 0.66 \\
Co-medication & adalimumab $(\mathrm{n}=35)$ & $26(33.3)$ & $9(27.3)$ & \\
& none & $27(34.6)$ & $13(39.5)$ & 0.97 \\
& prednisone & $10(12.8)$ & $4(12.1)$ & \\
& prednisone + MTX & $20(25.6)$ & $8(24.2)$ & \\
\hline
\end{tabular}

${ }^{a}$ Absolute numbers, percentages in parentheses and mean \pm SD if appropriate. GG, TNF- $\alpha$ G-308A wild type; $\mathrm{GA}$, heterozygote; AA, homozygote variant; MTX, methotrexate; $n$, number; SD, standard deviation. 
Nine $(8.1 \%)$ patients formed antibodies against infliximab and were switched to adalimumab $(n=4)$ or had to discontinue the TNF- $\alpha$ inhibitor treatment $(n=5)$. None of the patients developed antibodies against adalimumab. Adverse events were seen in 14 $(12.6 \%)$ out of 111 patients treated with TNF- $\alpha$ inhibitors. Documented adverse events were minor infections $(n=11)$, sepsis $(n=1)$, and the occurrence of herpes zoster infection $(n=5)$. Two patients suffered from an infusion reaction, after the fifth and eighth infliximab administrations, respectively. However, after adjustment of the infusion time no further problems emerged and the treatment was continued.

\section{Discussion}

To the best of our knowledge, this is the first study to demonstrate an association between the TNF- $\alpha$ G-308A polymorphism and responsiveness to TNF- $\alpha$ inhibitor treatment in sarcoidosis. Efficacy of TNF- $\alpha$ inhibitors was found in $75 \%$ of our sample of patients with refractory sarcoidosis who had failed to respond to conventional treatment. TNF- $\alpha$ inhibitor treatment was well tolerated. Patients without the TNF- $\alpha$ $308 \mathrm{~A}$ variant allele (GG-genotype) responded better to TNF- $\alpha$ inhibitors (93.6\% versus only $30.3 \%$ ), having a three-fold higher probability of improving compared with variant allele carriers (RR 3.09, 95\% $\mathrm{Cl} 1.84-5.20$ ). This suggests that this variant allele (GA/AAgenotypes) negatively affects TNF- $\alpha$ inhibitor treatment response. However, since the study population was relatively small, the associations should be interpreted with some caution.

It is well known that the clinical course and prognosis of sarcoidosis varies considerably, and research suggests that polymorphisms coding for TNF- $\alpha$ production might play a role. ${ }^{16,17}$ The TNF- $\alpha-308 \mathrm{~A}$ variant allele is associated with higher TNF- $\alpha$ production, and several studies have found the variant allele to be more frequently observed in patients with Löfgren's syndrome, who often showed spontaneous remission. ${ }^{16,17,27}$ The presence of the TNF- $\alpha-308 \mathrm{~A}$ variant allele has been found to have a more favorable impact on clinical outcome. ${ }^{18}$ By contrast, the GG-genotype has been associated with an unfavorable prognosis, with a significantly higher risk of developing persistent sarcoidosis and progression to more severe pulmonary involvement. ${ }^{18}$

In the present study, sarcoidosis patients with the TNF- $\alpha$ G-308A GG-genotype appeared to be more likely to be TNF- $\alpha$ inhibitor responders. The GA- or AA-genotype was found in $29.7 \%$ of our 111 patients, whereas in other studies these genotypes were found in about $35-40 \%$ of general sarcoidosis populations and/or healthy controls. $^{17,18,27}$ The slightly lower frequency of the AA- and GA-genotypes in our study population could be the result of selection bias, as more severe sarcoidosis cases tend to undergo TNF- $\alpha$ inhibitor therapy. The GG-genotype is more likely to be present in these cases, since this genotype has been associated with a more unfavorable sarcoidosis prognosis. ${ }^{18}$ 
The association between the TNF- $\alpha$ G-308A polymorphism and TNF- $\alpha$ inhibitor therapy has been more extensively studied in rheumatoid arthritis. In line with our results, rheumatoid arthritis patients with the GG-genotype had a better overall response rate. ${ }^{19,20,28}$ There have been no previous studies in sarcoidosis demonstrating this association. It was previously shown that patients with a severe disease course were more likely to respond to TNF- $\alpha$ inhibitor treatment. ${ }^{11,29}$ It is tempting to speculate that these patients most likely did not possess the variant A-allele. Since GGgenotype carriers are more likely to have an unfavorable outcome and to achieve a good response to TNF- $\alpha$ inhibitor treatment, the decision whether or not to start TNF- $\alpha$ inhibitors in these patients seems rather easy. In contrast, patients suffering from sarcoidosis with the variant A-allele are more likely to have a favorable prognosis with spontaneous resolution of the disease. In the present study, approximately $70 \%$ (23 out of 33) of these patients did not respond to TNF- $\alpha$ inhibitors. Nevertheless, a considerable proportion of the variant allele carriers showed stabilization of disease. Although stabilization was not considered a 'response' in the present study, in specific cases it might be regarded as a desirable aim. To date, too little evidence is available to decide whether these patients should not be given TNF- $\alpha$ inhibitor treatment.

The results of our study are in line with other case series demonstrating an efficacy of infliximab in $64-100 \%$ of sarcoidosis patients treated. ${ }^{12,30,31}$ In the present study, uveitis demonstrated the best response rate (74\%), followed by RFI (57\%), and SFN (54\%). These response rates are in line with previous research. ${ }^{11,23,29,31,32}$ It is probable that the higher response rate for uveitis is influenced by the shorter time between diagnosis and initiating TNF- $\alpha$ inhibitors $(4.5 \pm 4.3$ years for uveitis, compared with 6.3 \pm 5.6 years for SFN and $6.8 \pm 5.6$ years for $\mathrm{RFI}, p=0.05$ ). These results suggest that initiating TNF- $\alpha$ inhibitors early in the course of the disease might prevent serious organ damage and result in a more favorable outcome. This is in agreement with results in Crohn's disease. ${ }^{33,34}$

The TNF- $\alpha$ inhibitors adalimumab and infliximab were both generally well tolerated in our study, in agreement with data from other studies. ${ }^{35,36}$ Adverse events were observed in $12.6 \%$ of patients and a $4.5 \%$ discontinuation rate due to antibody formation was seen during at least 1 year of TNF- $\alpha$ inhibitor treatment. Outcome or adverse effects did not differ between infliximab and adalimumab, similar to findings for other chronic inflammatory diseases. ${ }^{34,37,38}$

Refractory uveitis is a registered indication for adalimumab treatment in The Netherlands, whereas patients with pulmonary and/or neurological symptoms have mainly been treated with infliximab. The choice between adalimumab and infliximab was, therefore, mainly based on insurance reimbursement issues.

Despite the overall efficacy of TNF- $\alpha$ inhibitors, there are limitations to the use of TNF- $\alpha$ inhibitor treatment for every sarcoidosis patient. In addition to the side-effects, another drawback of TNF- $\alpha$ inhibitors is the considerable treatment cost. $^{15}$ It is, therefore, important to tailor treatment. The present study provides a step forward in identifying sarcoidosis patients who might be at risk of developing a more severe 
manifestation of the disease and in selecting those most likely to have a good response to TNF- $\alpha$ inhibitor treatment. It might help to start an appropriate individual treatment regimen and, thus, avoid irreversible damage at an early stage. ${ }^{7}$ It is useful to know beforehand whether a patient is highly likely to respond to TNF- $\alpha$ inhibitor treatment, as this can be of great clinical and economic benefit. A better understanding may help achieve personalized, cost-effective treatment regimens. However, to date, too little evidence is available to decide whether TNF- $\alpha$ inhibitors should be withheld from sarcoidosis patients carrying the variant A-allele. For these patients there might be better alternative options. Prospective randomized controlled trials, with a sufficiently large study population, are needed to address the effect of TNF- $\alpha$ inhibitors in patients with the variant A-allele, compared with placebo and/or conventional therapy.

In conclusion, our results show that sarcoidosis patients without the TNF- $\alpha-308 \mathrm{~A}$ variant allele (GG-genotype) had a three-fold higher response to TNF- $\alpha$ inhibitor treatment than A-allele carriers. We also found that TNF- $\alpha$ inhibitors were efficacious in the treatment of refractory sarcoidosis (75\% response rate) and were well tolerated. Further research is needed to evaluate whether individualized treatment can be improved by basing decisions on the TNF- $\alpha$ G-308A polymorphism of sarcoidosis patients in whom conventional therapy has failed or proved intolerable.

\section{Acknowledgements}

This study was supported by a research grant from the ild care foundation. 


\section{References}

1. Statement on sarcoidosis. Joint Statement of the American Thoracic Society (ATS), the European Respiratory Society (ERS) and the World Association of Sarcoidosis and Other Granulomatous Disorders (WASOG) adopted by the ATS Board of Directors and by the ERS Executive Committee, February 1999. Am J Respir Crit Care Med 1999;160:736-755.

2. Iannuzzi MC, Fontana JR. Sarcoidosis: clinical presentation, immunopathogenesis, and therapeutics. JAMA 2011;305:391-399.

3. Fehrenbach H, Zissel G, Goldmann T, Tschernig T, Vollmer E, Pabst R, Muller-Quernheim J. Alveolar macrophages are the main source for tumour necrosis factor-alpha in patients with sarcoidosis. Eur Respir J 2003;21:421-428.

4. Baughman RP, Costabel U, du Bois RM. Treatment of sarcoidosis. Clin Chest Med 2008;29:533-548.

5. Baughman RP, Nunes H, Sweiss NJ, Lower EE. Established and experimental medical therapy of pulmonary sarcoidosis. Eur Respir J Supp/ 2013;41:1424-1438.

6. Grutters JC, Van den Bosch JM. Corticosteroid treatment in sarcoidosis. Eur Respir J 2006;28:627-636.

7. Baughman RP. Pulmonary sarcoidosis. Clin Chest Med 2004;25:521-530,vi.

8. Paramothayan S, Lasserson T. Treatments for pulmonary sarcoidosis. Respir Med 2008;102:1-9.

9. Sahoo DH, Bandyopadhyay D, Xu M, Pearson K, Parambil JG, Lazar CA, Chapman JT, Culver DA. Effectiveness and safety of leflunomide for pulmonary and extrapulmonary sarcoidosis. Eur Respir J Supp/ 2011;38:1145-1150.

10. Cremers JP, Drent M, Bast A, Shigemitsu H, Baughman RP, Valeyre D, Sweiss NJ, Jansen TL. Multinational evidence-based World Association of Sarcoidosis and Other Granulomatous Disorders recommendations for the use of methotrexate in sarcoidosis: integrating systematic literature research and expert opinion of sarcoidologists worldwide. Curr Opin Pulm Med 2013;19:545-561.

11. Baughman RP, Drent M, Kavuru M, Judson MA, Costabel U, du Bois R, Albera C, Brutsche M, Davis G, Donohue JF, Muller-Quernheim J, Schlenker-Herceg R, Flavin S, Lo KH, Oemar B, Barnathan ES. Infliximab therapy in patients with chronic sarcoidosis and pulmonary involvement. Am J Respir Crit Care Med 2006;174:795-802.

12. Judson MA, Baughman RP, Costabel U, Flavin S, Lo KH, Kavuru MS, Drent M. Efficacy of infliximab in extrapulmonary sarcoidosis: results from a randomised trial. Eur Respir J 2008;31:1189-1196.

13. Russell E, Luk F, Manocha S, Ho T, O'Connor C, Hussain H. Long term follow-up of infliximab efficacy in pulmonary and extra-pulmonary sarcoidosis refractory to conventional therapy. Semin Arthritis Rheum 2013;43:119-124.

14. Vorselaars AD, Verwoerd A, Moorsel Van CH, Keijsers RG, Rijkers GT, Grutters JC. Prediction of relapse after discontinuation of infliximab therapy in severe sarcoidosis. Eur Respir J 2013; Epub ahead of print.

15. Liu Y, Wu EQ, Bensimon AG, Fan CP, Bao Y, Ganguli A, Yang M, Cifaldi M, Mulani P. Cost per responder associated with biologic therapies for Crohn's disease, psoriasis, and rheumatoid arthritis. Adv Ther 2012;29:620-634.

16. Swider C, Schnittger L, Bogunia-Kubik K, Gerdes J, Flad H, Lange A, Seitzer U. TNF-alpha and HLA-DR genotyping as potential prognostic markers in pulmonary sarcoidosis. Eur Cytokine Netw 1999;10:143146.

17. Seitzer U, Swider C, Stuber F, Suchnicki K, Lange A, Richter E, Zabel P, Muller-Quernheim J, Flad HD, Gerdes J. Tumour necrosis factor alpha promoter gene polymorphism in sarcoidosis. Cytokine 1997;9:787-790.

18. Wijnen PA, Nelemans PJ, Verschakelen JA, Bekers O, Voorter CE, Drent M. The role of tumor necrosis factor alpha G-308A polymorphisms in the course of pulmonary sarcoidosis. Tissue Antigens 2010;75:262-268.

19. Mugnier B, Balandraud N, Darque A, Roudier C, Roudier J, Reviron D. Polymorphism at position -308 of the tumor necrosis factor alpha gene influences outcome of infliximab therapy in rheumatoid arthritis. Arthritis Rheum 2003;48:1849-1852.

20. Zeng Z, Duan Z, Zhang T, Wang S, Li G, Gao J, Ye D, Xu S, Xu J, Zhang L, Pan F. Association between tumor necrosis factor-alpha (TNF-alpha) promoter $-308 \mathrm{G} / \mathrm{A}$ and response to TNF-alpha blockers in rheumatoid arthritis: a meta-analysis. Mod Rheumatol 2013;23:489-495. 
21. Quanjer PH, Tammeling GJ, Cotes JE, Pedersen OF, Peslin R, Yernault JC. Lung volumes and forced ventilatory flows. Report Working Party Standardization of Lung Function Tests, European Community for Steel and Coal. Official Statement of the European Respiratory Society. Eur Respir J Suppl 1993;16:540.

22. Rothkrantz-Kos S, Van Dieijen-Visser MP, Mulder PG, Drent M. Potential usefulness of inflammatory markers to monitor respiratory functional impairment in sarcoidosis. Clin Chem 2003;49:1510-1517.

23. Erckens RJ, Mostard RL, Wijnen PA, Schouten JS, Drent M. Adalimumab successful in sarcoidosis patients with refractory chronic non-infectious uveitis. Graefes Arch Clin Exp Ophthalmol 2012;250:713720.

24. Hoitsma E, De Vries J, Drent M. The small fiber neuropathy screening list: Construction and crossvalidation in sarcoidosis. Respir Med 2011;105:95-100.

25. Hoitsma E, De Vries J, Van Santen-Hoeufft M, Faber CG, Drent M. Impact of pain in a Dutch sarcoidosis patient population. Sarcoidosis Vasc Diffuse Lung Dis 2003;20:33-39.

26. De Kleijn WP, De Vries J, Wijnen PA, Drent M. Minimal (clinically) important differences for the Fatigue Assessment Scale in sarcoidosis. Respir Med 2011;105:1388-1395.

27. Grutters JC, Sato H, Pantelidis P, Lagan AL, McGrath DS, Lammers JW, Van den Bosch JM, Wells AU, du Bois RM, Welsh KI. Increased frequency of the uncommon tumor necrosis factor $-857 \mathrm{~T}$ allele in British and Dutch patients with sarcoidosis. Am J Respir Crit Care Med 2002;165:1119-1124.

28. Marotte $\mathrm{H}$, Miossec $\mathrm{P}$. Biomarkers for prediction of TNFalpha blockers response in rheumatoid arthritis. Joint Bone Spine 2010;77:297-305.

29. Rossman MD, Newman LS, Baughman RP, Teirstein A, Weinberger SE, Miller W, Jr., Sands BE. A doubleblinded, randomized, placebo-controlled trial of infliximab in subjects with active pulmonary sarcoidosis. Sarcoidosis Vasc Diffuse Lung Dis 2006;23:201-208.

30. Croft AP, Situnayake D, Khair O, Giovanni G, Carruthers D, Sivaguru A, Gordon C. Refractory multisystem sarcoidosis responding to infliximab therapy. Clin Rheumatol 2012;31:1013-1018.

31. Ulbricht KU, Stoll M, Bierwirth J, Witte T, Schmidt RE. Successful tumor necrosis factor alpha blockade treatment in therapy-resistant sarcoidosis. Arthritis Rheum 2003;48:3542-3543.

32. Hoitsma E, Drent M, Sharma OP. A pragmatic approach to diagnosing and treating neurosarcoidosis in the 21st century. Curr Opin Pulm Med. 2010;16(5):472-479.

33. Beaugerie L, Sokol H. Clinical, serological and genetic predictors of inflammatory bowel disease course. World J Gastroenterol 2012;18:3806-3813.

34. D'Haens GR, Panaccione R, Higgins PD, Vermeire S, Gassull M, Chowers $Y$, Hanauer SB, Herfarth $H$, Hommes DW, Kamm M, Lofberg R, Quary A, Sands B, Sood A, Watermeyer G, Lashner B, Lemann M, Plevy S, Reinisch W, Schreiber S, Siegel C, Targan S, Watanabe M, Feagan B, Sandborn WJ, Colombel JF, Travis S. The London Position Statement of the World Congress of Gastroenterology on Biological Therapy for IBD with the European Crohn's and Colitis Organization: when to start, when to stop, which drug to choose, and how to predict response? Am J Gastroenterol 2011;106:199-212;quiz 213.

35. Winthrop KL, Baddley JW, Chen L, Liu L, Grijalva CG, Delzell E, Beukelman T, Patkar NM, Xie F, Saag KG, Herrinton $L$, Solomon DH, Lewis JD, Curtis JR. Association between the initiation of anti-tumor necrosis factor therapy and the risk of herpes zoster. JAMA 2013;309:887-895.

36. Grijalva CG, Chen L, Delzell E, Baddley JW, Beukelman T, Winthrop KL, Griffin MR, Herrinton LJ, Liu L, Ouellet-Hellstrom R, Patkar NM, Solomon DH, Lewis JD, Xie F, Saag KG, Curtis JR. Initiation of tumor necrosis factor-alpha antagonists and the risk of hospitalization for infection in patients with autoimmune diseases. JAMA 2011;306:2331-2339.

37. Kestens C, Van Oijen MG, Mulder CL, Van Bodegraven AA, Dijkstra G, Jong DD, Ponsioen C, Van Tuyl BA, Siersema PD, Fidder HH, Oldenburg B. Adalimumab and Infliximab Are Equally Effective for Crohn's Disease in Patients Not Previously Treated With Anti-Tumor Necrosis Factor-alpha Agents. Clin Gastroenterol Hepatol 2013;11:826-831.

38. Fenix-Caballero S, Alegre-Del Rey EJ, Castano-Lara R, Puigventos-Latorre F, Borrero-Rubio JM, LopezVallejo JF. Direct and indirect comparison of the efficacy and safety of adalimumab, etanercept, infliximab and golimumab in psoriatic arthritis. J Clin Pharm Ther 2013;38:286-293. 



\section{Chapter 9}

Summary, general discussion and directions for future research 


\section{Summary}

Clinical presentation and course of sarcoidosis are both highly variable, depending on several disease and patient characteristics. ${ }^{1-3}$ Most sarcoidosis patients show spontaneous resolution, but in patients with a severe disease course and poor prognosis a timely implementation of an appropriate customized individual pharmacological treatment regimen is important to avoid or slow down the development of complications and to alleviate the disease burden. ${ }^{4,5}$ Despite the availability of several immunosuppressive therapeutic options in sarcoidosis, standardized management strategies are lacking. The published data on the different pharmacological therapeutics are limited and the treatment therefore remains predominantly empiric. ${ }^{4,6}$

The aim of the studies presented in this thesis was to contribute in the optimization and improvement of pharmacotherapeutic options in sarcoidosis. Several aspects in terms of amelioration of treatment were investigated, with emphasis on the meaning of body composition profiling, the desirable handling of liver test abnormalities, and the development of practical recommendations for the optimal use of methotrexate (MTX) and tumor necrosis factor-alpha (TNF- $\alpha$ ) inhibitors in sarcoidosis. Furthermore, possible factors identifying responders to TNF- $\alpha$ inhibitors were explored. Four studies included data from sarcoidosis patients who were referred to a tertiary referral centre in the Netherlands. Two studies evaluated the experience with therapeutic agents amongst sarcoidosis experts worldwide by means of online web-based questionnaires, and combined these data with evidence from the literature. A general overview of the findings from this thesis is subsequently presented.

\section{Overview of main findings}

Chapter 1, the general introduction, presents a summary of the pathogenesis, clinical presentation and diagnostic approach of sarcoidosis. Furthermore, it describes the available first-, second-, and third-line therapeutic options in sarcoidosis. Lastly, an outline of the thesis is provided.

Chapter 2 provides an overview of the extent, distribution and consistency of organ involvement detected by fluorine18-fluorodeoxyglucose positron emission tomography/computed tomography $\left({ }^{18} \mathrm{~F}\right.$-FDG PET/CT or PET) in 158 sarcoidosis patients with persistent disabling symptoms. Positive PET findings were classified as thoracic and/or extrathoracic. The majority (93\%) of sarcoidosis patients had intrathoracic activity (79\% mediastinal and 64\% pulmonary activity, respectively) and $75 \%$ displayed extrathoracic activity (mainly peripheral lymph nodes, bone/bone marrow, and spleen). Hepatic positivity was always accompanied by splenic activity, whereas the majority of patients with parotid gland, splenic or bone/bone marrow activity showed lymph node activity. A substantial number of patients with PET positive pulmonary findings (86\%) had signs of respiratory functional impairment. No obvious association between 
hepatic, splenic or bone/bone marrow activity and their corresponding laboratory abnormalities suggestive of specific organ involvement, was found. PET can be especially useful in the assessment of extent, distribution and consistency of inflammatory activity in sarcoidosis to provide an explanation for persistent disabling symptoms and/or to provide a suitable location for biopsy.

Chapter 3 reports on the prevalence of muscle atrophy and cachexia in 423 Dutch sarcoidosis patients, and the association of these body composition profiles with sarcoidosis disease activity and severity. Fat-free mass was assessed as an indirect measure of muscle mass by bioelectrical impedance analysis. Patients were stratified based on body mass index (BMI) and fat-free mass index (FFMI). Muscle atrophy was defined as FFMI $<15 \mathrm{~kg} / \mathrm{m}^{2}$ for women and $<17 \mathrm{~kg} / \mathrm{m}^{2}$ for men corresponding to $<10^{\text {th }}$ percentile of current reference values; cachexia as BMI $<20$ combined with muscle atrophy. Relevant clinical data were gathered retrospectively. Muscle atrophy was present in $25 \%$ and cachexia in $5 \%$ of sarcoidosis patients. Patients with muscle atrophy showed significantly worse lung function (diffusing capacity for carbon monoxide (DLCO), forced expiratory volume in 1 second (FEV1), forced vital capacity (FVC), all $p$ values <0.01) and impaired exercise capacity (maximal oxygen uptake $\left(\mathrm{VO}_{2} \mathrm{max}\right)$, $p<0.001$ ). The associations were most pronounced in patients with cachexia. These results demonstrate that muscle atrophy and cachexia are substantial problems in sarcoidosis.

Chapter 4 describes the presence and severity of liver test abnormalities in 837 patients with confirmed sarcoidosis. Additionally, the association between severity of liver test abnormalities and histopathological abnormalities in hepatic sarcoidosis was evaluated. Over a 9-year period, relevant clinical data were gathered from medical records. Liver test abnormalities (alkaline phosphatase, $\gamma$-glutamyl transferase, alanine aminotransferase (ALT) or aspartate aminotransferase $>1.5$ times the upper limit of normal (ULN)) were classified according to severity into mild (zero liver tests $\geq 3$ times the ULN), moderate (one or two liver tests $\geq 3$ times the ULN) and severe (three or four liver tests $\geq 3$ times the ULN). In $24 \%$ of the studied patients, liver test abnormalities were present; in $15 \%$ highly likely because of hepatic involvement of sarcoidosis. In 22 of this latter group, a liver biopsy was obtained; 21 biopsies were compatible with hepatic sarcoidosis. The presence and degree of inflammation, fibrosis, and the distribution of granulomas in these liver biopsies were examined. Moderate and severe liver test abnormalities were associated with more advanced histopathological disease. In the management of hepatic sarcoidosis, for patients with moderate or severe liver test abnormalities a liver biopsy is recommended.

Chapter 5 provides an overview of the knowledge available in the literature about therapeutic options for sarcoidosis liver involvement, and combines these data into recommendations for the optimal therapeutic approach in clinical practice. Only 5-30\% of patients with hepatic sarcoidosis display symptoms. Nevertheless, in some cases hepatic sarcoidosis can have a rapid progressive course with serious complications, which stresses the importance of an appropriate and carefully timed therapeutic 
approach. Because symptomatic hepatic sarcoidosis is uncommon, therapeutic studies are scarce. Data regarding when to initiate which treatment regimen are lacking. Case reports describe beneficial effects of glucocorticosteroids and the augmentation with cytotoxic and/or TNF- $\alpha$ inhibitor therapy. However, because of small sample sizes, no meaningful conclusions can be drawn. In symptomatic hepatic sarcoidosis patients, it is recommended to start pharmacotherapy with glucocorticosteroids, preceded by ursodeoxycholic acid when signs of cholestasis disease are present. Furthermore, antioxidants can be considered. In refractory cases or when glucocorticosteroid weaning is impossible, cytotoxic drugs or TNF- $\alpha$ inhibitors should be considered. However, there is a need for future studies to assess the effect of treatment on disease progression and complications in hepatic sarcoidosis.

Chapter 6 presents the development of practical recommendations, on behalf of the World Association of Sarcoidosis and Other Granulomatous Disorders (WASOG), for the use of methotrexate (MTX) in sarcoidosis by integrating the evidence obtained through a systematic literature review and the opinions of sarcoidosis experts worldwide. The literature search identified 237 papers, 43 of which were included. Randomized controlled trial (RCT) evidence supporting the use of MTX in sarcoidosis was limited. An online survey concerning 10 clinical questions was sent through the WASOG newsletter to the experts. Forty-five per cent (113 of 250) of the sarcoidosis experts contacted, completed the survey (Europe 55\%, North America 26\%, and Asia $12 \%)$. Ten recommendations were formulated concerning the indications for use, starting dose, folic acid, work-up, contraindications, monitoring, administration options in case of adverse gastrointestinal effects, hepatotoxicity, long-term safety and use during pregnancy and breast feeding. The mean level of agreement for the total set of recommendations amongst the leading sarcoidologists was high (8.7, range 8.0-10). Furthermore, a mobile application (app) was developed for smartphone or tablet with these recommendations including some clinical sarcoidosis cases (Appendix 2). The app 'MTX in sarcoidosis' can be downloaded for free in the Apple Store or Google Play Store.

Chapter 7 describes the development of practical recommendations for the use of the TNF- $\alpha$ inhibitors infliximab and adalimumab in the treatment of refractory sarcoidosis. Evidence obtained from a literature search was combined with the results of a Delphi method of polling amongst sarcoidosis experts worldwide. The literature search identified 256 papers, 101 of which were included. RCTs about the use of TNF- $\alpha$ inhibitors in sarcoidosis are limited. Studies conducted in sarcoidosis were supplemented with data obtained from relevant studies in other inflammatory diseases. An online survey addressing 12 clinical questions was performed amongst 20 of the world's leading sarcoidologists to investigate consensus in case of inadequate data to determine an objective answer. Ninety-five per cent (19 of 20) of the sarcoidosis experts contacted completed the survey (Europe 68\%, North America 32\%). Nine recommendations were formulated concerning general aspects of TNF- $\alpha$ inhibitor use. Furthermore, specific sarcoidosis related items, including indications, starting and 
maintenance dosage, interval of treatment, treatment duration, and discontinuation regimen of infliximab and adalimumab, were also addressed. The recommendations intend to support the clinician in the management of refractory sarcoidosis patients.

In sarcoidosis, the presence of the GG-genotype of TNF- $\alpha$ G-308A polymorphism has been associated with poor prognosis. ${ }^{7}$ Chapter 8 assesses the association between the presence of the TNF- $\alpha$ G-308A polymorphism and the response to anti-TNF- $\alpha$ therapy amongst 111 patients with refractory sarcoidosis. The included patients were followed for at least 12 months after the initiation of infliximab $(n=76)$ or adalimumab $(n=35)$. Main symptoms in these patients were small fiber neuropathy $(82 \%)$, pulmonary involvement $(62 \%)$, uveitis $(28 \%)$ and/or fatigue $(90 \%)$. Patients were genotyped for the presence of the TNF- $\alpha$ G-308A polymorphism. Treatment response was assessed using clinical outcome measures and questionnaires. Of the total group of patients receiving TNF- $\alpha$ inhibitors, 75\% responded well. Of the patients with the GGgenotype of TNF- $\alpha$ G-308A polymorphism 93.6\% (73/78; $p<0.001)$ improved, while only $30.3 \%(10 / 33)$ of the TNF- $\alpha-308 \mathrm{~A}$ variant allele carriers responded favorably to the TNF- $\alpha$ inhibitor. Sarcoidosis patients without the TNF- $\alpha-308 \mathrm{~A}$ variant allele (GGgenotype) had a three-fold higher probability of response to TNF- $\alpha$ inhibitors. Further research is needed to evaluate the value of genotyping for the TNF- $\alpha$ G-308A polymorphism in order to customize and tailor TNF- $\alpha$ inhibitor treatment.

\section{Highlights of this thesis}

In conclusion, this thesis presents several aspects regarding optimization of pharmacotherapeutic options in sarcoidosis. First of all, cachexia and muscle atrophy are frequent problems in sarcoidosis and are associated with more severe pulmonary disease. These findings indicate the importance of considering body composition profiling in the management of sarcoidosis. Furthermore, in a substantial proportion (24\%) of sarcoidosis patients liver test abnormalities are present. In the majority, these abnormalities are probably associated with hepatic sarcoidosis. However, other causes should be excluded. When moderate or severe liver test abnormalities are present in probable hepatic sarcoidosis, a liver biopsy should be considered, since advanced histopathological disease is likely. The biopsy findings can be used in establishing an adequate therapeutic strategy of hepatic sarcoidosis, for which recommendations are presented in this thesis. Moreover, multinational recommendations for the use of MTX and TNF- $\alpha$ inhibitors are provided, based on findings from the literature combined with the opinions of sarcoidosis experts worldwide. Finally, the finding that sarcoidosis patients without the TNF- $\alpha-308 \mathrm{~A}$ variant allele (GG-genotype) have a three-fold higher probability of response to TNF- $\alpha$ inhibitors compared with TNF- $\alpha-308 \mathrm{~A}$ variant allele carriers (GA- or AA-genotype), indicates a possible role for genotyping for the TNF- $\alpha \mathrm{G}$ $308 \mathrm{~A}$ polymorphism in order to tailor anti-TNF- $\alpha$ treatment. However, future research is needed to evaluate possible factors identifying responders to TNF- $\alpha$ inhibitors and to assess the role for TNF- $\alpha$ G-308A genotyping in this process. 


\section{General discussion}

Optimization of the pharmacotherapeutic management of sarcoidosis is important and of great clinical relevance. Since sarcoidosis can present to any one of a variety of (organ) specialists, therapeutic decisions are dependent on the individual specialist's expertise. Application of pharmacotherapeutic options by inexperienced physicians can be improved by guidance consisting of therapeutic recommendations. A key issue of treatment must be the avoidance of unnecessary exposure of patients to consecutive pharmacological agents. Furthermore, a multidisciplinary approach is crucial, in which physicians develop a treatment regime after mutual consultation and in cooperation with the patient. The role for the patient in disease management becomes increasingly important. Pursuing personalized medicine is another major aspect in the optimization of therapeutic options. The meaning and implications of the different aspects presented in this thesis will be discussed subsequently.

\section{${ }^{18}$ F-FDG PET/CT, body composition profiling and liver test abnormalities in sarcoidosis disease management}

PET can be very helpful in sarcoidosis disease management and monitoring in several situations. ${ }^{8,9}$ One important function is the assessment of sarcoidosis activity, especially when routine diagnostic methods do not provide an explanation for disease related symptoms. ${ }^{10,11}$ Besides the assessment of sarcoidosis activity, depicting disease extent and severity is of great clinical relevance, as illustrated in chapter $2 .{ }^{12}$ Evaluation of the extent of disease can be helpful to explain persistent disabling (mainly extrathoracic) symptoms. ${ }^{13}$ Furthermore, it can support in the decision whether pharmacological therapy should be started and sometimes guide what drug regimen should be chosen.

As in other chronic diseases, ${ }^{14-17}$ muscle atrophy and cachexia were shown to be common problems in sarcoidosis (chapter 3). ${ }^{18}$ Therefore, considering body composition profiling in the management of sarcoidosis is important. Future research is necessary to assess the effect of a multidisciplinary rehabilitation program on muscle maintenance. Considering body composition is furthermore important in pharmacotherapeutic management. Drug dosing should among others be based on body weight and composition. Cachexia and wasting of chronic disease, for example, can lead to altered drugs pharmacokinetics and -dynamics. ${ }^{19}$

Liver test abnormalities are a frequently encountered problem in sarcoidosis, for which guidance is presented in chapter 4,5 and $6 .^{20-22}$ Liver test abnormalities in sarcoidosis can be the result of hepatic sarcoidosis itself, another (liver) disease or drug toxicity. The degree and type of liver test abnormalities cannot distinguish between these different causes. ${ }^{23}$ When abnormal values are present before the start of therapy, hepatic sarcoidosis is a likely cause..$^{20,23,24}$ When they develop after the start of an agent with potential hepatic adverse effects, liver test abnormalities are most likely the result 
of drug toxicity. Treatment with an anti-inflammatory agent in hepatic sarcoidosis can actually lead to improvement of liver test abnormalities. ${ }^{25,26}$

\section{Glucocorticosteroids in sarcoidosis}

In sarcoidosis clinical practice, glucocorticosteroids are the cornerstone therapeutic agent. $^{3,6,27,28}$ They have a positive short-term effect on lung function and symptoms, but their beneficial long-term effect remains uncertain. ${ }^{29}$ Prolonged use is associated with significant side-effects, such as weight gain, diabetes mellitus, osteoporosis, or striae distensae of the skin (Figure 9.1), making glucocorticosteroids undesirable for chronic disease management. ${ }^{3,27,30}$ Another important issue is the presence of glucocorticosteroid resistance, which complicates the treatment of several inflammatory diseases (including chronic obstructive pulmonary disease, asthma, rheumatoid arthritis and Crohn's disease), while the risks of side-effects persist. ${ }^{31,32}$ It is not only a problem in severe, but also in mild disease, often leading to the prescription of high steroid dosages without beneficial effect. ${ }^{31}$ Several molecular mechanisms of resistance have been identified. One factor is genetic susceptibility to steroid resistance due to different polymorphisms in different genes, a finding which can possibly contribute towards personalized therapy. ${ }^{31,33,34}$ Furthermore, interference with the steroid response by constitutive epithelial activation of pro-inflammatory mediators, including nuclear factor-kappa B (NF-kB), resulting in inhibition of glucocorticosteroid receptor transcriptional activity, is another possible mechanism. ${ }^{31-33}$ NF-kB activation is shown to be increased in sarcoidosis ${ }^{35-37}$ and its suppression by glucocorticosteroids seems less successful than the suppression of angiotensin-converting enzyme activity, ${ }^{36}$ indicating that glucocorticosteroid resistance is likely to be an important problem in sarcoidosis as well. When considering the limitations we are aware of nowadays, registration approval would be questionable if glucocorticosteroids were to be introduced at present. 


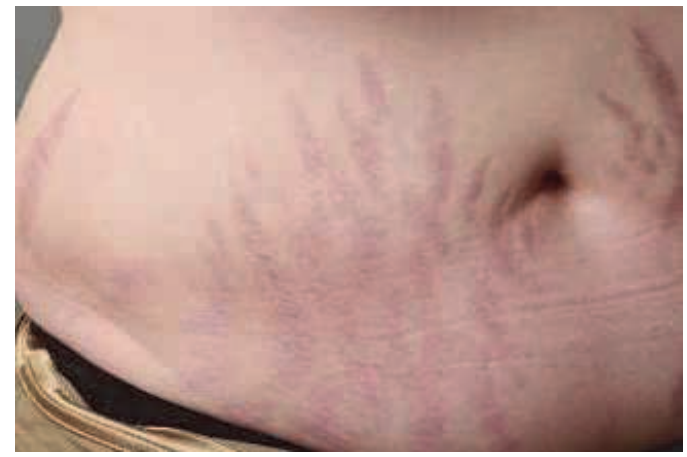

Figure 9.1 Extensive striae distensae of the skin in a young woman with sarcoidosis after 3 months of treatment with glucocorticosteroids because of uveitis.

\section{Methotrexate in sarcoidosis}

In steroid-refractory cases and in the presence of steroid-associated side-effects, second-line or disease-modifying antisarcoid drugs (DMASDs), with usually steroidsparing potency, are available. ${ }^{3,6,27,38,39}$ MTX is the central drug in the pharmacotherapeutic management of rheumatoid arthritis and other immune mediated inflammatory diseases. ${ }^{40,41}$ In pulmonary sarcoidosis, the glucocorticosteroidsparing potency of MTX has been demonstrated (Figure 9.2). ${ }^{42}$ Sarcoidosis experts consider MTX the first-choice DMASD. ${ }^{43}$ Unfortunately, the evidence to support the use of MTX in sarcoidosis is limited. Therefore, evidence extrapolated from studies in rheumatic inflammatory diseases and the expert opinions of sarcoidologists worldwide were used to help develop the MTX recommendations presented in chapter $6 .^{22}$ The broad range of participants should enhance the implementation of the recommendations in sarcoidosis practice. Their value is further strengthened by the high level of agreement amongst the world's leading experts. Nevertheless, due to the limited available high-quality studies, the recommendations lack in strength.

Inexperience among individual specialists can lead to suboptimal use of MTX. Especially at two specific points, progress can be made. Primarily, as discussed in chapter 6, a substantial part of sarcoidosis experts (11\%) did not prescribe MTX in sarcoidosis. The predominant reason consisted of fear for toxicity (70\%). However, experienced respondents reported MTX discontinuation because of side-effects in only $10 \%$ of the cases. Sarcoidosis case reports show even lower discontinuation rates. ${ }^{42,45}$ This finding is in line with rheumatoid arthritis studies, showing that withdrawals of MTX due to toxicity are less common than for most other DMARDs. ${ }^{46}$ 


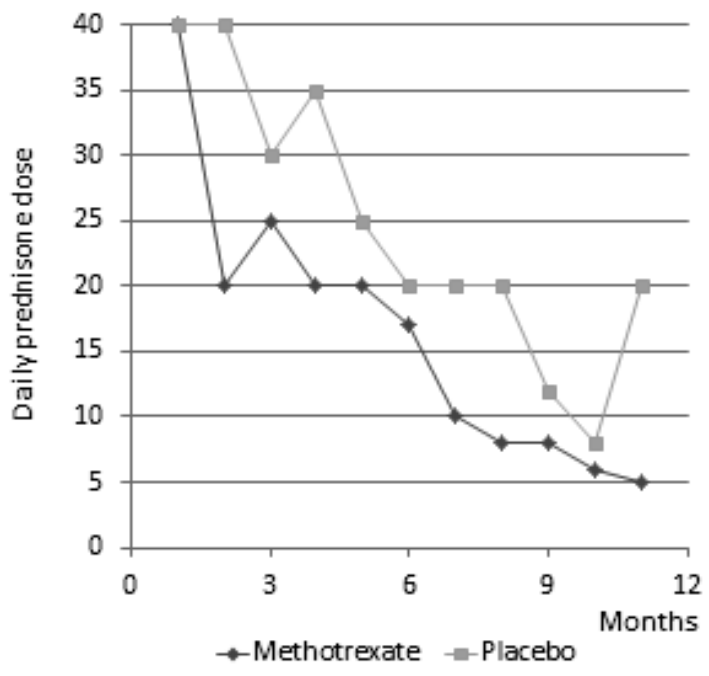

Figure 9.2 Average prednisone dosage at various time intervals for patients with acute pulmonary sarcoidosis receiving either placebo or methotrexate. There was a significant difference in the average prednisone dose after 6 months of therapy. Adapted from Baughman et al. ${ }^{42,44}$

A retrospective study performed in a large group of 607 sarcoidosis patients on MTX treatment and with evaluable blood work (Sarcoidosis Clinic at the University of Cincinnati Medical Centre, Cincinnati, Ohio, USA), investigated the occurrence of total and severe leucocytopenia respectively (defined as white blood cell (WBC) count $<3.8^{*} 10^{\wedge} 3 / \mu \mathrm{l}$ and $\left.<1.5^{*} 10^{\wedge} 3 / \mu \mathrm{l}\right)$; and total and severe liver test abnormalities respectively ( $A L T>1.5 x$ the upper limit of normal (ULN) and $>3 x$ ULN). Leucocytopenia was present in $11.9 \%$, severe leucocytopenia in $0.2 \%$, liver test abnormalities in $12.8 \%$ and severe liver test abnormalities in $1.6 \%$ of these patients. The results show that the occurrence of severe MTX-induced bone marrow or liver toxicity was low (unpublished data). In rheumatoid arthritis, long-term MTX use is not associated with an increased risk of serious infections. ${ }^{46-48}$ Recently, a meta-analysis in rheumatoid arthritis showed that MTX was associated with a small increased risk of respiratory infections (RR 1.11, 95\% Cl 1.02-1.21), without an increased risk of non-infectious respiratory events or pulmonary death compared to other DMASDs and biological agents, suggesting a lower risk than previously believed. ${ }^{49}$ There is no strong evidence for the development of malignancies during MTX use. ${ }^{46}$ A low risk of developing Epstein-Barr virus-related lymphoma has been suggested following exposure to MTX. ${ }^{46,47,50,51}$ A recent study in Japan indeed suggests that MTX is an independent risk factor for EBV-related lymphoproliferative disorders in rheumatoid arthritis patients, but further evidence still is required. ${ }^{52}$ Based on an acceptable safety profile, it can be said that MTX is appropriate for short- and long-term use in most patients. Fear for MTX among physicians often seems to be based on inexperience. The recommendations can serve to provide more guidance to MTX therapy in sarcoidosis. 
When considering gastrointestinal MTX intolerance, a recently developed questionnaire can be used to assess symptoms occurring before and after MTX administration. Studies in several rheumatic inflammatory diseases show that besides gastrointestinal symptoms after MTX, patients also experience these symptoms prior to and when thinking of MTX intake. Therefore, patients on MTX should be closely monitored for early detection of MTX intolerance, in order to intervene timely and avoid discontinuation of an effective treatment. ${ }^{53,54}$ Less than $50 \%$ of experienced sarcoidosis experts are aware of the possibilities of parenteral administration or splitting of the oral dose in case of MTX-induced gastrointestinal side-effects. In rheumatoid arthritis, parenteral administration is reported to have more efficacy, which can be explained by a higher bioavailability. ${ }^{55,56}$ Splitting the oral dose can lead to a higher efficacy of especially higher oral dosages, due to a limited absorption from the gastrointestinal tract when the dosage is ingested at once. ${ }^{57,58}$ Both methods can lead to less gastrointestinal toxicity, as illustrated in Figure 9.3. Before discontinuing MTX in case of insufficient response or gastrointestinal side-effects, it is important to consider these aspects.

a
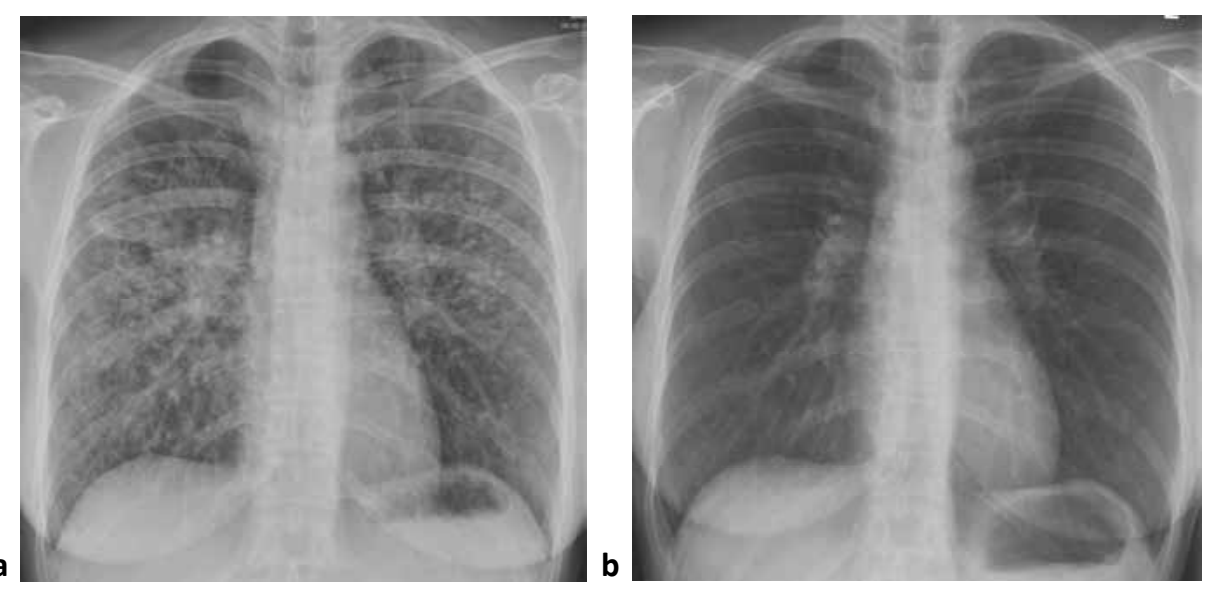

Figure 9.3 A 38-year-old woman had a 1-year history of biopsy-proven sarcoidosis. She had been previously treated with oral prednisone, starting at $40 \mathrm{mg}$ daily, because of respiratory functional impairment, fatigue, exercise intolerance and signs of inflammatory activity (solubleinterleukin2-receptor was $3117 \mathrm{pg} / \mathrm{mL}$, normal range $0-2500 \mathrm{pg} / \mathrm{ml}$ ). However, no improvement was achieved, so methotrexate (MTX) was started at $12.5 \mathrm{mg}$ once a week orally, together with folic acid $5 \mathrm{mg}$ twice a week. Additionally, treatment with prednisone was tapered off to $7.5 \mathrm{mg}$ daily. Due to gastrointestinal side-effects - mainly nausea - after MTX initiation, the administration of MTX $12.5 \mathrm{mg}$ once a week was changed from oral to subcutaneous. a. Chest radiograph before treatment with subcutaneous MTX showed both lymphadenopathy and multiple parenchymal infiltrates. b. Chest radiograph after 5 months of treatment with subcutaneous MTX showed substantial improvement. Patient also reported significant clinical improvement after treatment with subcutaneous MTX. 


\section{TNF- $\alpha$ inhibitors in sarcoidosis}

In some sarcoidosis patients, the available first- and second-line therapeutics do not provide a solution, despite their optimized application. The potent pro-inflammatory TNF- $\alpha$ plays a critical role in the immunopathogenesis of sarcoidosis by regulating and sustaining granuloma formation., ${ }^{2,59-61}$ In refractory cases, biological TNF- $\alpha$ inhibitors have therefore been introduced as third-line treatment options. ${ }^{6,27}$ Studies investigating the use of infliximab and adalimumab in sarcoidosis are limited, but have shown good results with regard to short-term efficacy. ${ }^{62-76}$ Chapter 8 also shows the effectiveness of infliximab and adalimumab in treating different disease manifestations of refractory sarcoidosis (Figure 9.4). ${ }^{77}$ To date, etanercept has not been proven effective in sarcoidosis disease management. ${ }^{78,79}$ Since the costs of TNF- $\alpha$ inhibitors are considerable and substantial side-effects are reported, optimal use is important. ${ }^{80-82}$ Sarcoidosis patients are in general treated by pulmonologists with usually less TNF- $\alpha$ inhibitor treatment experience. Moreover, evidence-based recommendations for infliximab and adalimumab therapy in sarcoidosis are lacking. Therefore, recommendations are needed to support the clinician in the use of TNF- $\alpha$ inhibitors, which are presented in chapter $7 .^{83}$ Given the limited available evidence in sarcoidosis, a Delphi method of polling to investigate consensus amongst sarcoidosis experts worldwide and data obtained from relevant studies in other inflammatory diseases were used to supplement possible lacunas.

a
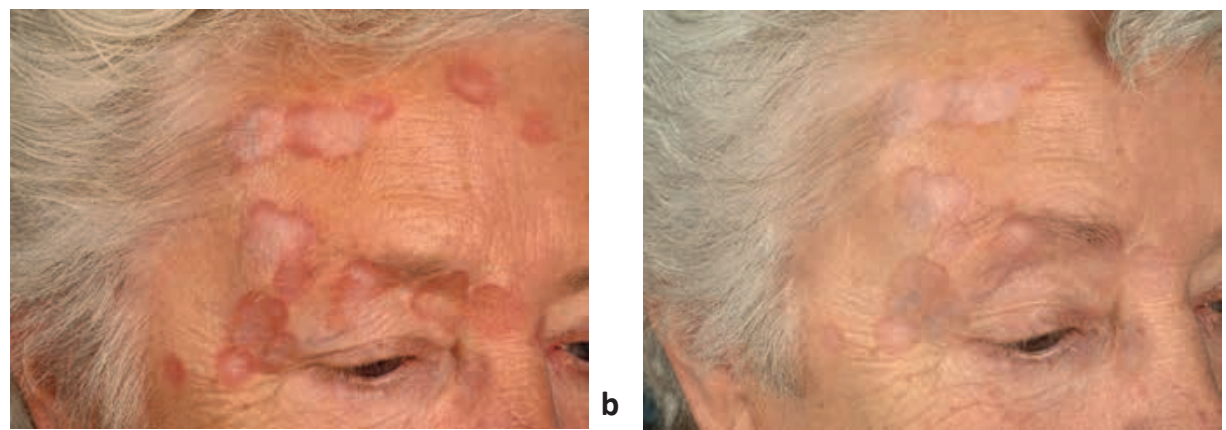

Figure 9.4 An example of a patient with skin manifestations. Photographs taken before (a), and after (b) 1 year of treatment with infliximab, showing a reduction of the intensity of the facial skin lesions.

As discussed in chapter 7, an approach specific for sarcoidosis is essential when initiating TNF- $\alpha$ inhibitor therapy. Experts in the field noticed that special attention should be paid to starting and maintenance dosages, interval and duration of treatment, and discontinuation regimens. The recommendations differ from regimens used in other inflammatory diseases, but are solely based on eminence- and experienced-based medicine. Therefore, future RCTs are necessary to investigate 
aspects such as the long-term effectiveness of TNF- $\alpha$ inhibitors in sarcoidosis; their use in different disease manifestations, including cardiac sarcoidosis; the comparison of different starting dosages, maintenance dosages and treatment intervals of infliximab and adalimumab respectively; and the optimal discontinuation regimen for infliximab and adalimumab to achieve 'biological free remission' (BFR), i.e. sustainability of remission after a biological agent is discontinued.

A difficult issue is discontinuation of TNF- $\alpha$ inhibitor treatment in stable disease. The first challenge is the identification of patients with stabilization of sarcoidosis disease, i.e. patients who might be possible candidates for sustained BFR after tapering down or stopping TNF- $\alpha$ inhibitor treatment. To identify stable disease, exact defined response criteria are necessary. ${ }^{84}$ Defining treatment response in sarcoidosis is difficult, since organ involvement and disease course may well be unpredictable. In chapter 8 , we made a first attempt. ${ }^{77}$ Prospective studies are needed to establish criteria for the identification of responders and non-responders when evaluating pharmacological treatment. Another difficulty is the establishment of the optimal period before successful withdrawal of TNF- $\alpha$ inhibitors is reasonable and of the indicators which can be used to ascertain this period. Vorselaars et al. ${ }^{85}$ showed that the majority of sarcoidosis patients $(29 / 47,62 \%)$ relapsed after discontinuation of infliximab after a mean treatment duration of 8.5 months. Future research is necessary to establish in which sarcoidosis patients and after what treatment duration, sustained BFR can be achieved, if this is an achievable goal at all.

\section{Pharmacogenetics in sarcoidosis}

Pharmacogenetics may provide an objective explanation for the discrepancies observed in response to pharmacotherapeutic agents amongst sarcoidosis patients. ${ }^{86}$ The genetic characteristics of the patient might interact with a certain drug, affecting its pharmacological action and ultimately leading to different treatment effects and toxicity risks. ${ }^{86}$ The principles of pharmacogenetics can potentially be applied to optimize pharmacological treatment. 'Gene chips' with a person's polymorphic genotype may be used, combined with characteristics of disease phenotype or appearance in the individual patient, to personalize drug treatment. ${ }^{87,88}$ Choosing the drug of most benefit for a particular patient would avoid unnecessary exposures to potentially toxic drugs and would lead to more effective, cheaper and faster disease control. $^{86}$

Genetic analysis has previously revealed a number of polymorphisms in genes coding for TNF- $\alpha$, with potential functional consequences. ${ }^{89}$ These polymorphisms might play a role in the clinical and prognostic diversity of sarcoidosis. The variant Aallele of the TNF- $\alpha$ G-308A gene (GA- or AA-genotype) is more frequently observed in patients with Löfgren's syndrome, an acute form of sarcoidosis with often spontaneous remission. ${ }^{89-93}$ The risk of progression to a more severe or persistent pulmonary disease course was found to be higher in patients without the TNF- $\alpha-308 \mathrm{~A}$ variant allele (GG- 
genotype). ${ }^{7}$ In addition to the TNF- $\alpha$ G-308A polymorphism, the TNF- $\alpha$ G-234A and LTA $\mathrm{Ncol}$ A252G polymorphisms were also suggested to have a possible role in sarcoidosis disease course. ${ }^{89,91,94}$ Furthermore, human leukocyte antigen (HLA)-DRB1*03 has been associated with a favorable prognosis. ${ }^{7,90}$ Because of the strong linkage between TNF- $\alpha$ G-308A and HLA-DRB1*03, genotyping of one simple and less expensive TNF- $\alpha$ single nucleotide polymorphism can be used to predict the prognosis of sarcoidosis in clinical practice. $^{7,90}$

The TNF- $\alpha$ G-308A polymorphism has been studied quite extensively in relation to prediction of TNF- $\alpha$ inhibitor treatment response in rheumatoid arthritis. Absence of the TNF- $\alpha-308 \mathrm{~A}$ variant allele was found to be associated with better response, suggesting a contribution of TNF- $\alpha$ G-308A polymorphism genotyping to the optimized use and distribution of available pharmacological sources. ${ }^{95-99}$ Chapter 8 of this thesis also shows a possible role for TNF- $\alpha$ G-308A polymorphism genotyping when tailoring TNF- $\alpha$ inhibitor therapy in sarcoidosis. ${ }^{77}$ However, the exact implications need to be evaluated, as well as other possible (genetic) factors identifying responders to TNF- $\alpha$ inhibitors.

In rheumatic inflammatory diseases, the value of polymorphism genotyping has also been studied to predict response to other therapeutic agents. For MTX genetics, studies have struggled to obtain consistent, replicable results. ${ }^{86}$ Several polymorphisms and genetic patterns have been investigated. Evidence suggests for example a favorable response in reduced folate carrier 1 (RFC1) G80A variant allele carriers. ${ }^{86,100,101}$ A recent meta-analysis showed that the odds of MTX efficacy increased by $42 \%$ for those with the RFC1 80AA-genotype compared to carriers of the wild type $\mathrm{G}$ allele (AA- versus AG/GG-genotype). ${ }^{102}$ Furthermore, many polymorphisms have been described for the methylenetetrahydrofolate reductase (MTHFR) gene. ${ }^{87,103}$ Of these, the C677T and A1298C polymorphisms have been associated with different toxicity or response effects to MTX therapy. ${ }^{87,103-105}$ HLA-DRB1 shared epitope-positive patients seem to respond worse to MTX, especially carriers of the HLA-DRB1*04 allele. ${ }^{86,106,107}$ In sarcoidosis, the value of polymorphism genotyping when tailoring MTX treatment, but also other agents, needs to be explored. In the most ideal situation, more insight into the influence of genetic variables on drug effectiveness and toxicity could lead to a more appropriate therapeutic choice, obviating a possibly unnecessary switch to other potentially less effective second-line alternatives or to more costly biologicals. ${ }^{86}$

\section{Directions for future research}

This thesis is an attempt to optimize pharmacotherapeutic options in sarcoidosis. Future research should focus on several other aspects to further improve management of sarcoidosis. Recommendations for MTX and TNF- $\alpha$ inhibitors in sarcoidosis are provided herein. Despite the fact that glucocorticosteroids are the first-line treatment option and are most commonly prescribed, guidelines for their use in sarcoidosis are 
not available. Furthermore, standardized management strategies for the use of other DMASDs, such as azathioprine or leflunomide, are lacking. The first step for future research should consist of the development of recommendations for the use of glucocorticosteroids and DMASDs in sarcoidosis, based on available evidence and combined with expert consensus if necessary, to supplement the guidance provided in this thesis.

Glucocorticosteroid resistance is an important issue of research in other inflammatory diseases. Until recently, therapy consisted of switching to alternative anti-inflammatory agents. However, many different molecular mechanisms of glucocorticoid resistance have now been elucidated, which can lead to new therapeutic strategies in the future, including the reversal of glucocorticoid resistance by blocking its underlying mechanisms. In sarcoidosis, the issue of resistance and its management needs to be evaluated.

In sarcoidosis, glucocorticosteroids and DMASDs are used for many years. Nevertheless, the RCT evidence supporting their use is limited. Most data come from observational case series. Treatment remains therefore predominantly empiric or is based on expert opinion. ${ }^{4,6}$ RCTs studying the effects of the different immunosuppressive agents on exact defined outcome measures for various disease manifestations and with a reasonable duration of follow-up to establish both short- and long-term efficacy, are necessary. Using defined endpoints and response criteria enables comparison of different DMASDs and comparison between different studies. Prospective RCTs are needed to establish criteria for the identification of responders and non-responders and can contribute to the improvement of current treatment strategies.

Recent studies support the use of new experimental treatment agents as alternative third-line therapy. Rituximab, inhaled vasoactive intestinal peptide and apremilast have been investigated. ${ }^{108-114}$ Abatacept en tocilizumab have been successfully used in rheumatoid arthritis. ${ }^{115,116}$ Regarding their immunopharmacological mode of action, one might consider them as promising in sarcoidosis as well. Future research is necessary to further explore these possibilities. New insights into sarcoidosis pathogenesis, can find other new possible drug targets. Fatigue and small fiber neuropathy, which are devastating problems in sarcoidosis, do not always respond to the 'standard' treatment strategies. New experimental treatment modalities have shown promising results in case series and/or pilot studies. ${ }^{117-120}$ Future research specifically addressing management of these problems is important.

Potentially, the principles of pharmacogenetics can be applied to optimize pharmacological treatment. This thesis made a first attempt to predict response to TNF$\alpha$ inhibitors. As mentioned before, further research is needed to evaluate other possible factors and genetic polymorphisms identifying responders to TNF- $\alpha$ inhibitors and to assess the role for TNF- $\alpha$ G-308A genotyping in this process. Also when tailoring other therapeutic agents, the value of pharmacogenetics including polymorphism genotyping needs to be explored. Furthermore, if specific patient and disease 
characteristics can possibly predict response to available therapy in sarcoidosis is practically unknown. The existence and value of these clinical predictors of response need to be explored. A better understanding of which patients will respond to therapy or develop toxicity based on the genetic and phenotypic characteristics, can prevent an unnecessary switch from one pharmacological agent to another. More insight could lead to both cost reduction and safer, more effective control of the disease, or in other words, help to pursue personalized medicine for the individual patient. 


\section{References}

1. Statement on sarcoidosis. Joint Statement of the American Thoracic Society (ATS), the European Respiratory Society (ERS) and the World Association of Sarcoidosis and Other Granulomatous Disorders (WASOG) adopted by the ATS Board of Directors and by the ERS Executive Committee, February 1999. Am J Respir Crit Care Med 1999;160:736-755.

2. Iannuzzi MC, Fontana JR. Sarcoidosis: clinical presentation, immunopathogenesis, and therapeutics. Jama 2011;305:391-399.

3. Valeyre D, Prasse A, Nunes H, Uzunhan Y, Brillet PY, Muller-Quernheim J. Sarcoidosis. Lancet 2013;Epub ahead of print.

4. Baughman RP, Nunes H. Therapy for sarcoidosis: evidence-based recommendations. Expert Rev Clin Immunol 2012;8:95-103.

5. Hunninghake GW, Costabel U, Ando M, Baughman R, Cordier JF, du Bois R, Eklund A, Kitaichi M, Lynch J, Rizzato G, Rose C, Selroos O, Semenzato G, Sharma OP. ATS/ERS/WASOG statement on sarcoidosis. American Thoracic Society/European Respiratory Society/World Association of Sarcoidosis and other Granulomatous Disorders. Sarcoidosis Vasc Diffuse Lung Dis 1999;16:149-173.

6. Baughman RP, Nunes $\mathrm{H}$, Sweiss NJ, Lower EE. Established and experimental medical therapy of pulmonary sarcoidosis. Eur Respir J 2013;41:1424-1438.

7. Wijnen PA, Nelemans PJ, Verschakelen JA, Bekers O, Voorter CE, Drent M. The role of tumor necrosis factor alpha G-308A polymorphisms in the course of pulmonary sarcoidosis. Tissue Antigens 2010;75:262-268.

8. Mostard RL, Van Kroonenburgh MJ, Drent M. The role of the PET scan in the management of sarcoidosis. Curr Opin Pulm Med 2013;19:538-544.

9. Sobic-Saranovic D, Artiko V, Obradovic V. FDG PET imaging in sarcoidosis. Semin Nucl Med 2013;43:404411.

10. Mostard RL, Voo S, Van Kroonenburgh MJ, Verschakelen JA, Wijnen PA, Nelemans PJ, Erckens RJ, Drent M. Inflammatory activity assessment by F18 FDG-PET/CT in persistent symptomatic sarcoidosis. Respir Med 2011;105:1917-1924.

11. Keijsers RG, Van den Heuvel DA, Grutters JC. Imaging the inflammatory activity of sarcoidosis. Eur Respir J 2013;41:743-751.

12. Cremers JP, Van Kroonenburgh MJ, Mostard RL, Vöö SA, Wijnen PA, Koek GH, Drent M. Extent of disease activity assessed by 18F-FDG PET/CT in a Dutch sarcoidosis population. Sarcoidosis Vasc Diffuse Lung Dis 2014;31:37-45.

13. Soussan M, Augier A, Brillet PY, Weinmann P, Valeyre D. Functional Imaging in Extrapulmonary Sarcoidosis: FDG-PET/CT and MR Features. Clin Nucl Med 2013; Epub ahead of print.

14. Schols AM, Soeters PB, Dingemans AM, Mostert R, Frantzen PJ, Wouters EF. Prevalence and characteristics of nutritional depletion in patients with stable COPD eligible for pulmonary rehabilitation. Am Rev Respir Dis 1993;147:1151-1156.

15. Van Bokhorst-De van der Schueren MA, Konijn NP, Bultink IE, Lems WF, Earthman CP, Van Tuyl LH. Relevance of the new pre-cachexia and cachexia definitions for patients with rheumatoid arthritis. Clin Nutr 2012;31:1008-1010.

16. Engelen MP, Schols AM, Baken WC, Wesseling GJ, Wouters EF. Nutritional depletion in relation to respiratory and peripheral skeletal muscle function in out-patients with COPD. Eur Respir J 1994;7:1793-1797.

17. Roca M, Mitu F, Roca IC, Mihaescu T. Body composition alterations in chronic obstructive pulmonary disease. Rev Med Chir Soc Med Nat lasi 2013;117:29-35.

18. Cremers JP, Drent M, Elfferich MD, Nelemans PJ, Wijnen PA, Witteman BJ, Schols AM. Body composition profiling in a Dutch sarcoidosis population. Sarcoidosis Vasc Diffuse Lung Dis 2014; 30:289299.

19. Trobec K, Kerec Kos M, von Haehling S, Springer J, Anker SD, Lainscak M. Pharmacokinetics of drugs in cachectic patients: a systematic review. PLoS One 2013;8:e79603.

20. Cremers J, Drent M, Driessen A, Nieman F, Wijnen P, Baughman R, Koek G. Liver-test abnormalities in sarcoidosis. Eur J Gastroenterol Hepatol 2012;24:17-24. 
21. Cremers JP, Drent M, Baughman RP, Wijnen PA, Koek GH. Therapeutic approach of hepatic sarcoidosis. Curr Opin Pulm Med 2012;18:472-482.

22. Cremers JP, Drent M, Bast A, Shigemitsu H, Baughman RP, Valeyre D, Sweiss NJ, Jansen TL. Multinational evidence-based World Association of Sarcoidosis and Other Granulomatous Disorders recommendations for the use of methotrexate in sarcoidosis: integrating systematic literature research and expert opinion of sarcoidologists worldwide. Curr Opin Pulm Med 2013;19:545-561.

23. Baughman RP, Koehler A, Bejarano PA, Lower EE, Weber FL, Jr. Role of liver function tests in detecting methotrexate-induced liver damage in sarcoidosis. Arch Intern Med 2003;163:615-620.

24. Devaney K, Goodman ZD, Epstein MS, Zimmerman HJ, Ishak KG. Hepatic sarcoidosis. Clinicopathologic features in 100 patients. Am J Surg Pathol 1993;17:1272-1280.

25. Lower EE, Baughman RP. The use of low dose methotrexate in refractory sarcoidosis. Am J Med Sci 1990;299:153-157.

26. Kennedy PT, Zakaria N, Modawi SB, Papadopoulou AM, Murray-Lyon I, du Bois RM, Jervoise NAH, Devlin J. Natural history of hepatic sarcoidosis and its response to treatment. Eur J Gastroenterol Hepatol 2006;18:721-726.

27. Korsten P, Mirsaeidi M, Sweiss NJ. Nonsteroidal therapy of sarcoidosis. Curr Opin Pulm Med 2013;19:516-523

28. Grutters JC, Van den Bosch JM. Corticosteroid treatment in sarcoidosis. Eur Respir J 2006;28:627-636.

29. Vorselaars AD, Van Moorsel CH, Deneer VH, Grutters JC. Current Therapy in Sarcoidosis, the Role of Existing Drugs and Future Medicine. Inflamm Allergy Drug Targets 2013;12:369-377.

30. Baughman RP. Pulmonary sarcoidosis. Clin Chest Med 2004;25:521-530, vi.

31. Barnes PJ, Adcock IM. Glucocorticoid resistance in inflammatory diseases. Lancet 2009;373:1905-1917.

32. Farrell RJ, Kelleher D. Glucocorticoid resistance in inflammatory bowel disease. J Endocrinol 2003;178:339-346.

33. Barnes PJ. Corticosteroid resistance in patients with asthma and chronic obstructive pulmonary disease. J Allergy Clin Immunol 2013;131:636-645.

34. Niess JH, Klaus J, Stephani J, Pfluger C, Degenkolb N, Spaniol U, Mayer B, Lahr G, von Boyen GB. NOD2 polymorphism predicts response to treatment in Crohn's disease--first steps to a personalized therapy. Dig Dis Sci 2012;57:879-886.

35. Culver DA, Barna BP, Raychaudhuri B, Bonfield TL, Abraham S, Malur A, Farver CF, Kavuru MS, Thomassen MJ. Peroxisome proliferator-activated receptor gamma activity is deficient in alveolar macrophages in pulmonary sarcoidosis. Am J Respir Cell Mol Biol 2004;30:1-5.

36. Drent $M$, Van den Berg R, Haenen GR, Van den Berg H, Wouters EF, Bast A. NF-kappaB activation in sarcoidosis. Sarcoidosis Vasc Diffuse Lung Dis 2001;18:50-56.

37. Abdallah A, Sato H, Grutters JC, Veeraraghavan S, Lympany PA, Ruven HJ, Van den Bosch JM, Wells AU, du Bois RM, Welsh KI. Inhibitor kappa B-alpha (IkappaB-alpha) promoter polymorphisms in UK and Dutch sarcoidosis. Genes Immun 2003;4:450-454.

38. Paramothayan S, Lasserson T. Treatments for pulmonary sarcoidosis. Respir Med 2008;102:1-9.

39. Paramothayan S, Lasserson TJ, Walters EH. Immunosuppressive and cytotoxic therapy for pulmonary sarcoidosis. Cochrane Database Syst Rev 2006:CD003536.

40. Suarez-Almazor ME, Belseck E, Shea B, Wells G, Tugwell P. Methotrexate for rheumatoid arthritis. Cochrane Database Syst Rev 2000:CD000957.

41. Gordon PA, Winer JB, Hoogendijk JE, Choy EH. Immunosuppressant and immunomodulatory treatment for dermatomyositis and polymyositis. Cochrane Database Syst Rev 2012;8:CD003643.

42. Baughman RP, Winget DB, Lower EE. Methotrexate is steroid sparing in acute sarcoidosis: results of a double blind, randomized trial. Sarcoidosis Vasc Diffuse Lung Dis 2000;17:60-66.

43. Schutt AC, Bullington WM, Judson MA. Pharmacotherapy for pulmonary sarcoidosis: a Delphi consensus study. Respir Med 2010;104:717-723.

44. Baughman R, Drent M. The treatment of pulmonary sarcoidosis. In: Judson MA, ed. Pulmonary sarcoidosis: A guide for the practicing clinician. New York: Respiratory Medicine, 2014; 41-64.

45. Vucinic VM. What is the future of methotrexate in sarcoidosis? A study and review. Curr Opin Pulm Med 2002;8:470-476.

46. Salliot C, Van der Heijde D. Long-term safety of methotrexate monotherapy in patients with rheumatoid arthritis: a systematic literature research. Ann Rheum Dis 2009;68:1100-1104. 
47. Visser K, Katchamart W, Loza E, Martinez-Lopez JA, Salliot C, Trudeau J, Bombardier C, Carmona L, Van der Heijde D, Bijlsma JW, Boumpas DT, Canhao H, Edwards CJ, Hamuryudan V, Kvien TK, Leeb BF, Martin-Mola EM, Mielants H, Muller-Ladner U, Murphy G, Ostergaard M, Pereira IA, Ramos-Remus C, Valentini G, Zochling J, Dougados M. Multinational evidence-based recommendations for the use of methotrexate in rheumatic disorders with a focus on rheumatoid arthritis: integrating systematic literature research and expert opinion of a broad international panel of rheumatologists in the $3 \mathrm{E}$ Initiative. Ann Rheum Dis 2009;68:1086-1093.

48. Doran MF, Crowson CS, Pond GR, O'Fallon WM, Gabriel SE. Predictors of infection in rheumatoid arthritis. Arthritis Rheum 2002;46:2294-2300.

49. Conway R, Low C, Coughlan RJ, O'Donnell MJ, Carey JJ. Methotrexate and lung disease in rheumatoid arthritis - A meta-analysis of randomized controlled trials. Arthritis Rheum 2013;Epub ahead of print.

50. Wolfe F, Michaud K. Lymphoma in rheumatoid arthritis: the effect of methotrexate and anti-tumor necrosis factor therapy in 18,572 patients. Arthritis Rheum 2004;50:1740-1751.

51. Mariette X, Cazals-Hatem D, Warszawki J, Liote F, Balandraud N, Sibilia J. Lymphomas in rheumatoid arthritis patients treated with methotrexate: a 3-year prospective study in France. Blood 2002;99:39093915.

52. Kameda T, Dobashi H, Miyatake N, Inoo M, Onishi I, Kurata N, Mitsunaka H, Kawakami K, Fukumoto T, Susaki K, Izumikawa M, Nakashima S, Shimada H, Takeuchi Y, Haba R, Mano S, Onishi H, Imataki O, Matsunaga T. Higher methotrexate dose is associated with lymphoproliferative disorders onset in rheumatoid arthritis patients. Arthritis Care Res (Hoboken) 2014; Epub ahead of print.

53. Bulatovic M, Heijstek MW, Verkaaik M, van Dijkhuizen EH, Armbrust W, Hoppenreijs EP, Kamphuis S, Kuis W, Egberts TC, Sinnema G, Rademaker CM, Wulffraat NM. High prevalence of methotrexate intolerance in juvenile idiopathic arthritis: development and validation of a methotrexate intolerance severity score. Arthritis Rheum 2011;63:2007-2013.

54. Bulatovic Calasan M, van den Bosch OF, Creemers MC, Custers M, Heurkens AH, van Woerkom JM, Wulffraat NM. Prevalence of methotrexate intolerance in rheumatoid arthritis and psoriatic arthritis. Arthritis Res Ther 2013;15:R217.

55. Jundt JW, Browne BA, Fiocco GP, Steele AD, Mock D. A comparison of low dose methotrexate bioavailability: oral solution, oral tablet, subcutaneous and intramuscular dosing. J Rheumatol 1993;20:1845-1849.

56. Hoekstra M, Haagsma C, Neef C, Proost J, Knuif A, Van de Laar M. Bioavailability of higher dose methotrexate comparing oral and subcutaneous administration in patients with rheumatoid arthritis. $J$ Rheumatol 2004;31:645-648.

57. Hoekstra M, Haagsma C, Neef C, Proost J, Knuif A, Van de Laar M. Splitting high-dose oral methotrexate improves bioavailability: a pharmacokinetic study in patients with rheumatoid arthritis. J Rheumatol 2006;33:481-485.

58. Van Roon EN, Van de Laar MA. Methotrexate bioavailability. Clin Exp Rheumatol 2010;28:S27-32.

59. Ziegenhagen MW, Rothe ME, Zissel G, Muller-Quernheim J. Exaggerated TNFalpha release of alveolar macrophages in corticosteroid resistant sarcoidosis. Sarcoidosis Vasc Diffuse Lung Dis 2002;19:185-190.

60. Antoniu SA. Targeting the TNF-alpha pathway in sarcoidosis. Expert Opin Ther Targets 2010;14:21-29.

61. Loza MJ, Brodmerkel C, Du Bois RM, Judson MA, Costabel U, Drent M, Kavuru M, Flavin S, Lo KH, Barnathan ES, Baughman RP. Inflammatory profile and response to anti-tumor necrosis factor therapy in patients with chronic pulmonary sarcoidosis. Clin Vaccine Immunol 2011;18:931-939.

62. Baughman RP, Drent M, Kavuru M, Judson MA, Costabel U, du Bois R, Albera C, Brutsche M, Davis G, Donohue JF, Muller-Quernheim J, Schlenker-Herceg R, Flavin S, Lo KH, Oemar B, Barnathan ES. Infliximab therapy in patients with chronic sarcoidosis and pulmonary involvement. Am J Respir Crit Care Med 2006;174:795-802.

63. Rossman MD, Newman LS, Baughman RP, Teirstein A, Weinberger SE, Miller W, Jr., Sands BE. A doubleblinded, randomized, placebo-controlled trial of infliximab in subjects with active pulmonary sarcoidosis. Sarcoidosis Vasc Diffuse Lung Dis 2006;23:201-208.

64. Russell E, Luk F, Manocha S, Ho T, O'Connor C, Hussain H. Long term follow-up of infliximab efficacy in pulmonary and extra-pulmonary sarcoidosis refractory to conventional therapy. Semin Arthritis Rheum 2013;43:119-124. 
65. Erckens RJ, Mostard RL, Wijnen PA, Schouten JS, Drent M. Adalimumab successful in sarcoidosis patients with refractory chronic non-infectious uveitis. Graefes Arch Clin Exp Ophthalmol 2012;250:713720.

66. Milman N, Graudal N, Loft A, Mortensen J, Larsen J, Baslund B. Effect of the TNF-alpha inhibitor adalimumab in patients with recalcitrant sarcoidosis: a prospective observational study using FDG-PET. Clin Respir J 2012;6:238-247.

67. Kamphuis LS, Lam-Tse WK, Dik WA, Van Daele PL, Van Biezen P, Kwekkeboom DJ, Kuijpers RW, Hooijkaas H, Van Laar JA, Bastiaans J, Baarsma GS, Van Hagen PM. Efficacy of adalimumab in chronically active and symptomatic patients with sarcoidosis. Am J Respir Crit Care Med 2011;184:1214-1216.

68. Elfferich MD, Nelemans PJ, Ponds RW, De Vries J, Wijnen PA, Drent M. Everyday cognitive failure in sarcoidosis: the prevalence and the effect of anti-TNF-alpha treatment. Respiration 2010;80:212-219.

69. Pariser RJ, Paul J, Hirano S, Torosky C, Smith M. A double-blind, randomized, placebo-controlled trial of adalimumab in the treatment of cutaneous sarcoidosis. J Am Acad Dermatol 2013;68:765-773.

70. Judson MA, Baughman RP, Costabel U, Flavin S, Lo KH, Kavuru MS, Drent M. Efficacy of infliximab in extrapulmonary sarcoidosis: results from a randomised trial. Eur Respir J 2008;31:1189-1196.

71. Hostettler KE, Studler U, Tamm M, Brutsche MH. Long-term treatment with infliximab in patients with sarcoidosis. Respiration 2012;83:218-224.

72. Orum M, Hilberg O, Krag S, Bendstrup E. Beneficial effect of infliximab on refractory sarcoidosis. Dan Med J 2012;59:A4535.

73. Keijsers RG, Verzijlbergen JF, Van Diepen DM, Van den Bosch JM, Grutters JC. 18F-FDG PET in sarcoidosis: an observational study in 12 patients treated with infliximab. Sarcoidosis Vasc Diffuse Lung Dis 2008;25:143-149.

74. Saleh S, Ghodsian S, Yakimova V, Henderson J, Sharma OP. Effectiveness of infliximab in treating selected patients with sarcoidosis. Respir Med 2006;100:2053-2059.

75. Doty JD, Mazur JE, Judson MA. Treatment of sarcoidosis with infliximab. Chest 2005;127:1064-1071.

76. Baughman RP, Lower EE, Ingledue R, Kaufman AH. Management of ocular sarcoidosis. Sarcoidosis Vasc Diffuse Lung Dis 2012;29:26-33.

77. Wijnen PA, Cremers JP, Nelemans PJ, Erckens RJ, Hoitsma E, Jansen TL, Bekers O, Drent M. Association of the TNF- $\alpha$ G-308A polymorphism with TNF-inhibitor response in sarcoidosis. Eur Respir J 2014;In press.

78. Utz JP, Limper AH, Kalra S, Specks U, Scott JP, Vuk-Pavlovic Z, Schroeder DR. Etanercept for the treatment of stage II and III progressive pulmonary sarcoidosis. Chest 2003;124:177-185.

79. Baughman RP, Lower EE, Bradley DA, Raymond LA, Kaufman A. Etanercept for refractory ocular sarcoidosis: results of a double-blind randomized trial. Chest 2005;128:1062-1047.

80. Liu Y, Wu EQ, Bensimon AG, Fan CP, Bao Y, Ganguli A, Yang M, Cifaldi M, Mulani P. Cost per responder associated with biologic therapies for Crohn's disease, psoriasis, and rheumatoid arthritis. Adv Ther 2012;29:620-634.

81. Rosenblum H, Amital H. Anti-TNF therapy: safety aspects of taking the risk. Autoimmun Rev 2011;10:563-568.

82. Singh JA, Wells GA, Christensen R, Tanjong Ghogomu E, Maxwell L, Macdonald JK, Filippini G, Skoetz N, Francis D, Lopes LC, Guyatt GH, Schmitt J, La Mantia L, Weberschock T, Roos JF, Siebert H, Hershan S, Lunn MP, Tugwell P, Buchbinder R. Adverse effects of biologics: a network meta-analysis and Cochrane overview. Cochrane Database Syst Rev 2011:CD008794.

83. Drent $\mathrm{M}$, Cremers J, Jansen $\mathrm{T}$, Baughman R. Practical eminence and experience-based recommendations for use of TNF- $\alpha$ inhibitors in sarcoidosis. Sarcoidosis Vasc Diffuse Lung Dis 2014;Accepted for publication.

84. Baughman RP, Drent M, Culver DA, Grutters JC, Handa T, Humbert M, Judson MA, Lower EE, Mana J, Pereira CA, Prasse A, Sulica R, Valyere D, Vucinic V, Wells AU. Endpoints for clinical trials of sarcoidosis. Sarcoidosis Vasc Diffuse Lung Dis 2012;29:90-98.

85. Vorselaars AD, Verwoerd A, Van Moorsel CH, Keijsers RG, Rijkers GT, Grutters JC. Prediction of relapse after discontinuation of infliximab therapy in severe sarcoidosis. Eur Respir J 2013;43:602-609.

86. Romao VC, Canhao H, Fonseca JE. Old drugs, old problems: where do we stand in prediction of rheumatoid arthritis responsiveness to methotrexate and other synthetic DMARDs? BMC Med 2013;11:17. 
87. Ranganathan P, Eisen S, Yokoyama WM, McLeod HL. Will pharmacogenetics allow better prediction of methotrexate toxicity and efficacy in patients with rheumatoid arthritis? Ann Rheum Dis 2003;62:4-9.

88. Daien $\mathrm{Cl}$, Morel J. Predictive Factors of Response to Biological Disease Modifying Antirheumatic Drugs: Towards Personalized Medicine. Mediators Inflamm 2014; Epub ahead of print.

89. Seitzer U, Swider C, Stuber F, Suchnicki K, Lange A, Richter E, Zabel P, Muller-Quernheim J, Flad HD, Gerdes J. Tumour necrosis factor alpha promoter gene polymorphism in sarcoidosis. Cytokine 1997;9:787-790.

90. Swider C, Schnittger L, Bogunia-Kubik K, Gerdes J, Flad H, Lange A, Seitzer U. TNF-alpha and HLA-DR genotyping as potential prognostic markers in pulmonary sarcoidosis. Eur Cytokine Netw 1999;10:143146.

91. Mrazek F, Holla LI, Hutyrova B, Znojil V, Vasku A, Kolek V, Welsh KI, Vacha J, du Bois RM, Petrek M. Association of tumour necrosis factor-alpha, lymphotoxin-alpha and HLA-DRB1 gene polymorphisms with Lofgren's syndrome in Czech patients with sarcoidosis. Tissue Antigens 2005;65:163-171.

92. Kieszko R, Krawczyk P, Chocholska S, Dmoszynska A, Milanowski J. TNF-alpha and TNF-beta gene polymorphisms in Polish patients with sarcoidosis. Connection with the susceptibility and prognosis. Sarcoidosis Vasc Diffuse Lung Dis 2010;27:131-137.

93. Petkovic TR, Pejcic T, Videnovic-Ivanov J, Stoimenov TJ, Jankovic I, Borovac DN, Radojkovic D. Tumor necrosis factor alpha gene polymorphism in serbian patients with sarcoidosis. Srp Arh Celok Lek 2013;141:169-172.

94. Grutters JC, Sato H, Pantelidis P, Lagan AL, McGrath DS, Lammers JW, Van den Bosch JM, Wells AU, du Bois RM, Welsh KI. Increased frequency of the uncommon tumor necrosis factor -857T allele in British and Dutch patients with sarcoidosis. Am J Respir Crit Care Med 2002;165:1119-1124.

95. Mugnier B, Balandraud N, Darque A, Roudier C, Roudier J, Reviron D. Polymorphism at position -308 of the tumor necrosis factor alpha gene influences outcome of infliximab therapy in rheumatoid arthritis. Arthritis Rheum 2003;48:1849-1852.

96. Zeng Z, Duan Z, Zhang T, Wang S, Li G, Gao J, Ye D, Xu S, Xu J, Zhang L, Pan F. Association between tumor necrosis factor-alpha (TNF-alpha) promoter $-308 \mathrm{G} / \mathrm{A}$ and response to TNF-alpha blockers in rheumatoid arthritis: a meta-analysis. Mod Rheumatol 2013;23:489-495.

97. Cuchacovich M, Ferreira L, Aliste M, Soto L, Cuenca J, Cruzat A, Gatica H, Schiattino I, Perez C, Aguirre A, Salazar-Onfray F, Aguillon JC. Tumour necrosis factor-alpha (TNF-alpha) levels and influence of -308 TNF-alpha promoter polymorphism on the responsiveness to infliximab in patients with rheumatoid arthritis. Scand J Rheumatol 2004;33:228-232.

98. Cuchacovich M, Soto L, Edwardes M, Gutierrez M, Llanos C, Pacheco D, Sabugo F, Alamo M, Fuentealba C, Villanueva L, Gatica H, Schiattino I, Salazaro L, Catalan D, Valenzuela O, Salazar-Onfray F, Aguillon JC. Tumour necrosis factor (TNF)alpha $-308 \mathrm{G} / \mathrm{G}$ promoter polymorphism and TNFalpha levels correlate with a better response to adalimumab in patients with rheumatoid arthritis. Scand I Rheumatol 2006;35:435-440.

99. Seitz M, Wirthmuller U, Moller B, Villiger PM. The -308 tumour necrosis factor-alpha gene polymorphism predicts therapeutic response to TNFalpha-blockers in rheumatoid arthritis and spondyloarthritis patients. Rheumatology (Oxford) 2007;46:93-96.

100. Drozdzik M, Rudas T, Pawlik A, Gornik W, Kurzawski M, Herczynska M. Reduced folate carrier-1 80G>A polymorphism affects methotrexate treatment outcome in rheumatoid arthritis. Pharmacogenomics $J$ 2007;7:404-407.

101. Baslund B, Gregers J, Nielsen CH. Reduced folate carrier polymorphism determines methotrexate uptake by B cells and CD4+ T cells. Rheumatology (Oxford) 2008;47:451-453.

102. Kung TN, Dennis J, Ma Y, Xie G, Bykerk V, Pope J, Thorne C, Keystone E, Siminovitch KA, Gagnon F. RFC$180 \mathrm{G}>\mathrm{A}$ is a genetic determinant of methotrexate efficacy in Rheumatoid Arthritis: A HuGE review and meta-analysis of observational studies. Arthritis Rheum 2013;Epub ahead of print.

103. Hughes LB, Beasley TM, Patel H, Tiwari HK, Morgan SL, Baggott JE, Saag KG, McNicholl J, Moreland LW, Alarcon GS, Bridges SL, Jr. Racial or ethnic differences in allele frequencies of single-nucleotide polymorphisms in the methylenetetrahydrofolate reductase gene and their influence on response to methotrexate in rheumatoid arthritis. Ann Rheum Dis 2006;65:1213-1218.

104. Schmeling H, Biber D, Heins S, Horneff G. Influence of methylenetetrahydrofolate reductase polymorphisms on efficacy and toxicity of methotrexate in patients with juvenile idiopathic arthritis. $J$ Rheumatol 2005;32:1832-1836. 
105. Wessels JA, De Vries-Bouwstra JK, Heijmans BT, Slagboom PE, Goekoop-Ruiterman YP, Allaart CF, Kerstens PJ, Van Zeben D, Breedveld FC, Dijkmans BA, Huizinga TW, Guchelaar HJ. Efficacy and toxicity of methotrexate in early rheumatoid arthritis are associated with single-nucleotide polymorphisms in genes coding for folate pathway enzymes. Arthritis Rheum 2006;54:1087-1095.

106. Ferraccioli GF, Gremese E, Tomietto P, Favret G, Damato R, Di Poi E. Analysis of improvements, full responses, remission and toxicity in rheumatoid patients treated with step-up combination therapy (methotrexate, cyclosporin A, sulphasalazine) or monotherapy for three years. Rheumatology (Oxford) 2002;41:892-898.

107. Mori S, Hirose J, Yonemura K. Contribution of HLA-DRB1*04 alleles and anti-cyclic citrullinated antibodies to development of resistance to disease-modifying antirheumatic drugs in early rheumatoid arthritis. Clin Rheumatol 2010;29:1357-1366.

108. Beccastrini E, Vannozzi L, Bacherini D, Squatrito D, Emmi L. Successful treatment of ocular sarcoidosis with rituximab. Ocul Immunol Inflamm 2013;21:244-246.

109. Bomprezzi R, Pati S, Chansakul C, Vollmer T. A case of neurosarcoidosis successfully treated with rituximab. Neurology 2010;75:568-570.

110. Belkhou A, Younsi R, El Bouchti I, El Hassani S. Rituximab as a treatment alternative in sarcoidosis. Joint Bone Spine 2008;75:511-512.

111. Gottenberg JE, Guillevin L, Lambotte O, Combe B, Allanore Y, Cantagrel A, Larroche C, Soubrier M, Bouillet L, Dougados M, Fain O, Farge D, Kyndt X, Lortholary O, Masson C, Moura B, Remy P, Thomas T, Wendling D, Anaya JM, Sibilia J, Mariette X. Tolerance and short term efficacy of rituximab in 43 patients with systemic autoimmune diseases. Ann Rheum Dis 2005;64:913-920.

112. Baughman RP, Judson MA, Ingledue R, Craft NL, Lower EE. Efficacy and safety of apremilast in chronic cutaneous sarcoidosis. Arch Dermatol 2012;148:262-264.

113. Prasse A, Zissel G, Lutzen N, Schupp J, Schmiedlin R, Gonzalez-Rey E, Rensing-Ehl A, Bacher G, Cavalli V, Bevec D, Delgado M, Muller-Quernheim J. Inhaled vasoactive intestinal peptide exerts immunoregulatory effects in sarcoidosis. Am J Respir Crit Care Med 2010;182:540-548.

114. Lower EE, Baughman RP, Kaufman AH. Rituximab for refractory granulomatous eye disease. Clin Ophthalmol 2012;6:1613-1618.

115. Takahashi N, Kojima T, Kaneko A, Kida D, Hirano Y, Fujibayashi T, Yabe Y, Takagi H, Oguchi T, Miyake H, Kato T, Fukaya N, Ishikawa H, Hayashi M, Tsuboi S, Kanayama Y, Kato D, Funahashi K, Matsubara H, Hattori Y, Hanabayashi M, Hirabara S, Terabe K, Yoshioka Y, Ishiguro N. Clinical efficacy of abatacept compared to adalimumab and tocilizumab in rheumatoid arthritis patients with high disease activity. Clin Rheumatol 2013; Epub ahead of print.

116. Pers YM, Fortunet C, Constant E, Lambert J, Godfrin-Valnet M, De Jong A, Mercier G, Pallot Prades B, Wendling D, Gaudin P, Jorgensen C, Marotte H, Maillefert JF. Predictors of response and remission in a large cohort of rheumatoid arthritis patients treated with tocilizumab in clinical practice. Rheumatology (Oxford) 2014;53:76-84.

117. Lower EE, Malhotra A, Surdulescu V, Baughman RP. Armodafinil for sarcoidosis-associated fatigue: a double-blind, placebo-controlled, crossover trial. J Pain Symptom Manage 2013;45:159-169.

118. Lower EE, Harman S, Baughman RP. Double-blind, randomized trial of dexmethylphenidate hydrochloride for the treatment of sarcoidosis-associated fatigue. Chest 2008;133:1189-1195.

119. Heij L, Dahan A, Hoitsma E. Sarcoidosis and pain caused by small-fiber neuropathy. Pain Res Treat 2012;2012:256024.

120. Heij L, Niesters M, Swartjes M, Hoitsma E, Drent M, Dunne A, Grutters JC, Vogels O, Brines M, Cerami A, Dahan A. Safety and efficacy of ARA 290 in sarcoidosis patients with symptoms of small fiber neuropathy: a randomized, double-blind pilot study. Mol Med 2012;18:1430-1436. 


\section{Samenvatting}




\section{Inleiding}

Sarcoïdose is een multisysteemaandoening, waarvan de oorzaak niet bekend is. De ziekte wordt gekenmerkt door ontstekingsactiviteit met de vorming van nietverkazende granulomen. In de meeste gevallen zijn de longen aangedaan, maar vrijwel ieder orgaansysteem kan betrokken zijn. Sarcoïdose is het resultaat van een proces dat bestaat uit een immuunrespons tegen verschillende omgevingstriggers in een genetisch vatbaar individu, waarbij ook oxidatieve stress een rol speelt. De ziekte presenteert zich bij zowel mannen als vrouwen van alle rassen over de gehele wereld. Bij mensen van het negroïde ras is het beloop over het algemeen ernstiger. Sarcoïdose kan individuen van alle leeftijden treffen, maar komt het meeste voor tussen het $20^{\mathrm{e}}$ en $40^{\mathrm{e}}$ levensjaar. Bij vrouwen bestaat een tweede piek na de menopauze. Patiënten kunnen zich met een grote verscheidenheid aan klachten en klinische verschijnselen presenteren. Ook de ernst van de ziekte is variabel, wisselend van minimale orgaan-betrokkenheid tot verstoring van de fysiologie leidend tot ernstige functionele beperkingen. Een voorbeeld hiervan is het ontstaan van longfibrose ten gevolge van veelal langdurige sarcoïdose ziekteactiviteit.

De meeste patiënten tonen spontane remissie zonder de noodzaak tot systemische medicamenteuze behandeling. Echter, bij mensen met een ernstiger ziektebeloop en slechte prognose is een tijdige implementatie van een geschikt individueel beleid noodzakelijk om complicaties te voorkomen en de ziektelast te verlichten. Bij de meerderheid van de patiënten bij wie behandeling gewenst is, is een lage dosering van een immunosuppressief middel voldoende. Ongeveer $10 \%$ van alle patiënten behoeft langdurige systemische therapie. Ondanks de beschikbaarheid van een verscheidenheid aan immunosuppressieve therapeutische opties, is er een gebrek aan gestandaardiseerde behandelstrategieën bij sarcoïdose. De gepubliceerde studies beschikbaar voor de verschillende farmacologische middelen zijn beperkt. Behandeling blijft daardoor vooral empirisch.

Het optimaliseren van farmacotherapeutische opties bij sarcoïdose is van groot belang. Aangezien patiënten zich kunnen presenteren bij verschillende (orgaan)specialisten, is het ingestelde behandelplan veelal afhankelijk van de ervaring van een individuele specialist. Het toepassen van therapeutische opties door onervaren artsen kan worden verbeterd middels begeleiding via richtlijnen of aanbevelingen. Daarnaast geldt dat een multidisciplinaire benadering - waar de patiënt centraal staat en de artsen in goed onderling overleg samen met de patiënt een behandelplan opstellen - cruciaal is. De patiënt heeft een steeds belangrijker rol in het management. In het behandelplan dient voorop te staan dat onnodige blootstelling van patiënten aan opeenvolgende farmacologische middelen zoveel mogelijk wordt voorkomen. Gezien de veelbelovende resultaten van studies naar het gebruik van biologicals bij sarcoïdosepatiënten met refractaire klachten en ziektekenmerken, lijkt er onder zorgverleners een trend te ontstaan met een lage drempel voor de switch van tweedelijns naar de derdelijns tumor necrose factor-alfa (TNF- $\alpha$ ) remmende middelen. 
Echter, het gebruik van TNF- $\alpha$ remmers is niet zonder risico's en brengt aanzienlijke kosten met zich mee. Verbetering van het gebruik van effectieve en minder kostbare tweedelijns middelen, oftewel disease-modifying antisarcoid drugs (DMASDs), kan bijdragen aan het betaalbaar en toegankelijk houden van het gezondheidszorgsysteem. TNF- $\alpha$ remmende therapie dient alleen te worden gestart op de juiste indicatie en onder deskundige begeleiding. Aangezien sarcoïdose zich zo divers kan presenteren, zal het optimaal gebruik maken van therapeutische opties voor de individuele patiënt bijdragen aan het nastreven van zorg op maat.

Het doel van de studies die in dit proefschrift worden beschreven, is het bijdragen aan het optimaliseren van farmacotherapie voor sarcoïdosepatiënten. Verschillende aspecten van therapeutische opties bij sarcoïdose worden geëvalueerd. De nadruk ligt op de betekenis van lichaamssamenstelling bij sarcoïdosepatiënten, de betekenis van afwijkende levertesten, en de ontwikkeling van praktische aanbevelingen voor het gebruik van methotrexaat (MTX) en TNF- $\alpha$ remmers. Tevens wordt gezocht naar factoren die het mogelijk maken om patiënten met een gunstige reactie op TNF- $\alpha$ remmers te identificeren. Vier studies maken gebruik van data afkomstig van sarcoïdosepatiënten die worden behandeld in een tertiair verwijscentrum in Nederland. Twee studies evalueren de ervaring van wereldwijde sarcoïdose-experts met therapeutische middelen door middel van een online vragenlijst en combineren deze informatie met gegevens tot nu toe beschikbaar in de literatuur. Een algemeen overzicht van de bevindingen gepresenteerd in dit proefschrift volgt hierna.

\section{Overzicht bevindingen}

In hoofdstuk 1 wordt als algemene inleiding een overzicht gegeven van de pathogenese, klinische presentatie en diagnostiek van sarcoïdose. Speciale aandacht gaat uit naar de beschikbare eerste-, tweede- en derdelijns behandelopties bij sarcoïdose. Tot slot wordt een overzicht van het proefschrift gepresenteerd.

In hoofdstuk $\mathbf{2}$ wordt de uitgebreidheid, verdeling en samenstelling van orgaanbetrokkenheid, vastgesteld middels de fluorine18-fluorodeoxyglucose positron emissie tomografie/computertomografie ( $\left({ }^{18} \mathrm{~F}-\mathrm{FDG}\right.$ PET/CT of PET) scan, bij 158 sarcoïdosepatiënten met onverklaarbare persisterende invaliderende symptomen beschreven. PET-positieve bevindingen werden ingedeeld als thoracaal en/of extrathoracaal. De meerderheid (93\%) van de sarcoïdosepatiënten had intrathoracale activiteit (79\% mediastinale en $64 \%$ pulmonale activiteit, respectievelijk) en $75 \%$ toonde extrathoracale activiteit (hoofdzakelijk perifere lymfeklieren, bot/beenmerg en milt). Lever PET-positiviteit ging in alle gevallen samen met milt activiteit, terwijl de meerderheid van de patiënten met activiteit van de glandula parotis, milt of bot/beenmerg, lymfeklieractiviteit liet zien. Een aanzienlijk aantal patiënten met PETpositieve pulmonale bevindingen ( $86 \%$ ) vertoonde tekenen van functionele respiratoire beperkingen. Er werd geen duidelijke associatie gevonden tussen activiteit van lever, 
milt of bot/beenmerg en hun corresponderende laboratorium afwijkingen suggestief voor specifieke orgaanbetrokkenheid. PET blijkt vooral van belang bij het vaststellen van de uitgebreidheid, verdeling en samenstelling van ontstekingsactiviteit bij het verklaren van persisterende invaliderende symptomen bij sarcoïdose en/of om een geschikte plaats te vinden voor het verrichten van een biopt.

In hoofdstuk 3 wordt het onderzoek naar de prevalentie van spieratrofie en cachexie bij 423 Nederlandse sarcoïdosepatiënten en de associatie van lichaamssamenstelling met sarcoïdose ziekteactiviteit en ernst weergegeven. Vet-vrije massa werd gemeten als een indirecte maat voor spiermassa met behulp van bioelektrische impedantie analyse. Patiënten werden ingedeeld in verschillende categorieën op basis van de body mass index (BMI) en vet-vrije massa index (VVMI). Spieratrofie werd gedefinieerd als VVMI $<15 \mathrm{~kg} / \mathrm{m}^{2}$ voor vrouwen en $<17 \mathrm{~kg} / \mathrm{m}^{2}$ voor mannen, overeenkomend met de tiende percentiel van huidige referentiewaarden; cachexie als $\mathrm{BMI}<20$ gecombineerd met spieratrofie. Relevante klinische data werden retrospectief verzameld. Spieratrofie bleek aanwezig te zijn bij $25 \%$ en cachexie bij $5 \%$ van de sarcoïdosepatiënten. Patiënten met spieratrofie toonden een significant slechtere longfunctie (diffusiecapaciteit voor koolstofmonoxide (DLCO), geforceerd expiratoir volume in 1 seconde (FEV1), geforceerde vitale capaciteit (FVC), alle pwaarden $<0.001$ ) en verminderde inspanningscapaciteit (maximale zuurstofopnamevermogen $\left.\left(\mathrm{VO}_{2} \mathrm{max}\right), \mathrm{p}<0.001\right)$. De associaties waren het meest uitgesproken bij patiënten met cachexie. De resultaten laten zien dat spieratrofie en cachexie aanzienlijke problemen vormen bij sarcoïdose.

Hoofdstuk 4 onderzoekt de aanwezigheid en ernst van levertestafwijkingen bij 837 patiënten met een bevestigde diagnose sarcoïdose. Verder wordt de associatie tussen de ernst van levertestafwijkingen en histopathologische afwijkingen bij leversarcoïdose geëvalueerd. Gedurende een periode van 9 jaar werden relevante klinische data uit medische dossiers verzameld. Levertestafwijkingen (alkalische fosfatase, $\gamma$-glutamyl transferase, alanine aminotransferase of aspartaat aminotransferase $>1.5$ keer de bovengrens van normaal (ULN)) werden ingedeeld op basis van ernst in mild (nul levertesten $\geq 3$ keer de ULN), matig (één of twee levertesten $\geq 3$ keer de ULN) en ernstig (drie of vier levertesten $\geq 3$ keer de ULN). Bij $24 \%$ van de onderzochte sarcoïdosepatiënten waren levertestafwijkingen aanwezig. Bij $15 \%$ was dit meest waarschijnlijk het gevolg van betrokkenheid van de lever in het sarcoïdoseproces. Bij 22 van deze laatste groep was eerder een leverbiopt verricht, waarvan 21 biopten compatibel bleken met leversarcoïdose. De aanwezigheid en mate van inflammatie, fibrose, en verdeling van de granulomen in deze leverbiopten werden onderzocht. De aanwezigheid van matige of ernstige levertestafwijkingen bleek geassocieerd met vergevorderde histopathologische afwijkingen. Daarom wordt bij sarcoïdosepatiënten met matige of ernstige levertestafwijkingen een leverbiopt aanbevolen.

Hoofdstuk 5 geeft een overzicht van de kennis beschikbaar in de literatuur omtrent therapeutische opties voor sarcoïdosebetrokkenheid van de lever. Deze data zijn samengevoegd in aanbevelingen voor de optimale therapeutische benadering in de 
klinische praktijk. Slechts $5-30 \%$ van de patiënten met leversarcoïdose tonen symptomen. Echter, in sommige gevallen kan leversarcoïdose een progressief beloop hebben met ernstige complicaties. Dit onderstreept het belang van een passende en zorgvuldig getimede therapeutische benadering. Aangezien symptomatische leversarcoïdose ongewoon is, zijn studies naar therapie schaars. Antwoorden op vragen wanneer welke behandelstrategie moet worden gestart, zijn niet beschikbaar. Casuïstiek beschrijvingen wijzen op gunstige effecten van glucocorticosteroïden, immunomodulerende en TNF- $\alpha$ remmende middelen. Vanwege de kleine onderzoekspopulaties kunnen op basis van deze studies geen goede conclusies worden getrokken. Bij symptomatische leversarcoïdosepatiënten wordt aanbevolen om te starten met glucocorticosteroïden, de gebruikelijk geadviseerde behandeling van sarcoïdose, voorafgegaan door behandeling met ursodeoxycholzuur indien tekenen van cholestase aanwezig zijn. Ook kunnen antioxidanten worden overwogen. In refractaire gevallen of wanneer afbouw van glucocorticosteroïden niet mogelijk is, kunnen cytotoxische middelen of TNF- $\alpha$ remmende therapie worden overwogen. Toekomstig onderzoek is noodzakelijk om het effect van behandeling op ziekteprogressie en complicaties bij leversarcoïdose nader uit te zoeken.

In hoofdstuk 6 wordt de ontwikkeling van praktische aanbevelingen, geformuleerd namens de World Association of Sarcoidosis and Other Granulomatous Disorders (WASOG), voor het gebruik van MTX bij sarcoïdose gepresenteerd. Kennis verkregen via een systematische literatuur review werd geïntegreerd met de expert opinion van sarcoïdose-experts wereldwijd. Literatuuronderzoek leverde 237 artikelen op, waarvan 43 werden geïncludeerd. Er bleek slechts een enkele gerandomiseerde gecontroleerde studie naar het gebruik van MTX bij sarcoïdose beschikbaar. Een online vragenlijst betreffende 10 klinische vragen werd verzonden via de WASOG nieuwsbrief naar de experts. Vijfenveertig procent (113 van 250) van de gecontacteerde sarcoïdose-experts vulden de vragenlijst volledig in (Europa 55\%, Noord-Amerika $26 \%$ en Azië $12 \%$ ). Tien aanbevelingen werden geformuleerd betreffende de indicaties voor gebruik, startdosering, foliumzuur, work-up, contra-indicaties, monitoren, toedieningsopties in geval van gastro-intestinale bijwerkingen, levertoxiciteit, veiligheid op de lange termijn en gebruik tijdens zwangerschap en borstvoeding. Het gemiddelde niveau van overeenstemming betreffende het totale aantal aanbevelingen onder de leidende sarcoïdose-experts bleek hoog (8.7, range 8.0-10). Tevens werd een mobiele applicatie (app) ontwikkeld voor smartphone of tablet met deze aanbevelingen en nuttige praktijkvoorbeelden (Appendix 2). De app 'MTX in sarcoidosis' is gratis te downloaden via de Apple Store of Google Play Store.

Hoofdstuk 7 beschrijft de ontwikkeling van praktische aanbevelingen voor het gebruik van de TNF- $\alpha$ remmers infliximab en adalimumab om de clinicus te ondersteunen bij de behandeling van refractaire sarcoïdose. Kennis verkregen via een literatuuronderzoek werd gecombineerd met de resultaten van een Delphi studie onder sarcoïdose-experts wereldwijd. Literatuuronderzoek leverde 256 artikelen op, waarvan 101 werden geïncludeerd. Er bleken slechts enkele gerandomiseerde gecontroleerde 
studies naar het gebruik van TNF- $\alpha$ remmers bij sarcoïdose beschikbaar. Informatie werd aangevuld met kennis beschikbaar van studies verricht bij andere inflammatoire aandoeningen. Een online vragenlijst betreffende 12 klinische vragen werd verzonden naar de experts om consensus na te gaan wanneer onvoldoende data beschikbaar bleken voor objectieve antwoorden. Vijfennegentig procent (19 van 20) van de gecontacteerde sarcoïdose-experts vulden de vragenlijst volledig in (Europa 68\%, Noord-Amerika 32\%). Negen aanbevelingen betreffende algemene aspecten rondom het gebruik van TNF- $\alpha$ remmers werden geformuleerd. Tevens werden aanbevelingen gedaan betreffende items specifiek gerelateerd aan sarcoïdose, namelijk indicaties, start- en onderhoudsdosering, interval van behandeling, behandelduur en de methode van staken van infliximab en adalimumab.

De aanwezigheid van het GG-genotype van het TNF- $\alpha$ G-308A polymorfisme is geassocieerd met een slechte prognose bij sarcoïdose. In hoofdstuk 8 wordt de associatie tussen de aanwezigheid van het TNF- $\alpha$ G-308A polymorfisme en de respons op TNF- $\alpha$ remmers bij 111 patiënten met refractaire sarcoïdose onderzocht. De geïncludeerde patiënten werden gedurende minimaal 12 maanden vervolgd na de start van infliximab $(n=76)$ of adalimumab $(n=35)$. De belangrijkste symptomen bij deze patiënten bestonden uit dunne vezel neuropathie (82\%), pulmonale betrokkenheid (62\%), uveïtis (28\%) en/of moeheid (90\%). De aanwezigheid van het TNF- $\alpha$ G-308A polymorfisme werd met behulp van genotypering vastgesteld. Behandelrespons werd vastgesteld op basis van klinische kenmerken en vragenlijsten. Van de totale groep patiënten die TNF- $\alpha$ remmende therapie kregen, verbeterden $75 \%$. Van de patiënten met het GG-genotype van het TNF- $\alpha$ G-308A polymorfisme verbeterden $93.6 \%$ (73/78; $\mathrm{p}<0.001)$, terwijl slechts $30.3 \%$ (10/33) van de TNF- $\alpha-308 \mathrm{~A}$ variant allel dragers gunstig reageerden op de TNF- $\alpha$ remmer. Sarcoïdosepatiënten zonder de TNF- $\alpha-308 \mathrm{~A}$ variant allel (GG-genotype) bleken een driemaal hogere waarschijnlijkheid van respons op TNF$\alpha$ remmers te hebben. Toekomstig onderzoek is noodzakelijk om de waarde van TNF- $\alpha$ G-308A polymorfisme genotypering bij het op maat aanpassen van TNF- $\alpha$ remmende therapie te evalueren.

De belangrijkste bevindingen beschreven in dit proefschrift, evenals de hieruit voortvloeiende mogelijkheden voor toekomstig onderzoek, worden besproken in hoofdstuk 9. Enkele aandachtspunten met betrekking tot het gebruik van MTX en TNF$\alpha$ inhibitors worden toegelicht. Opvallend bij het gebruik van MTX is het voorkomen van angst voor bijwerkingen bij een aanzienlijk deel van de artsen die sarcoïdose behandelen. Meestal is dit het gevolg van gebrek aan ervaring met het middel. In geval van gastro-intestinale bijwerkingen of onvoldoende effectiviteit van MTX, kan het toepassen van de parenterale toedieningsvorm uitkomst bieden. Een probleem waar clinici vaak tegenaan lopen bij het voorschrijven van TNF- $\alpha$ remmers bestaat uit de overweging bij welke patiënten en na welke behandelperiode in geval van stabiele ziekte staken of 'taperen' van farmacotherapie overwogen zou kunnen worden. Bij het optimaliseren van farmacotherapie kan gebruik worden gemaakt van farmacogenetica. 'Genetische chips' met het individuele polymorfe genotype, gecombineerd met het 
fenotype oftewel de klinische presentatie, kunnen worden gebruikt bij het nastreven van 'personalized medicine'. Zo kan onnodige blootstelling aan potentieel schadelijke middelen worden voorkomen. Bovendien kan effectiever, sneller en goedkoper controle van ziekteactiviteit worden bereikt. In dit proefschrift werd hiertoe een eerste aanzet gegeven bij het instellen van TNF- $\alpha$ remmende therapie bij sarcoïdose door gebruik te maken van het TNF- $\alpha$ G-308A polymorfisme. Toekomstig onderzoek is noodzakelijk om de klinische waarde van farmacogenetica bij het op maat instellen van therapeutische middelen na te gaan. Er zijn slechts weinig studies naar de verschillende farmacotherapeutische opties bij sarcoïdose verricht en gestandaardiseerde behandelstrategieën ontbreken. Dit maakt dat gerandomiseerde gecontroleerde studies en het opstellen van aanbevelingen voor glucocortico-steroïden en tweedelijns middelen belangrijke onderwerpen voor toekomstig onderzoek zijn. Nader inzicht in glucocorticosteroïd resistentie en nieuwe experimentele therapieën, zoals rituximab, verdienen eveneens aandacht.

\section{Conclusie}

Dit proefschrift presenteert verschillende aspecten met als doel een bijdrage te leveren aan het optimaliseren van farmacotherapeutische opties bij sarcoïdose. Cachexie en spieratrofie blijken frequent voorkomende problemen te zijn bij sarcoïdose, geassocieerd met ernstigere pulmonale betrokkenheid. Deze bevindingen geven aan dat het bepalen van lichaamssamenstelling bij de behandeling van sarcoïdose van belang is. Verder zijn bij een aanzienlijk deel van de sarcoïdosepatiënten levertestafwijkingen aanwezig, bij de meerderheid waarschijnlijk ten gevolge van leversarcoïdose. Wanneer matige of ernstige levertestafwijkingen aanwezig zijn bij een patiënt die verdacht wordt van leversarcoïdose, moet een leverbiopt worden overwogen vanwege de grote kans op vergevorderde histopathologische afwijkingen. De informatie af te leiden uit biopsie kan worden gebruikt bij de implementatie van een adequate behandelstrategie van leversarcoïdose. De aanbevelingen voor de behandeling van leversarcoïdose worden in dit proefschrift gepresenteerd. Ook worden internationale aanbevelingen voor het gebruik van MTX en TNF- $\alpha$ remmers beschreven, gebaseerd op bevindingen van de literatuur gecombineerd met de expert opinion van sarcoïdose-experts wereldwijd. Tot slot toont de bevinding dat sarcoïdosepatiënten zonder TNF- $\alpha$-308A variant allel (GG-genotype) een driemaal grotere waarschijnlijkheid van respons op TNF- $\alpha$ remmers hebben in vergelijking met TNF- $\alpha-308 \mathrm{~A}$ variant allel dragers (GA- of AA-genotype), een mogelijke rol voor TNF- $\alpha$ G-308A polymorfisme genotypering bij het op maat instellen van TNF- $\alpha$ remmende therapie. Verder onderzoek is wenselijk naar methodes om responders op TNF- $\alpha$ remmende therapie te identificeren en naar de mogelijke rol die $T N F-\alpha$ G-308A genotypering hierbij zou kunnen spelen. 


\section{List of publications}




\section{List of publications}

Verpoest W, Van Landuyt L, Desmyttere S, Cremers J, Devroey P, Liebaers I. The incidence of monozygotic twinning following pre-implantation genetic diagnosis (PGD) is not increased. Hum Reprod 2009;24:2945-2950.

Cremers J, Drent M, Driessen A, Nieman F, Wijnen P, Baughman R, Koek G. Liver-test abnormalities in sarcoidosis. Eur J Gastroenterol Hepatol 2012;24:17-24.

Cremers J, Drent M, Baughman R, Wijnen P, Koek G. Therapeutic approach of hepatic sarcoidosis. Curr Opin Pulm Med 2012;18:472-482.

Cremers J, Drent M, Bast A, Shigemitsu H, Baughman R, Valeyre D, Sweiss N, Jansen T. Multinational evidence-based World Association of Sarcoidosis and Other Granulomatous Disorders recommendations for the use of methotrexate in sarcoidosis: integrating systematic literature research and expert opinion of sarcoidologists worldwide. Curr Opin Pulm Med 2013;19:545-561.

Cremers J, Drent M, Elfferich M, Nelemans P, Wijnen P, Witteman B, Schols A. Body composition profiling in a Dutch sarcoidosis population. Sarcoidosis Vasc Diffuse Lung Dis 2013;30:289-299.

Drent $\mathrm{M}$, Cremers J, Jansen T. Pulmonology meets rheumatology in sarcoidosis: a review on the therapeutic approach. Curr Opin Rheumatol 2014;26:276-84.

Video abstract: http://links.Iww.com/COR/A13

Cremers J, Van Kroonenburgh M, Mostard R, Vöö S, Wijnen P, Koek G, Drent M. Extent of disease activity assessed by ${ }^{18}$ F-FDG PET/CT in a Dutch sarcoidosis population. Sarcoidosis Vasc Diffuse Lung Dis 2014;31:37-45.

Drent M, Cremers J, Jansen T, Baughman R. Practical eminence and experience-based recommendations for use of TNF- $\alpha$ inhibitors in sarcoidosis. Sarcoidosis Vasc Diffuse Lung Dis 2014; accepted for publication.

Wijnen P, Cremers J, Nelemans P, Erckens R, Hoitsma E, Jansen T, Bekers O, Drent M. Association of the TNF- $\alpha$ G-308A polymorphism with TNF-inhibitor response in refractory sarcoidosis. Eur Respir J 2014; in press.

Vorselaars A*, Cremers J*, Grutters J, Drent M. Cytotoxic agents in sarcoidosis, which one? Submitted. * shared first authorship 



\section{Dankwoord}




\section{Dankwoord}

Aan de totstandkoming van dit proefschrift hebben velen bijgedragen en zonder hen zou het niet zijn geworden tot wat het nu is. Een aantal mensen wil ik graag in het bijzonder bedanken voor hun steun en begeleiding tijdens mijn promotietraject.

Allereerst gaat vele dank uit naar mijn promotor, prof. dr. M. Drent. Beste Marjolein, grote bewondering heb ik voor je enthousiasme en eindeloze ideeën. Jij was degene die met het idee kwam om dit project op te zetten en die er ook voor gezorgd heeft dat het daadwerkelijk gerealiseerd werd. Vele dank hiervoor! Graag wil ik je bedanken voor je motiverende en leerzame begeleiding, de leuke tijd, en je onuitputtelijke energie die me hebben laten zien dat alles mogelijk is.

Dank ook aan mijn copromotor, dr. T. Jansen. Beste Tim, jouw goede ideeën, adviezen en heldere commentaar zijn van grote waarde geweest voor mijn proefschrift. Dank voor de ontzettend fijne samenwerking. Bedankt ook voor het laten zien dat reumatologie een ontzettend mooi vak is!

Prof. R. Baughman and prof. E. Lower, dear Bob and Elyse, thank you very much for giving me the opportunity to complete part of my research at your clinic in Cincinnati. My stay was amazing thanks to the hospitality of you and your staff. I am impressed by the passionate way you run your clinic and research centre. Many thanks for the fantastic and educational time!

Graag wil ik de leden van de beoordelingscommissie, prof. dr. A. Nieuwenhuijzen Kruseman, prof. dr. J. Bijlsma, prof. dr. M. van Dieijen-Visser, prof. dr. P. Geusens en prof. dr. C. Neef, hartelijk bedanken voor de grondige beoordeling van mijn manuscript.

Een speciaal woord van dank aan dr. Petal Wijnen, a.k.a. PW / Kwek / Vraag het Mona. Dankjewel voor je hulp op allerlei gebieden. Allereerst voor je belangrijke bijdrage aan de onderzoeken in dit proefschrift. Ook blijk jij met endnote en SPSS te kunnen toveren en posters zien er na jouw aanpassingen fantastisch uit. Maar minstens zo belangrijk, bedankt ook voor de gezelligheid tijdens alle bijeenkomsten en als kamergenote in Parijs.

Marjon Elfferich, mijn dank voor het vele werk dat je hebt verzet, de gezelligheid en de fijne samenwerking. Je prettige uitstraling werkt rustgevend. Ook je nuttige presentatie tips zal ik zeker niet vergeten!

Via dr. Ger Koek maakte ik kennis met de sarcoïdose wereld. Dank voor deze introductie en voor de prettige begeleiding tijdens het onderzoek naar afwijkende levertesten bij sarcoïdose. Ik kijk met plezier terug naar deze tijd. 
Graag wil ik ook prof. dr. Ben Witteman en prof. dr. Annemie Schols bedanken voor de leerzame en leuke begeleiding. Dank voor de nuttige onderzoeksbijeenkomsten en de hulp bij het 'body composition-verhaal' van dit proefschrift.

Dr. Patty Nelemans, dank voor je hulp, deskundige adviezen en begeleiding bij de statistiek gedeelten. Tijdens onze bijeenkomsten heb ik veel geleerd!

Dr. Rémy Mostard en dr. Marinus van Kroonenburgh, veel dank voor de prettige samenwerking en jullie mooie bijdrage aan het 'PET-verhaal'. Dank aan dr. Stefan Vöö en Wouter Broos voor alle hulp en het uitzoeken van geschikte PET beelden voor mijn onderzoek. Ook wil ik dr. Ann Driessen bedanken voor de beoordeling van de leverbiopten en dr. Roel Erckens voor de belangrijke bijdrage aan hoofdstuk 8 van dit proefschrift. Prof. dr. Aalt Bast, dank voor de bruikbare suggesties en aanvullingen.

Alle overige co-auteurs wil ik ook hartelijk danken voor hun bijdrage, kritische en waardevolle feedback op mijn manuscripten en voor de prettige samenwerking. I would also like to thank the foreign co-authors for their critical and valuable feedback on my manuscripts. I appreciate the pleasant cooperation.

Rik Marcellis, ik kijk met plezier terug naar de gezellige bijeenkomsten. Veel succes met de afronding van je proefschrift!

Natuurlijk was dit onderzoek niet mogelijk geweest zonder de medewerking van een groot aantal sarcoïdosepatiënten. Ondanks hun klachten namen zij de moeite mee te werken en tijd ter beschikking te stellen. Graag wil ik hen hartelijke bedanken voor hun bijdrage.

Veel dank aan alle sarcoïdose-experts wereldwijd, die tijd en energie staken in het invullen van de vragenlijsten. Ik waardeer deze medewerking zeer. I really appreciate the efforts of all sarcoidosis experts worldwide by completing the questionnaires. Many thanks.

Dank aan de afdeling Longfunctie van het Maastricht Universitair Medisch Centrum+ (MUMC+) voor het verrichten van alle onderzoeken en metingen.

Afdeling Centraal Diagnostisch Laboratorium van het MUMC+, bedankt voor het verrichten van de polymorfisme genotyperingen.

De afdeling Longziekten van Ziekenhuis Gelderse Vallei (ZGV) te Ede wil ik graag bedanken voor het mede mogelijk maken van het onderzoeksjaar in Ede. Dank aan de afdeling Longfunctie en Fysiotherapie van het ZGV voor al het verrichte werk voor de nog lopende studies. 
Maggie Sharma, thank you so much for your valuable help and fantastic suggestions to improve my thesis. I really appreciate your time and efforts.

Wim van Ratingen, heel erg bedankt dat ik het prachtige tweeluik 'Vogelperikelen' heb mogen gebruiken voor de omslag van mijn proefschrift. Dank ook aan Theo Finger voor de fotografische techniek, zodat de vogels ook op papier goed tot hun recht komen. Ik weet nu dat daar heel wat bij komt kijken. Bedankt voor alle tijd en moeite. Ik ben erg blij met het mooie eindresultaat!

Tiny Wouters, jouw hulp bij het opmaken van mijn proefschrift en de goede adviezen hebben geleid tot een fraaie lay-out. Bedankt voor al het werk.

Alle collega's en oud-collega's van de interne geneeskunde, dankjulliewel voor de getoonde interesse, maar daarnaast ook voor de gezellige feestjes en etentjes. Dank ook aan dr. Jacqueline Buijs, opleider interne geneeskunde, voor de enthousiaste reactie en het mede mogelijk maken van mijn onderzoeksjaar.

Een speciaal woord van dank aan Tonnie, Marien, Sammie en Seb. Heel erg bedankt voor jullie enorme gastvrijheid en gezelligheid. Jullie gaven me het gevoel iedere maandagavond naar een 'tweede thuis' te gaan. Ik heb een fantastische tijd gehad!

Lieve Liana, dankjewel voor alle hulp, de leuke gesprekken en de gezelligheid van het afgelopen jaar!

Lieve vrienden en vriendinnen, dankjulliewel voor alle morele steun en medeleven. Dank ook voor alle gezellige avonden uit, etentjes en theeleut momenten.

Mijn paranimfen, Esther en Valérie, geweldig dat jullie me vandaag willen bijstaan. Lieve Esther, hilarische en gedenkwaardige momenten samen met jou zijn er te veel om op te noemen. Dankjewel voor je onvoorwaardelijke vriendschap. Lieve Valérie, dankjewel voor iedere lach en traan die we samen hebben kunnen delen. Fantastisch om te weten dat jij altijd voor me zult klaarstaan.

Lieve opa en oma, bedankt voor alles. Ik ben heel gelukkig dat jullie bij al deze belangrijke stappen in mijn leven aanwezig zijn.

Elleke, Eefje, Daan en Jarno, lieve zusjes en schoonbroers, bedankt voor jullie steun en alle mooie momenten samen. Dank dat ik altijd bij jullie terecht kan. 
Lieve papa en mama, bedankt voor jullie vertrouwen in mij en jullie onvoorwaardelijke steun op alle fronten. Dankjulliewel voor alle kansen die jullie me gegeven hebben. Het is fijn om te weten dat ik altijd op jullie kan terugvallen. Ik kan niet beschrijven hoeveel dat voor me betekent!

Lieve Quincy, de laatste bijzondere woorden van dit dankwoord zijn voor jou. Dankjewel voor je liefde, vertrouwen en onbeschrijfelijke steun. Je grote hulp de afgelopen periode waardeer ik enorm. Ondanks dat we verschillend zijn, horen we zo moeiteloos bij elkaar...Jij hebt mijn hart ingenomen. 


\section{Curriculum vitae}




\section{Curriculum vitae}

Anne (Johanna Petronella) Cremers was born on January $7^{\text {th }}$, 1985 in Heerlen, The Netherlands. In 2003, she completed secondary school at the Sint-Janscollege in Hoensbroek. She then started studying medicine at Maastricht University, Maastricht, The Netherlands, where she obtained her medical degree in 2010. Subsequently, she was trained in internal medicine at the Atrium Medical Centre in Heerlen. In 2014 she will start her training in rheumatology at the Sint Maartenskliniek in Nijmegen and the University Medical Centre Sint Radboud in Nijmegen. The research project

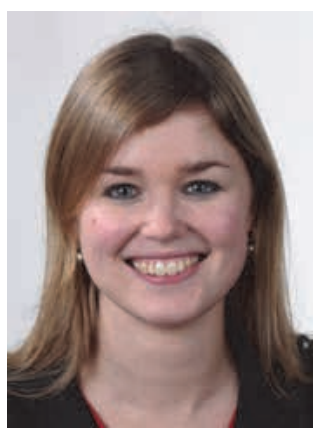
described in this thesis started in 2010 at Maastricht University, supervised by prof. Marjolein Drent. During 2013 she performed research as a full-time member of the interstitial lung diseases care (ild care) team at the Gelderse Vallei Hospital in Ede. During the same year, she completed part of her research work under the supervision of prof. Robert P. Baughman and prof. Elyse E. Lower at the Interstitial Lung Disease and Sarcoidosis Clinic at the University of Cincinnati Medical Centre in Cincinnati, Ohio, USA. During her stay there, she presented the study on the development of multinational recommendations for the use of methotrexate in sarcoidosis as an invited speaker at the 2013 American Association of Sarcoidosis and Other Granulomatous Disorders (AASOG) meeting in Chicago, Illinois, USA. Her research work was awarded with the Research Grant 2014 of the Sarcoïdose Belangenvereniging Nederland (SBN). 



\section{Appendix 1}

Overview of studies on the use of methotrexate in sarcoidosis 


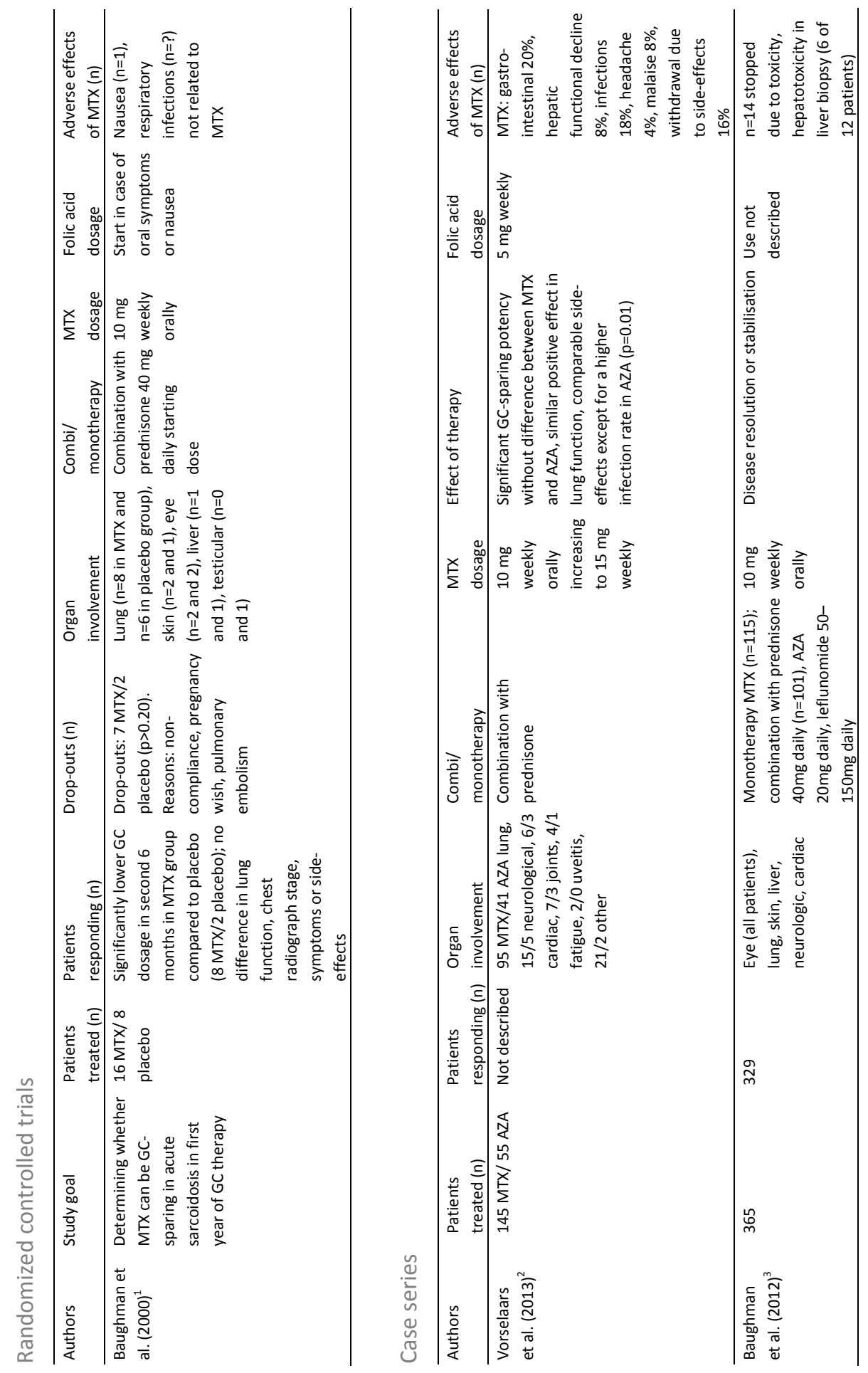




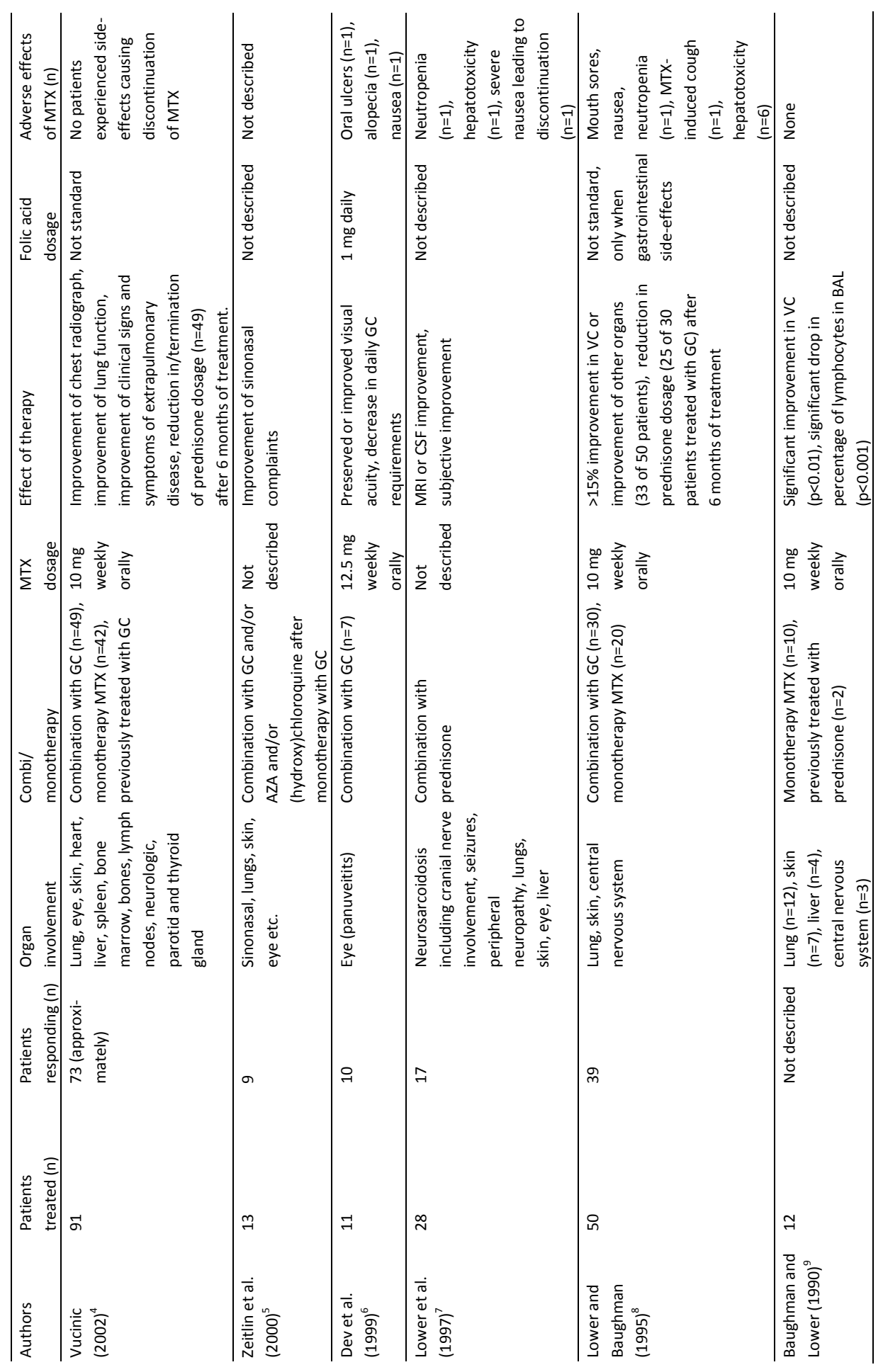




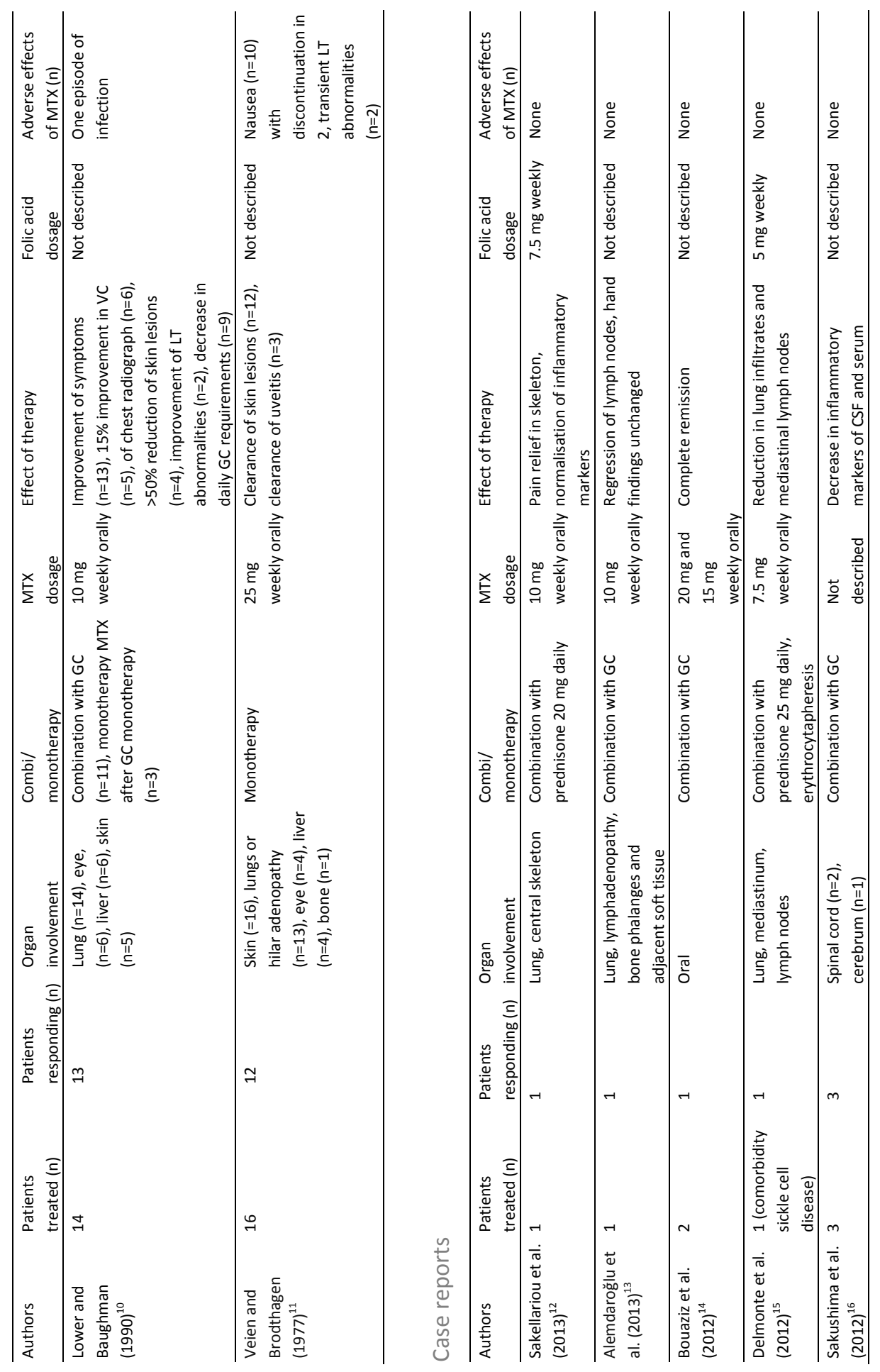




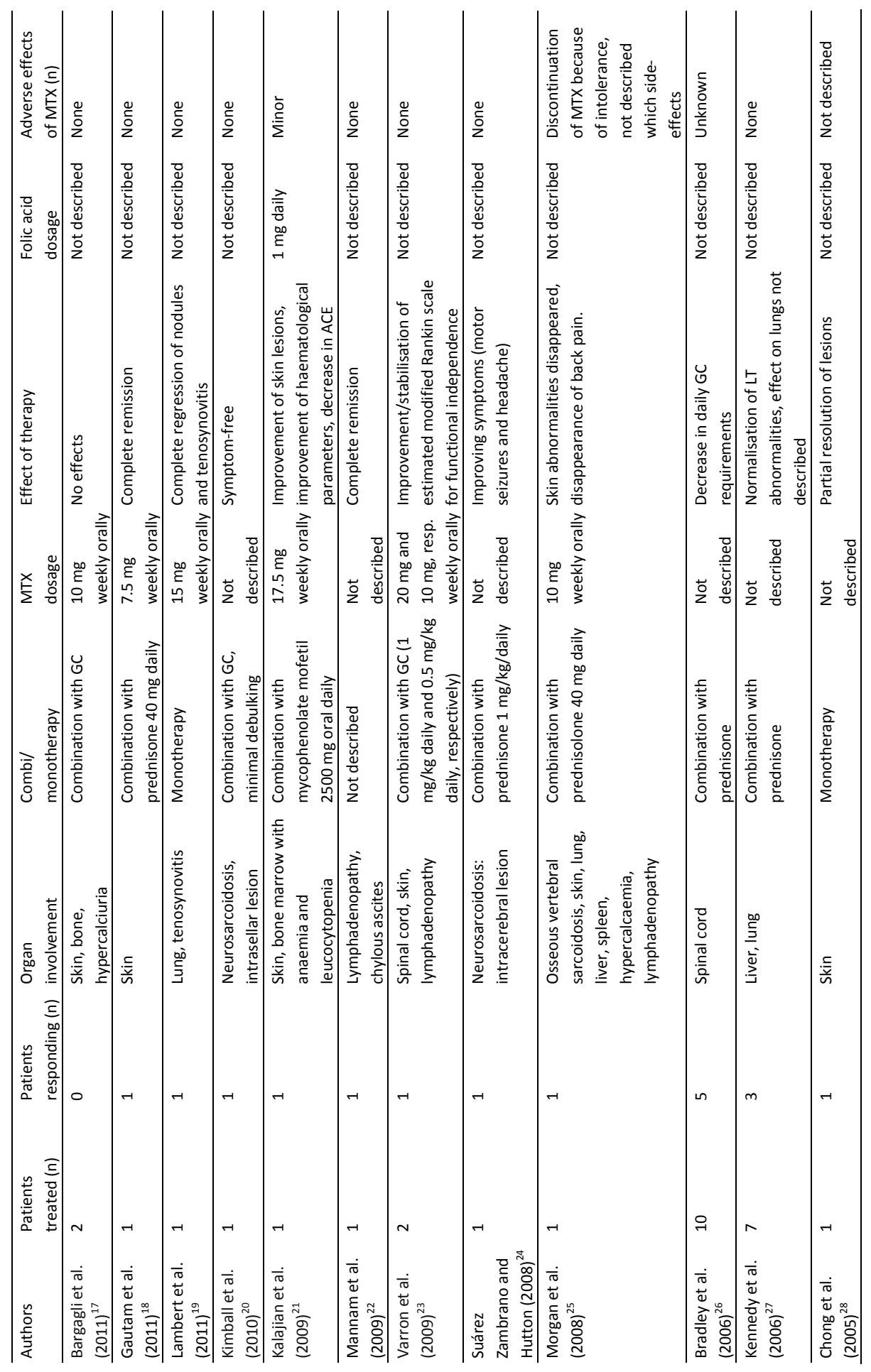




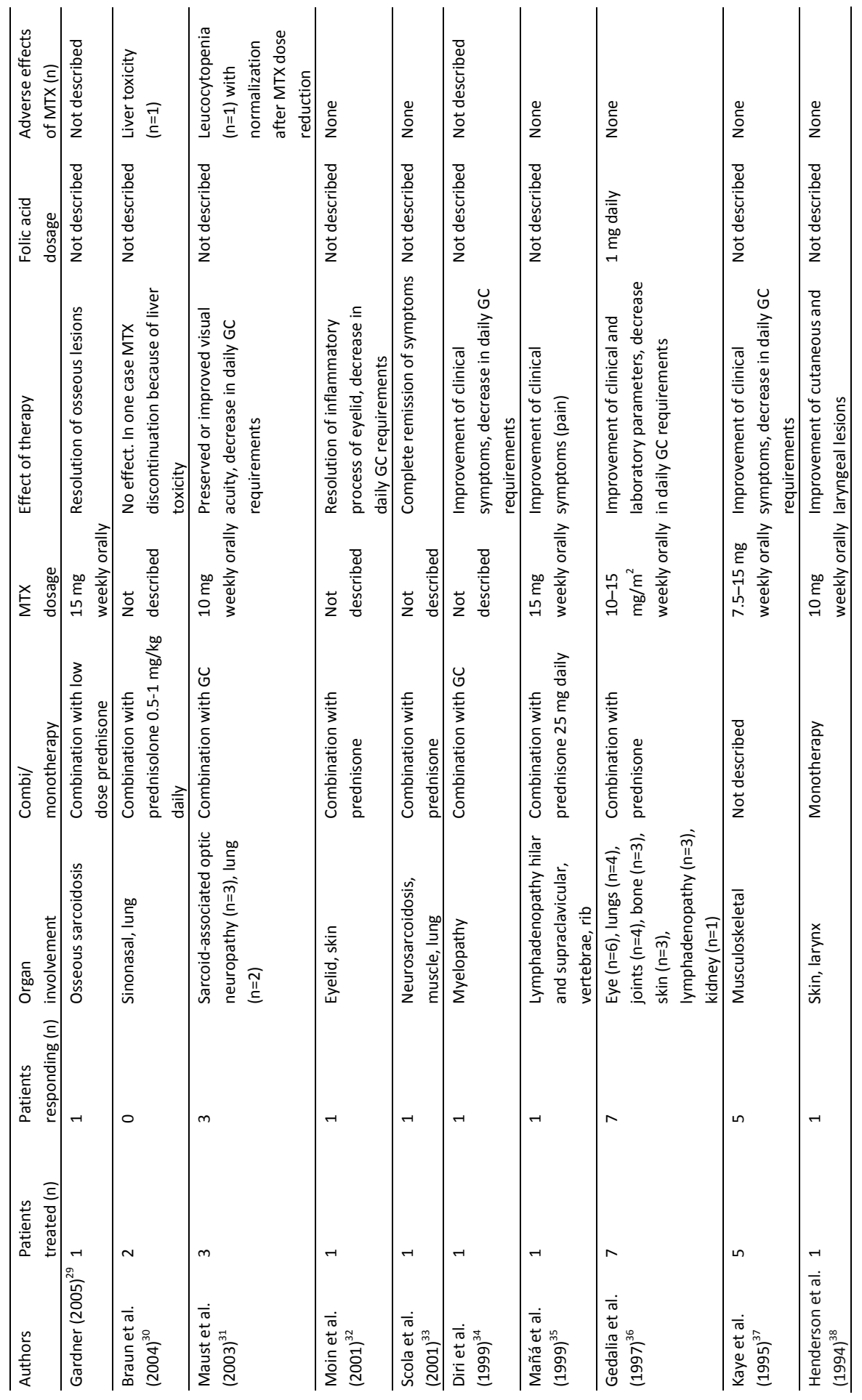


Appendix 1

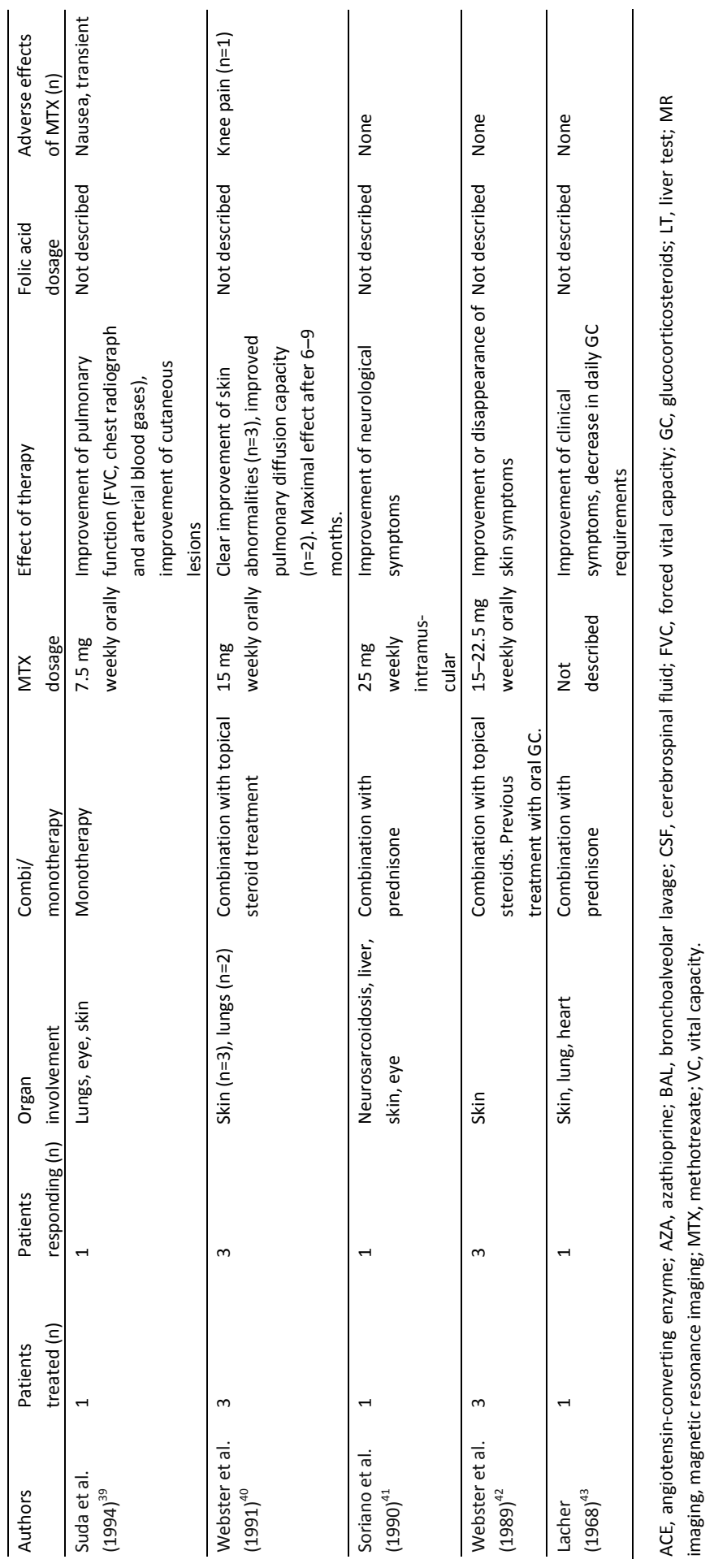

224 


\section{References}

1. Baughman RP, Winget DB, Lower EE. Methotrexate is steroid sparing in acute sarcoidosis: results of a double blind, randomized trial. Sarcoidosis Vasc Diffuse Lung Dis 2000;17:60-66.

2. Vorselaars AD, Wuyts WA, Vorselaars VM, Zanen $P$, Deneer VH, Veltkamp $M$, Thomeer $M$, Van Moorsel $\mathrm{CH}$, Grutters JC. Methotrexate versus azathioprine in second line therapy of sarcoidosis. Chest 2013;144:805-812.

3. Baughman RP, Lower EE, Ingledue R, Kaufman AH. Management of ocular sarcoidosis. Sarcoidosis Vasc Diffuse Lung Dis 2012;29:26-33.

4. Vucinic VM. What is the future of methotrexate in sarcoidosis? A study and review. Curr Opin Pulm Med 2002;8:470-476.

5. Zeitlin JF, Tami TA, Baughman R, Winget D. Nasal and sinus manifestations of sarcoidosis. Am J Rhinol 2000;14:157-161.

6. Dev S, McCallum RM, Jaffe GJ. Methotrexate treatment for sarcoid-associated panuveitis. Ophthalmology 1999;106:111-118.

7. Lower EE, Broderick JP, Brott TG, Baughman RP. Diagnosis and management of neurological sarcoidosis. Arch Intern Med 1997;157:1864-1868.

8. Lower EE, Baughman RP. Prolonged use of methotrexate for sarcoidosis. Arch Intern Med 1995; 155:846-851.

9. Baughman RP, Lower EE. The effect of corticosteroid or methotrexate therapy on lung lymphocytes and macrophages in sarcoidosis. Am Rev Respir Dis 1990;142:1268-1271.

10. Lower EE, Baughman RP. The use of low dose methotrexate in refractory sarcoidosis. Am J Med Sci 1990;299:153-157.

11. Veien NK, Brodthagen H. Cutaneous sarcoidosis treated with methotrexate. Br J Dermatol 1977;97: 213-216.

12. Sakellariou GT, Anastasilakis AD, Karanikolas D, Vounotrypidis P, Berberidis C. Central skeletal sarcoidosis: a case report with sustained remission only on methotrexate, and a literature review on the imaging approach, treatment, and assessment of disease activity. Mod Rheumatol 2013;23: 175-181.

13. Alemdaroglu E, Erturk A, Eroglu AG. A sarcoidosis patient with hand involvement and large pulmonary lymph nodes: results of 1-year treatment with methotrexate. Clin Rheumatol 2013;32(suppl):S71-73.

14. Bouaziz A, Le Scanff J, Chapelon-Abric C, Varron L, Khenifer S, Gleizal A, Bentz MH, Barthel A, Valeyre D, Seve P. Oral involvement in sarcoidosis: report of 12 cases. Qjm 2012;105:755-767.

15. Delmonte L, Zamo A, Cantini M, De Franceschi L. An unusual case of sarcoidosis in an adult patient with sickle cell disease: Management with methotrexate and low dose of steroid. Am J Hematol 2012; $88: 243$.

16. Sakushima K, Yabe I, Nakano F, Yoshida K, Tajima Y, Houzen H, Maruo Y, Sasaki H. Clinical features of spinal cord sarcoidosis: analysis of 17 neurosarcoidosis patients. J Neurol 2011;258:2163-2167.

17. Bargagli E, Olivieri C, Penza F, Bertelli P, Gonnelli S, Volterrani L, Rottoli P. Rare localizations of bone sarcoidosis: two case reports and review of the literature. Rheumatol Int 2011;31:1503-1506.

18. Gautam M, Patil S, Munde P. Skin as a marker of internal disease: a case of sarcoidosis. Indian J Dermatol 2011;56:439-441.

19. Lambert L, Riemer EC, Judson MA. Rapid development of sarcoid tenosynovitis. J Clin Rheumatol 2011;17:201-203.

20. Kimball MM, Wind JJ, Codispoti KE, Jones RV, Leiphart JW. Neurosarcoidosis presenting as an isolated intrasellar mass: case report and review of the literature. Clin Neuropathol 2010;29:156-162.

21. Kalajian AH, Van Meter JR, Callen JP. Sarcoidal anemia and leukopenia treated with methotrexate and mycophenolate mofetil. Arch Dermatol 2009;145:905-909.

22. Mannam P, Boselli JM, Schulman ES. Successful treatment of chylous ascites secondary to sarcoidosis with methotrexate. Hosp Pract (Minneap) 2009;37:144-146.

23. Varron L, Broussolle C, Candessanche JP, Marignier R, Rousset H, Ninet J, Seve P. Spinal cord sarcoidosis: report of seven cases. Eur J Neurol 2009;16:289-296.

24. Suarez Zambrano GA, Hutton GJ. Heart-shaped lesion secondary to neurosarcoidosis. Arch Neurol 2008;65:1388-1389. 
25. Morgan SS, Aslam MB, Mukkanna KS, Ampat G. A rare presentation of sarcoidosis, back pain and spondylolisthesis. J Bone Joint Surg Br 2008;90:240-242.

26. Bradley DA, Lower EE, Baughman RP. Diagnosis and management of spinal cord sarcoidosis. Sarcoidosis Vasc Diffuse Lung Dis 2006;23:58-65.

27. Kennedy PT, Zakaria N, Modawi SB, Papadopoulou AM, Murray-Lyon I, du Bois RM, Jervoise NAH, Devlin J. Natural history of hepatic sarcoidosis and its response to treatment. Eur J Gastroenterol Hepatol 2006;18:721-726.

28. Chong WS, Tan HH, Tan SH. Cutaneous sarcoidosis in Asians: a report of 25 patients from Singapore. Clin Exp Dermatol 2005;30:120-124.

29. Gardner GC, Hunter JC. Clinical images: Radiographic healing of osseous sarcoidosis. Arthritis Rheum 2005;52:2225.

30. Braun JJ, Gentine A, Pauli G. Sinonasal sarcoidosis: review and report of fifteen cases. Laryngoscope 2004;114:1960-1963.

31. Maust HA, Foroozan R, Sergott RC, Niazi S, Weibel S, Savino PJ. Use of methotrexate in sarcoidassociated optic neuropathy. Ophthalmology 2003;110:559-563.

32. Moin M, Kersten RC, Bernardini F, Kulwin DR. Destructive eyelid lesions in sarcoidosis. Ophthal Plast Reconstr Surg 2001;17:123-125.

33. Scola RH, Werneck LC, Prevedello DM, Greboge P, Iwamoto FM. Symptomatic muscle involvement in neurosarcoidosis: a clinicopathological study of 5 cases. Arq Neuropsiquiatr 2001;59:347-352.

34. Diri E, Espinoza CG, Espinoza LR. Spinal cord granulomatous vasculitis: an unusual clinical presentation of sarcoidosis. J Rheumatol 1999;26:1408-1410.

35. Mana J, Gomez-Vaquero C, Dorca J, Pujol R. Vertebral and rib sarcoidosis: long-term clinical remission with methotrexate. Clin Rheumatol 1999;18:492-494.

36. Gedalia A, Molina JF, Ellis GS, Jr., Galen W, Moore C, Espinoza LR. Low-dose methotrexate therapy for childhood sarcoidosis. J Pediatr 1997;130:25-29.

37. Kaye O, Palazzo E, Grossin M, Bourgeois P, Kahn MF, Malaise MG. Low-dose methotrexate: an effective corticosteroid-sparing agent in the musculoskeletal manifestations of sarcoidosis. $\mathrm{Br} J$ Rheumatol 1995;34:642-644.

38. Henderson CA, Ilchyshyn A, Curry AR. Laryngeal and cutaneous sarcoidosis treated with methotrexate. J R Soc Med 1994;87:632-633.

39. Suda T, Sato A, Toyoshima M, Imokawa S, Yoshitomi A, Tamura R, Suganuma H, Yagi T, Hayakawa H, Shirai M, Chida K. Weekly low-dose methotrexate therapy for sarcoidosis. Intern Med 1994;33:437440.

40. Webster GF, Razsi LK, Sanchez M, Shupack JL. Weekly low-dose methotrexate therapy for cutaneous sarcoidosis. J Am Acad Dermatol 1991;24:451-454.

41. Soriano FG, Caramelli P, Nitrini R, Rocha AS. Neurosarcoidosis: therapeutic success with methotrexate. Postgrad Med J 1990;66:142-143.

42. Webster GF, Razsi LK, Sanchez M, Shupack JR. Methotrexate therapy in cutaneous sarcoidosis. Ann Intern Med 1989;111:538-539.

43. Lacher MJ. Spontaneous remission or response to methotrexate in sarcoidosis. Ann Intern Med 1968;69:1247-1248. 


\section{Appendix 2}

Mobile application 'MTX in sarcoidosis' 


\section{Mobile application 'MTX in sarcoidosis'}

Based on the expert opinions from the world's leading sarcoidologists combined with evidence from the literature, a mobile application (app) was developed for smartphone or tablet with 10 recommendations on how to use methotrexate in sarcoidosis clinical practice.

The complete statement of the experts, published in Current Opinion in Pulmonary Medicine, can also be found. Useful links to the latest scientific publications in this field, along with clinical cases demonstrating the effect of methotrexate, are available as well.

The app was developed on behalf of the ild care foundation in cooperation with the World Association of Sarcoidosis and Other Granulomatous Disorders (WASOG). You can download the app for free in the Apple Store or Google Play Store.

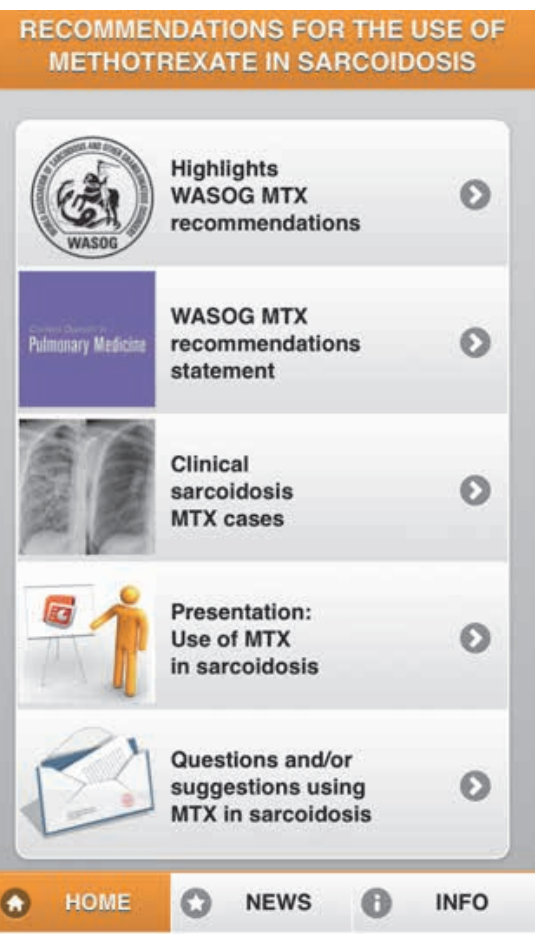

\section{Acknowledgements}

This app was developed with the help of Medix Publishers; it was supported by an educational grant from the ild care foundation and TEVA The Netherlands. 



\section{Appendix 3}

Overview of studies on the use of

TNF- $\alpha$ inhibitors in sarcoidosis 


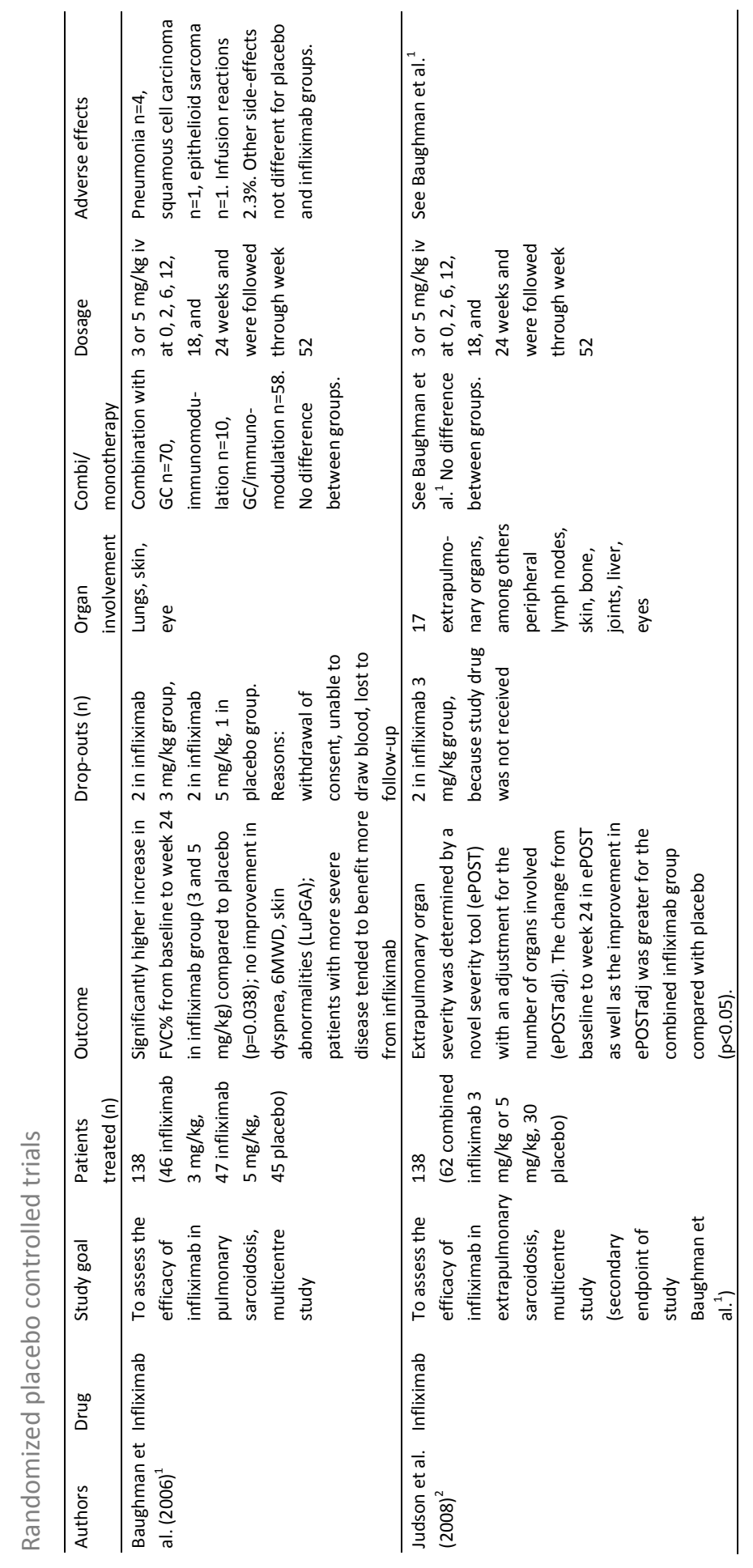




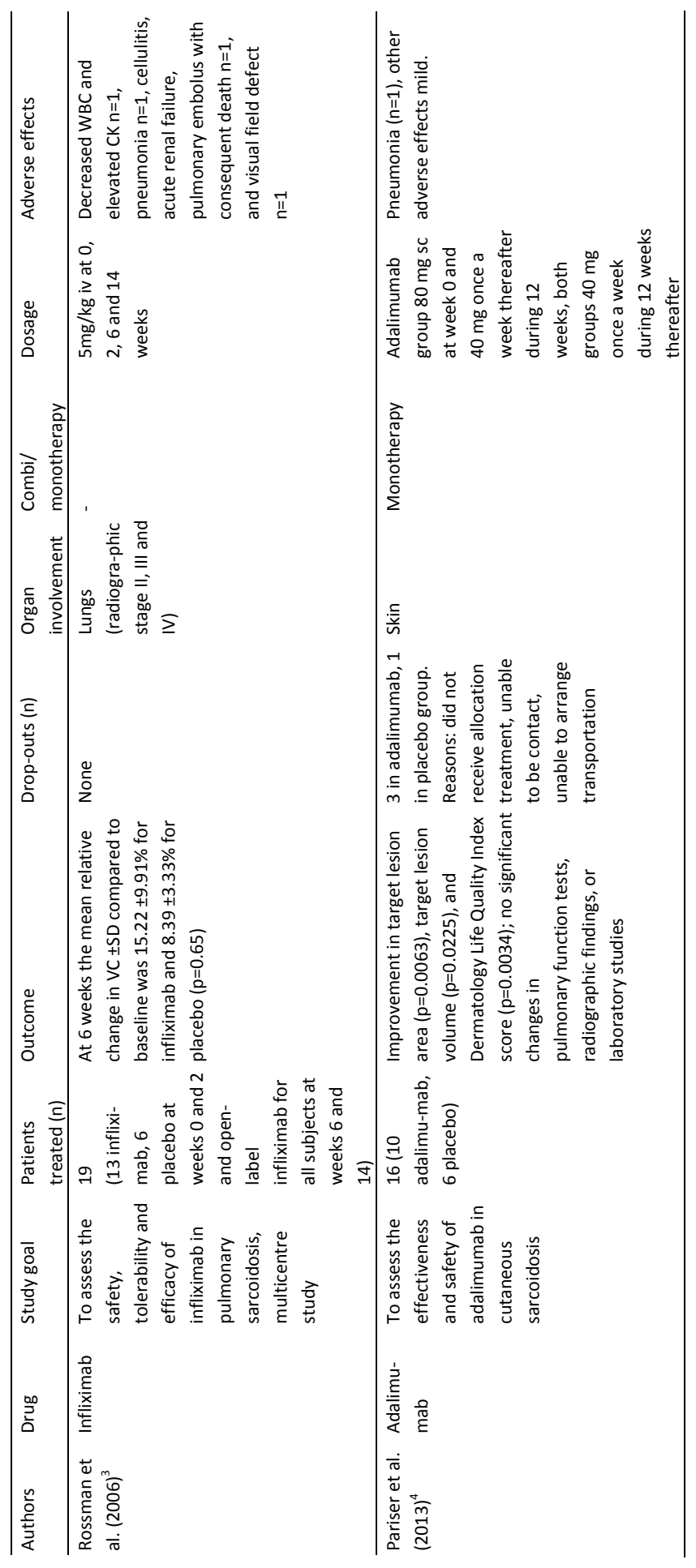




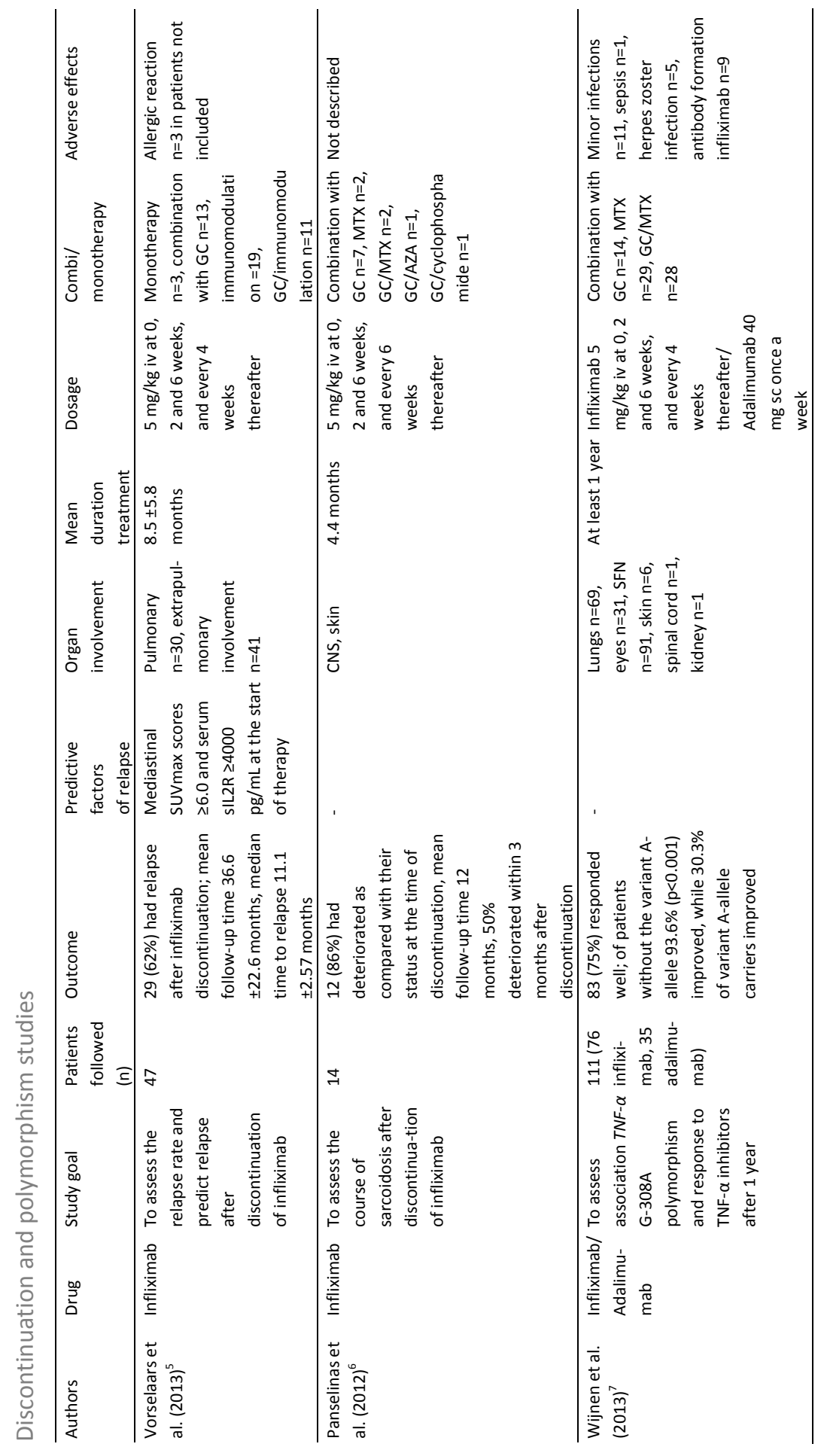




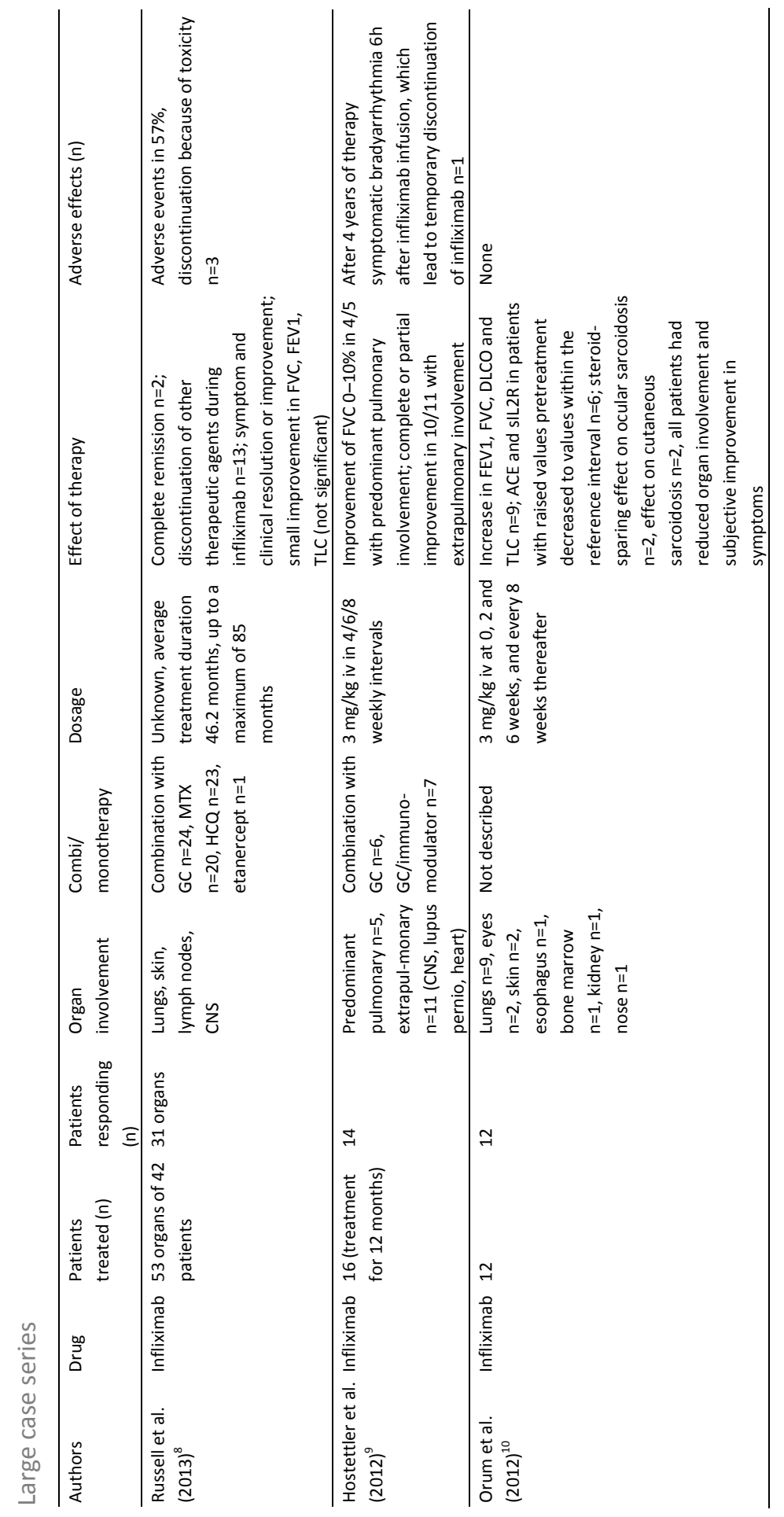




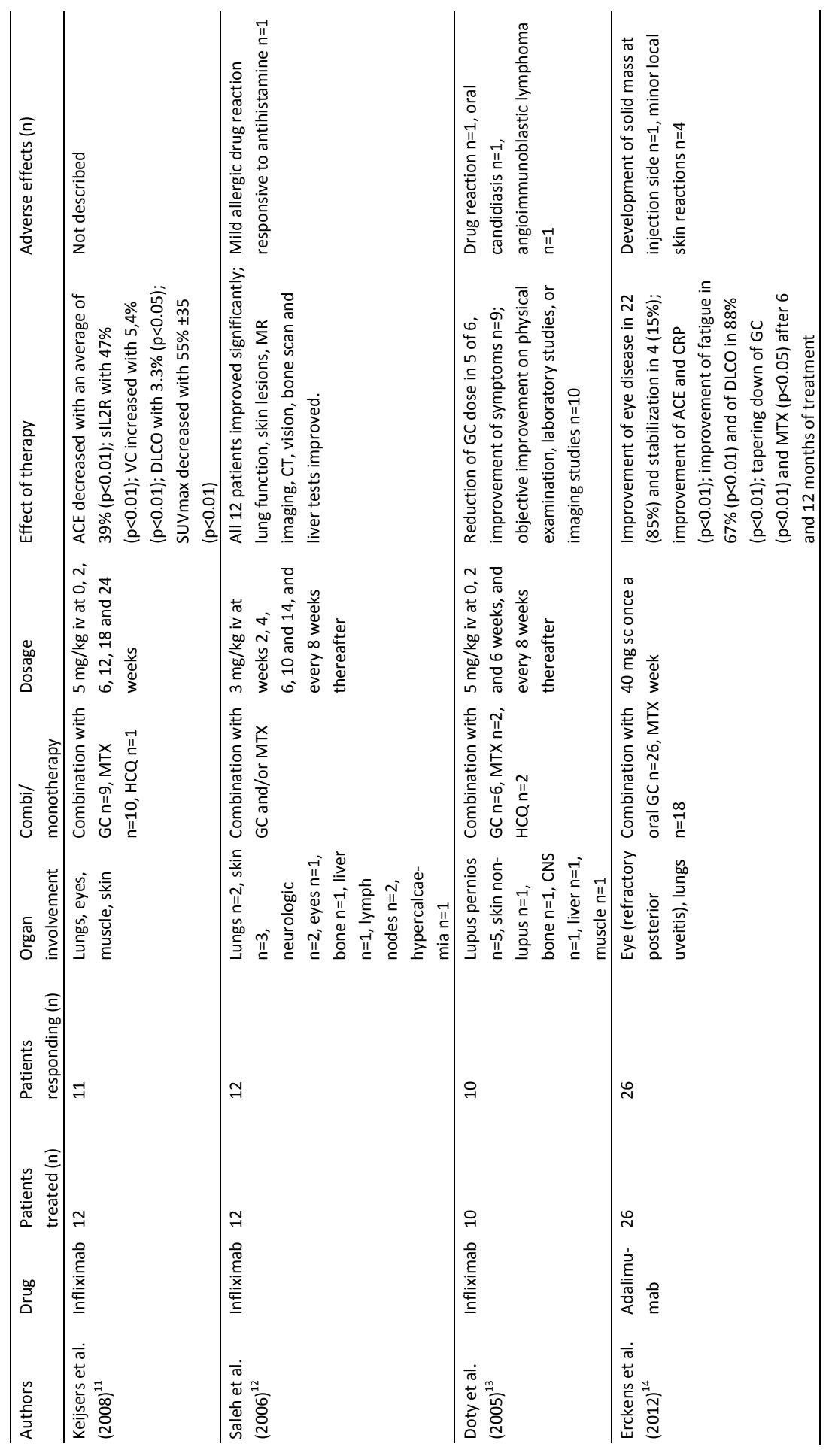




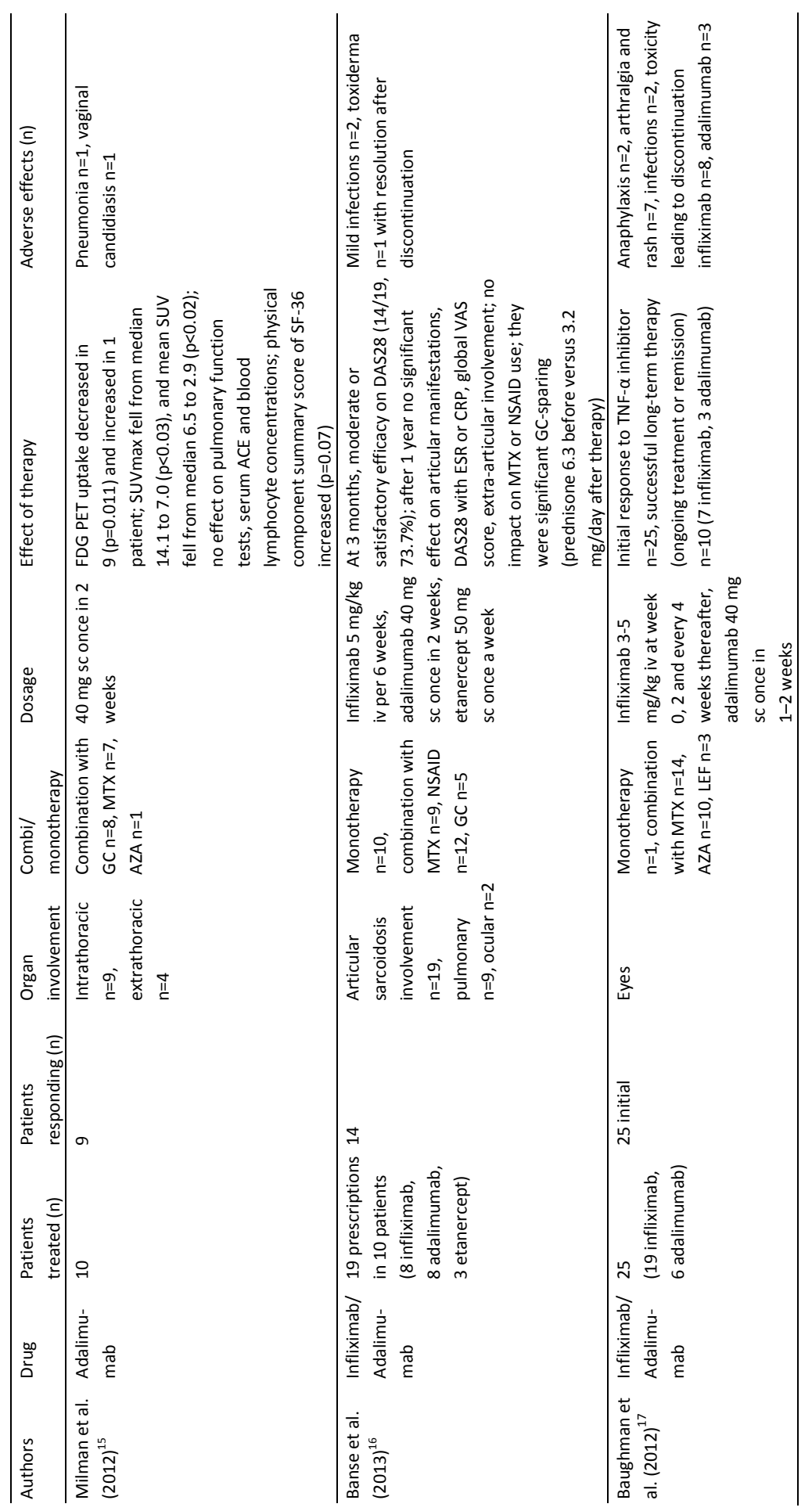




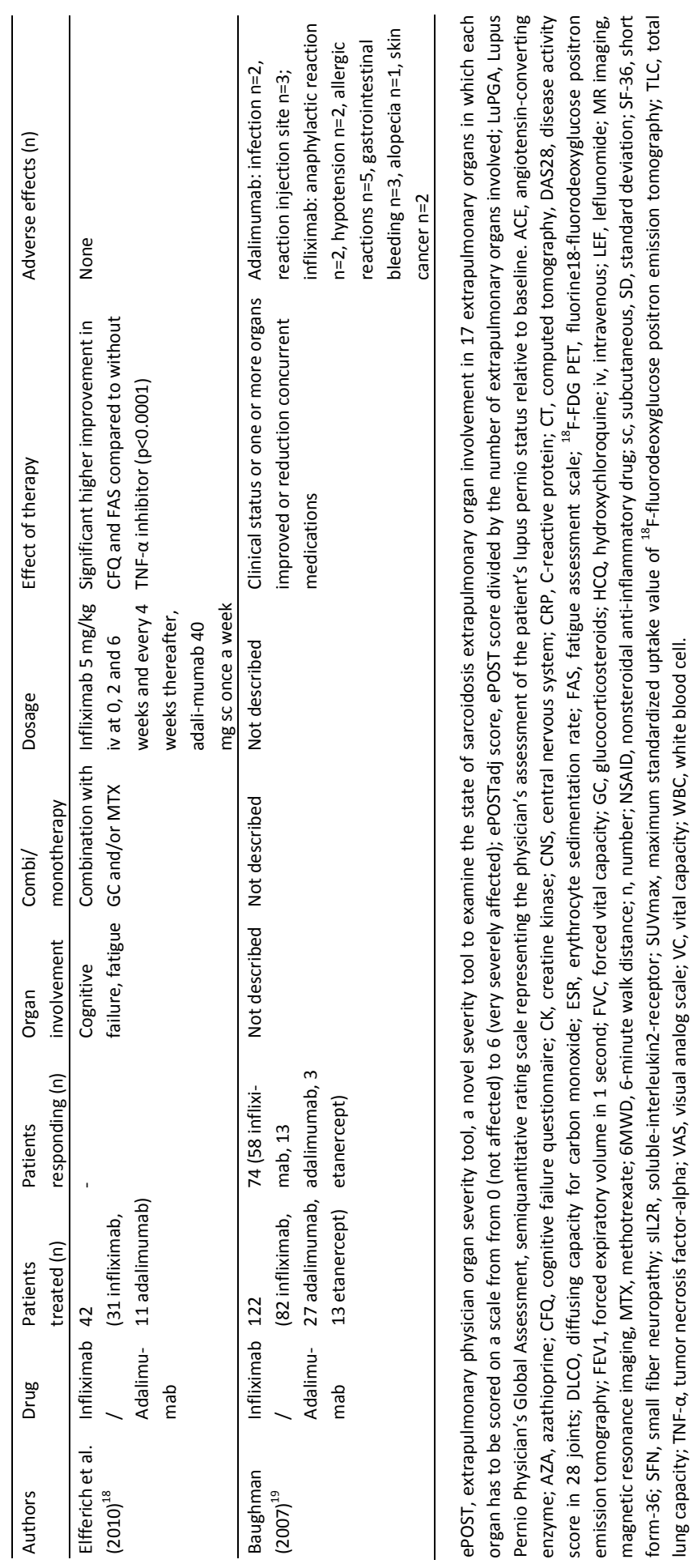




\section{References}

1. Baughman RP, Drent M, Kavuru M, Judson MA, Costabel U, du Bois R, Albera C, Brutsche M, Davis G, Donohue JF, Muller-Quernheim J, Schlenker-Herceg R, Flavin S, Lo KH, Oemar B, Barnathan ES. Infliximab therapy in patients with chronic sarcoidosis and pulmonary involvement. Am J Respir Crit Care Med 2006;174:795-802.

2. Judson MA, Baughman RP, Costabel U, Flavin S, Lo KH, Kavuru MS, Drent M. Efficacy of infliximab in extrapulmonary sarcoidosis: results from a randomised trial. Eur Respir J 2008;31:1189-1196.

3. Rossman MD, Newman LS, Baughman RP, Teirstein A, Weinberger SE, Miller W, Jr., Sands BE. A double-blinded, randomized, placebo-controlled trial of infliximab in subjects with active pulmonary sarcoidosis. Sarcoidosis Vasc Diffuse Lung Dis 2006;23:201-208.

4. Pariser RJ, Paul J, Hirano S, Torosky C, Smith M. A double-blind, randomized, placebo-controlled trial of adalimumab in the treatment of cutaneous sarcoidosis. J Am Acad Dermatol 2013;68:765-773.

5. Vorselaars AD, Verwoerd A, Van Moorsel CH, Keijsers RG, Rijkers GT, Grutters JC. Prediction of relapse after discontinuation of infliximab therapy in severe sarcoidosis. Eur Respir J 2013

6. Panselinas E, Rodgers JK, Judson MA. Clinical outcomes in sarcoidosis after cessation of infliximab treatment. Respirology 2009;14:522-528.

7. Wijnen PA, Cremers JP, Nelemans PJ, Erckens RJ, Hoitsma E, Jansen TL, Bekers O, Drent M. Association of the TNF- $\alpha$ G-308A polymorphism with TNF-inhibitor response in sarcoidosis. Eur Respir J 2014; In press.

8. Russell E, Luk F, Manocha S, Ho T, O'Connor C, Hussain H. Long term follow-up of infliximab efficacy in pulmonary and extra-pulmonary sarcoidosis refractory to conventional therapy. Semin Arthritis Rheum 2013;43:119-124.

9. Hostettler KE, Studler U, Tamm M, Brutsche MH. Long-term treatment with infliximab in patients with sarcoidosis. Respiration 2012;83:218-224.

10. Orum M, Hilberg O, Krag S, Bendstrup E. Beneficial effect of infliximab on refractory sarcoidosis. Dan Med J 2012;59:A4535.

11. Keijsers RG, Verzijlbergen JF, Van Diepen DM, Van den Bosch JM, Grutters JC. 18F-FDG PET in sarcoidosis: an observational study in 12 patients treated with infliximab. Sarcoidosis Vasc Diffuse Lung Dis 2008;25:143-149.

12. Saleh S, Ghodsian S, Yakimova V, Henderson J, Sharma OP. Effectiveness of infliximab in treating selected patients with sarcoidosis. Respir Med 2006;100:2053-2059.

13. Doty JD, Mazur JE, Judson MA. Treatment of sarcoidosis with infliximab. Chest 2005;127:1064-1071.

14. Erckens R, Mostard R, Wijnen P, Schouten J, Drent M. Adalimumab successful in sarcoidosis patients with refractory chronic non-infectious uveitis. Graefes Arch Clin Exp Ophthalmol 2012;250:713-720.

15. Milman N, Graudal N, Loft A, Mortensen J, Larsen J, Baslund B. Effect of the TNF-alpha inhibitor adalimumab in patients with recalcitrant sarcoidosis: a prospective observational study using FDGPET. Clin Respir J 2012;6:238-247.

16. Banse C, Bisson-Vaivre A, Kozyreff-Meurice M, Vittecoq O, Goeb V. No impact of tumor necrosis-factor antagonists on the joint manifestations of sarcoidosis. Int J Gen Med 2013;6:605-611.

17. Baughman RP, Lower EE, Ingledue R, Kaufman AH. Management of ocular sarcoidosis. Sarcoidosis Vasc Diffuse Lung Dis 2012;29:26-33.

18. Elfferich MD, Nelemans PJ, Ponds RW, De Vries J, Wijnen PA, Drent M. Everyday cognitive failure in sarcoidosis: the prevalence and the effect of anti-TNF-alpha treatment. Respiration 2010;80:212-219.

19. Baughman R. Tumor necrosis factor inhibition in treating sarcoidosis: the American experience. Rev Port de Pneumologia 2007;8:S47-S50. 